\title{
Economics of Alaska North Slope Gas Utilization Options
}

Engineering Laboratory

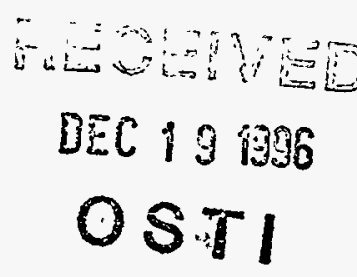

Charles P. Thomas

Tom C. Doughty

John H. Hackworth

Walter B. North

Eric P. Robertson

\section{MASTER}

DISTRIBUTION OF THS DOCUMENT IS UMRUMED

LOCKHEED MARTIN

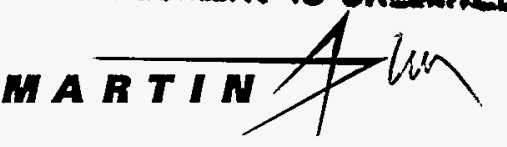




\section{DISCLAIMER}

This report was prepared as an account of work sponsored by an agency of the United States Government. Neither the United States Government nor any agency thereof, nor any of their employees, makes any warranty, express or implied, or assumes any legal liability or responsibility for the accuracy, completeness, or usefulness of any information, apparatus, product or process disclosed, or represents that its use would not infringe privately owned rights. References herein to any specific commercial product, process, or service by trade name, trademark, manufacturer, or otherwise, does not necessarily constitute or imply its endorsement, recommendation, or favoring by the United States Government or any agency thereof. The views and opinions of authors expressed herein do not necessarily state or reflect those of the United States Government or any agency thereof. 
INEL-96/0322

\section{Economics of Alaska North Slope Gas Utilization Options}

Charles P. Thomas

Tom C. Doughty John H. Hackworth

Walter B. North

Eric P. Robertson

Published August 1996

Idaho National Engineering Laboratory Advanced Engineering Development Laboratory

Lockheed Martin Idaho Technologies Company Idaho Falls, Idaho $\mathbf{8 3 4 1 5}$

Prepared for the

U.S. Department of Energy

Office of Fossil Energy

Under DOE Idaho Operations Office

Contract DE-AC07-94ID13223 


\section{DISCLAMMER}

Portions of this document may be illegible in electronic image products. Images are produced from the best available original document. 


\title{
ECONOMICS OF ALASKA NORTH SLOPE GAS UTILIZATION OPTIONS
}

\begin{abstract}
The recoverable natural gas available for sale in the developed and known undeveloped fields on the Alaskan North Slope (ANS) total about 26 trillion cubic feet (TCF), including 22 TCF in the Prudhoe Bay Unit (PBU) and 3 TCF in the undeveloped Point Thomson Unit (PTU). No significant commercial use has been made of this large natural gas resource because there are no facilities in place to transport this gas to current markets. To date the economics have not been favorable to support development of a gas transportation system. However, with the declining trend in ANS oil production, interest in development of this huge gas resource is rising, making it important for the U.S. Department of Energy, industry, and the State of Alaska to evaluate and assess the options for development of this vast gas resource.
\end{abstract}

The purpose of this study was to assess whether gas-to-liquids (GTL) conversion technology would be an economic alternative for the development and sale of the large, remote, and currently unmarketable ANS natural gas resource, and to compare the long term economic impact of a GTL conversion option to that of the more frequently discussed natural gas pipeline/liquefied natural gas (LNG) option. The major components of the study are: an assessment of the ANS oil and gas resources; an analysis of conversion and transportation options; a review of natural gas, LNG, and selected oil product markets; and an economic analysis of the LNG and GTL gas sales options based on publicly available input needed for assumptions of the economic variables. Uncertainties in assumptions are evaluated by determining the sensitivity of project economics to changes in baseline economic variables.

The projects evaluated assume gas sales from PBU start in 2005 and reach a peak rate of 2.05 billion cubic feet per day (BCFPD) in 2009, and sales from PTU starting in 2008 at 0.44 BCFPD, for a combined peak rate of $2.49 \mathrm{BCFPD}$. This results in sales of 17 million metric tonnes per year of LNG, or 300 thousand barrels per day of a GTL liquid hydrocarbon product compatible with the North Slope crude oil and transportable in the Trans Alaska Pipeline System (TAPS). The total investment (1995\$) for the LNG option is $\$ 17$ billion and $\$ 13$ billion for the GTL option. Both include investments necessary to develop PTU.

The results of the economic evaluations, prepared using the Energy Information Administration 1995 Reference Oil Price forecast that anticipates real oil price growth of about $2.4 \% / y r$, indicate that both LNG and GTL project options will be profitable (10\% rate of return on investment) for the gas project developers. In addition, economic returns to the PBU and PTU gas producing units will be higher than they would be without gas sales. Also, of the two options, the GTL route assures minimum flow rates needed to extend TAPS operability for about 20 years after existing North Slope oil-producing reservoirs are largely depleted.

In summary, both the LNG and the GTL options are economically promising and warrant consideration in industry and government decision-making. However, at this point in time, it is not possible to conclude that one option is significantly better than the other. Focussed follow-up investigations to this study would be of value to industry and State of Alaska decision makers, and are recommended. 


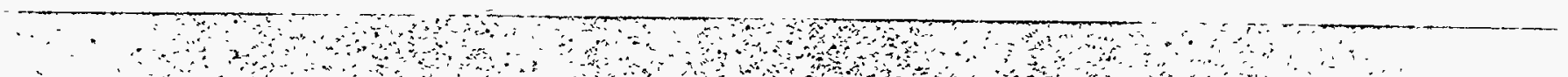




\section{ECONOMICS OF ALASKA NORTH SLOPE GAS UTILIZATION OPTIONS}

\section{EXECUTIVE SUMMARY}

\section{Introduction}

The technically recoverable conventional natural gas resources in the developed and known undeveloped oil and gas fields on the Alaska North Slope (ANS) total about 38 TCF. No significant commercial use has yet been made of this large natural gas resource because there are no facilities in place to transport this gas to current markets, which are outside of the North Slope. To date the economics have not been favorable to support development of a gas transportation system. In addition to the known gas resources, the U.S. Geological Survey's (USGS) most recently published estimate of technically recoverable conventional natural gas resources in undiscovered fields in Northern Alaska has a mean value of 64 TCF (USGS, 1995).

Figure 1 is a map showing the known oil and gas accumulations and selected dry holes and suspended wells on the North Slope. Although discoveries of oil and gas have been made across Northern Alaska, the only development that has occurred is around the super giant Prudhoe Bay field. It is unlikely that any of the other North Slope fields would have been developed without facility cost-sharing made possible by the development of the Prudhoe Bay infrastructure and the construction of the Trans Alaska Pipeline System (TAPS).

About 26 TCF of the 38 TCF of technically recoverable gas is estimated to be available for sale. The balance will be consumed in oil and gas production operations on the North Slope. Although, there has been a high level of interest in developing a capability to bring the huge North Slope natural gas resource to market since the discovery of the Prudhoe Bay field, the urgency to develop the capability to sell the large, currently unmarketable, North Slope gas resources has increased in recent years because of the steep decline in North Slope oil production. ANS production has accounted for almost $25 \%$ of the daily U.S. domestically produced oil since production was initiated from the Prudhoe Bay field in 1977. As shown in Figure 2, North Slope oil production peaked in 1988 at 2.0 million barrels per day, declined to 1.5 million barrels per day in 1994, and will continue to decline, reaching about 200 million barrels per day by about 2015 unless large discoveries and developments are brought on line before then. North Slope oil production is dominated by the Prudhoe Bay field, which began to decline 1988. Continued decline of Prudhoe Bay oil production and its ultimate oil depletion is inevitable. Prudhoe Bay and Point Thomson (a smaller, undeveloped gas/gas condensate field 50 miles east of Prudhoe Bay) contain about 25 TCF of the 26 TCF 


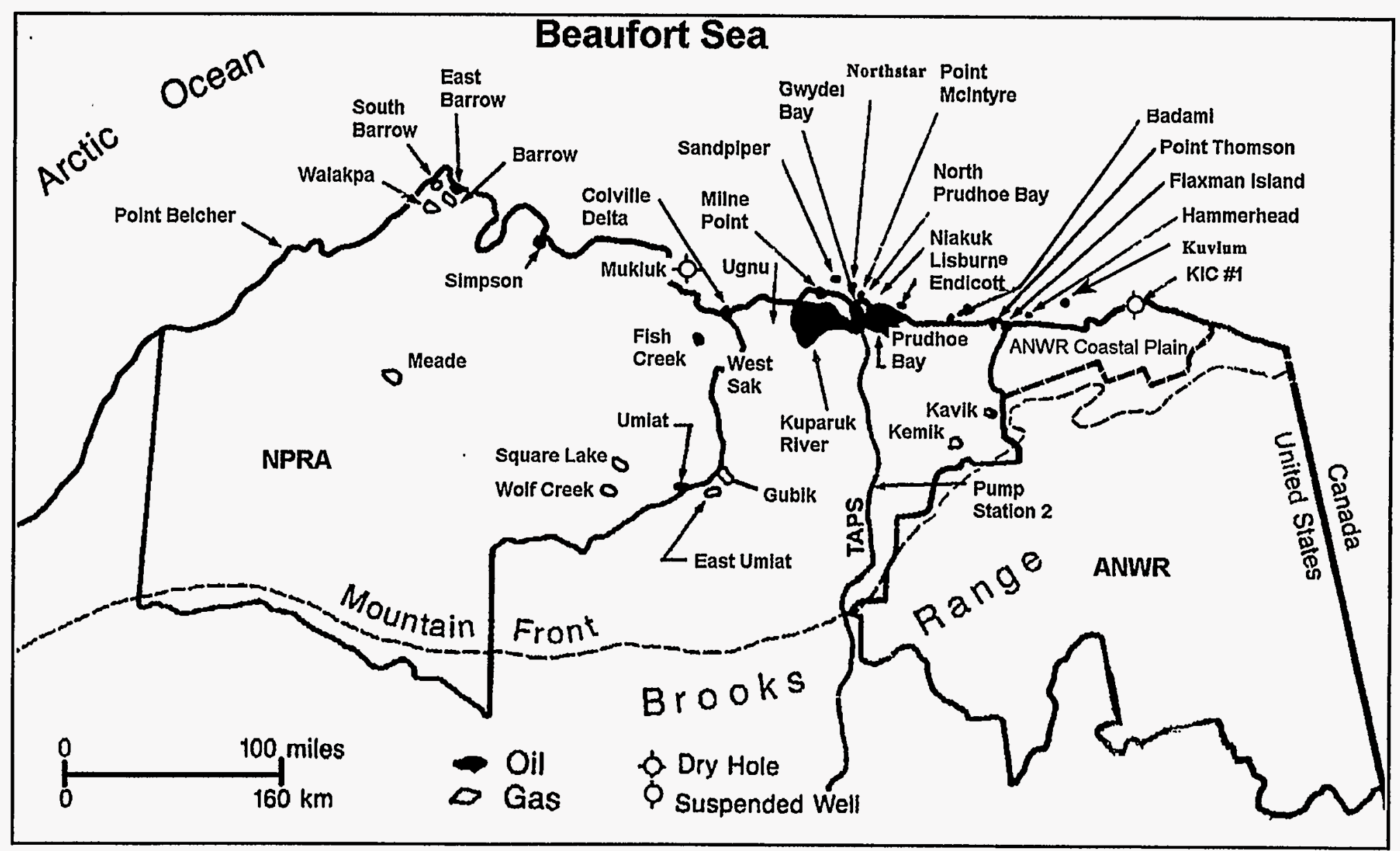

Figure 1. Known oil and gas accumulations, selected dry holes and suspended wells, and NPRA-ANWR boundaries, North Slope Alaska (DOE, 1991, ADNR, 1991a). 
of the estimated recoverable natural gas discovered on the North Slope. This is a highly significant resource (over 4 billion barrels of oil equivalent) addition to the estimated remaining recoverable reserves of about 6 billion barrels (as of January 1, 1995) from producing North Slope fields.

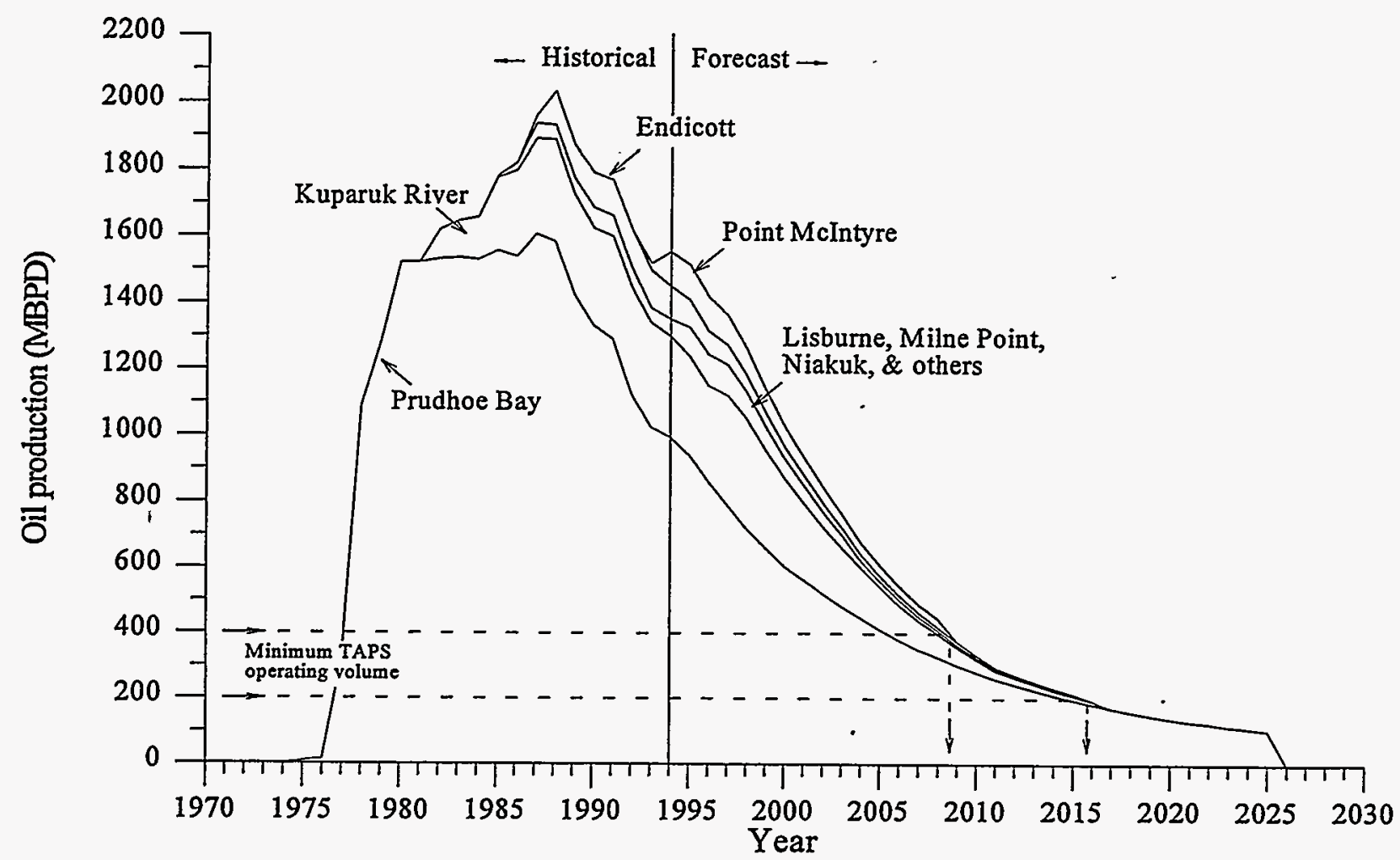

Figure 2. The Alaska North Slope historical production and production forecast at the Energy Information Administration (EIA) Reference Oil Price (economically recoverable oil).

The dashed lines at the bottom of Figure 2 indicate the currently estimated range of the minimum liquid throughput rate for continued TAPS operation, which illustrates the looming potential of a shutdown of TAPS because of ANS production dropping to a minimum throughput rate for the pipeline in the 2009 to 2016 time frame. Such a shut down could result in the loss of as much as 1 billion barrels economically producible ANS reserves. The intersection of the ANS oil production trend and the pipeline minimum throughput range, coupled with the long lead time of 5 to 10 years required to bring major ANS development projects on line, make clear the urgency of evaluating the technical options that could influence the future of ANS oil production, as well as gas production.

To date, the only use of the gas that is currently produced at Prudhoe Bay with the crude oil, aside from local ANS use and the extraction of NGLs for sale with the crude oil, has been for reinjection to enhance recovery of crude oil. The use of the gas for improved oil recovery has been very successful as 
demonstrated by the increase in reserves for the Prudhoe Bay Unit (PBU) from the early estimates of under 10 billion barrels oil (BBO) to the current estimate of $13 \mathrm{BBO}$ ( $56 \%$ of the original oil in place). Thus, the natural gas reinjected into the reservoirs has had significant interim value to the producers in improving production rates and ultimate oil recovery. However, the use of Prudhoe Bay gas for oil recovery is becoming less important and less valuable with the decline in oil production, which increases the urgency to develop the capability to market the gas, thereby extending the life of North Slope operations and continuing the generation of employment and revenue for the State of Alaska and the nation.

The possibility of exporting the gas via a pipeline from the North Slope to a Valdez LNG plant, followed by tanker shipment to Asian buyers, has long been suggested and studied as an ANS gas sales option. This study, however, sought to assess the economic and technical feasibility of a second option, based on newer technology than that well-established for LNG. This option involves the chemical conversion of gas to a distillate-type hydrocarbon liquid that could be transported and sold with continuing ANS crude oil production via the existing TAPS and tanker fleet. With the gas-to-liquids (GTL) option, a gas pipeline would not have to be built and additional volumes of hydrocarbon liquids would be available for transport through TAPS. This added liquid volume would assist in maintaining the viability of TAPS and result in lower tariffs for all liquids transported in TAPS. Lower TAPS tariffs return a higher net liquid sales price for all fields and projects, those currently producing and future developments.

\section{Purpose}

The primary purpose of this study was to provide a technical and economic evaluation of the feasibility of using technology for chemical conversion of natural gas-to-hydrocarbon liquids for bringing the large, remote, and currently unmarketable ANS natural gas resource to market. However, because of the long-standing interest and high visibility of the LNG option, which involves construction of a natural gas pipeline to an all-weather Alaska port and construction of a new plant for physical conversion of gas to LNG, with subsequent tanker transport and sale of the LNG to Asian buyers, it was apparent that an examination of how the gas-to-liquids (GTL) conversion option compares to the LNG option was necessary. The objective of these comparisons was to provide a basis for discussion and evaluation of the interrelated, complex issues and concerns involved in the development and sale of the ANS gas resource. 
The results of the evaluations and economic comparisons are intended to provide information to assist industry, the State of Alaska, and the federal government in making a better assessment of how to realize the maximum benefit from the ANS oil and gas resources.

The report is organized as follows:

Section 1. Introduction describing the issues and problems associated with major gas sales from the ANS.

Section 2. Assessment of the ANS oil and gas resources.

Section 3. Discussion of the gas resource utilization options and technologies for physical conversion of natural gas to LNG and chemical conversion to hydrocarbon liquids.

Section 4. Overview of LNG and GTL product markets.

Section 5. Description of the economic analysis framework, the economic assumptions; and results of the baseline economic analysis, and the sensitivity analysis.

Section 6. Conclusions and recommendations for follow-up analyses by interested parties.

Appendix A. Descriptions of ANS fields currently producing and fields with development potential, and forecasts of production, investments, and operating costs.

Appendix B. Description of the procedures and input variables used in the economic analysis.

Appendix C. Description of the economic model.

Appendix D. Tables of values from the model runs.

Appendix E. Bibliography.

The following sections contain summaries of the approach, the economic variables used, the economic results, and the conclusions and recommendations.

\section{Assessment Approach}

The first step was to develop an updated outlook for prospective oil production from producing ANS reservoirs. These updated forecasts provide the basis for assessing the economic effects of major gas sales options on future ANS oil production and were necessary before the feasibility of the GTL option could be evaluated and compared with the LNG option. Prospective gas conversion technology was then examined for both the more established physical conversion to LNG, and the less well established GTL chemical conversion to liquid hydrocarbons. This examination included not only the state-of-the-art GTL technology but also included the most promising technology advancements known to DOE researchers that conceivably 
could have application on the North Slope. In spite of proponent optimism that such cost-cutting technology could be ready for application on a large scale by the time of decision making on ANS gas sales, about 4 to 7 years (consistent with investment lead time requirements and gas owner indications that the window of opportunity for major gas sales will be after 2005), the more conservative state-of-the-art LNG and GTL technologies were used as a basis for the evaluations. The GTL technology used for the assessment, assumes Shell's Middle Distillate Synthesis plant that has been operating in Malaysia since 1993. Likewise, the LNG option for gas sales assumes LNG conversion technology as planned by Yukon Pacific Corporation.

The projects and options were evaluated using a standard discounted cash flow analysis. The results were presented in terms of net present value using a discount rate of $10 \%\left(\mathrm{NPV}_{10}\right)$. The $\mathrm{NPV}_{10}$ captures the sum, in 1995\$, of annual revenues less expenses and investments, adjusted for a discount rate that provides a $10 \%$ rate of return on investment. The NPV 10 analysis required the following input information:

(a) Oil and gas recovery forecasts for all developed and producing ANS oil fields and a forecast for the undeveloped PTU to provide the expected pipeline flow for determination of TAPS tariff schedules.

(b) A determination of the technology that might be employed to transport and convert ANS gas to a transportable and marketable commodity and estimates of the capital and operating costs for each option.

(c) A requirement that the gas sales option (LNG or GTL) provide a reasonable rate of return (assumed to be $10 \%$ ) as a stand-alone operation before any "gas product net back" could be calculated for payment to the gas producing units.

The evaluations presented did not assume that major new discoveries would be made, but were based on oil (crude oil, condensate, and NGL) production from the currently developed fields coupled with major gas sales from the two principal ANS gas fields, the Prudhoe Bay field and the currently undeveloped Point Thomson field. The two gas sales options were evaluated as stand-alone projects that purchase gas from each of the fields. Finally, the impact on federal, state, and industry revenues for the combined field and gas sales project options were estimated. 


\section{Baseline Economic Variables}

Baseline assumptions for the key economic variables were:

(a) The EIA 1995 Reference Oil Price (AEO95) case was used for the baseline economics. This case projects a future world oil price with a predicted real oil price increase of about $2.4 \%$ per year.

(b) The hydrocarbon composition and heating value of the ANS gas provided as feedstock to LNG or GTL options is assumed to remain consistent over the project life at $1150 \mathrm{BTU} / \mathrm{SCF}$.

(c) Final product sales price is a direct function of world oil prices, adjusted upwards for their special value and desirability as a fuel. The adjustment for LNG is a $10 \%$ Asian bonus and a $\$ 5 / \mathrm{BBL}$ premium for GTL liquids.

(d) Annual operating costs of each gas project are assumed to be $5 \%$ of total capital investments for the LNG project and \$6/BBL for the GTL project.

(e) Operation efficiencies relative to the conversion of feedstock gas to salable product is assumed to be $91 \%$ for LNG and $60 \%$ for GTL.

(f) No additional investments are required to sell gas from PBU because of the extensive gas-handling facilities already in place at PBU for separation and reinjection of 7.5 BCFPD. The estimated capital investment required to develop PTU is $\$ 900$ million (1995\$).

(g) Excluding PTU development costs, the total investment requirements for the LNG project are adjusted upward from the $\$ 14$ billion $(1995 \$$ ) publicly announced in 1994 by Yukon Pacific for its proposed 14 MMTPA LNG project, to $\$ 16$ billion (1995\$) for the 17 MMTPA LNG project required to accommodate concurrent gas sales from PBU and PTU at 2.49 BFCPD. For the GTL option to handle the same gas volume as the LNG option, the plant investment is $\$ 12$ billion (1995\$), based on $\$ 40,000$ per daily barrel of liquid (DBL) of output capacity for a large scale (300 MBPD) stateof-the-art GTL operation in the Prudhoe Bay field area. 
(h) Major gas sales from PBU, starting in 2005 and ramping up to 2.05 BCFPD in 5 years, will reduce PBU oil recovery by 400 million barrels oil (MMBO). PBU gas sales will end in 2036.

(i) Gas sales from PTU start in 2008 at 0.44 BCFPD, providing a peak rate of gas sales from PBU and PTU of 2.49 BCFPD. PTU gas sales end in 2027.

(j) Federal and State of Alaska taxes and other charges are assumed to remain as they are at this date.

\section{Baseline Economic Results}

The economic model results for the baseline assumptions show that the LNG option would yield an $\mathrm{NPV}_{10}$ of $\$ 11.5$ billion (1995\$), while the GTL option could be expected to yield a $\$ 10.7$ billion (1995\$) $\mathrm{NPV}_{10}$, or about $7 \%$ less. These results compare to the $\$ 8.6$ billion (1995\$) for the no major gas sales case. The total incremental investments required for these yields, however, would be $24 \%$ greater for the LNG option than for the GTL option, $\$ 16.9$ billion compared to $\$ 12.9$ billion. These results are shown in Table 1 . The discounted cash flow model takes into account all income and expenses and provides for a $10 \%$ rate of return on the incremental investment for preparing and transporting the gas to market for the respective gas sales options. These comparative calculations show that, in spite of potential reductions in PBU recovery of as much as $400 \mathrm{MMBO}$ upon major gas sales, both LNG and GTL gas sales options have a greater payoff than the option of not selling the gas and continuing to reinject gas until the oil recovery reaches its economic limit. It is not nearly as clear which gas sales option is more preferable, however.

Table 1. Summary of gas sales options NPV's and investments.

\begin{tabular}{|c|c|c|}
\hline & $\begin{array}{c}\text { NPV }_{10} \text { LNG Option } \\
\text { (1995\$, billions) }\end{array}$ & $\begin{array}{l}\text { NPV }_{10} \text { GTL Option } \\
\text { (1995\$, billions) }\end{array}$ \\
\hline Prudhoe Bay Unit - No major gas sales & 8.6 & 8.6 \\
\hline Prudhoe Bay Unit & 11.1 & 10.4 \\
\hline Point Thomson Unit & 0.4 & 0.3 \\
\hline Total NPV 10 & 11.5 & 10.7 \\
\hline \multicolumn{3}{|c|}{ Total Investment (1995\$, billions) } \\
\hline Gas option investment & 16.0 & 12.0 \\
\hline Point Thomson development & 0.9 & 0.9 \\
\hline Total & 16.9 & 12.9 \\
\hline
\end{tabular}


Estimated baseline government revenues under the gas sales options for the State increase from the no gas sales case from $\$ 21$ to $\$ 32$ billion with the LNG option, and from $\$ 21$ to $\$ 31$ billion with the GTL option. Income tax proceeds for the federal treasury increase from $\$ 8$ to $\$ 34$ billion for the LNG option and from $\$ 8$ to $\$ 26$ billion for the GTL option (1995\$).

\section{Sensitivity Analysis}

Analysis of the sensitivity of project economics to the variables used in the calculations was performed to determine which economic input factors were most important. By knowing which variables cause the greatest change in project economics, efforts can be focussed to decrease critical costs, refine critical technology, or evaluate tax incentives, whichever the case may be. Variables analyzed include: (a) gas product net back fraction, (b) royalty rates, (c) State and federal income taxes, (d) GTL liquids premium, (e) field pipeline tariffs, $(f)$ GTL plant efficiency, $(f)$ investments, $(g)$ operating costs, $(\mathrm{h})$ gas usage for the LNG project, (I) the BTU content of the gas sold from the Units, and (j) the Asian LNG bonus.

The sensitivity analysis shows that a major cost driver for both the GTL and LNG conversion projects is initial investment costs. If this variable can be lowered or even held at the assumed value, both projects provide a $10 \%$ rate of return for the reference oil price, while providing the Units a reasonable price for their gas. Plant conversion efficiency is of even greater significance to the GTL conversion project. An increase in plant efficiency not only increases the profit stream by increasing liquid product sales volume, but the increased volume also decreases TAPS transportation costs for all transported liquids, providing a higher North Slope oil price than without GTL conversion. In the case of LNG, the delivered price as reflected by both the gas BTU content and the Asian bonus appear to be the most critical variables.

PBU is most affected by altering State and federal income taxes. For PTU, because it is less profitable, other variables such as gas product net back fraction and field tariffs come into play, as well as State and federal taxes and royalties. Because of its borderline economic status, government agencies are in a position to assist in improving the economic viability of the Point Thomson field.

An additional sensitivity was performed using a flat oil price forecast of $\$ 18 / \mathrm{BBL}(1995 \$)$ to evaluate the gas sales scenarios for a much more conservative oil price forecast than the EIA 1995 reference oil price forecast. Neither gas sales option is economic (does not provide a $10 \%$ rate of return) for the $\$ 18 / \mathrm{BBL}$ flat oil price forecast. Breakeven flat oil prices were calculated that would provide a $10 \%$ rate of 
return for the gas projects and gas sales from PBU alone. For the LNG scenario, the breakeven flat oil price was $\$ 19.36 / \mathrm{BBL}$; while the breakeven flat oil price for the GTL scenario was slightly higher at \$19.94/BBL. Conversely, the sensitivity results showed that the delay of gas sales by as much as 5 yrs has only a slight effect on profitability of both the LNG and GTL options, assuming product sales are not deterred by such delay.

These sensitivity results, clearly show that changes in one or more of these assumptions could significantly alter the financial results:

- For example, in considering the LNG option, there are a large number of would be LNG suppliers in the world seeking to fill the expected LNG demand growth from gas-short Asian nations. Many of these suppliers are thought to have smaller capital outlays (not having the necessity of building an $800-\mathrm{mi}$ gas pipeline as is required at the start for the Alaskan LNG project), and it is quite possible the LNG project Asian fuel bonus and its base LNG price will be less than anticipated, thereby reducing the LNG base economics. On the positive side, it is also possible, as more large LNG projects are designed and built around the world, that cost-saving measures will be found that would improve the LNG base economics.

- Likewise, for the GTL option, conversion efficiency might prove to be closer to the $57 \%$ level of the older South African plants rather than to the plant design level of $63 \%$ efficiency level for Shell's newer plant, thereby reducing the GTL base economics (a $60 \%$ conversion efficiency was used as the baseline assumption). In contrast, the target efficiency of 70 to $75 \%$ for advanced GTL technology under development may prove out in time to be ready for the rapid GTL deployment envisioned (or for major portions of the development, if such GTL development is phased in more slowly), which would improve the GTL base economics.

- Clearly, the economics of both of the gas sales options could be seriously impacted if investment cost contingencies associated with Alaska's climate, remoteness, and related factors prove to be underestimated; or if stand-alone projects such as the LNG and GTL projects require a greater than $10 \%$ rate of return to attract investors; or if world oil prices prove to be substantially lower than the DOE EIA reference oil price forecast (neither LNG nor GTL were found to be financially feasible at an $\$ 18 / \mathrm{BBL}$ flat oil price in this study's sensitivity analysis). 


\section{Conclusions}

At this point in time, if the assumptions for the economic variables are valid, both the LNG and the GTL option can be considered as economically promising and warrant consideration in the decision-making process. (Although the variables are subject to normal levels of uncertainty, we believe they are valid based on the public information available to us.) However, it is not possible to conclude that one option is significantly better than the other.

This evaluation does, however, answer the specific question it was directed to address, namely: Is GTL conversion a feasible alternative for bringing ANS natural gas to market? The conclusion from this assessment is that state-of-the-art GTL conversion technology appears to be feasible and could be deployed within a meaningful time frame to sustain ANS and TAPS oil operations for 20 or more years beyond what might be anticipated without GTL.

Placing the issue of GTL feasibility aside, this ANS gas utilization assessment is not expected to be the last of what has been a number of studies focused on the marketing of Alaska's large, and potentially much larger, remote natural gas reserve. Alaskans face difficult gas development and marketing decisions in the near future, and need to develop the most complete understanding of the options possible. This is particularly so with respect to likely requests for State tax incentives and other actions that might be desired to move private commitments forward.

\section{Recommendations}

To assist in responding to such requests and other decisions that must be made to implement the sale of ANS gas, this report concludes with a number of recommended follow-up analyses that interested industry, State and federal parties may wish to pursue in a timely manner:

1. Existing Infrastructure Savings-The economics of both of the options could benefit through the utilization of portions of the infrastructure existing at Prudhoe Bay and along the TAPS pipeline. These possibilities should be examined on a site-specific basis, not only for a GTL plant that would be built on the North Slope, but also for the LNG gas pipeline and prospective Valdez liquefaction and shipping facilities. (YPC reports that basic engineering and design have been completed, but it is likely that further engineering 
and design involving the Prudhoe Bay operators and Alyeska Pipeline Service Company will lead to additional refinements.)

2. Specific Cost Estimates--More precise, process- and site-specific cost estimates of the LNG and GTL options should be developed because of the important sensitivity of the economics of both of these options to capital costs in particular. These estimates should incorporate the latest in technologies and designs, attempting also to provide sufficient detail on the cost impact of technology advances possible within a meaningful timeframe.

3. TAPS Tariff Impact on Future Oil Production--A more complete assessment is desirable concerning the effect of reduced TAPS tariffs, anticipated from the envisioned GTL product volumes, on future ANS oil production from all existing fields and potential developments. The several dollar per barrel reduction suggested by this study could be important in determining how long selected ANS reservoirs might continue to produce, and could affect whether non-producing reservoirs might be brought on line.

4. Optimization of GTL Product Composition--To better refine the operating cost and price estimates of proposed GTL operations, technical assessments should be directed to delineating potential liquid product compositions with respect to: (a) feasible process chemistry, (b) methods of TAPS shipment (mixed with the crude or stored and batched separately, similar to oil product pipelines), (c) crude and GTL product separation and the refining process(es) required to obtain the ultimate GTL product value, and (d) other factors as appropriate.

5. ANS Cost Factors--A clearer picture should be developed of the cost penalties associated with capital construction and facility operation in the arctic climate and remote location of the ANS. This should be done for both GTL and LNG options and should also examine general Lower 48 and Alaskan capital and operating cost differences to provide the most reliable cost estimates for gas sales decision making.

6. Gas Sales Benefit to Alaska-The potential economic benefits of each gas commercialization option on the various regions and overall State should be assessed in detail to aid in decision making. Such examination might include: (a) an analysis of the types and aggregate of manufacturing and labor components for construction and operation of each gas option and the resulting stimulation of State and local economic development, (b) direct and indirect local employment to be generated (and saved or extended, 
if such be the case), and (c) gross and net revenues to State and local jurisdictions through prevailing or alternative tax schedules, etc.

7. Alternative GTL Development Schedule--The GTL option does not have to be developed at the pace required for the LNG project (resulting from the requirement to build the pipeline up front). The development scale was chosen to match the proposed TAGS LNG scale, pace, and scope in an attempt to make the obvious comparisons between the two options as comparable as possible. Hence, it would be useful to consider a slower development of GTL that could take advantage of the learning curve associated with deployment of new technology to lower costs and potentially take advantage of advanced GTL technology in the later modules for improved conversion efficiencies. Slower, incremental development would also reduce the magnitude of the capital outlays required in the early years and allow them to be offset by the increased profits from GTL sales. Such a development scenario increases the possibility of constructing more of the plant modules in Alaska and pacing the development over a long period of time to sustain higher employment and infrastructure levels within the State.

xvii 
xviii

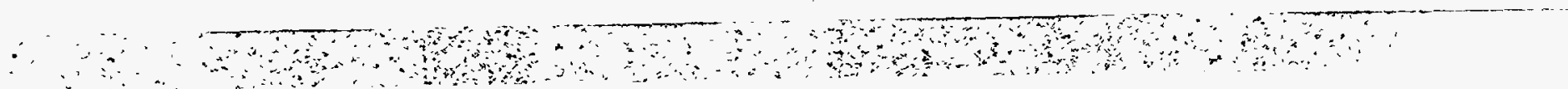




\section{ACRONYMS AND ABBREVIATION}

ACE

ACRS

ADEC

AND

ADNR

ADOR

AEO

AJC

ANS

ANGTS

ANWR

AOGCC

AOGR

API

ARCO

AT

ATRR

BBBL

BBL

$\mathrm{BBO}$

$\mathrm{BCF}$

BCFPD

BOPD

BP

BTF

BTU

CRS

DBL

DGC

DIU
U.S. Army Corps of Engineers

Accelerated cost recovery system

Alaska Department of Environmental Conservation

Anchorage Daily News

Alaska Department of Natural Resources

Alaska Department of Revenue

Annual Energy Outlook

Alaska Journal of Commerce, The

Alaska North Slope

Alaska Natural Gas Transportation System

Arctic National Wildlife Refuge

Alaska Oil and Gas Conservation Commission

Alaska Oil and Gas Reporter

American Petroleum Institute

Atlantic Richfield Company

Anchorage Times

Annual Total Revenue Requirement

billion barrels

barrel

billion barrels of oil

billion cubic feet

billions cubic feet per day

barrels of oil per day

BP Exploration [Alaska] Inc.

barrels of total fluid

British Thermal Units

Congressional Research Service

daily barrel liquid

Division of Governmental Coordination

Duck Island Unit

xix 
DOC

DOE

DOI

DR

DST

ED

EIA

ELF

FERC

FOP

FWS

GNP

GRI

GTL

IDC

INEL

IRR

JPT

KPA

KRU

$\mathrm{kg}$

kW-hr

LSMI

LNG

LPA

LPC

M

MBPD

MEFS

MI

MM

MMBBLS

MMBO
U.S. Department of Commerce

U.S. Department of Energy

U.S. Department of the Interior

Discount Rate - \%

drill stem test

Energy Daily

Energy Information Administration

economic limit factor

Federal Energy Regulatory Commission

Flat Oil Price

U.S. Fish and Wildlife Service

Gross National Product

Gas Research Institute

gas-to-liquids conversion

intangible drilling costs

Idaho National Engineering Laboratory

internal rate of return

Journal of Petroleum Technology

Kuparuk Participating area

Kuparuk River Unit

kilogram

kilowatthour - energy units

large scale miscible injectant project

liquefied natural gas

Lisburne Participating area

Lisburne Production Center

thousand

thousand barrels of oil per day

minimum economic field size

miscible injectant

million

millions barrels

million barrels of oil 
MMBOPD

MMBW

MMCF

MMCFPD

MMS

MMTPA

MPKPA

MPU

NEPA

NGL(s)

NMFS

NPA

NPBSA

NPC

NPI

NPRA

NSB

NWMP

OD

OGIP

OGJ

OOIP

PA

PBMGP

PBU

PGI

PIC

PMPA

POD

PS

PTU

PW

SBPA million barrels of oil per day

million barrels of water

million cubic feet

million cubic feet gas per day

Minerals Management Service

million metric tonnes LNG annually

Milne Point Kuparuk participating area

Milne Point Unit

National Environmental Policy Act

natural gas liquid(s)

National Marine Fisheries Service

Niakuk participating area

North Prudhoe Bay State participating area

National Petroleum Council

net profits interest

National Petroleum Reserve - Alaska

North Slope Borough

Northwest Milne Point area

Oil Daily

original gas in place

Oil \& Gas Journal

original oil in place

participating area

Prudhoe Bay Miscible Gas Project

Prudhoe Bay Unit or Permo-Triassic participating area

Petroleum Gas Intelligence

Petroleum Information Corporation

Point McIntyre participating area

Plan of Development

pump station

Point Thompson Unit

present worth

Schrader Bluff participating area 
SDNPA

TAGS

TAPS

TCF

USDOI

WASH

WBPA

WF

WI

WO

WSJ

YPC
Sag Delta North participating area

Trans-Alaska Gas System

Trans Alaska Pipeline System

trillion cubic feet

U.S. Department of the Interior

Washington Post

West Beach participating area

waterflood

water injection

World Oil

Wall Street Journal

Yukon Pacific Corporation

xxii 


\section{CONTENTS}

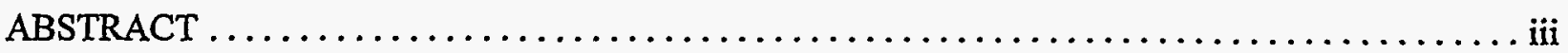

EXECUTIVE SUMMARY $\ldots \ldots \ldots \ldots \ldots \ldots \ldots \ldots \ldots \ldots \ldots \ldots \ldots \ldots \ldots \ldots \ldots \ldots$

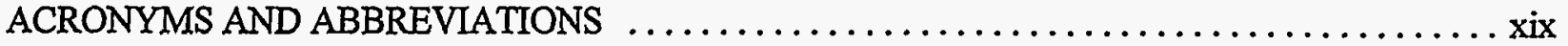

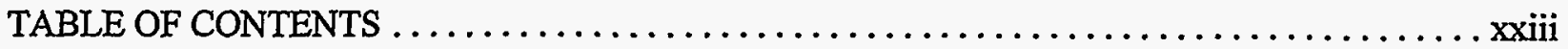

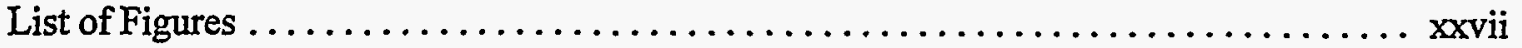

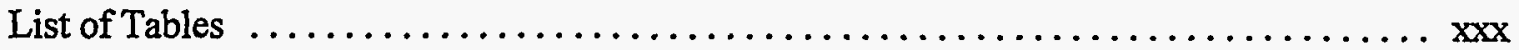

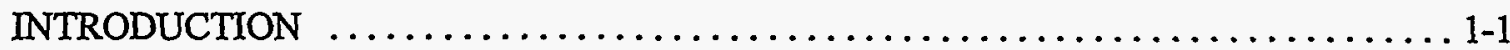

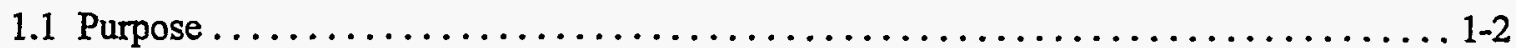

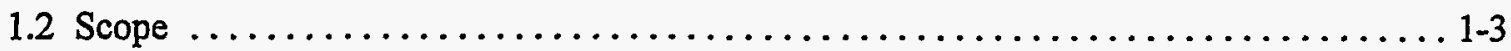

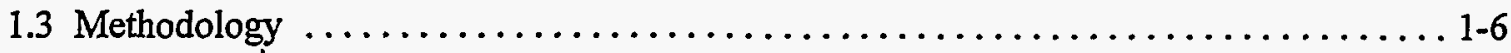

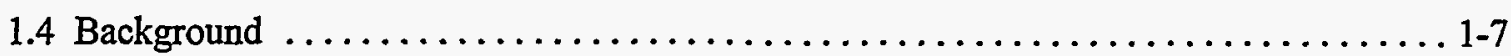

1.4.1 Key Issues Impacting ANS Gas Utilization $\ldots \ldots \ldots \ldots \ldots \ldots \ldots \ldots \ldots$

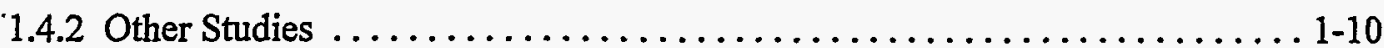

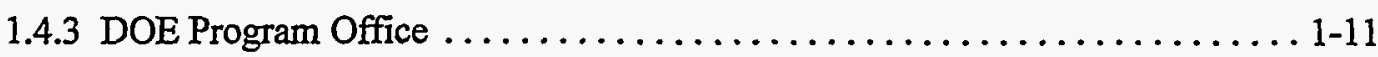

2. NORTH SLOPE OIL AND GAS RESOURCE ASSESSMENT $\ldots \ldots \ldots \ldots \ldots \ldots \ldots .2-1$

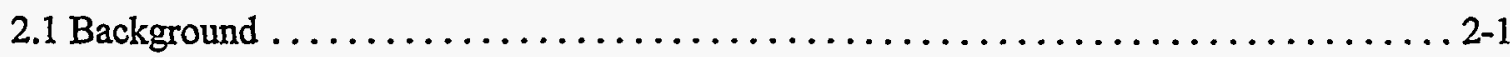

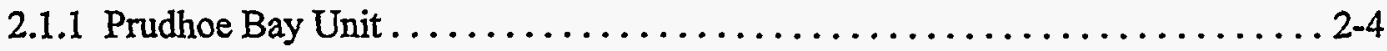

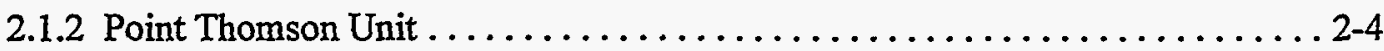

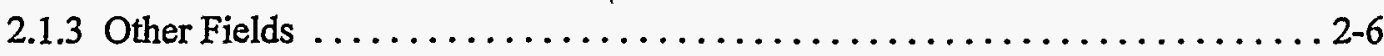

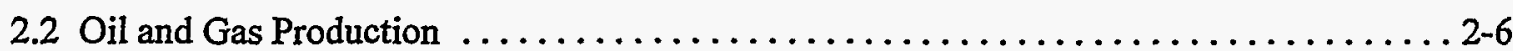

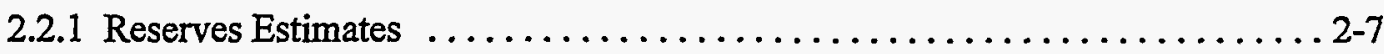

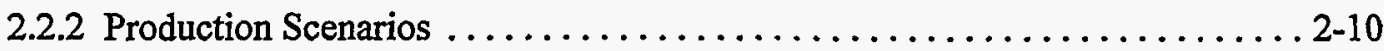

xxiii 


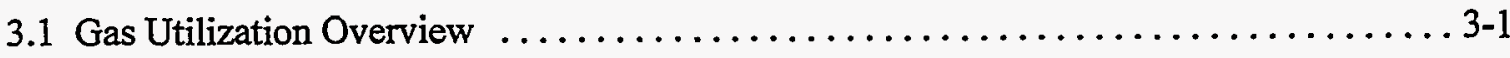

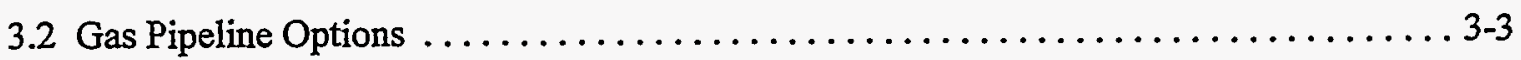

3.2.1 Alaskan Natural Gas Transportation System (ANGTS) ............ 3-4

3.2.2 Trans-Alaska Gas System (TAGS) LNG Project ............... 3-4

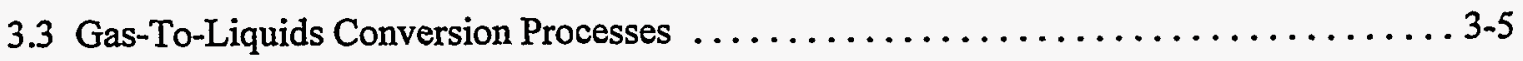

3.3.1 Overview ..............................

3.3.2 Synthesis Gas Conversion Processes . . . . . . . . . . . . . . . 3-7

3.3.3 Pyrolysis Gas Conversion Processes . . . . . . . . . . . . . .

3.3.4 LNG Liquefaction and Transportation $\ldots \ldots \ldots \ldots \ldots \ldots \ldots \ldots \ldots \ldots \ldots \ldots \ldots \ldots \ldots .14$

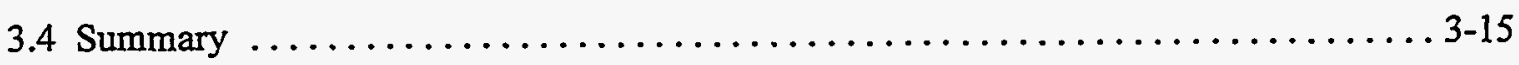

4. LNG AND GTL PRODUCTS MARKETS $\ldots \ldots \ldots \ldots \ldots \ldots \ldots \ldots \ldots \ldots \ldots \ldots \ldots \ldots$

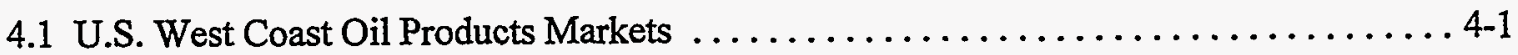

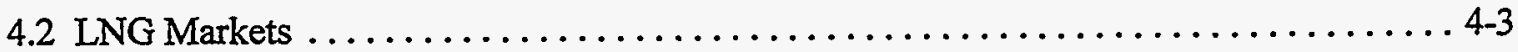

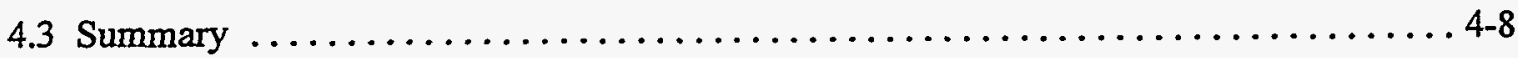

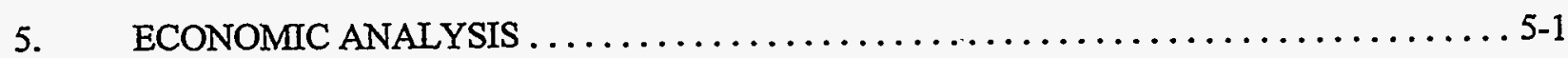

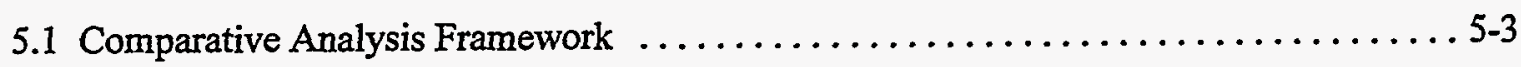

5.1.1 Fixed Economic and Technical Parameters ................ 5-4

5.1.2 Variable Economic Parameters and Base Assumptions . . . . . . . . 5-6

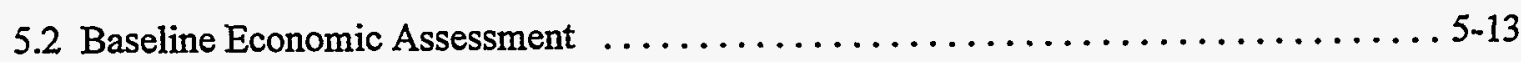

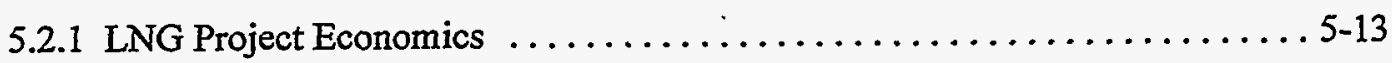

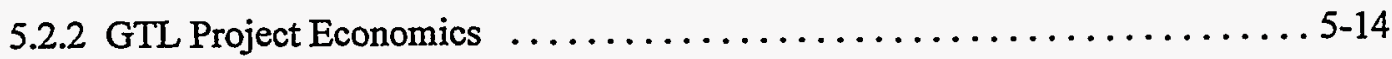

5.2.3 Economics for Prudhoe Bay Unit with Major Gas Sales .......... 5-15

5.2.4 Economics for Point Thomson Unit with Major Gas Sales . . . . . . . . . 5-17 
5.2.5 State and Federal Government Revenue $\ldots \ldots \ldots \ldots \ldots \ldots \ldots \ldots . . \ldots \ldots$

5.2.6 Baseline Economic Summary ..................... 5-19

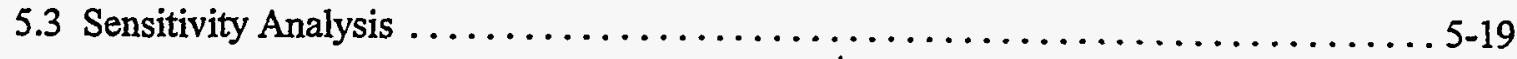

5.3.1 PBU and PTU Economic Sensitivity with Gas Sales to LNG Project ... . . 5-20

5.3.2 PBU and PTU Economic Sensitivity with Gas Sales to a GTL Plant. . . . . . 5-21

5.3.3 LNG Project Economic Sensitivity .................... 5-23

5.3.4 GTL Conversion Plant Economic Sensitivity ............... 5-23

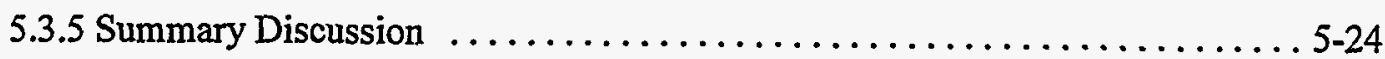

5.4 Analyses Using the Flat Oil Price Forecast $\ldots \ldots \ldots \ldots \ldots \ldots \ldots \ldots \ldots \ldots \ldots \ldots \ldots \ldots \ldots \ldots \ldots \ldots .25$

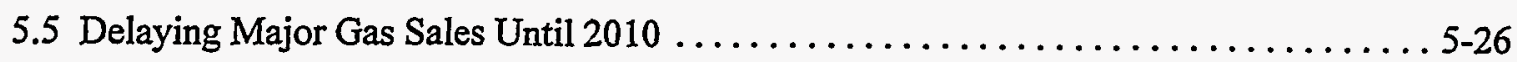

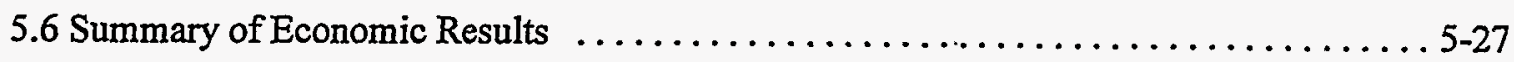

6. DISCUSSION, CONCLUSIONS, AND RECOMMENDATION $\ldots \ldots \ldots \ldots \ldots \ldots \ldots$.

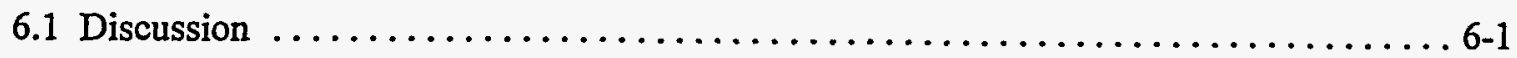

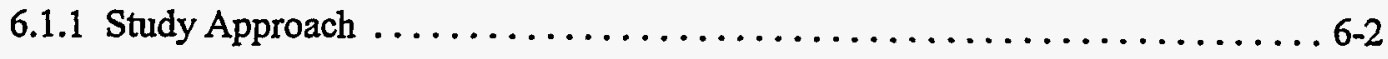

6.1 .2 Gas Sales - Base Economics ....................... 6-3

6.1 .3 Gas Sales - Economic Variables .....................6.3

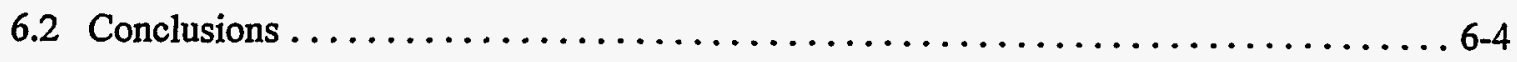

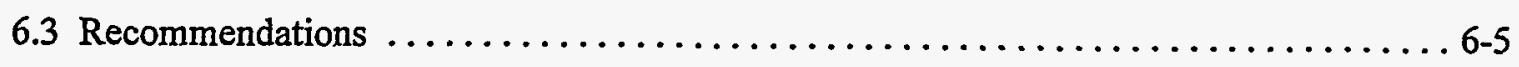

APPENDIX A - STATUS OF NORTH SLOPE DEVELOPMENT AND PRODUCTION ........ A-1

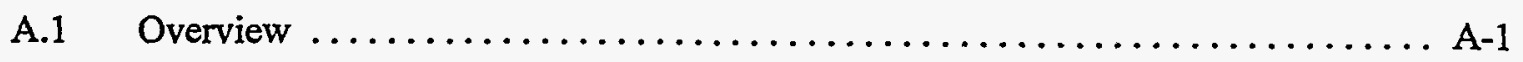

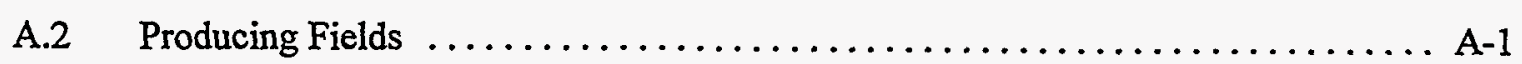

A.2.1 Prudhoe Bay Unit - Oil Production .................... A-1

A.2.2 Prudhoe Bay Unit - With Gas Sales to an LNG Project . . . . . . . . . . A A-7

A.2.3 Prudhoe Bay Unit - With Gas Sales to a GTL Project .............. A-11

A.2.4 Kuparuk River Unit $\ldots \ldots \ldots \ldots \ldots \ldots \ldots \ldots \ldots \ldots \ldots \ldots \ldots \ldots \ldots \ldots \ldots \ldots \ldots \ldots \ldots$

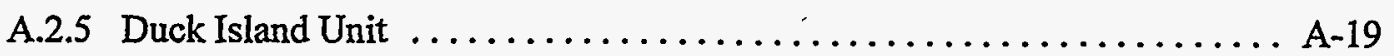

A.2.6 Milne Point Kuparuk Participating Area $\ldots \ldots \ldots \ldots \ldots \ldots \ldots \ldots$ A-26

A.2.7 Schrader Bluff Participating Area $\ldots \ldots \ldots \ldots \ldots \ldots \ldots \ldots \ldots \ldots$ A-31

A.2.8 Northwest Milne Point Area ...................... A-34 
A.2.9 Lisburne Participating Area $\ldots \ldots \ldots \ldots \ldots \ldots \ldots \ldots \ldots \ldots \ldots \ldots \ldots \ldots$

A.2.10 Point McIntyre $\ldots \ldots \ldots \ldots \ldots \ldots \ldots \ldots \ldots \ldots \ldots \ldots \ldots \ldots \ldots \ldots \ldots \ldots \ldots \ldots \ldots$

A.2.11 Niakuk ............................... A 4 . 45

A.2.12 Other Fields $\ldots \ldots \ldots \ldots \ldots \ldots \ldots \ldots \ldots \ldots \ldots \ldots \ldots \ldots \ldots \ldots \ldots \ldots \ldots \ldots \ldots$

A.2.13 Summary of Producing Fields $\ldots \ldots \ldots \ldots \ldots \ldots \ldots \ldots \ldots \ldots \ldots \ldots \ldots \ldots \ldots \ldots$

A.3 Fields with Development Potential $\ldots \ldots \ldots \ldots \ldots \ldots \ldots \ldots \ldots \ldots \ldots \ldots \ldots \ldots \ldots \ldots \ldots \ldots \ldots$

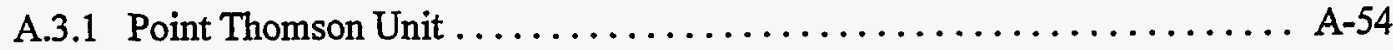

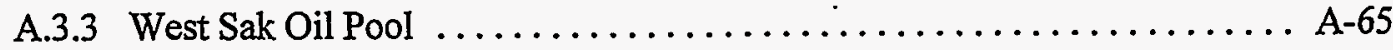

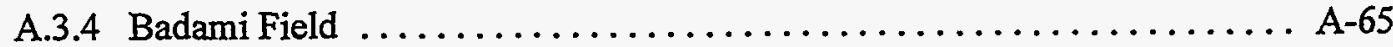

A.3.5 Kuukpik Unit $\ldots \ldots \ldots \ldots \ldots \ldots \ldots \ldots \ldots \ldots \ldots \ldots \ldots \ldots \ldots \ldots \ldots \ldots \ldots \ldots \ldots \ldots$

A.3.6 Thetis Island Unit . . . . . . . . . . . . . . . . . . . . . A

A.3.7 Kuvlum Field . . . . . . . . . . . . . . . . . . . . . . . . A 67

A.3.8 Cascade Oil Pool $\ldots \ldots \ldots \ldots \ldots \ldots \ldots \ldots \ldots \ldots \ldots \ldots \ldots \ldots \ldots \ldots$ A $68 \ldots \ldots$

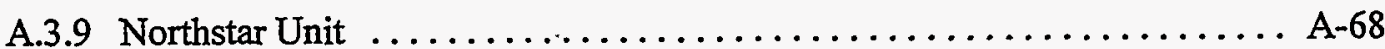

A.3.10 Sandpiper Unit . . . . . . . . . . . . . $\ldots \ldots \ldots \ldots \ldots \ldots$ A 69

A.3.11 Summary of Fields with Potential $\ldots \ldots \ldots \ldots \ldots \ldots \ldots \ldots \ldots$ A 69

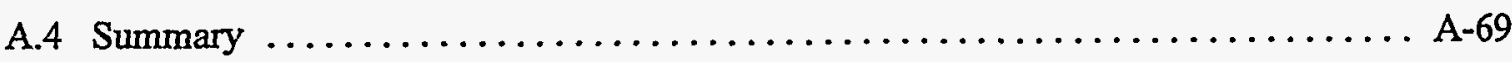

APPENDIX B - ECONOMIC ANALYSIS $\ldots \ldots \ldots \ldots \ldots \ldots \ldots \ldots \ldots \ldots \ldots \ldots \ldots \ldots \ldots \ldots \ldots \ldots$

B.1 Definitions and Assumptions of Technical and Economic Parameters ......... B-1

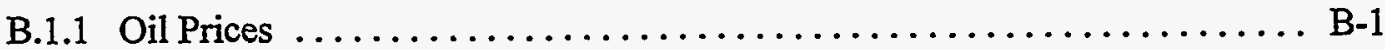

B.1.2 GTL Hydrocarbon Pricing $\ldots \ldots \ldots \ldots \ldots \ldots \ldots \ldots \ldots \ldots \ldots \ldots \ldots \ldots$

B.1.3 Gas Prices ................................ B-10

B.1.4 Inflation Adjustment $\ldots \ldots \ldots \ldots \ldots \ldots \ldots \ldots \ldots \ldots \ldots \ldots \ldots \ldots \ldots \ldots \ldots$

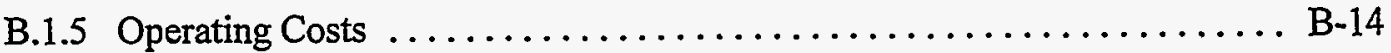

B.1.6 GTL Plant Efficiency ........................ B-17

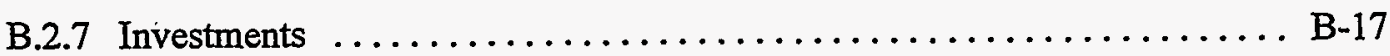

B.1.8 Production Forecasts $\ldots \ldots \ldots \ldots \ldots \ldots \ldots \ldots \ldots \ldots \ldots \ldots \ldots \ldots \ldots \ldots \ldots \ldots \ldots \ldots$

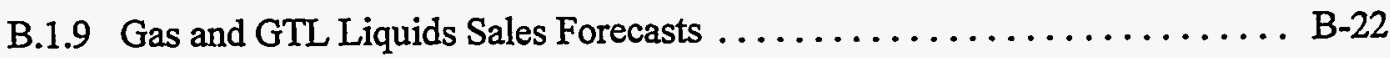

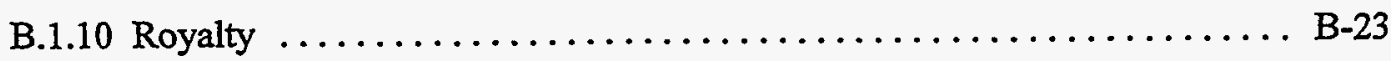

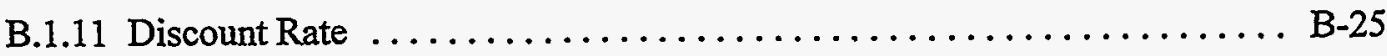

$x x v i$ 


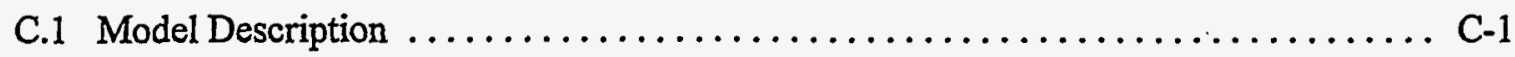

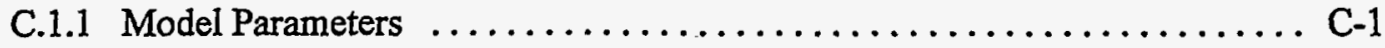

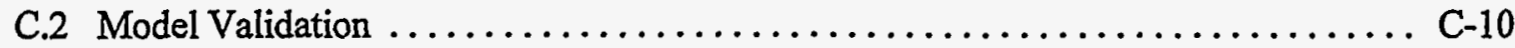

APPENDIX D - VALUES OF ECONOMIC ANALYSES $\ldots \ldots \ldots \ldots \ldots \ldots \ldots \ldots \ldots \ldots \ldots$ D-1

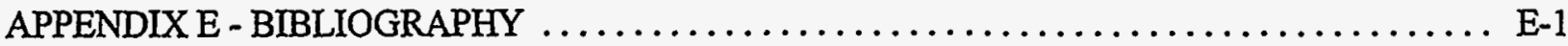

\section{FIGURES}

Figure 1.1

Figure 1.2

Figure 2.1

Figure 2.2

Figure 2.3

Figure 2.4

Figure 2.5

Figure 2.6

Figure 2.7

Figure 2.8

Figure 2.9

Figure 3.1

Figure 3.2

Figure 3.3
Assessing economics of future North Slope natural gas utilization

$1-4$ The Alaska North Slope historical production and production forecast at the EIA Reference Oil Price (economically recoverable oil)

Known oil and gas accumulations, selected dry holes and suspended wells, and NPRA-ANWR boundaries, North Slope Alaska ............. 2-2 Location of North Slope oil and gas accumulations and fields $\ldots \ldots \ldots .2-3$ PBU gas handling and reservoir mechanism schematic $\ldots \ldots \ldots \ldots \ldots .2-5$ PBU currently estimated reserve components compared to $1977 \ldots \ldots \ldots .2-5$ Net hydrocarbon gas available for sale from PBU $\ldots \ldots \ldots \ldots \ldots \ldots \ldots 2-9$ Net hydrocarbon gas available for sale from PTU $2-9$ Composite North Slope producing fields production forecast - no major gas sales $2-12$ Composite North Slope oil and gas production forecast with major gas sales from PBU and PTU .

Composite North Slope production forecast with gas-to-liquids conversion from PBU and PTU

Processes for conversion of natural gas to liquid fuels $\ldots \ldots \ldots \ldots \ldots \ldots$ 3-6

Fischer-Tropsch process schematic 3-9

Molecular Mass Distribution in Raw Product 3-11

xxvii 
Figure 3.4

Figure 4.1

Figure 4.2

Figure 4.3a

Figure $4.3 \mathrm{~b}$

Figure 4.4

Figure 4.5

Figure 4.6

Figure 5.1

Figure 5.2

Figure 5.3

Figure 5.4

Figure 5.5

Figure 5.7

Figure 5.8

Figure 5.9

Figure 5.10
Schematic of the Plasma Quench Process for conversion of natural gas to liquid fuels

U.S. average annual wholesale prices for gasoline, No. 2 fuel oil, and imported crude oil in dollars of the day $\ldots \ldots \ldots \ldots \ldots \ldots \ldots \ldots \ldots \ldots .2$

Historical world oil prices and oil price forecasts in $1 / 1 / 95 \$ \ldots \ldots \ldots \ldots 4-3$

LNG world supply volumes and regions $\ldots \ldots \ldots \ldots \ldots \ldots \ldots \ldots .4$

LNG world regional demand $\ldots \ldots \ldots \ldots \ldots \ldots \ldots \ldots \ldots . \ldots .4 . \ldots \ldots$

Historical prices for $L N G$ and crude oil $\ldots \ldots \ldots \ldots \ldots \ldots \ldots \ldots .7$

Example of relationship for a long-range LNG contract showing dependence on crude oil prices $\ldots \ldots \ldots \ldots \ldots \ldots \ldots \ldots \ldots \ldots .4$

Estimated Pacific Rim delivery costs for LNG from various sources . . . . 4-9

Schematic of gas and liquid flows from PBU for gas sales options

Average marine transportation costs to deliver crude oil from

Valdez, $\mathrm{AK}$ to lower 48

TAPS tariffs for three North Slope production scenarios

Wellhead gas and oil prices for the Prudhoe Bay Unit under LNG

and GTL scenarios for the AEO95 reference oil price forecast (1995\$) . . . 5-16 Variable sensitivity plot for Prudhoe Bay Unit with gas sales to a LNG project with illustration showing effect of lowering state and federal taxes by $15 \%$ - reference oil price forecast 5-20

Sensitivity plot for Point Thomson Unit with gas sales to a LNG project - reference oil price forecast

Variable sensitivity plot for Prudhoe Bay Unit with gas sales to GTL plant reference oil price

Variable sensitivity plot for PTU with gas sales to a GTL plant

- reference oil price.

Variable sensitivity plot for LNG project showing effect of altering variables on project net present value - reference oil price

Variable sensitivity plot for GTL plant showing effect of changing input variables on the net present value of the plant (with a constant net back of $11.6 \%$ ) - reference oil price 5-24

xxviii 
Figure 5.11

Figure 5.12

Figure A.1

Figure A.2

Figure A.3

Figure A.4

Figure A.5

Figure A.6

Figure A.7

Figure A.8

Figure A.9

Figure A.10

Figure A.11

Figure A.12

Figure A.13

Figure A.14

Figure A.15

Figure B.1

Figure B.2

Figure B.3

Figure B.4

Figure B.5

Figure B.6

Figure B.7

Figure B.8

Analysis to determine the break-even $\left(\mathrm{NPV}_{10}=0\right)$ flat oil price for each gas sales

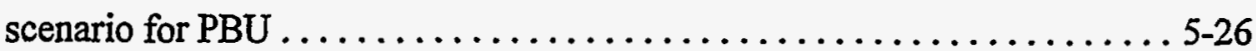

Effect of delaying gas sales from PBU from 2005 to 2010 using AEO95 reference oil price $5-27$

The Alaska North Slope historical production and production forecast at the EIA Reference Oil Price (economically recoverable oil) $\ldots \ldots \ldots \ldots \ldots \ldots$ A-2 PBU Permo-Triassic percent water cut versus percent recovery curve ..... A-6 Curve illustrating the determination of future PBU operating costs .....A-10

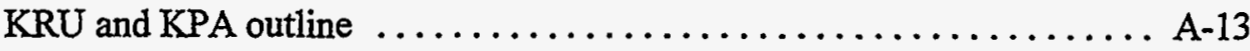

$\mathrm{KRU}$ water cut versus cumulative production as percent of

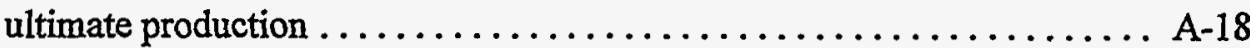

Endicott Participating Area of the Duck Island Unit $\ldots \ldots \ldots \ldots \ldots \ldots$ A-20

Sag Delta North Participating area $\ldots \ldots \ldots \ldots \ldots \ldots \ldots \ldots \ldots$ A-21

Endicott formation - percent water cut versus percent recovery .......A-25 MPKPA of the Milne Point Unit . . . . . . . . . . . . . . . . A-27

MPU - model data of percent water cut versus percent of ultimate recovery A-30 Lisburne Participation Area of PBU . . . . . . . . . . . . . . A-39

PTU possible reservoir limit $\ldots \ldots \ldots \ldots \ldots \ldots \ldots \ldots \ldots \ldots \ldots \ldots \ldots \ldots \ldots$

PTU possible development plan for gas sales $\ldots \ldots \ldots \ldots \ldots \ldots \ldots$ A-56

PTU possible sales pipelines and main road corridor $\ldots \ldots \ldots \ldots \ldots \ldots$ A-57

Curves illustrating several types of liquid behavior of condensate systems A-59

Historical world oil prices and world oil price assumption $\ldots \ldots \ldots \ldots$. B-2 Average marine transportation costs to deliver crude oil from Valdez, AK to lower $48 \ldots \ldots \ldots \ldots \ldots \ldots \ldots \ldots \ldots \ldots \ldots \ldots . \ldots \ldots$

TAPS tariffs for three North Slope production scenarios $\ldots \ldots \ldots \ldots \ldots$ B-6 PBU wellhead liquid prices under different production scenarios ........ B-7 North Slope Unit map showing field pipelines $\ldots \ldots \ldots \ldots \ldots \ldots \ldots$ B-8 Taps Quality Adjustment for North Slope liquid product .......... B-10 LNG Prices showing high and low price restrictions ............ B-12 Historical annual percent change in the Gross National price deflator .... B-14 


\section{TABLES}

Table 2.1

Table 2.2

Table 2.3

Table 3.1

Table 4.1

Table 4.2

Table 4.3

Table 5.1

Table 5.2

Table 5.3

Table 5.4

Table 5.5

Table 5.6

Table 5.7

Table 5.8

Table A.1

Table A.2

Table A.3

Table A.4

Table A.5

Table A.6

Table A.7

Table A.8

Table A.9

Table A.10
North Slope undeveloped oil and gas accumulations as of January 1, $1992 \ldots$ 2-7 Potential future production (without major gas sales) for

North Slope oil fields $2-8$

Potential future production (available for major gas sales) for

North Slope gas fields

Product selectivities of SASOL commercial reactors $3-10$

Comparative forecasts of world oil prices $\ldots \ldots \ldots \ldots \ldots \ldots \ldots \ldots, 4$

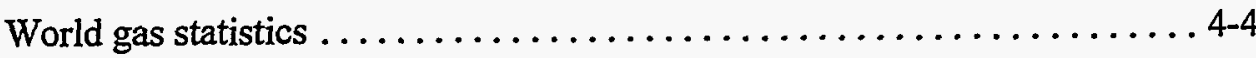

World $L N G$ demand forecast $\ldots \ldots \ldots \ldots \ldots \ldots \ldots \ldots \ldots \ldots \ldots, 6$

Example composition for PBU CGF residue gas . . . . . . . . . . . 5-9

LNG project costs and net revenues

GTL project costs and net revenues

Prudhoe Bay Unit economics - summary

Point Thomson Unit economics - summary

State of Alaska revenues under three producing scenarios - summary . . . 5-18

Federal government revenues under three producing scenarios - summary . 5-18

Summary of gas sales options NPV's and investments . . . . . . . 5-29

PBU production forecast $\ldots \ldots \ldots \ldots \ldots \ldots \ldots \ldots \ldots \ldots \ldots \ldots .4$

PBU drilling and investment schedule $\ldots \ldots \ldots \ldots \ldots \ldots \ldots \ldots \ldots \ldots$

PBU percent water cut and percent recovery data $\ldots \ldots \ldots \ldots \ldots \ldots$ A 6

PBU production forecast - with major gas sales $\ldots \ldots \ldots \ldots \ldots \ldots \ldots$ A-8

PBU gas sales forecast - with $L N G$ project $\ldots \ldots \ldots \ldots \ldots \ldots \ldots \ldots$ A-9

Prudhoe Bay Unit economics - summary . . . . . . . . . . . . A-12

KPA production forecast $\ldots \ldots \ldots \ldots \ldots \ldots \ldots \ldots \ldots \ldots \ldots \ldots \ldots \ldots \ldots \ldots \ldots \ldots$

KPA drilling and investment schedule $\ldots \ldots \ldots \ldots \ldots \ldots \ldots \ldots \ldots$ A-17

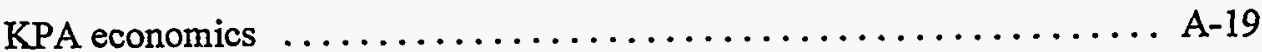

Endicott and Sag Delta North production forecast .............A-23 
Table A.11

Endicott drilling and investment schedule A-24

Table A.12

Table A.13

Table A.14

Table A.15

Table A.16

Table A.17

Table A.18

Table A.19

Table A.20

Table A.21

Table A.22

Table A.23

Table A.24

Table A.25

Table A.26

Table A.27

Table A.28

Table A.29

Table A.30

Table A.31

Table A.32

Table A.33

Table A.34

Table A.35

Table B.1

Table B.2

Table B.3

Table B.4

Table B.5

Table B.6

Table B.7

DIU economics

MPKPA production forecast .

A-28

MPKPA drilling and investment schedule

A-29

MPKPA economics A-31

SBPA production forecast A-33

SBPA drilling and investment schedule A-33

SBPA economics A-35

NWMP production forecast A-36

NWMP drilling and investment schedule A-37

NWMP economics A-38

LPA production forecast A-39

LPA drilling and investment schedule A-40

LPA economics A-41

PMPA drilling and investment schedule $\ldots \ldots \ldots \ldots \ldots \ldots \ldots \ldots . \ldots .43$

PMPA production forecast $\ldots \ldots \ldots \ldots \ldots \ldots \ldots \ldots \ldots \ldots \ldots \ldots \ldots \ldots \ldots$

PMPA economics $\ldots \ldots \ldots \ldots \ldots \ldots \ldots \ldots \ldots \ldots \ldots \ldots \ldots \ldots \ldots \ldots \ldots \ldots$

Niakuk drilling and investment schedule $\ldots \ldots \ldots \ldots \ldots \ldots \ldots \ldots$ A-47

Niakuk production forecast $\ldots \ldots \ldots \ldots \ldots \ldots \ldots \ldots \ldots \ldots \ldots \ldots \ldots$

Niakuk economics $\ldots \ldots \ldots \ldots \ldots \ldots \ldots \ldots \ldots \ldots \ldots \ldots \ldots \ldots$ A -50

PTU production forecasts $\ldots \ldots \ldots \ldots \ldots \ldots \ldots \ldots \ldots \ldots \ldots \ldots \ldots$

PTU drilling and investment schedule $\ldots \ldots \ldots \ldots \ldots \ldots \ldots \ldots \ldots$ A-61

PTU gas and liquids production forecasts $\ldots \ldots \ldots \ldots \ldots \ldots \ldots \ldots$ A-64

Point Thomson Unit economics - summary . . . . . . . . . . . . A-67

Summary ANS production forecasts $\ldots \ldots \ldots \ldots \ldots \ldots \ldots \ldots \ldots$ A-71

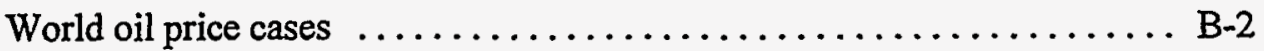

Marine transportation costs, Valdez to Lower $48 \ldots \ldots \ldots \ldots \ldots \ldots$ B-4

TAPS tariff schedule for currently producing fields $\ldots \ldots \ldots \ldots \ldots$ B-6

Field pipeline tariffs $\ldots \ldots \ldots \ldots \ldots \ldots \ldots \ldots \ldots \ldots \ldots \ldots$ B-9

North Slope gas sales prices for LNG project $\ldots \ldots \ldots \ldots \ldots \ldots \ldots$ B-12

North Slope gas prices for GTL project $\ldots \ldots \ldots \ldots \ldots \ldots \ldots \ldots \ldots$ B-13

Investment for a GTL plant on the Alaskan North Slope .......... B-19 
Table B.8

Table B.9

Table B.10

Table B.11

Table B.12

Table B.13

Table C.1

Table D.1

Table D.2

Table D.3
GTL plant investment schedule

LNG Project Investment Breakdown

LNG Project Investment Schedule B-22

Production forecast parameters B-23

Annual gas sales and converted liquids volumes-GTL project B-24

Royalty oil processing fees

Cost components used for each field C-3

Base values of input variables used in sensitivity analyses

D-1

Variable sensitivity values for LNG scenario for AEO95 reference oil price D-2 Variable sensitivity values for GTL scenario for AEO95 reference price .. D-3 


\section{ECONOMICS OF ALASKA NORTH SLOPE GAS UTILIZATION OPTIONS}

\section{INTRODUCTION}

The recoverable conventional natural gas resources in the developed and known undeveloped fields on the Alaska North Slope (ANS) total about 38 trillion cubic feet (TCF). No significant commercial sales have been made of this large natural gas resource because there are no existing facilities in place to economically transport this gas to current markets, all of which are outside of the North Slope. In addition to the known gas resources, the U. S. Geological Survey's (USGS) most recently published estimate of technically recoverable conventional natural gas resources in undiscovered fields in Northern Alaska has a mean value of 64 TCF (USGS, 1995).

About 26 TCF of the 38 TCF recoverable natural gas are estimated to be available for sale. ${ }^{\mathrm{a}}$ The balance will be consumed in oil and gas production operations on the North Slope. The 26 TCF equates to over 4 billion barrels of oil equivalent (BBOE). These known gas resources coupled with the potential for large additional gas discoveries in Northern Alaska, make it important for the U.S. Department of Energy (DOE), industry, and the State of Alaska to evaluate and assess the options for development of this vast gas resource to obtain the maximum benefit for Alaska and the nation, and to determine the impact that development would have on Alaska's economy and U.S. domestic energy supply, jobs, and balance of payments.

Currently, ANS gas is not marketed off the North Slope except in the form of natural gas liquids (NGLs), which are composed chiefly of butane and higher hydrocarbons that are blended with crude oil for transport in the Trans Alaska Pipeline System (TAPS). All of the produced gas, except that used for production operations, TAPS fuel, and local sales, has been reinjected back into the reservoirs to maintain reservoir pressure and for improved oil recovery projects. It has always been the intent of the North Slope operators to sell this gas when a market develops. In the interim, the use of the gas for improved oil recovery has been very successful as demonstrated by the increase in reserves for the Prudhoe Bay Unit (PBU) from the early estimates of under 10 billion barrels oil (BBO) to the current estimate of $13 \mathrm{BBO}(56 \%$ of the

a. Reserves and resource estimates in this report were developed by the authors using data publicly available from reports in the news media, the Alaska Department of Natural Resources, the Department of Energy, the Department of the Interior, and industry. These estimates and specific references are provided in the body of the report in Section 2 and Appendix A. 
original oil in place). Thus, the natural gas reinjected into the reservoirs has had significant value to the producers in improving production rates and ultimate oil recovery. However, the value of the gas for these purposes can be expected to decrease as the gas/oil ratio (GOR) continues to increase in PBU, which will require shut in of the higher GOR wells or additional investment to expand gas handling facilities beyond the current capacity of 7.5 billion cubic feet per day (BCFPD). As PBU oil production continues to decline, the value of the gas for interim use for enhancement of oil recovery at PBU will decline, making it more urgent that a means be developed to market the available ANS gas to obtain its maximum benefit.

Numerous options for use and sale of the ANS gas resources have been studied since the discovery of the Prudhoe Bay field. Two gas pipeline options that have been explored in the past are a gas pipeline from the ANS through Alaska to Canada and then to the U.S. lower 48 states for direct delivery of the ANS gas to the U.S. natural gas distribution system, and a gas pipeline through Alaska to an ice-free port for conversion to liquefied natural gas (LNG) for sale to Japan and other Asian countries. Recent advances in gas-to-liquids (GTL) conversion technology that may provide the means to economically convert natural gas to hydrocarbon liquids compatible with the ANS crude oil have raised the interest in this alternative option for ANS gas utilization. Such an option would mean that a gas pipeline would not have to be built and would provide a higher volume of hydrocarbon liquids to transport through TAPS. This added liquid volume would assist in maintaining the viability of TAPS operations and result in lower tariffs for all liquids transported in TAPS. Lower TAPS tariffs return a higher net oil price (wellhead oil price) for all fields, those currently producing as well as future developments. Given the ample gas supply potential in Canada and the U.S. that is closer to conventional Lower 48 gas markets than Alaska, only LNG and GTL options appear to be practical and merit study for ANS gas utilization at this time.

\subsection{Purpose}

The purposes of this study are:

(a) To provide a technical and economic evaluation of using technology for chemical conversion of natural gas-to-hydrocarbon liquids for bringing the large, remote, and currently unmarketable ANS natural gas resource to market.

(b) To examine how the gas-to-liquids (GTL) conversion option compares to the more frequently discussed option of construction of a natural gas pipeline to an all-weather Alaska port and 
construction of a new plant for physical conversion of gas to LNG, with subsequent tanker transport and sale of the LNG to Asian buyers.

(c) To provide a basis for discussion and evaluation of the interrelated, complex issues and concerns involved in the development and sale of the ANS gas resource.

The results of the evaluations and economic comparisons are intended to provide information to assist industry, the State of Alaska, and the federal government in making a better assessment of how to realize the maximum benefit from the ANS oil and gas resources.

\subsection{Scope}

First, locations of the known natural gas resources on the North Slope of Alaska are identified and recoverable natural gas volumes estimated. Next, the impact of major ANS gas sales on current and future oil production is assessed based on two potentially viable ANS gas sales scenarios, an LNG project and a GTL conversion project. The two gas sales scenarios are then technically and economically evaluated. Major components of the evaluation include an assessment of conversion and transportation options; a review of natural gas, LNG, crude oil, and products markets; and a return-on-investment economic analysis of the alternatives. The economic analysis is driven by gas and oil prices available on the world market and allows comparable examination of the two different gas sales scenarios. These components are schematically illustrated in Figure $\mathbf{1 . 1}$.

The resource assessment component is illustrated by the left side of Figure 1.1 and discussed in detail in Section 2. In evaluating the options for utilization of ANS natural gas, it is necessary to account for the interaction of ANS gas production with ANS oil production. While some of the known gas resources on the North Slope are in gas reservoirs that have been capped waiting for commercial production opportunities, such as the Point Thomson Unit (PTU), or were discovered during oil exploration activities and were left undeveloped, most of the known gas available for potential major gas sales is associated gas that is co-produced along with the oil production from PBU. The current rate of gas production from PBU is about 7.5 BCFPD. Except for gas used locally on the North Slope as fuel for field and TAPS operations, this gas is now being reinjected to maintain reservoir pressure and to increase oil production. Thus, ANS natural gas has a current use and value to the producers, but the value of the gas for reinjection to increase PBU oil recovery is expected to decrease over the life cycle of oil production as the benefits of pressure 


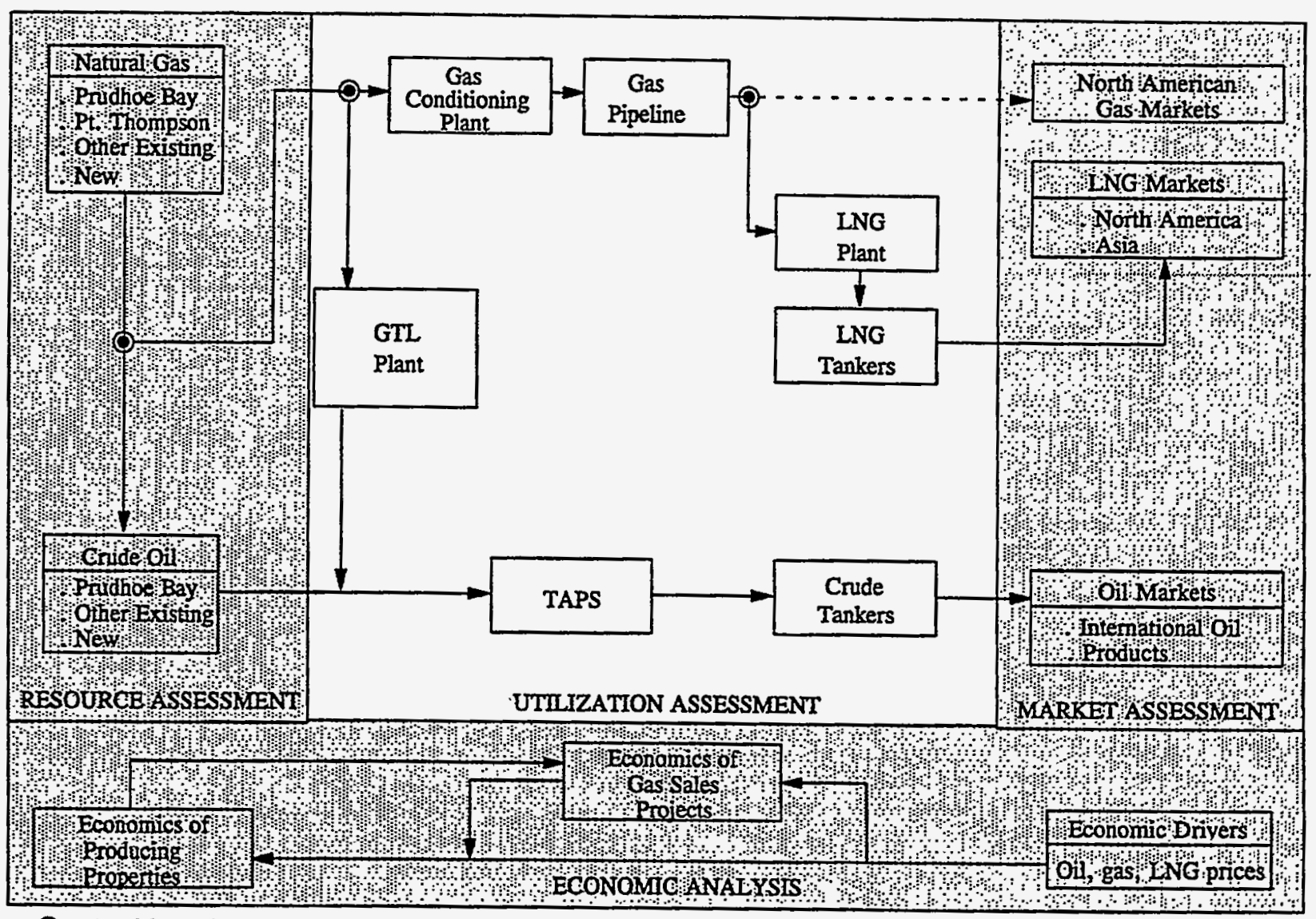

Q = Decision point for process options

Figure 1.1. Assessing economics of future Alaska North Slope natural gas utilization.

maintenance diminish and enhanced recovery projects using natural gas and NGLs are completed. There is also an interaction between potential LNG and GTL projects on the continued economic life of the ANS oil fields. A successful LNG project may extend the economic life of oil production at PBU by increasing field overall profitability and -- provided TAPS operations remain viable -- enabling some additional oil recovery to take place that would replace some of the oil that may not be recovered due to major gas sales. Similarly, a successful GTL project would also potentially increase the profitability of PBU through sale of gas to the project. In addition, the liquid hydrocarbon product made from the gas would increase the volume of liquids being transported through TAPS, which would result in lower pipeline tariffs for crude oil and GTL liquids. The lower TAPS transportation costs would also increase the wellhead oil price for all ANS oil production and potentially extend the oil producing life of a number of ANS fields, including PBU.

The conversion and transportation options are represented by the middle portion of Figure 1.1. The three optional paths from reserves to end markets represented are (1) gas delivered via a new gas pipeline 
from the North Slope connecting to a gas pipeline system through Canada to U.S. markets, (2) gas delivered via a new gas pipeline to an LNG facility where it is liquefied and then transported by LNG tanker to a gas market, and (3) gas delivered to an ANS GTL conversion plant where it is converted to a liquid and then delivered to TAPS where it is blended with ANS crude oil and transported to the oil market. (An alternative that was not examined in this study would be to transport the GTL product as intermittent slugs in TAPS). The first optional path, gas transported via a new gas pipeline to an existing gas pipeline, is described briefly in Section 3.2.1, but is not analyzed because the economics are generally recognized to be unfavorable.

For the two options analyzed in detail, the individual component pieces are selected to make the resulting evaluations as comparable as possible. LNG technology is a mature technology and the challenges involved in making a decision to develop the LNG option are primarily economic. Major environmental concerns have not been raised at this point. In comparison, GTL conversion technology is rapidly evolving and projects with the large scale envisioned in the North Slope scenario examined in this study do not exist today. Hence, the comparisons developed in this study are based on input data for both options that have different ranges of uncertainty in cost estimates. Currently, the GTL conversion option has a broader range of uncertainty than the LNG option. The same gas sales rates and the same development schedules are assumed for both options. Also, the gas price that is paid to the gas owners (the producers) is determined by requiring that each option provide a $10 \%$ rate of return on investment to the project developers. $\mathrm{A}$ sensitivity analysis is performed to indicate the effects changing the variables would have on the economics of each option. Gas conversion processes and the advantages and disadvantages of each of the two transportation options are discussed in Section 3.

The right side of the illustration in Figure 1.1, represents the market forces that influence and drive the prices for natural gas, LNG, and oil and petroleum products. The inclusion of the GTL conversion option for use of ANS gas means that not only are gas and LNG markets important to ANS gas sales but also crude oil and product markets. Current and future prices of pipeline gas in the U.S. and gas as LNG in Asian markets are determined by different market factors. U.S. natural gas market prices are determined by the domestic supply/demand balance. The U.S. gas supply has generally been in surplus for the past 10 years and prices have fallen on a constant dollar basis. The cost of finding and developing new gas reserves is not a very significant factor in determining prices in Asian LNG markets at the present time. LNG markets typically utilize gas reserves in remote production areas where available gas reserves exceed production capability and local gas demand. In those locations, the primary market factors are the availability of LNG facilities, cost of liquefaction, and cost of LNG transportation. The economics of the GTL conversion option 
depends on prices in oil product markets, which are primarily dependent on the international crude market, rather than prices in gas markets. The oil and gas market assessments are described in Section 4.

The three assessment components of Figure 1.1 are brought together in the economic analyses of the no-major-gas sales reference case and the comparison of an LNG option to a GTL conversion option (presented in Section 5). International gas and oil markets drive the prices, which influence the optimum timing for major gas sales from the fields and the viability of the gas sales options. The economic analyses of the two gas sales options also include the impact of major gas sales on future ANS oil recovery potential. Section 5 provides comparative economics and evaluations of the sensitivity of the analyses to cost estimates for new process technologies and other cost elements. The two gas sales scenarios (LNG and GTL) are evaluated such that all project developers receive a $10 \%$ rate of return on their investments. This is accomplished by varying the price paid to the producers (North Slope unit owners) for their gas through the use of a gas product net back fraction applied to the price received for the LNG or the GTL liquid product. The North Slope gas price (derived from the gas product price times the gas product net back) is used in evaluating the effects of each gas sales option on the economics of the producing units. The actual gas prices received by the gas producers from the gas project owners would be determined by a gas sales contract and could involve sharing of facilities, risks, and other factors. The effects of major North Slope gas sales on industry, State of Alaska, and federal income are also estimated.

Detailed discussions of the status of ANS oil and gas development, including the basic data and forecasts used in the economic analyses, the description of the economic model, details of the sensitivity analyses, and the bibliography are included in Appendices $\mathbf{A}$ through $\mathbf{E}$.

Conclusions based on the results of the analyses are presented in Section 6.

\subsection{Methodology}

Discounted cash-flow analyses are performed to determine the economic limit for the producing fields, the value of each field's resources, and the economic viability of each of the gas utilization options. The value of the projects are quantified in terms of the net present value (NPV). A project that produces a return exactly equal to the discount rate (DR) has a net present value of zero $\left(N P V_{D R}=0\right)$, indicating that the investment earns the minimum acceptable rate of return. The minimum acceptable rate of return for new projects may vary for different companies depending on their internal assessment of variables such as project 
risks, oil and gas price expectations, and alternative investment opportunities on a worldwide basis. All of the major developments on the North Slope, including infrastructure such as TAPS, have multiple owners with varying ownership levels and competing interests, which makes it impossible to choose a discount rate that would be representative for each company.

The gas sales options are evaluated as stand-alone projects that purchase gas from the producing units based on the gas product net back fraction. The owners of the gas utilization projects could include the unit owners, developers such as YPC, and possibly purchasers such as Japanese companies in an arrangement similar to TAPS. No attempt is made in this study to evaluate impacts of arrangements such as these.

Uncertainties in assumptions are evaluated by determining the sensitivity of project economics to changes in economic variables. The effects of changing variables such as oil price forecasts, operating costs, capital investment, process efficiencies, and federal and State taxes are evaluated.

\subsection{Background}

The possibility of commercializing the huge North Slope gas reserves has been the subject of numerous studies since 1970 (State of Alaska, 1996). These studies have involved evaluations of proposed projects for exporting the Alaskan gas to supply natural gas markets in the lower 48 states as well as foreign markets. One option that has been considered in the past is the Alaskan Natural Gas Transportation System (ANGTS), which would involve a gas pipeline through Alaska and Canada to markets in the lower 48 states. Another plan was proposed in the early 1980's for a Trans-Alaska Gas System (TAGS) project that has evolved into the project proposed by Yukon Pacific Corporation (YPC), a division of CSX Corporation. Under this plan a gas pipeline would be built paralleling TAPS to transport the gas to a liquefaction plant located on Prince William Sound (Valdez, AK), where it would be converted to LNG and exported to Asian ING markets. Recently, a major feasibility study for LNG options was conducted by the three major North Slope oil and gas producers (Arco, BP, and Exxon). The study has not been released outside of the participant companies; however, it was reported in July 1995 that the major gas owners on the North Slope had concluded that a large Alaska LNG project could not compete in today's Pacific Rim markets and is at least 10 years off, probably longer (Oil Daily, 1995a; Energy Daily, 1995).

Investments in oil recovery projects have overshadowed development of natural gas resources on 
the ANS almost entirely because of uneconomic gas market conditions. Furthermore, existence of North Slope oil production and transportation infrastructure has caused the operators to direct their exploratory and development efforts to oil projects that utilize and prolong the effective life of these installations. Major gas sales were anticipated at the initial unitization of PBU and have been the subject of continuing studies and evaluations over the life of the field. However, the operators will continue to be unwilling to invest in exploration and production for gas until there is greater certainty in market timing and gas value.

The primary drawback to any ANS gas utilization project is the ability of the market to provide a reasonable wellhead gas price. Hence, major gas sales from PBU, developing other proven North Slope gas resources, and exploration targeted to the large potential undiscovered natural gas resource on the North Slope cannot be expected to occur until the market value of the gas is greater than its value for the production of oil on the North Slope. This study evaluates the LNG and GTL conversion options to determine if they can be expected to provide viable markets for ANS gas.

\subsubsection{Key Issues Impacting ANS Gas Utilization}

There are several interrelated factors, issues, and concerns that need to be considered by industry, State, and federal interests in order to properly assess ANS gas utilization. It is the need to address these issues and to determine their impact on the overall ANS resource assessment that prompted this study to be undertaken at this time. These issues are as follows:

- ANS oil production, which has accounted for almost $25 \%$ of the daily U.S. domestically produced oil since production was initiated from the Prudhoe Bay field in 1977, has been declining since its peak of over 2 million barrels of oil per day (MMBOPD) in 1987 to just over 1.5 MMBOPD in 1995. This production will continue to decline in the future as shown in Figure 1.2. The production forecasts shown were developed by the authors based on publicly available data and are discussed in Section 2 and Appendix A. This decline is dominated by the production decline from the Prudhoe Bay field and clearly cannot be halted or reversed without major new discoveries and developments.

- TAPS has a minimum throughput at which it can be operated [U.S. Department of Energy (DOE), 1993a]. The minimum throughput will be determined by both technical constraints and operating and maintenance costs. The dashed lines and arrows at the bottom of Figure 1.2 indicate the range 
of minimum TAPS throughput of 200 to 400 thousand barrels of oil per day (MBOPD) discussed in the DOE (1993a) report. With that throughput range and projected current field operations, TAPS shutdown could occur between 2009 and 2016. This range has not been firmly established and it is certain that every effort will be put forth by industry and the State of Alaska to maintain the viability of TAPS for as long as possible. Although it is a common belief by many parties in Alaska that these efforts will be successful and the lower limit will be reduced to $100 \mathrm{MBOPD}$ or less, there are no known studies by Alyeska Pipeline Service Company or the major owners of TAPS to confirm this. Hence, the 200 to $400 \mathrm{MBOPD}$ range is used in this study to illustrate the effects that a shutdown would have on ANS production. The end of ANS production will more likely be dictated by oil pipeline transportation costs considerations than by production costs of North Slope fields. A shutdown, mothballing, or abandonment of TAPS and consequently other existing ANS infrastructure would significantly burden the economics of future ANS exploration and development projects and discourage efforts to pursue any developments except very large, major ANS exploration prospects. Additional large volumes of liquid production from new discoveries and field developments or major new projects, such as GTL conversion, prior to TAPS shutdown would extend the operational life of TAPS and result in the recovery of significant additional oil from existing producing ANS fields, as well as production from future potential fields and projects.

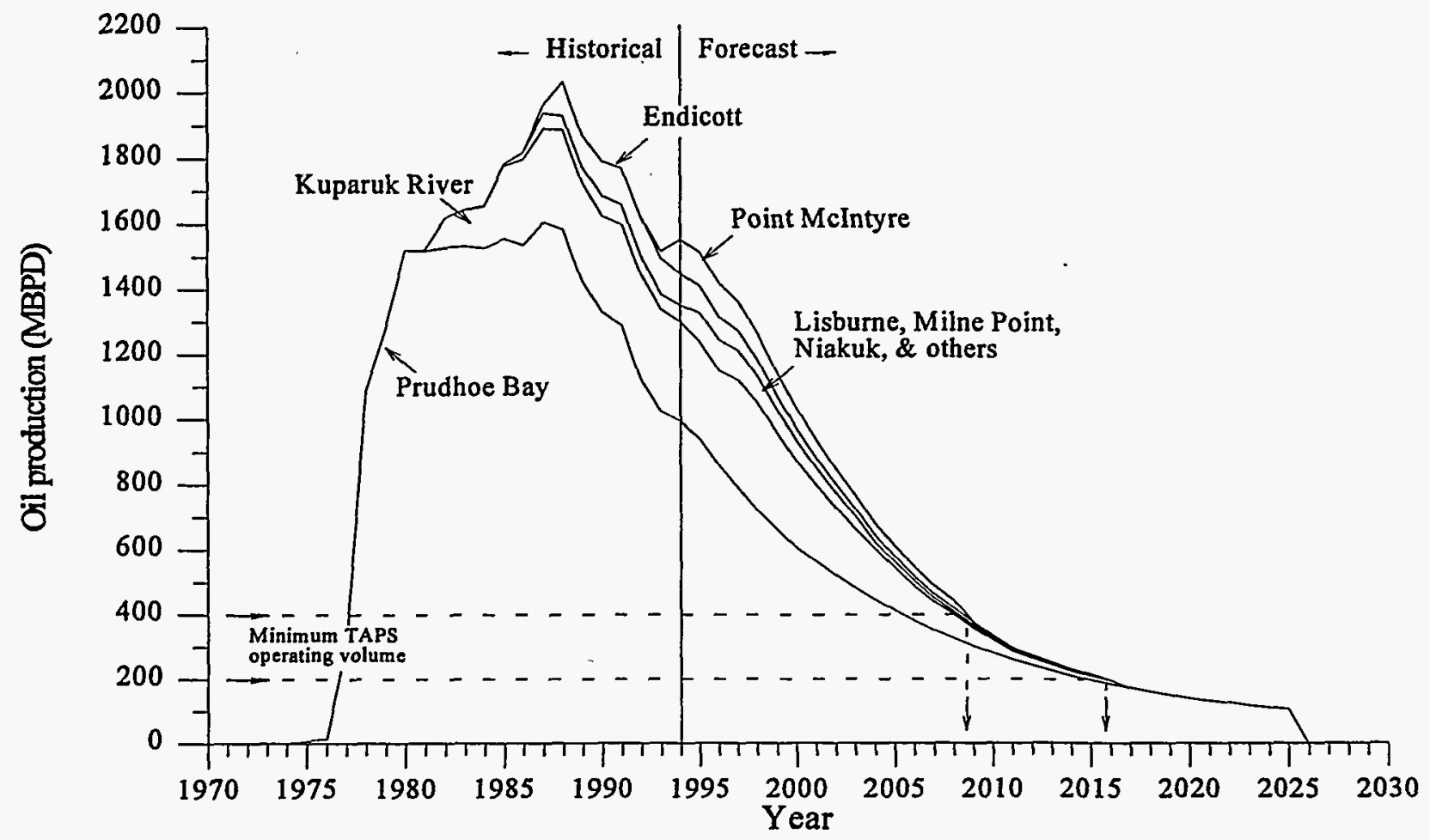

Figure 1.2. The Alaska North Slope historical production and production forecast at the Energy Information Administration (EIA) Reference Oil Price (economically recoverable oil). 
- Gas pipeline and LNG plant scenarios have historically been considered as the most likely commercialization route for ANS gas. However, advances in GTL conversion technology and the development of commercial projects around the world have increased the possibility that the conversion of natural gas to high-value, environmentally desirable, hydrocarbon liquids compatible with the TAPS transportation system has become a viable option for utilizing ANS gas resources.

- Long lead times, on the order of 5 to 10 years, are required to bring major ANS development projects on production. Hence, the time for public and private policy debate attaining optimum use of the remote ANS gas before TAPS shutdown (possibly as early as 2009) is becoming relatively short.

- In addition to the impact of GTL processes on the future of the ANS gas utilization, the development of economical hydrocarbon conversion processes for production and upgrading of heavy oils and tar on the North Slope could also have a significant impact. The West Sak and Ugnu fields are estimated to contain about 35 billion barrels of original heavy oil and bitumen in place (Mahmood, 1995) (see Figure 2.1 and Figure 2.2). The exploitation of these resources may depend on maintaining the viability of TAPS operations until these resources can be economically developed.

\subsubsection{Other Studies}

In 1990, the DOE Office of Fossil Energy, in cooperation with the State of Alaska, conducted a study of the Alaska North Slope oil and gas resources. A report titled, "Alaska Oil and Gas - Energy Wealth or Vanishing Opportunity?" was released on March 12, 1991 (DOE, 1991). The history of exploration and development up to early 1990 is described in that publication. The report presented an analysis of several potential scenarios concerning future production from the North Slope. Five producing oil fields, two fields nearing development, four discovered but undeveloped fields and three potential exploratory areas were analyzed for their effect on the lifetime of TAPS.

The National Energy Strategy (NES) issued in February 1991 included a call for accelerated development of five undeveloped Alaskan North Slope fields (West Sak, Point Thomson, Gwyder Bay, Seal Island/Northstar, and Sandpiper Island). The DOE was directed in the NES to establish a task force to identify specific technical and regulatory barriers to the development of these fields and make recommendations for their resolution. A report titled "Alaska North Slope National Energy Strategy 
Initiative - Analysis of Five Undeveloped Fields," was released in May 1993 (DOE, 1993). The report presented an analysis of environmental, regulatory, technical, and economic information relating to the development potential of the five fields.

These two earlier Alaska North Slope oil and gas resource studies and the study presented in this report have been performed at the DOE's Idaho National Engineering Laboratory (INEL) in Idaho Falls, Idaho. This study makes full use of INEL's previous studies of Alaska's North Slope oil outlook in 1991 and 1993, and new information gathered by the authors to update and expand upon these earlier efforts to assess the potential for development of the natural gas resource.

\subsubsection{DOE Program Office}

The study presented in this report was funded by the DOE Office of Fossil Energy through the Gas Processing program, a component of the Natural Gas (Supply) Research Program. It was directed and managed by DOE's Morgantown Energy Technology Center, which implements most of the Natural Gas Research Program, and by the Gas Processing program within the Office of Fossil Energy's Washington, D.C. headquarters Office of Gas and Petroleum Technology. 


\section{NORTH SLOPE OIL AND GAS RESOURCE ASSESSMENT}

This section provides a review of ANS oil and gas resources and an assessment of the fields and quantities of those resources. This section also contains a review of the historical oil and gas production on the North Slope, the factors that will influence future production of oil and gas, a summary of the production forecasts described in detail in Appendix A, and the anticipated impact of major gas sales on ANS oil and gas production.

\subsection{Background}

The remaining gas and oil resources in the developed and known undeveloped fields on Alaska's North Slope at the beginning of 1995 totaled over 38 TCF of recoverable gas and over 6 billion barrels of recoverable oil (crude, condensate, and NGLs). Undiscovered, technically recoverable, conventional natural gas resources in northern Alaska are estimated by the U.S. Geological Survey to be between 23 TCF (95\% probability) and 124 TCF (5\% probability), with a mean value of 64 TCF (USGS, 1995). Figure 2.1 shows the known oil and gas accumulations and selected dry holes and suspended wells across the North Slope. Figure 2.2 is a North Slope map showing the locations of producing pool and unit boundaries and undeveloped discoveries and accumulations. It is unlikely that any of the other North Slope fields would have been developed without facility cost-sharing made possible by the development of the Prudhoe Bay field infrastructure and the existence of TAPS. A more detailed discussion of the history of North Slope oil and gas exploration is presented in Section 2 of a 1991 DOE report entitled "Alaska Oil and Gas - Energy Wealth or Vanishing Opportunity" (DOE, 1991). The fields and pools shown in Figure 2.2 are described in Appendix A.

All of the major producing ANS fields contain both oil and gas in common reservoirs and gas is being produced along with the oil as a part of the oil production process. All of the produced gas, except that used for production operations, NGL components sold with crude oil production, and local sales, has been reinjected back into the reservoirs to maintain reservoir pressure and for improved oil recovery projects. ANS gas that is injected back into the reservoirs will be available for sale when a gas marketing system is developed. 


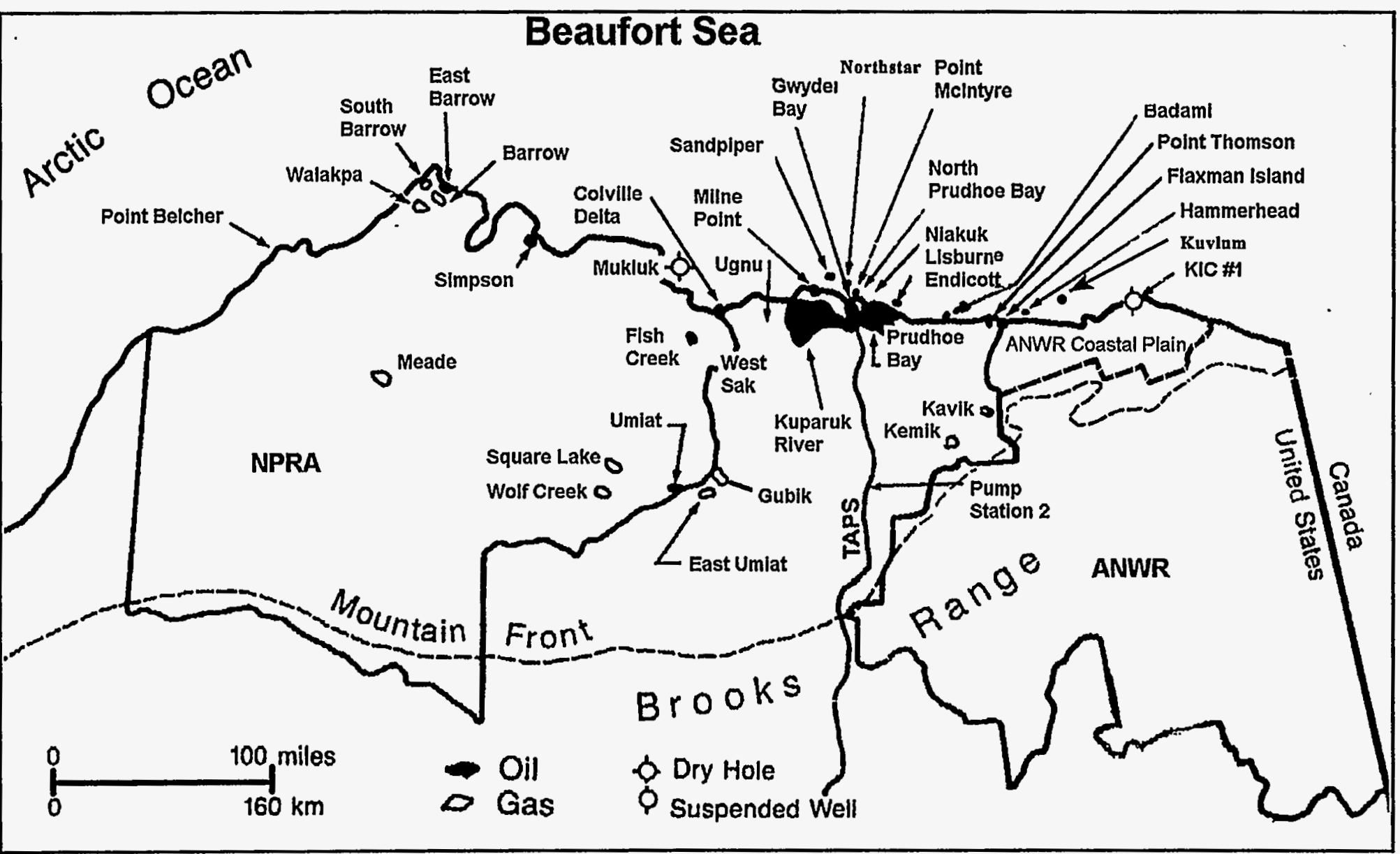

Figure 2.1. Known oil and gas accumulations, selected dry holes and suspended wells, and NPRA-ANWR boundaries, North Slope Alaska (DOE, 1991, ADNR, 1991a). 


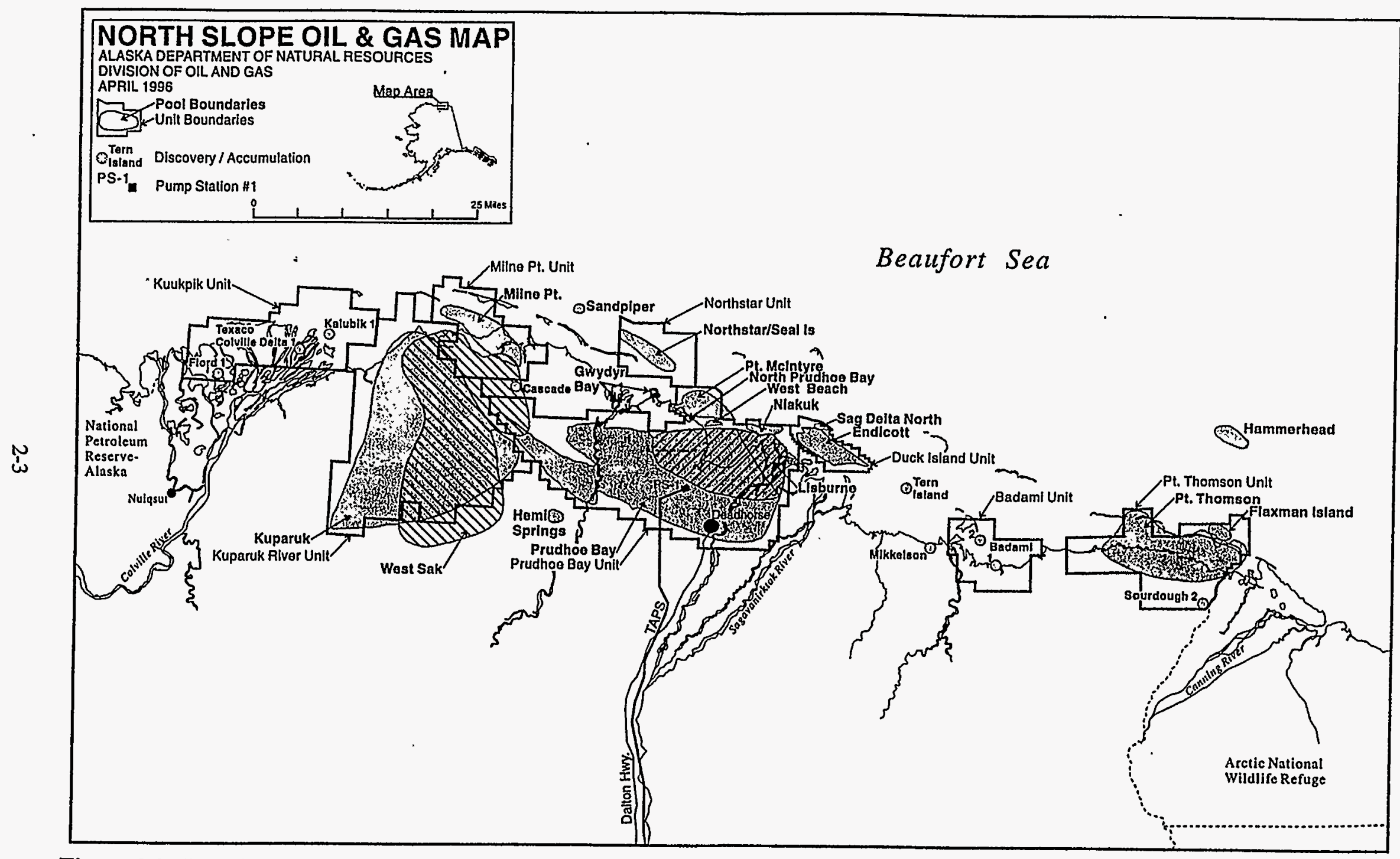
Figure 2.2. Location of North Slope oil and gas accumulations and fields (courtesy of Alaska Department of Natural Resources,
Division of Oil and Gas). 


\subsubsection{Prudhoe Bay Unit}

The Prudhoe Bay field, discovered in 1968, is the largest oil field in North America and is located adjacent to the Beaufort Sea coast line about 200 miles east of Point Barrow, Alaska (see Figure 2.1). The field was unitized as the Prudhoe Bay Unit (PBU) in 1976 and production started in 1977. PBU production peaked at 1,600 MBPD during 1987 and had declined to 1,057 MBPD by December 1994. The decline has continued into 1996.

The extensive efforts to increase oil recovery beyond the early estimates throughout the life of the PBU have been highly successful. These efforts include gas reinjection for pressure maintenance, recycled gas to strip retrograde condensate and residual oil above the gas/oil contact (compositional/vaporization incremental production), miscible injectant (MI) in a water-alternating-gas (WAG) enhanced oil recovery process, waterflooding, and the drilling of infill and horizontal wells. It is anticipated that such efforts will continue but are not expected to significantly alter the present rate of decline in production.

PBU facilities have a current gas handling capacity of about 7.5 BCFPD. Most of the gas is used in PBU operations with some being sold in the form of NGLs and minor amounts sold for non-unit consumption on the North Slope. The gas handling facilities are depicted schematically in Figure 2.3.

The successful recovery projects and processes have increased the current total estimated ultimate recovery to $13 \mathrm{BBO}$, as compared to the estimate at startup in 1977 of less than $10 \mathrm{BBO}$ ultimate recovery (AOGCC, 1991). The currently estimated reserve components compared to 1977 are shown in Figure 2.4.

\subsubsection{Point Thomson Unit}

The other known major gas field on the ANS is the Point Thomson field (see Figure 2.2). Point Thomson, discovered in 1977, is a gas condensate field about 50 miles east of TAPS PS No. 1. The Point Thomson Unit (PTU) was formed in 1977 and currently contains about 83,000 acres. PTU is listed in the by the Alaska Department of Natural Resources, Division of Oil and Gas (ADNR, 1996) as containing 200 million barrels (MMBBLS) of recoverable oil and condensate and 3 TCF of recoverable gas (earlier estimates were 300 MMBBLS condensate and 5 TCF gas) (DOE, 1993a). PTU currently covers a deep, overpressured reservoir that is located mostly offshore (see Figure 2.2). Development of PTU is hindered by the lack of existing infrastructure and facilities that benefit fields in the vicinity of PBU. A PTU 


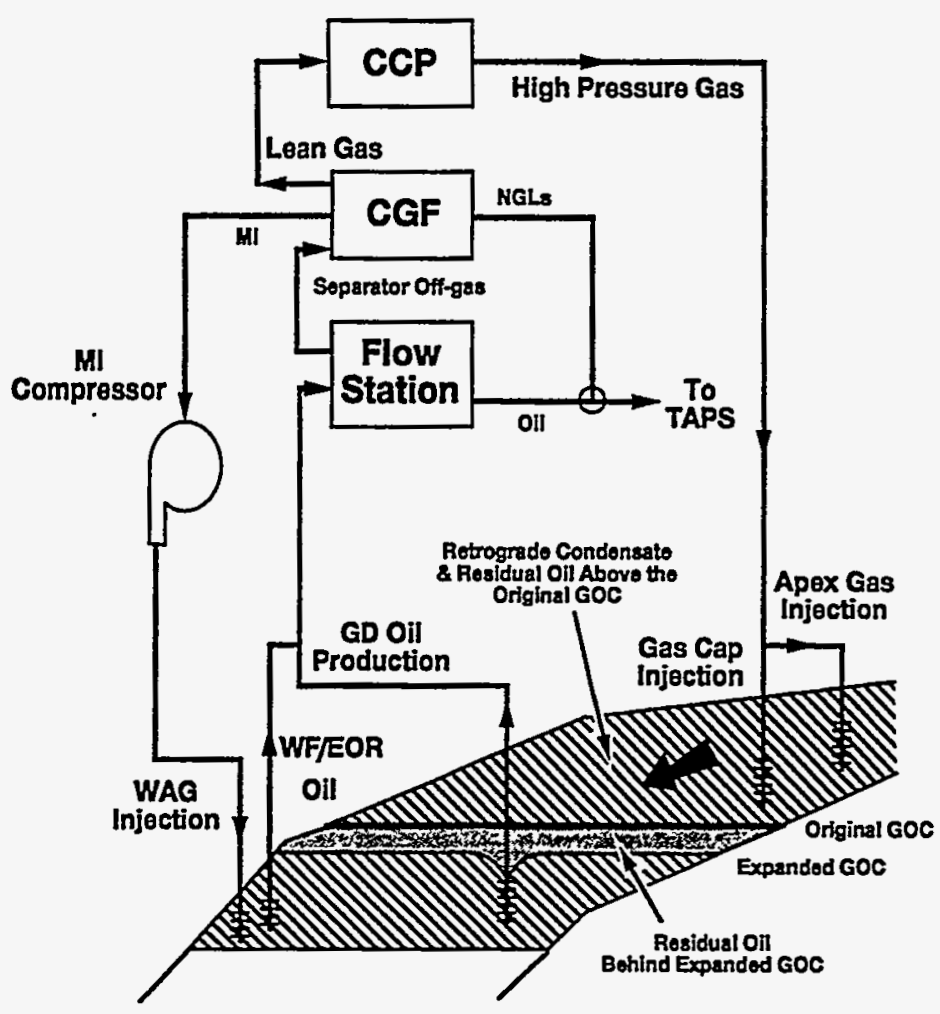

Figure 2.3. PBU gas handling and reservoir mechanism schematic (AOGCC, 1992). (GD - Gravity drainage area; WF/EOR - Waterflood/Enhanced Oil Recovery; CGF - Central Gas Facility; CCP - Central Compression Plant, MI - miscible injectant, GOC - gas/oil contact).

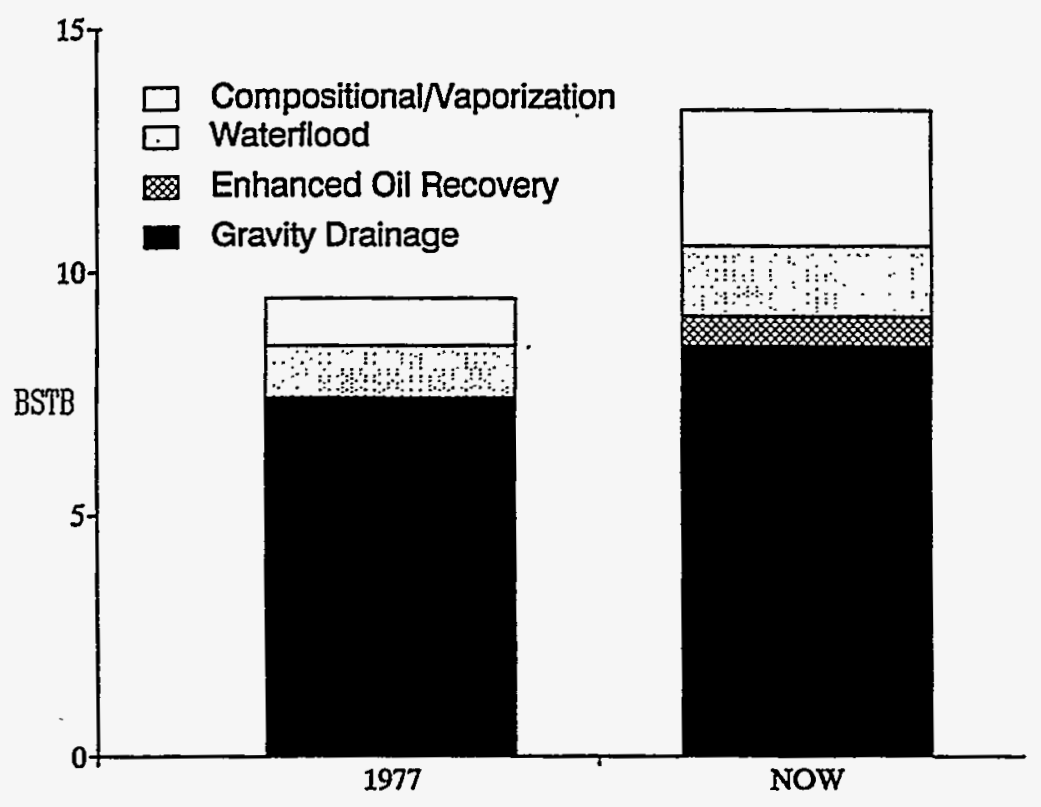

Figure 2.4. PBU currently estimated reserve components compared to 1977 (AOGCC, 1992). 
development project must support the construction of field delivery lines to the Prudhoe Bay field area that will encounter five major river crossings as they cross the Arctic Coastal Plain. The impact of these conditions will not be determined until environmental assessments are conducted.

\subsubsection{Other Fields}

There are a number of non-producing gas fields, other than the Point Thomson field, scattered over the North Slope in the vicinity of TAPS (see Figure 2.1 and Table 2.1 and Oil \& Gas J., 1995c). These fields were discovered in the course of oil exploration but were never sufficiently explored to establish the size of the accumulations. These gas fields could collectively contain as much as 1 TCF of recoverable gas.

Because the area is remote from existing gas pipeline systems and historically the economics of ANS gas sales projects have been poor, there has been virtually no exploration specifically for gas on the North Slope. Several small gas fields (Walakpa - 28 BCF, East Barrow - 6 BCF, and South Barrow - 4 BCF) located near Barrow, Alaska have been developed to supply local area natural gas market needs (ADNR, 1995c, p. 4). Other ANS gas discoveries, such as Square Lake - 58 BCF, Wolf Creek - unknown, East Umiat - 4 BCF, Gubik - 600 BCF, Kavik - unknown, and Kemik - unknown, have been temporarily abandoned without additional delineation (DOE, 1991, p. 2-19). Until an acceptable ANS gas market is established, further ANS gas field delineation and future ANS gas exploration cannot be economically justified.

\subsection{Oil and Gas Production}

This review is limited to currently producing fields and the undeveloped PTU. By the end of 1994, ANS fields had produced 10.5 billion barrels of oil (BBO), 84\% from PBU, $11 \%$ from Kuparuk River Unit (KRU), and 4\% from the combined other pools (ADNR, 1995c). PBU is currently expected to ultimately produce $13 \mathrm{BBO}$. The ANS historical and projected production for currently producing fields is shown in Figure 1.2 in Section 1. The projected production in Figure 1.2 is a composite of individual forecasts developed in Appendix A in this study based on publicly available information obtained from North Slope producers, the Alaska Department of Natural Resources (Oil and Gas Conservation Commission and Division of Oil and Gas), and previous studies performed for the DOE at the INEL (DOE, 1991; DOE, 1993a). 
Table 2.1. North Slope undeveloped oil and gas accumulations as of January 1, 1992 (after Bird, 1990).

\begin{tabular}{|c|c|c|}
\hline Location & Year & Amount \\
\hline Umiat & 1946 & $70 \mathrm{MMBO}$ \\
\hline Fish Creek & 1949 & Oil \\
\hline Simpson & 1950 & $12 \mathrm{MMBO}$ \\
\hline Meade & 1950 & $20 \mathrm{BCF}$ \\
\hline Wolf Creek & 1951 & Gas \\
\hline Gubik & 1951 & $600 \mathrm{BCF}$ \\
\hline Square Lake & 1952 & $58 \mathrm{BCF}$ \\
\hline E. Umiat & 1963 & $4 \mathrm{BCF}$ \\
\hline Kavik & 1969 & Gas \\
\hline West Sak & 1969 & $20 \mathrm{BBO}^{\mathrm{a}}$ \\
\hline Ugnu & 1969 & $15 \mathrm{BBO}^{\mathrm{a}}$ \\
\hline Gwydyr Bay & 1969 & $30-60 \mathrm{MMBO}$ \\
\hline No. Prudhoe & 1970 & 75 (?) MMBO \\
\hline Kemik & 1972 & Gas \\
\hline Flaxman Island & 1975 & Oil \\
\hline Point Thomson & 1977 & $300 \mathrm{MMBO},{ }^{b} 5000 \mathrm{BCF}$ \\
\hline Walakpa & 1980 & Gas \\
\hline Niakuk & 1981 & $58 \mathrm{MMBO}, 30 \mathrm{BCF}$ \\
\hline Tern Island & 1982 & Oil \\
\hline Seal Island & 1984 & $150 \mathrm{MMBO}$ \\
\hline Hammerhead & 1985 & Oil \\
\hline Colville Delta & 1985 & Oil \\
\hline Sandpiper & 1986 & Oil and Gas \\
\hline Barrow & 1988 & Gas \\
\hline Point McIntyre & 1988 & $300 \mathrm{MMBO}$ \\
\hline Badami & 1990 & Oil \\
\hline $\begin{array}{l}\text { a. Heavy oil (M } \\
\text { b. Condensate }\end{array}$ & & \\
\hline
\end{tabular}

\subsubsection{Reserves Estimates}

Original oil in place (OOIP) for PBU is estimated at about $23 \mathrm{BBO}$ and the original gas in place (OGIP) is estimated at about $46 \mathrm{TCF}$. The Point Thomson field is estimated to contain about 400 million barrels of oil (MMBO), principally condensate, and the original gas in place is estimated at about 5 TCF (Appendix A.3.1). In addition to PBU, there may be some gas from the other currently producing oil fields that will be available for sale. Although it is estimated that the KRU contains 0.68 TCF of recoverable gas, it is expected that KRU will need all of that gas for field use and that there will be no net gas available for major gas sales. 
In addition to PBU and KRU, there are several smaller fields currently producing oil and gas. These other fields are Point McIntyre, Endicott, Lisburne, Milne Point, Niakuk/Alapah, North Prudhoe Bay State, and West Beach. Of these fields only Point McIntyre, Endicott, and Lisburne may have gas reserves in excess of lease operation requirements. The total volume of potential sales gas could be about 1 TCF.

A summary of oil production and remaining potentially recoverable oil reserves (as of $1 / 1 / 95$ ) without major gas sales is presented in Table 2.2. The oil reserves forecasts are developed by continuing production to the economic limit for each field without being impacted by a shutdown of TAPS. Table 2.3 is a summary of estimated OGIP, recoverable natural gas, net gas production (i.e., produced gas, including $\mathrm{CO}_{2}$, that has not been reinjected), and net hydrocarbon gas available for major gas sales (i.e., after $\mathrm{CQ}$ removal, lease usage, local sales, and shrinkage) -- referred to hereafter as potential gas sales volumes. These future oil and gas reserves estimates are discussed in detail in Appendix A. The method of estimating the potential gas sales volumes from PBU and PTU are depicted on Figures 2.5 and 2.6, respectively.

Table 2.2. Potential future production (without major gas sales) for North Slope oil fields.

\begin{tabular}{||l|r|r|r|r||}
\hline \multicolumn{1}{|c|}{ Fields } & $\begin{array}{c}\text { Original Oil } \\
\text { In Place }\end{array}$ (BBO) & $\begin{array}{c}\text { Producible } \\
\text { Oil }^{\mathbf{2}} \text { (BBO) }\end{array}$ & $\begin{array}{c}\text { Production } \\
\left.\text { to } \mathbf{1 9 9 5}^{\mathbf{2}} \mathbf{( B B O}\right)\end{array}$ & $\begin{array}{c}\text { Potential Future } \\
\text { Production }^{\mathbf{2}} \text { (BBO) }\end{array}$ \\
\hline \hline Prudhoe Bay & 23.0 & 13.0 & 8.8 & 4.2 \\
\hline Kuparuk & 4.0 & 2.3 & 1.2 & 1.1 \\
\hline Pt. Thompson & 0.4 & 0.2 & 0.0 & 0.2 \\
\hline Other Fields & 3.3 & 1.3 & 0.5 & 0.8 \\
\hline Total & 30.7 & 16.8 & 10.5 & 6.3 \\
\hline a. Oil volumes include crude oil. condensate, and NGLs.
\end{tabular}

The estimates in Table 2.2 indicate that $63 \%$ of the potential economically producible North Slope oil has already been produced. The remaining potential North Slope oil is estimated at $6.3 \mathrm{BBO}$. In contrast, except for a small amount of local use there has been no commercial North Slope gas sales.

Table 2.3. Potential future production (available for major gas sales) for North Slope gas fields.

\begin{tabular}{|c|c|c|c|c|c|}
\hline \multirow{2}{*}{ Fields } & \multirow{2}{*}{$\begin{array}{l}\text { Original Gas } \\
\text { in Place (TCF) }\end{array}$} & \multirow{2}{*}{$\begin{array}{c}\text { Recoverable } \\
\text { Gas (TCF) }\end{array}$} & \multirow{2}{*}{$\begin{array}{c}\text { Net Gas } \\
\text { Prod. to } \\
1995 \text { (TCF) }\end{array}$} & \multicolumn{2}{|c|}{ Potential Gas Sales Volumes } \\
\hline & & & & Gas (TCF) & Eq. Oil (BBO) \\
\hline Prudhoe Bay & 46.0 & $\overline{33.6}$ & $\overline{1.9}$ & $\overline{21.8}$ & $\overline{\overline{3.8}}$ \\
\hline Kuparuk & 1.4 & 1.0 & 0.3 & 0.0 & 0.0 \\
\hline Pt. Thompson & 5.3 & 3.7 & 0.0 & 3.2 & 0.5 \\
\hline Other Fields & 3.0 & 2.1 & 0.2 & 1.0 & 0.2 \\
\hline Total & 55.7 & 40.4 & 2.4 & 26.0 & 4.5 \\
\hline
\end{tabular}




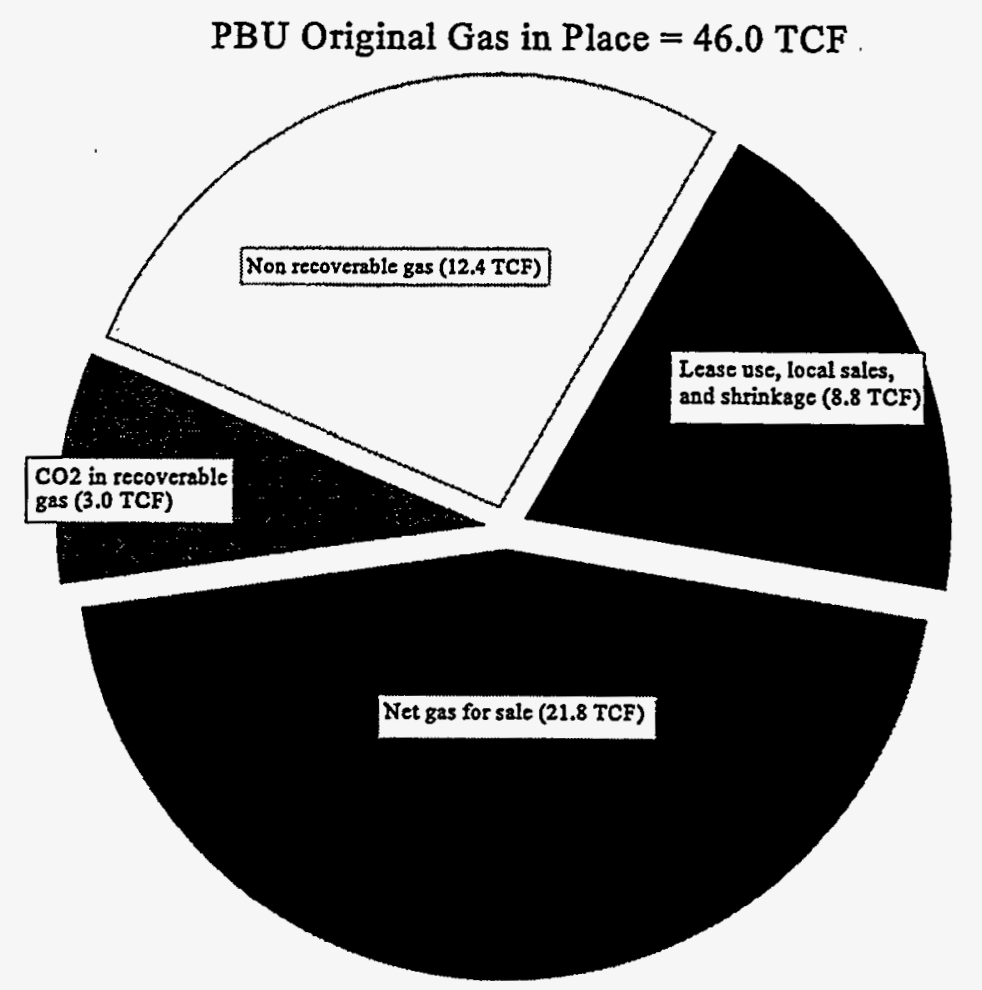

Figure 2.5. Net hydrocarbon gas available for sale from PBU.

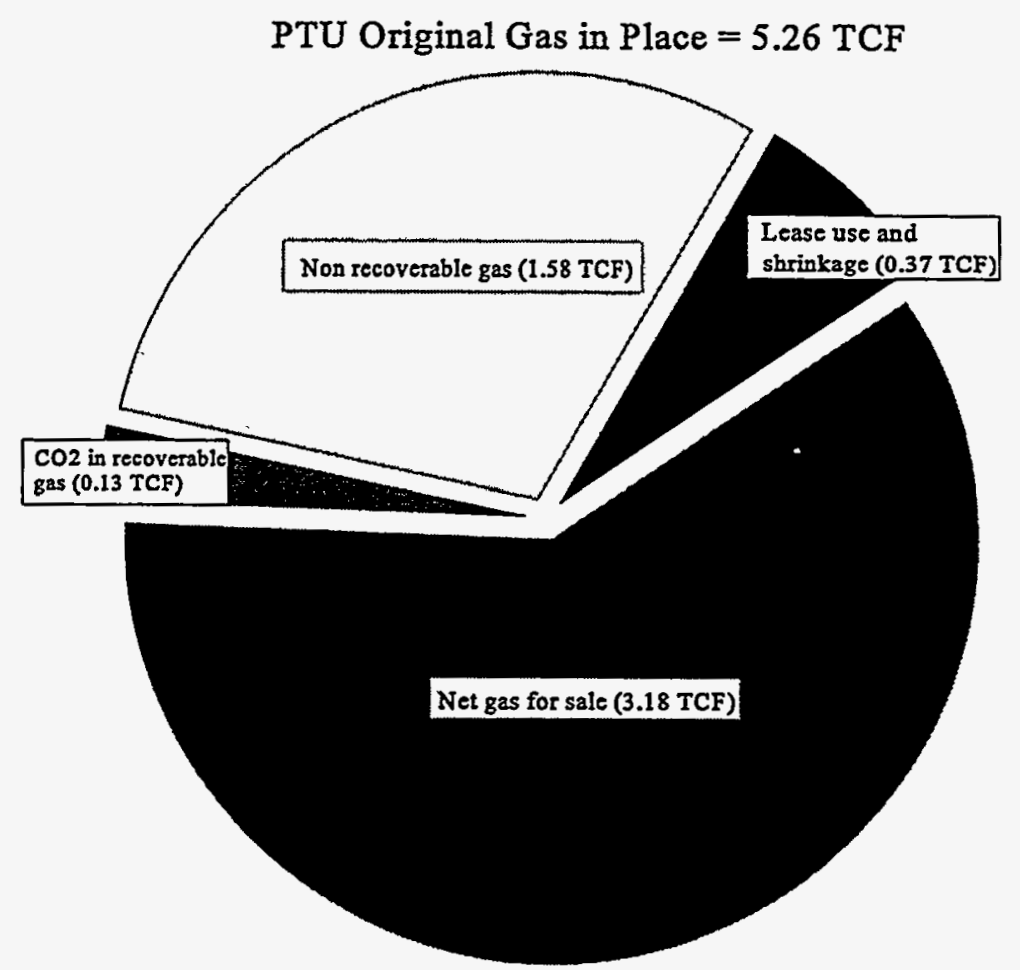

Figure 2.6. Net hydrocarbon gas available for sale from PTU. 


\subsubsection{Production Scenarios}

Future North Slope oil and gas production will depend on a number of factors:

- Oil Production:

- World oil prices

- Remaining oil reserves

- Natural gas production and disposition (major commercial sales vs. field usage)

- Future oil reserve additions and timing for available production

- Continued operation of TAPS.

- Gas Production:

$\bullet$

World oil and gas prices

- Remaining gas reserves

- Need and value of gas for oil production

- Availability of gas pipeline or GTL conversion facilities, or both

- $\quad$ Future gas reserve additions.

As these factors indicate, the future production scenarios possible for the ANS will be determined by: (a) world oil and gas prices; (b) government (State of Alaska and federal) policy for exploration and production opportunities; (c) technology development for enhancing oil and gas exploration and production capabilities; and (d) development of infrastructure for marketing gas; e.g., LNG facilities or GTL conversion facilities, or both. Prices and technology development will determine the ability of industry to develop ANS heavy oil resources, to continue development of marginal fields across the North Slope, to continue exploration activities, and to develop facilities for major gas sales.

The evaluations presented in this study do not assume that major new discoveries will be made but are based on oil production from the currently developed fields coupled with major gas sales from the PBU and development and sales of gas and condensate from the currently undeveloped PTU. The two gas sales options evaluated are an LNG project and a GTL conversion project. These projects are evaluated as standalone projects that purchase gas from the units. 
Although the scenarios and options evaluated do not cover all possibilities, they provide a basis for evaluating the requirements for GTL processes to be viable on the North Slope and allow some LNG and GTL options to be compared for their impact on current and future ANS development.

\subsubsection{Production Forecasts}

The sources and quantities of gas available for sale on the ANS are discussed in the following sections. Because oil production and gas production are integral with each other, oil production forecasts are developed for each ANS producing field using production, investment, and operating cost forecasts using available sources of information as described in detail in Appendix A. The production forecasts are first developed assuming no major gas sales, then modified, where necessary, to take into account the impact of major gas sales.

First, an oil production profile is estimated based only on oil reserves remaining at $1 / 1 / 95$, assuming no major commercial sales of gas. Estimated remaining oil reserves as of 1/1/95 are shown in Table 2.2. The composite production forecast for the ANS producing fields without major commercial gas sales is shown in Figure 2.7. The production curve extends to 2026 when costs would bring about a shutdown of production. However, production could actually be stopped earlier because of minimum throughput requirements for TAPS. The estimates for the minimum throughput volume necessary to keep TAPS operating range from $200 \mathrm{MBPD}$ to $400 \mathrm{MBPD}$ (DOE, 1993a). If the higher level of $400 \mathrm{MBPD}$ is assumed, then the pipeline and oil production would be terminated in 2009, as indicated by Point $A$ in Figure 2.7, with a loss in ultimate ANS recovery of $1.2 \mathrm{BBO}$. At the lower end of the range, $200 \mathrm{MBPD}$, the pipeline and production shutdown would come in 2016 (Point B), with a corresponding loss in ultimate ANS recovery of $0.5 \mathrm{BBO}$. It is clear that it is in the best interest of industry and State and federal governments to continue the operation of TAPS as long as oil can be economically produced from any of the fields and transported in an environmentally safe manner. This could result in operation of TAPS to a level of $100 \mathrm{MBPD}$ or lower, which would mean all the economically recoverable oil from PBU would be recovered.

The potential gas sales volume available for major gas sales is estimated to be 26.0 TCF (Table 2.3). However, the gas production forecasts used in the economic evaluations for the two gas sales scenarios only include gas production for PBU and PTU since they are the only currently known fields with gas reserves greater than 1 TCF. The gas production forecasts for PBU and PTU total about 25 TCF (Table 2.3). As described in Appendix A.2.2.1.3 for PBU, this forecast provides for a 32-yr gas project life with a maximum 


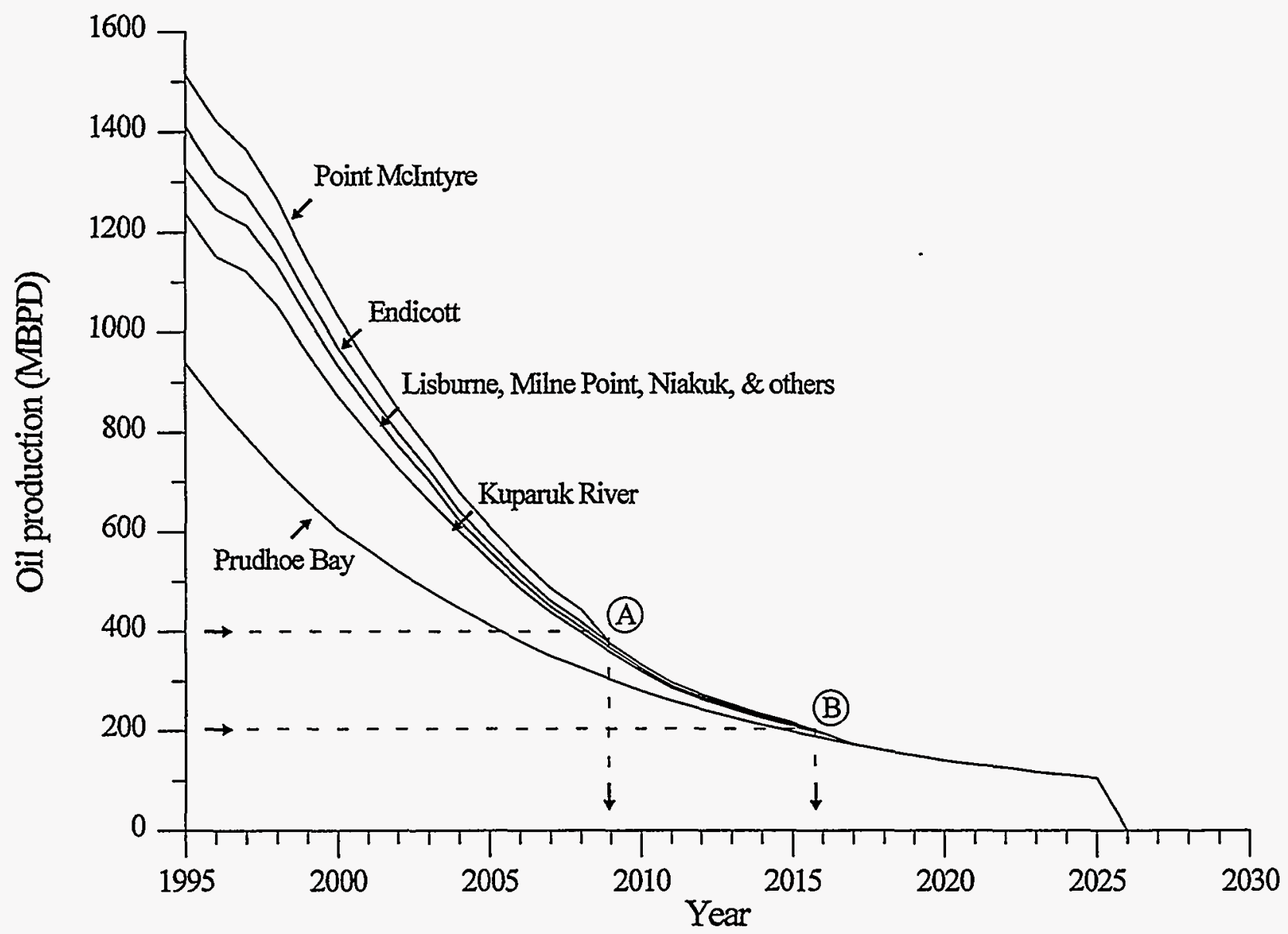

Figure 2.7. Composite North Slope producing fields production forecasts - no major gas sales.

rate of 2.05 BCFPD for a total of 21.8 TCF. It is assumed that PBU will be capable of delivering this sustained rate throughout the project life without significant falloff until the last year of production. As discussed in Appendix A.3.1.3.4 for PTU, the PTU forecast provides for a 20-yr gas project life at a maximum rate of $0.44 \mathrm{BCFPD}$ for a total of $3.18 \mathrm{TCF}$. This forecast also assumes that PTU will be capable of delivering gas at the assumed gas sales rate without a falloff until the last year of production. For both of the options for commercial sale of North Slope natural gas (LNG or GTL), gas production is assumed to begin from PBU in 2005 and from PTU in 2008. The maximum production rate of 2.49 BCFPD (2.05 BCFPD from PBU and 0.44 BCFPD from PTU) would be reached in 4 years and be maintained for about 19 years (until 2026). At that time, PTU gas sales will decrease to 0.35 BCFPD for 1 yr and then cease. The sales rate drops to 2.05 BCFPD from PBU alone and continues at this rate through 2035, as shown in Figure 2.8 (see also Appendix B, Table B.12). 


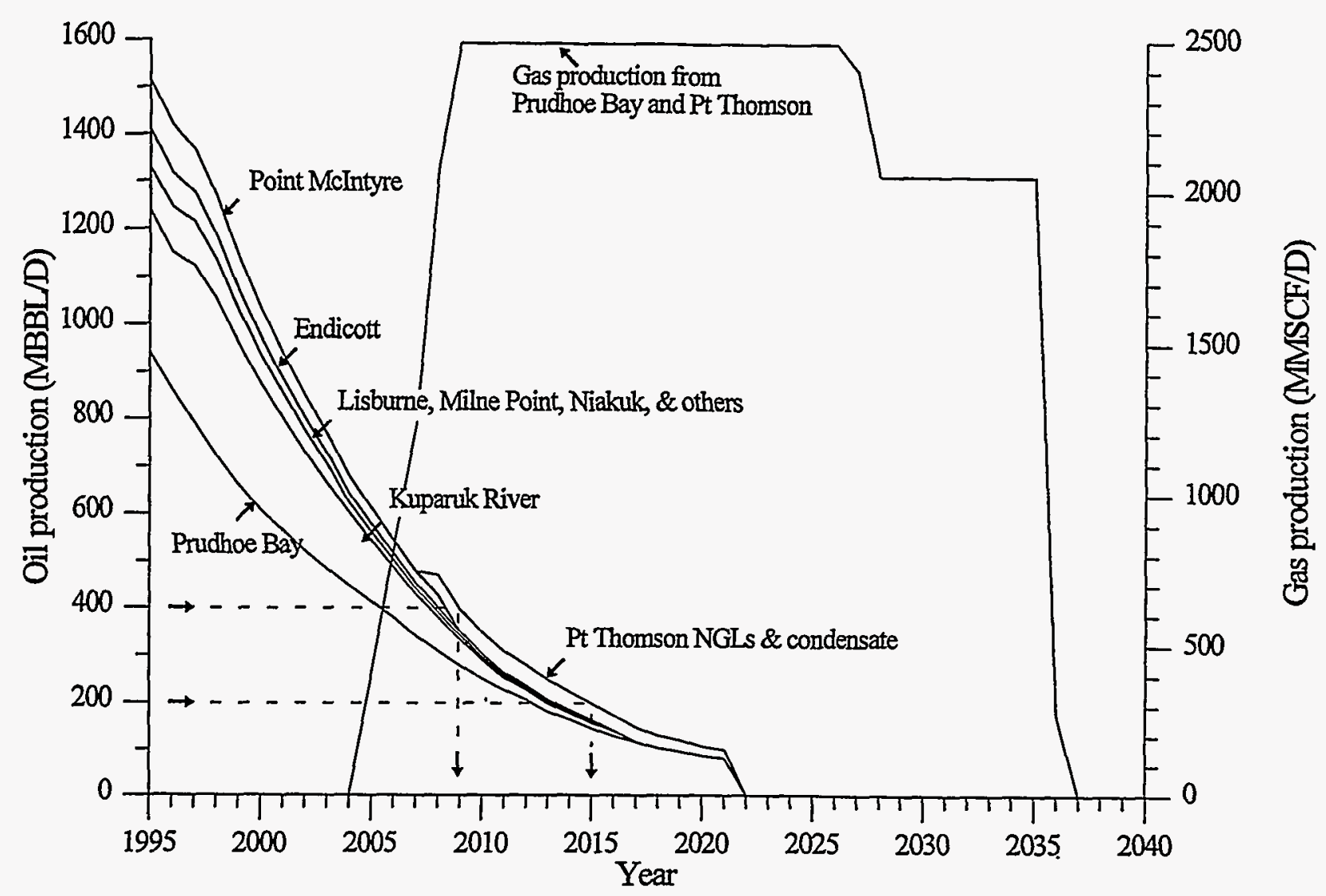

Figure 2.8. Composite North Slope oil and gas production forecast with major gas sales from PBU and PTU.

\subsubsection{Impact of Major Gas Sales on ANS Activities}

Major gas sales will have an impact on ANS production rates and remaining oil recovery, TAPS operations, and future ANS development activities. The extent of this impact depends on such things as the timing of gas sales, the major gas sales scenario chosen (LNG plant scenario, GTL conversion plant scenario, or both), and the volumes of gas available for sale.

2.2.4.1 Impact of Gas Sales on Oil Production. When gas production begins for commercial sales, it will significantly reduce the gas available for reinjection and continuation of the on-going improved oil recovery processes in the Prudhoe Bay field. Major gas sales from the Prudhoe Bay field could result in a reduction in the total oil recovery achieved depending on the timing and rate of gas sales. The reduction in oil recovery could vary from about $900 \mathrm{MMBO}$ for major gas sales starting as early as 2000 , to $400 \mathrm{MMBO}$ 


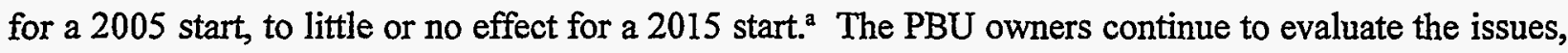
impacts, and options for major gas sales and to review the options for reducing the influence on oil recovery (Petro. Information Corp., 1994a; Energy Daily, 1995; Oil Daily, 1995a).

A loss in oil recovery of $400 \mathrm{MMBO}$ is assumed for the economic evaluation in Section 5 as a result of major gas sales starting in 2005. It is assumed that the impact on oil production will begin in 2007 at low volumes and increase over time (see Table A.1 and Table A.4, Appendix A). The oil production schedule during major gas sales resulted in a shortened oil recovery period of 4 years, as can be seen from Figure 2.7 and Figure 2.8, and a total recovery of $12.6 \mathrm{BBO}$. The PBU gas production forecast is given in Table A.5. This forecast also assumes that TAPS remains operational as required to recover the $12.6 \mathrm{BBO}$. This forecast is used for both gas sales scenarios. It is possible that some or all of this initial loss in oil recovery will be made up on the tail end of the production and result in a delay in recovery rather than in a permanent loss of reserves. However, this can only happen if TAPS remains in operation and the economics allow continued operation of the field.

2.2.4.2 Impact of GTL Conversion Scenario on Oil Production. Whether the gas production goes to LNG or GTL production, it is assumed that major gas sales have the same impact on reducing PBU annual crude production as discussed above. However, the GTL conversion option would also act to increase the total cumulative ANS oil production in two ways through the additional GTL liquids for transport in TAPS.

Without the addition of any new liquid streams, the minimum TAPS throughput rates of 200 and $400 \mathrm{MBPD}$ would be reached in the years 2009 to 2016. (The effects of a lower limit for TAPS such as $100 \mathrm{MBPD}$, can be estimated directly from the forecast in Table A.4). There would be a significant loss of recoverable oil as compared to producing the fields to their economic limits, as illustrated by the arrows shown in Figure 2.8. The GTL scenario produces an additional 300 MBPD of liquids that can be shipped through TAPS with the oil from 2009 through 2026 and 250 MBPD from 2027 through 2035 (See Appendix B, Table B.12). With the additional GTL conversion liquids, TAPS shutdown could be delayed until somewhere between 2021 and 2035 at the minimum TAPS throughput rates, as illustrated by the arrows in Figure 2.9. This would allow ANS production to continue until it reached the economic limit for each producing property. The life of TAPS and of the producing properties, would be extended beyond the point in time at which TAPS shutdown would occur without major gas sales.

a. ARCO Alaska, Inc., personal communication, March 1995. 


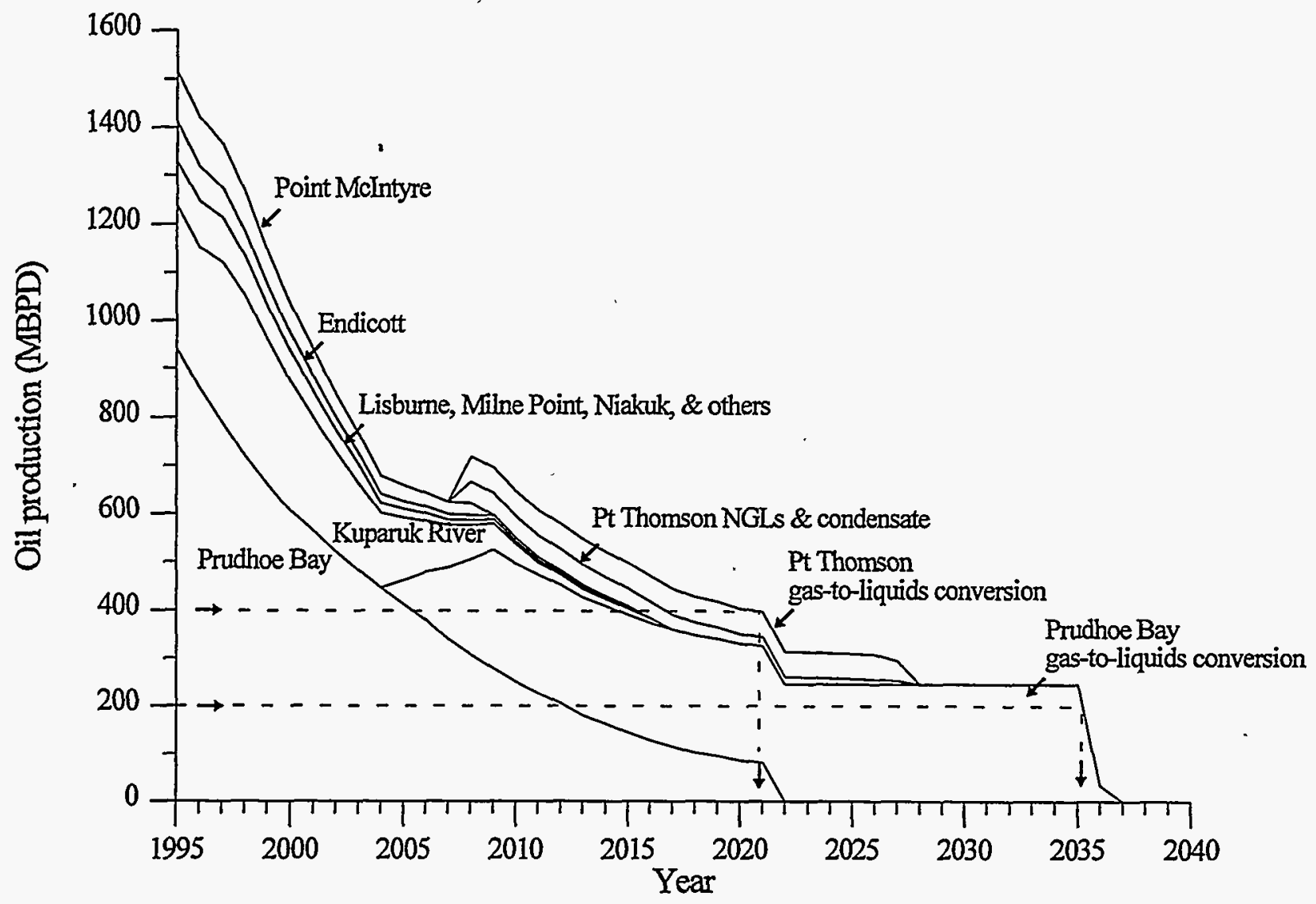

Figure 2.9. Composite North Slope production forecast with GTL conversion from PBU and PTU.

The other benefit is that the additional volume of liquids from the GTL conversion process, when blended with the ANS oil production, would increase the TAPS throughput volume used in determining TAPS tariffs. The TAPS tariff, calculated by distributing the allowed pipeline costs over the total throughput volume, would decrease, providing a higher wellhead oil price. These effects on TAPS tariffs are discussed further in Section 5. Hence, the GTL scenario would be more likely to allow the recovery of the lost or delayed PBU production than the LNG option through the reduction in tariffs resulting from more liquids for transport in TAPS.

\subsection{Summary}

The technically recoverable undiscovered conventional natural gas resources on the ANS are estimated by the U.S. Geological Survey to have a mean value of 64 TCF. The remaining potentially recoverable oil reserves without major gas sales and the remaining potential net gas production (gas, including $\mathrm{CO}_{2}$, produced and not reinjected) are estimated to be $6.3 \mathrm{BBO}$ and $38 \mathrm{TCF}$ of gas. About $26 \mathrm{TCF}$ 
of hydrocarbon gas will be available for major gas sales after $\mathrm{CO}_{2}$ removal, lease usage, local sales, and shrinkage. Forecasted net gas sales volumes for this evaluation are 21.8 TCF from PBU, and 3.2 TCF from PTU. In addition to PBU and PTU, potential gas sales volumes exist in some producing fields in the PBU area. During ANS oil exploration efforts, numerous small, isolated gas reservoirs have been discovered. Except for fields furnishing gas to Barrow, Alaska, these accumulations have not been developed. ANS fields had produced 10.5 BBO and 2.4 BCF of net gas at the end of 1994. All of the produced North Slope gas, except for that used for production operations, local gas sales, and recovered NGLs, has been reinjected into the reservoirs to maintain reservoir pressure and to improve oil recovery potential. Currently, ANS gas is not marketed off the North Slope, except for recovered NGLs, because there are no gas transportation facilities providing access to the existing gas markets. Major gas sales possibilities include a gas pipeline/LNG project for transport to Asian LNG markets, and a GTL conversion option delivering converted hydrocarbon liquids to TAPS to be blended (or batched) with produced oil and transported to existing oil markets.

ANS major gas sales will depend on establishing an acceptable gas market, the economic optimization of gas utilization between oil recovery and gas sales, and the continuation of production operations on the North Slope to maintain the existing infrastructure. Studies by the major PBU owners indicate that the most likely timing for ANS major gas sales from PBU will occur after 2005 with a maximum rate of about $2.05 \mathrm{BCFPD}$ and continue to the depletion of the economic gas reserves (Energy Daily, 1995; Oil Daily, 1995a). Development of PTU is estimated to add 0.44 BCFPD and is assumed to start selling gas in 2008. It is estimated that gas sales starting in 2005 and building up to a rate of 2.05 BCFPD over 5 years will reduce PBU oil recovery by 400 MMBO. Establishing an ANS gas market will have the effect of encouraging ANS gas exploration activities, and in the course of that exploration activity, provide for the possibility of additional oil as well as gas discoveries.

In addition to the gas resource utilization, it is assumed that the GTL conversion option, using the 2.49 BCFPD from PBU and PTU would produce an additional $300 \mathrm{MBPD}$ of gasoline/diesel quality hydrocarbon liquids that can be blended with the produced oil being delivered to TAPS and transported to existing oil product markets. This additional liquid volume would extend the operational life of TAPS to 2035 and result in reduced TAPS tariffs for all liquid throughput volumes. Extending TAPS operational life will allow ANS production from existing fields to continue for several additional years, resulting in increased ultimate oil recovery, and providing additional time for ANS exploration activities. 


\section{NORTH SLOPE GAS RESOURCE UTULIZATION OPTIONS}

This section provides an overview of conversion and transportation options for utilization of North Slope gas resources. Liquid conversion options are described and factors impacting the LNG and GTL options are discussed.

\subsection{Gas Utilization Overview}

One of the two principal options discussed for utilizing ANS gas requires a gas pipeline to a southern Alaska port where gas is converted to LNG for shipment by LNG tankers. The other option is GTL conversion of gas to hydrocarbon liquids which, if made on the North Slope, could be shipped to market with the ANS crude oil. Although there are a number of approaches to GTL conversion, those that are the most established involve Fischer-Tropsch (FT) synthesis gas technology. This study makes the assumption that current state-of-the-art FT technology would be used for GTL conversion on the North Slope. However, current research efforts by industry and the DOE Gas-to-Liquids program to develop improved FT technology and alternative conversion processes appear promising and may yield technology advances in time to be of significance before the final decisions are made for major gas sales from the North Slope. Both LNG and GTL conversion options have advantages and disadvantages that need to be considered in determining the optimum North Slope gas utilization option.

Remote gas refers to gas that is distant from consuming markets and is not marketable via existing or easily built gas pipelines connecting to a distribution system for delivery to customers. Gas value is established by competitive fuel prices in the consuming market and, if transportation costs to market are high, the value at the production site will be low. This is the case for the ANS gas resource, which has much in common with other remote gas resources around the world; i.e., the economic return has not been thought to be adequate to support development needed to get the gas to world markets. The major ANS gas owners (Arco Alaska, BP Exploration, and Exxon) reported July 1995 at the conclusion of a recent joint 2-yr study that it remains uneconomic to build a pipeline to bring ANS gas to market, but they remain committed to the project and believe there will be a window of opportunity for the pipeline after 2005 (Energy Daily, 1995; Oil Daily, 1995a). In the interim, gas from PBU will continue to be used for improving oil recovery in PBU and other ANS fields, such as in the Kuparuk River Unit (KRU) as evidenced by the recent announcement of the Large Scale Miscible Injection (LSMI) project that will purchase miscible injectant from PBU for KRU injection (Petroleum Information Corp., 1994a). The value of the gas for enhancing oil recovery can 
be expected to decrease over time as ANS oil fields mature, which will increase the incentive to develop an economic means of getting the gas to market.

To use natural gas directly as a gaseous fuel without first going to LNG or hydrocarbon liquids requires a suitable market, a gas pipeline for delivery to the distribution system, and a distribution system for delivery to customers. Natural gas cannot be transported in oil pipelines; thus, a separate gas pipeline is required. For remote gas resources, where pipeline-to-market costs would be prohibitive, conversion to a liquid form, termed LNG, by simple liquefaction to a low-pressure cryogenic liquid at $-160^{\circ} \mathrm{C}$ for transportation in LNG tankers followed by subsequent revaporization to a gas at the market site has generally been the development option used (Fox, 1988). The alternative of converting the gas to a liquid form by a chemical conversion process that converts the methane to a higher molecular weight hydrocarbon that is liquid at normal ambient conditions (i.e., a GTL conversion process) enables transport of the gas in conventional oil pipelines and tankers. The type of process chosen (LNG or GTL conversion) depends on conversion costs, transportation costs, and current and perceived future market values of the various liquid fuels into which gas can be converted. LNG is vaporized back into a gaseous state for use in the gas market, whereas GTL products remain liquid and enter directly into the oil market. The market values of the various liquid choices are discussed in Section 4.

In the case of the remote gas on the North Slope of Alaska, there is an added consideration to the type of liquid chosen. Because of the existence and excess capacity of TAPS and the existing oil products market and distribution system, conversion of the natural gas in an ANS GTL conversion plant to a hydrocarbon liquid that is compatible with the produced oil being transported in TAPS and compatible with existing tankers is an attractive alternative for utilization of the North Slope gas resource, provided it is economically viable. Such a development option could be built either rapidly or be undertaken more slowly in a stepwise manner, which would provide the opportunity for improvements in technology and reductions in costs for later modules. Conversely, for the LNG option, an 800-mi gas pipeline to transport ANS gas to a LNG plant, a LNG plant, and a marine transportation terminal will have to be constructed, and a LNG tanker fleet acquired up front in order to market LNG. This significant up-front cost is a financial requirement that the LNG option must support in its competition with other LNG projects throughout the world, and with other options for marketing North Slope gas. Still, LNG technology is a proven technology and may be perceived as a lower risk option than GTL conversion processes that are not as technically mature. 


\subsection{Gas Pipeline Options}

Since the discovery of the Prudhoe Bay field in 1968, numerous plans and ideas have been proposed for developing markets and a transportation system for North Slope gas. These proposals have generally been to transport the ANS gas by gas pipeline either directly to gas markets in the U.S. lower 48 states (Lower 48) or to an LNG facility for liquefaction and transport by LNG tanker to an LNG market.

The earliest option considered was the Alaskan Natural Gas Transportation System (ANGTS), which would have required a 2,102-mile pipeline through Alaska and Canada to markets in the Lower 48. This option is not economically viable at current gas market conditions, which reflect continuing surpluses of Canadian and Lower 48 gas supplies.

Currently the most talked about concept for gas sales is the Trans-Alaska Gas System (TAGS). As promoted by Yukon Pacific Corporation (YPC), this option calls for construction of a gas-conditioning plant on the North Slope, an 800-mile pipeline, a LNG plant and marine terminal near Valdez, Alaska, and a LNG tanker fleet to transport LNG to Japan and other Pacific Rim countries for market.

As part of a recent study, the North Slope operators included the options of gas pipelines to LNG plants at either of two ports on the northwestern coast of Alaska, Wainwright or Kivalina (Oil Daily, 1995a), to reduce the capital costs involved in building the 800-mi gas pipeline in the YPC LNG project. However, these optional routes would require the use of ice-breaking LNG tankers, which is a technology that would have to be developed (Energy Daily, 1995). The joint study by Arco Alaska, BP Exploration, and Exxon concluded that all gas pipeline options remain uneconomic at this time, but they believe there will be a window of opportunity for the pipeline after 2005, when demand in Asia may justify the project. YPC believes that further study will show that the southern route to Valdez will be the only feasible route for a pipeline (Energy Daily, 1995). The YPC LNG project is assumed as the model for the LNG option examined in this evaluation.

Although large LNG markets exist in Pacific Rim countries, (a) low world oil and gas prices, (b) potential competition from overseas projects (e.g., Qatar, Natuna, and Sakhalin), (c) the large initial investments required for a gas pipeline/LNG plant, and (d) technical and economic uncertainty about when major gas sales should begin from PBU continue to delay ANS gas sales development. 


\subsubsection{Alaskan Natural Gas Transportation System (ÄNGTS).}

The ANGTS scenario is a 2,102-mile pipeline (DOE, 1991) linking ANS gas production through Alaska and Canada to markets in the Lower 48. The pipeline would run parallel to TAPS from the North Slope to central Alaska and then across Canada where it would connect to the existing prebuilt section of ANGTS that is in service. This section, with a northern terminal at Caroline, Alberta, is comprised of 576 miles of pipeline and in 1994 transported 850 BCF of Canadian gas to the U.S. Numerous permits, right-ofways, and approvals have been obtained for the proposed pipeline route through Canada and Alaska. Extensive studies have been conducted in pursuit of technological advances with the goal of reducing costs for transporting ANS gas to markets in the Lower 48.

A recent estimate of the cost to construct the ANGTS pipeline segments linking ANS gas production to the existing northernmost terminal at Caroline, Alberta is $\$ 16.7$ billion (1995\$) (ANGTS, 1995). Advanced technology could reduce this estimate to between $\$ 11.7$ and $\$ 14.7$ billion. The cost of service to deliver the gas to market ranges from a high of $\$ 4.17 / \mathrm{MCF}$ to a low of $\$ 2.82 / \mathrm{MCF}$ (ANGTS, 1995). Based on an average current sales price of $\$ 2.11 / \mathrm{MCF}$ for U. S. natural gas at the wellhead (EIA, 1995), it appears unlikely that this project will be pursued any time in the near future. No further analysis on this option is included in this study.

\subsubsection{Trans-Alaska Gas System (TAGS) LNG Project}

The TAGS project as proposed by YPC is used as the model for evaluation in this study. The TAGS scenario is a $\$ 14$ billion (1/1/95\$) system consisting of a gas-conditioning plant on the North Slope; an 800-mile, 42-inch, chilled, buried pipeline; a LNG plant and marine terminal at Valdez; and a LNG tanker fleet. LNG would be transported to Japan and other Pacific Rim countries. YPC has obtained major permits for construction of TAGS and export of ANS natural gas to Asia (YPC, 1995). TAGS has received the Final Environmental Impact Statement (EIS) prepared by the Federal Energy Regulatory Commission (FERC) for the LNG facility and terminal (FERC, 1995). The EIS is yet to be prepared for the pipeline. The TAGS design takes advantage of the following: (a) the existing infrastructure on the North Slope for construction and operation of a gas plant to pre-condition the gas; (b) the TAPS right-of-way and haul road for construction and operation of the gas pipeline; (c) a year-round ice-free port at Anderson Bay, Valdez, Alaska, for its gas liquefaction plant and shipping terminal sites; (d) the in-place environmental and maritime protection practices at Valdez; (e) the use of LNG tankers for transport (a well proven technology); and (f) an 
established and growing LNG market in Japan and other Pacific Rim countries (see Section 4.2). Construction of the project depends on obtaining long-term sales and purchase contracts with the North Slope owners for the gas supply and the LNG buyers in Asia. YPC believes the large scale of the project, which requires $2.05 \mathrm{BCFPD}$ of ANS gas to yield 14 million metric tons of LNG annually (MMTPA) or about 1.87 BCFPD, will create an economy of scale that will allow this gas to be competitive with other LNG projects that do not have to support the construction of an 800-mile gas pipeline. Its current design is for a 42-inch line that can be boosted to a capacity of 25 MMTPA (3.3 BCFPD) through the addition of 5 to 7 more compressor stations, if the market should become available (Alaska Conservation Foundation, 1994).

\subsection{Gas-To-Liquids Conversion Processes}

The purpose of this section is to provide a brief review of the current state of the art for converting natural gas to hydrocarbon liquids.

\subsubsection{Overview}

GTL conversion processes to fully exploit remote natural gas resources around the world have received a great deal of interest and research in recent years (OGJ, 1995; Shields, 1985; Tijm, 1993; Eisenberg, 1994). Figure 3.1 gives an overview of the major processes for converting natural gas to liquid fuels. Natural gas can be (a) converted to LNG; (b) converted to synthesis gas [mixture of carbon monoxide (CO) and hydrogen $\left(\mathrm{H}_{2}\right)$ - frequently termed "syngas"], which is then converted to a variety of liquid fuels; or (c) reacted directly to produce other intermediates, which in turn are converted to liquid fuels.

A fundamental problem in converting natural gas into other commercial products is the chemical stability of the methane molecule. The bonds in methane are among the most unreactive of any of the hydrocarbons. Reactions that convert methane to other chemical forms are usually irreversible and difficult to control. For example, combustion or complete oxidation gives carbon dioxide and water $\left(\mathrm{CO}_{2}\right.$ and $\left.\mathrm{H}_{2} \mathrm{O}\right)$, neither of which can be used as a fuel. Therefore, the more conventional indirect GTL processes first convert the natural gas to a synthesis gas $\left(\mathrm{CO}\right.$ and $\left.\mathrm{H}_{2}\right)$ by steam reforming under a set of reaction conditions designed to only partially oxidize the methane to $\mathrm{CO}$ and $\mathrm{H}_{2}$. Then, other reaction conditions are provided such that synthesis gas is converted to liquid hydrocarbon products. A FT catalytic process is frequently used for the conversion step from synthesis gas to gasoline, diesel, or other liquid products or combinations of products. 


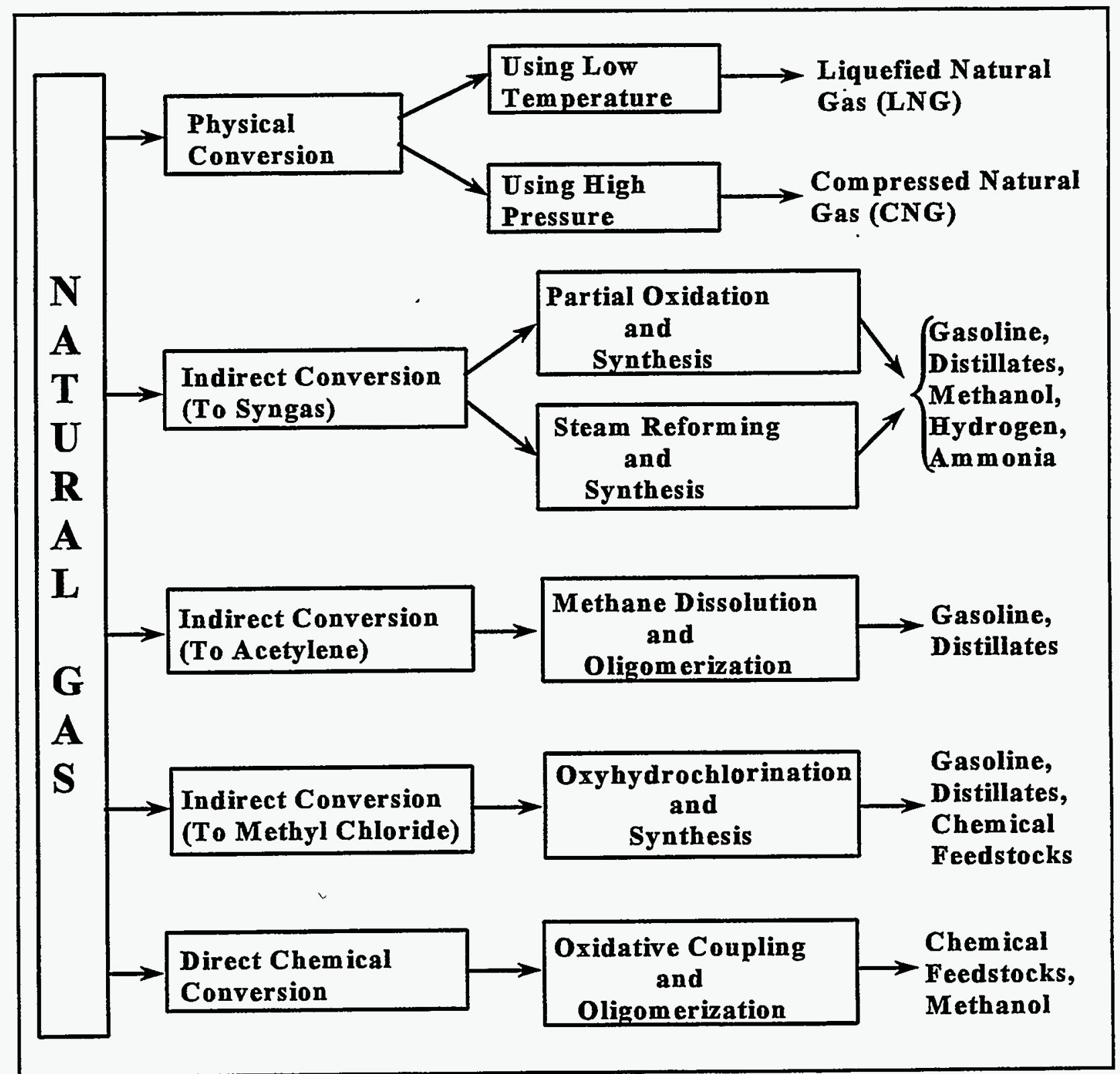

Figure 3.1. Processes for conversion of natural gas to liquid fuels.

Other indirect conversion approaches include: oxyhydrochlorination, where chlorine reacts with methane to form the building block of methyl chloride; and methane pyrolysis, where methane is injected into a hydrogen plasma and broken down to form an intermediary product - acetylene, which is then converted to liquid hydrocarbon products. Direct methane conversion processes also exist but tend to be more complex and limited more to yields of simpler and lower-valued chemical feedstocks. An R\&D objective for some years has been to find direct, and also indirect, conversion processes that are less 
expensive that the synthesis gas route (Fox, 1990). However, at the present stage of development, none match the FT synthesis gas conversion process in liquid yield and cost (Hackworth et al. - DOE, 1995).

Discussion of the GTL conversion processes that have some commercialization history, FT synthesis gas and methane pyrolysis, follows along with observations about prospective improvements potentially forthcoming in the near term.

\subsubsection{Synthesis Gas Conversion Processes}

A number of GTL processes that start with the synthesis gas step have achieved some degree of commercial success. Methanol is being produced from synthesis gas in many commercial plants by methods such as the ICI and Lurgi processes (Fox, 1988). A significant volume of methanol is then used in the production of MTBE, silicones, and other products.

The conversion of natural gas to hydrocarbon liquids suitable for transportation fuels reached commercialization in 1985 in New Zealand with the Gas-to-Gasoline (GTG) project using the Mobil Methanol to Gasoline (MTG) process. This plant first produces methanol from synthesis gas and then converts it into gasoline using a zeolite catalyst (Shields, 1985; Eisenberg, 1994). The first natural gas to fuels project in South Africa was commissioned in 1992 by the South African Coal, Oil and Gas Corporation (SASOL) at Mossel Bay. This FT plant uses the Lurgi combined reforming process for synthesis gas production, followed by SASOL's Synthol reactor technology and a variety of olefin conversion processes to produce finished fuel products (Eisenberg, 1994). In 1993, a FT-type plant was constructed in Malaysia to convert natural gas to diesel fuel using the Shell Middle Distillate Synthesis (SMDS) process (Eilers, 1990; Tijm, 1993; OGJ, 1995).

Exxon has developed and pilot tested a process designated AGC-21 that uses a three-step process including: (1) a fluidized bed synthesis gas generator, (2) a multi-phase slurry reactor combined with a high performance catalyst system for hydrocarbon synthesis, and (3) a fixed bed hydroprocessing step resulting in a refinery feedstock that can be readily shipped by pipeline or conventional crude oil tanker (Eisenberg, 1994). Eisenberg states that "The liquid product is typically water-clear at room temperature, with just a hint of paraffinic odor." He further states "The synthetic refinery feedstock produced by the AGC-21 process is free of most of the impurities found in conventional crude oil. It is totally free of sulfur, nitrogen, nickel, vanadium, asphaltenes, multi-ring aromatics, and salt. To a modern refinery or petrochemical complex, it 
offers a wide range of product options, including premium quality diesel and jet fuel, specialties such as lube oils and waxes, and chemicals for the manufacture of solvents, alcohols, and polymers. As gas conversion liquids become readily available, they are sure to provide new product opportunities in response to ever increasing environmental challenges and market demands."

Exxon has invested over $\$ 150$ million to date on development of this process in recent years. Pilot plant run lengths of 2 to 3 months of round-the-clock operation were typical and throughput rates approached $200 \mathrm{BPD}$ of product. Eisenberg states that the demonstration program has provided the information needed for confident scale-up to design commercial facilities capable of producing 50,000 to $100,000 \mathrm{BPD}$ or more of liquid product. Very little economic information is provided except that "Sizes will likely be in the 50 to $100 \mathrm{kB} / \mathrm{D}$ range, and total investment for a grass roots remote site may easily exceed two billion dollars." (Eisenberg, 1994).

3.3.2.1 Fischer-Tropsch Process. For the economic analysis in this study, a FT-type process was selected as the model GTL process because it has reached the early stages of commercialization, provides the best available data for estimating capital and operating costs, and exhibits the lowest cost structure of early plant development. This is in contrast to several other indirect and direct conversion processes, several of which are still at the bench scale R\&D stage.

FT process development began with the work of Fischer and Tropsch in Germany in the 1920's. They reported synthesis of higher hydrocarbons from a synthesis gas $\left(\mathrm{H}_{2}\right.$ and $\left.\mathrm{CO}\right)$ using a cobalt-based catalyst at atmospheric pressure. The FT process consists of three steps: (1) generation of synthesis gas, (2) the FT synthesis step, and (3) the separation and upgrading step as shown in Figure 3.2. The values below each step give the approximate percentage of the total cost for each step. The generation of synthesis gas can be achieved through several processes; a partial oxidation synthesis gas generation is represented in the scheme shown in Figure 3.2. Using methane, the partial oxidation process can produce a 2 to $1 \mathrm{H}_{2} / \mathrm{CO}$ ratio, synthesis gas product, which is near the ideal stoichiometry for FT synthesis.

Efforts to improve FT process economics have focused most recently in the synthesis gas generation part of the processes. This area represents $60 \%$ of the investment of the full FT process. One area of interest is autothermal reforming, which is a combination of partial oxidation and steam reforming (see Figure 3.1) that permits a decrease in maximum temperature and results in reduced oxygen consumption and cost (Rostrup-Nielson, 1994). 


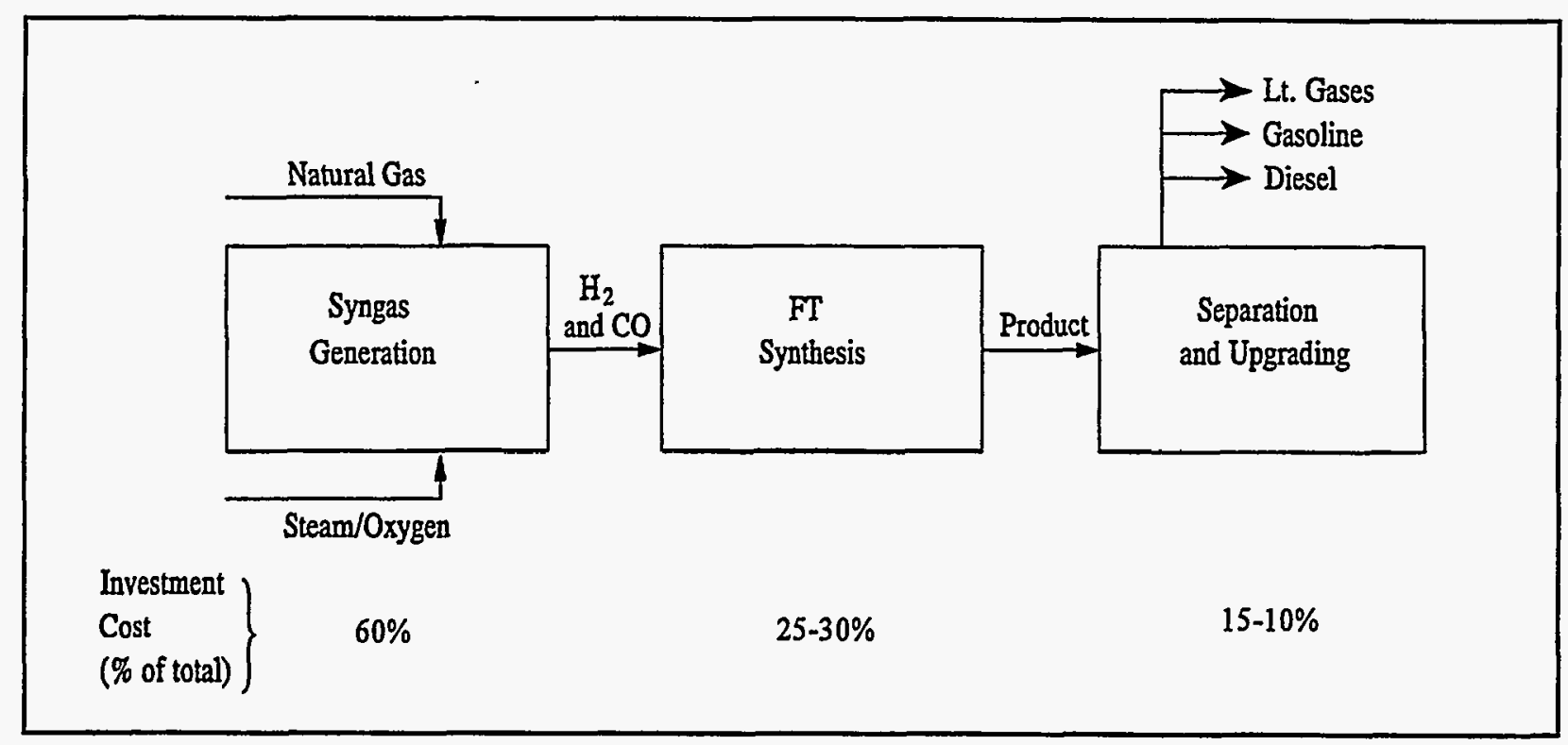

Figure 3.2. Fischer-Tropsch process schematic.

Another recent development by the Argonne National Laboratory and industry collaborators uses a mixed-ion conducting membrane for oxygen production from air, replacing the expensive cryogenic oxygen impact on the cost of synthesis gas generation (Balachandran, 1994). This concept of using a membrane to separate oxygen from air and then deliver the oxygen to react with the methane presents possibilities for reducing the cost by $25 \%$ or more for state-of-the-art synthesis gas production and subsequent FT products. Such process improvement is only in the development stage at this time; however, both DOE and the inventors have plans to step up the pace of cost-shared development of this technology. Although the mixed-ion membrane process is promising, it is premature to assume its availability for purposes of this ANS gas assessment.

The second step in the FT process is the FT synthesis step. The overall reaction for FT synthesis from $\mathrm{CO}$ and $\mathrm{H}_{2}$ generates a range of paraffin, olefin, and oxygenated products with the average molecular weight distribution determined by catalyst type, synthesis gas $\mathrm{H}_{2} / \mathrm{CO}$ ratio, and operating temperature and pressure. The range of products from the FT synthesis is illustrated in Figure 3.3 and shown in detail in Table 3.1 (Mills, 1994). These data are for SASOL's two Fischer-Tropsch, coal-based, 50,000 to 65,000 BPD plants and its newer, gas-based, 60,000 to 75,000 BPD plant at Mossel Bay, South Africa. These plants use an iron-based catalyst and have product distributions that are consistent with a 0.75 SchultzFlory parameter $(\alpha)$, where $\alpha$ is the probability of chain growth, as illustrated in Figure 3.3 (Tijm, 1993). 
Table 3.1. Dimensions and product selectivities of SASOL commercial reactors (from Mills, 1994).

\begin{tabular}{|c|c|c|c|}
\hline Reactor Type & \multicolumn{2}{|c|}{ SASOL I } & \multirow{2}{*}{\begin{tabular}{l}
\multicolumn{1}{c}{ SASOL II } \\
Synthol (Fixed \\
Fluid Bed)
\end{tabular}} \\
\hline Operating Conditions & Arge (Fixed Bed) & $\begin{array}{l}\text { Synthol (Circ. } \\
\text { Fluid Bed) }\end{array}$ & \\
\hline Catalyst, alkali promoted $\mathrm{Fe}$ & Precipitated & Fused & Fused \\
\hline Catalyst circulation rate, $\mathrm{MgH}$ & 0 & 8000 & -- \\
\hline $\mathrm{T}\left({ }^{\circ} \mathrm{C}\right)$ & $220-225$ & 315 & 320 \\
\hline $\mathrm{P}(\mathrm{MPa})$ & $2.5-2.6$ & $2.3-2.4$ & 2.2 \\
\hline Fresh feed $\mathrm{H}_{2}-\mathrm{CO}(\mathrm{mol})$ & $1.75-2.5$ & $2.0-3.0$ & -- \\
\hline Recycle ratio (mol) & $1.5-2.5$ & $2.0-3.0$ & - \\
\hline $\mathrm{H}_{2}+\mathrm{CO}$ conversion (mol\%) & $60-68$ & $79-85$ & -- \\
\hline Fresh feed $\left(\mathrm{km}^{3} \mathrm{~h}^{-1}\right)$ & $20-28$ & $70-125$ & $300-350$ \\
\hline Diameter $\mathrm{x}$ height $(\mathrm{m})$ & $3 \times 17$ & $2.2 \times 36$ & $3 \times 75$ \\
\hline \multicolumn{4}{|c|}{ Product Selectivity (wt\%) } \\
\hline $\mathrm{C}_{1}$ & 5.0 & 10.0 & 11.0 \\
\hline $\mathrm{C}_{2=\mathrm{a}}$ & 0.2 & 4.0 & \\
\hline $\mathrm{C}_{2}$ & 2.4 & 6.0 & 7.5 \\
\hline $\mathrm{C}_{3=\mathrm{a}}$ & 2.0 & 12.0 & \\
\hline $\mathrm{C}_{3}$ & 2.8 & 2.0 & 13.0 \\
\hline $\mathrm{C}_{4=\mathrm{a}}$ & 3.0 & 8.0 & \\
\hline $\mathrm{C}_{4}$ & 2.2 & 1.0 & 11.0 \\
\hline $\mathrm{C}_{5}-\mathrm{C}_{12}$ (gasoline range) & 22.5 & 39.0 & $37.0\left(\mathrm{C}_{5}-191^{\circ} \mathrm{C}\right)$ \\
\hline $\mathrm{C}_{13}-\mathrm{C}_{18}$ (diesel range) & 15.0 & 5.0 & $11.0\left(191-399^{\circ} \mathrm{C}\right)$ \\
\hline$C_{19}-C_{21}$ & 6.0 & 1.0 & $3.0\left(399-521^{\circ} \mathrm{C}\right)$ \\
\hline $\mathrm{C}_{22}-\mathrm{C}_{30}$ & 17.0 & 3.0 & \\
\hline $\mathrm{C}_{30}$ & 18.0 & 2.0 & $0.05\left(>521^{\circ} \mathrm{C}\right)$ \\
\hline Non-acid chemicals & 3.5 & 6.0 & 6.0 \\
\hline Acids & 0.4 & 1.0 & -- \\
\hline
\end{tabular}




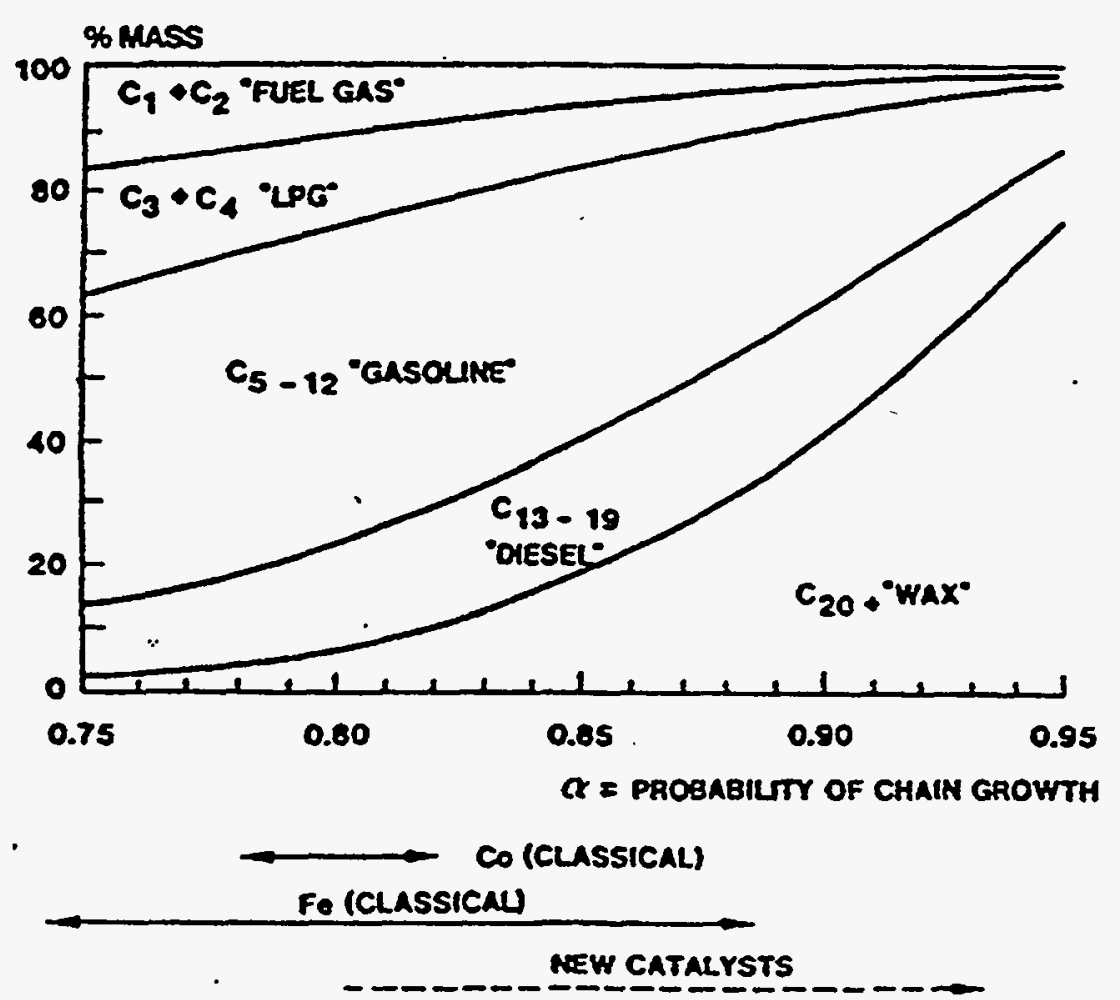

Figure 3.3. Molecular mass dstribution in raw product (Tijm, 1993).

The newer Shell Middle Distillate Synthesis (SMDS) plant in Bintulu, Malaysia, employs a different FT process approach. The plant is designed to produce 12,000 BPD of liquids from $100 \mathrm{MMCFPD}$ of natural gas (Tijm, 1993). The overall design thermal efficiency of the plant is $63 \%$, compared to a theoretical maximum of $78 \%$ for conversion of methane into paraffins (Eilers, 1990). The Shell SMDS process uses a new cobalt-based catalyst in a fixed bed reactor that operates at lower temperatures than the iron-based catalyst used in the SASOL plants, and produces low yields of light gas and high-yields of heavier paraffin wax product.

The final step in the FT process is upgrading of the FT liquid product by conventional refining processes. Lighter gases can be isomerized, naphtha can be reformed, and diesel material prepared for blending. The heavy $\left(C_{19+}\right)$ wax material can be cracked in a fluid cracking unit or a hydrocracker. The Shell process uses hydrocracking because the desired product is diesel fuel. Hydrocracking has the selectivity capability to produce a narrow boiling range product, most of which will be in the diesel boiling range. The products of the Shell SMDS process are pure paraffins, free from impurities such as nitrogen and sulfur and from aromatic species. Hence, the products have a low environmental impact upon combustion, which makes them ideal for blending with gasoline or diesel from normal petroleum refining for upgrading the 
products to meet newer emission standards (Eilers, 1990).

Shell's published information states that the specific capital cost of a 10,000 BPD plant built on a developed site in an industrialized country would be around $\$ 30,000$ per daily barrel liquid (DBL), where a similar plant in a remote, undeveloped location, could cost up to double that amount. On the other hand, larger plants in the 25,000 to $60,000 \mathrm{BPD}$ range might only be $\$ 25,000$ to $\$ 30,000 / \mathrm{DBL}$ in a remote area because of economics of scale (Tijm, 1993).

For this evaluation, the primary source of economic data for the FT case was a Bechtel study that evaluated the economics of direct conversion processes (Fox, 1990). Bechtel has done many economic studies of FT but generally with coal as feedstock rather that natural gas. The Bechtel study (Fox, 1990) focused on a modest-scale plant of 14,500 barrels per stream day (B/SD). The thermal efficiency of the overall facility was about $55 \%$. A detailed material balance was not provided but a selectivity to $\mathrm{C}_{5}$ and heavier compounds of $84 \%$ was assumed and operating conditions and yield were based on Gulf-Badger data (Singleton, 1988). Referring to Figure 3.3, this would mean the yield would be at an $\alpha$ (Schultz-Flory parameter) of approximately 0.86 with relatively low light-gas yields and intermediate yields of diesel and heavier $\mathrm{C}_{20+}$ yields. The subsequent economic study by Hackworth (DOE, 1995) indicates that later work has shown that improvement in the Bechtel case could be achieved by use of different reactors (such as slurry reactors), catalysts, and potentially with an improved synthesis gas production process.

The results described above, support an assumption that an overall conversion efficiency of $60 \%$ is achievable with current state-of-the-art technology for 40, 000 to 50,000 BPD, Fischer-Tropsch GTL plants.

\subsubsection{Pyrolysis Gas Conversion Processes}

Natural gas can be pyrolyzed to acetylene $\left(\mathrm{C}_{2} \mathrm{H}_{2}\right)$, which in turn can be converted to liquid fuels by catalytic processes similar to the synthesis gas approach. Acetylene can also be used as a building block for the synthesis of commercially important compounds such as vinyl chloride, vinyl acetate, butadiene, and neoprene. Acetylene production by pyrolysis of natural gas is based on the fact that the free energy of formation of acetylene decreases with increasing temperature, which is the opposite of other hydrocarbons (EPRI, 1982). At temperatures above $1600 \mathrm{~K}$, the most stable species in a hydrocarbon mixture is acetylene; it is even more stable than its component elements. 
Pyrolysis is achieved using an electric plasma arc to dissociate methane to carbon and hydrogen which are then quenched to form acetylene and other by-products. Acetylene is then oligomerized to liquid hydrocarbon products. Methane pyrolysis has been practiced in the past with varying degrees of success (EPRI, 1982; Gladisch, 1962). The only significant gas conversion application of pyrolysis technology is at a BASF plant producing acetylene in Germany (Gold, 1978). Begun in 1925, the plant and process were expanded and modified by Huels in 1939 to produce 100,000 tons per year (t/y) of acetylene for production of synthetic rubber (Gladisch, 1962). Today the plant produces acetylene, ethylene, hydrogen, and carbon black for chemicals production and synthetic rubber. The Huels plant uses 19 plasma arc reactors operated at 8.3 MW each. A mixture of $C_{1}$ to $C_{4}$ hydrocarbons is fed into the arc region of the reactor. Downstream, hydrocarbon liquids are used to quench the hot reaction gases, followed by further quenching with a water spray.

The major drawback to pyrolysis conversion has been the inability to raise the temperature of the natural gas feed stream very rapidly and to quench the products to a non-reacting mixture quickly enough to avoid the formation of non-selective by-products via secondary reactions. Historically, direct quench and direct reactive quench using liquefied petroleum gas pyrolysis has been studied in this regard (EPRI, 1982).

Recently, an aerodynamic quench using a converging-diverging nozzle has been demonstrated at the DOE's Idaho National Engineering Laboratory (INEL) to provide quenching in a very short residence time, under 2 milliseconds (Detering, 1995). Perfect conversion would yield 3 moles of hydrogen for each mole of acetylene produced $\left(2 \mathrm{C}_{1} \mathrm{H}_{4} \rightarrow \mathrm{C}_{2} \mathrm{H}_{2}+3 \mathrm{H}_{2}\right)$. Acetylene yields above $90 \%$ of the theoretical yield have been achieved in the INEL research; the balance is made up of very small amounts of carbon and unreacted methane. After the reaction and quench, acetylene can be hydrogenated to ethylene and then oligomerized to gasoline, diesel, or fuel-oil hydrocarbons. Except for recycle and hydrogenation requirements, the hydrogen would be available for other uses, including generating electricity needed to power the plasma reactor. The plasma quench process is illustrated in Figure 3.4.

The plasma quench process under development by INEL and industrial collaborators advances the plasma arc technology developed by Huels for acetylene production. In the plasma quench process, hydrogen gas is heated by an electric plasma arc and natural gas feed material is injected into the hot plasma jet for conversion into acetylene. The electric power requirements for the plasma quench process at the prepilot scale are about $6 \mathrm{~kW}-\mathrm{hr} / \mathrm{kg} \mathrm{C} \mathrm{C}_{2} \mathrm{H}_{2}$ compared to the Huels process requirements of $11 \mathrm{~kW}-\mathrm{hr} / \mathrm{kg} \mathrm{C} \mathrm{H}_{2}$. Preliminary economic analysis results indicate that the plasma quench process costs could be comparable 


\section{Plasma Quench Process}

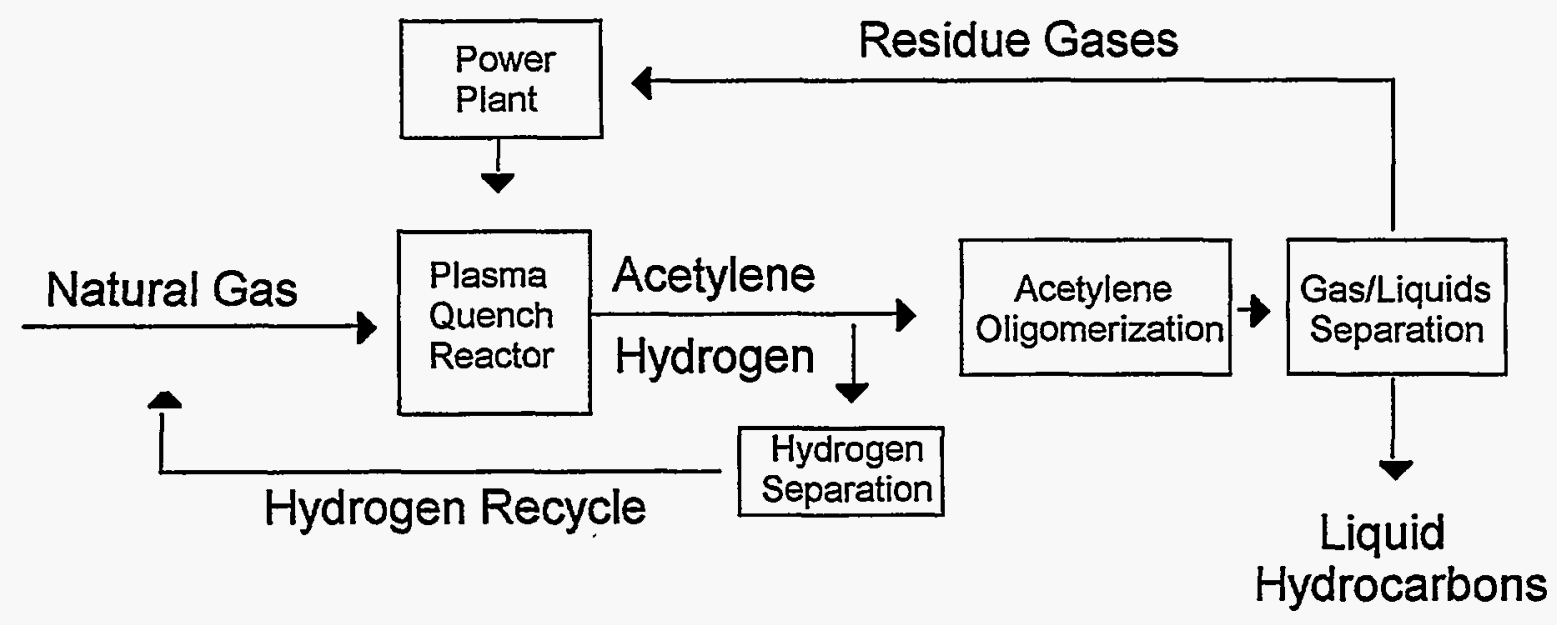

Figure 3.4. Schematic of the Plasma Quench Process for conversion of natural gas to liquid fuels.

to those of conventional FT processes for production of liquid fuels from natural gas (Detering, 1995). However, as is the case with the prospective ceramic membrane advance in FT technology, the rapid quench advancement is still in the bench scale development stage and is not used in the evaluation.

\subsubsection{LNG Liquefaction and Transportation}

Where gas pipeline connection from the source directly to the market is impractical or uneconomic, the utilization of low-cost natural gas by liquefaction to LNG and transport to distant gas markets is well established. The LNG process involves the physical conversion of natural hydrocarbon gas to a low-pressure cryogenic liquid at $-160^{\circ} \mathrm{C}$ at an LNG facility for transport to market in specially designed cryogenic marine tankers. LNG is then revaporized to the gaseous state for use in the gas market.

A LNG liquefaction plant employs a low-temperature refrigeration cycle, typically a multi-train plant of about 6,600 tons per day/train capacity (Fox, 1988) to chill and liquefy the natural gas. Feed pretreatment and refrigerant component recovery sections are normally a part of the plant facility. The LNG plant is usually located at or near a marine tanker loading terminal and natural gas is transported via gas pipeline from the gas field to the plant. LNG storage capacity is required at the loading terminal to accommodate tanker loading. The LNG marine tankers either consume boiloff gas as fuel or re-liquefy the gas and burn 
diesel oil as fuel. A typical LNG marine tanker has a capacity of about 125,000 cubic meters.

Published information on costs of LNG plants and tankers provide a cost range estimate from about $\$ 1.3$ to 2.2 million/MCFPD for plants and about $\$ 250$ million per LNG tanker (Cornot-Gandolphe, 1995; Hawkshaw, 1995). The cost data available for the TAGS project indicates a plant cost of about $\$ 1.2$ million/MCFD and a tanker cost of about $\$ 240$ million/tanker (Alaska Conservation Foundation, 1994; FERC, 1995).

\subsection{Summary}

The utilization of the ANS natural gas resource requires the transportation of that gas from the North Slope to existing markets in the Lower 48 or to overseas markets. Such a transportation system does not currently exist although several options are being considered. The two potential options seen to be feasible are a gas pipeline/LNG project and a GTL conversion process that uses an existing oil pipeline to transport the resulting liquids. The LNG process converts natural gas to a low-pressure cryogenic liquid in a refrigeration cycle for transport in special LNG tankers. The GTL process (assumed for this study) converts natural gas to stable hydrocarbon liquid fuels through the synthesis gas/FT process and then to hydrocarbon fuels by catalytic processes.

Commercial-scale GTL conversion projects do exist but are few in number and inadequate for stateof-the-art GTL conversion economic viability to be considered well established. However, GTL conversion technology is rapidly developing and could result in significant improvement in conversion economics over those of existing plants. Likewise, GTL operation economics will benefit from the sophisticated infrastructure and high level of experience in arctic construction and operations that exist on the North Slope. It will also benefit from the envisioned larger plant sizes than that of the current FT gas conversion demonstration plant in Malaysia. Liquid fuels from the conversion of natural gas have a large existing market. Gasoline/diesel range hydrocarbon liquids with excellent environmental characteristics that can be produced from a GTL conversion process receive a premium price in world oil markets (see Section 4.1).

Of the various types of conversion processes, the Fischer-Tropsch indirect conversion process is the most established existing process although conversion costs remain high. The FT process first produces a synthesis gas from partial oxidation of methane followed by a catalytic process to convert the synthesis gas to liquid hydrocarbons that can be upgraded by conventional refining processes to gasoline, diesel fuel, or 
both. A hybrid of partial oxidation and steam reforming and recently developed ceramic membrane oxygen production technologies both may offer significant conversion cost reductions for FT processes. Likewise, methane pyrolysis to yield acetylene which is then synthesized to hydrocarbon liquid products also holds promise for less expensive GTL conversion. Research is expanding the FT, pyrolysis, and other GTL conversion technology base and there is good reason to expect conversion costs will be less in the years ahead.

In comparison, LNG projects and technology are well established worldwide and a significant LNG market already exists, although competition in that market is significant. An ANS gas pipeline/LNG project will require a very sizable investment (over $\$ 6$ billion in 1995\$) for a trans-Alaska gas pipeline to transport the gas to a seaport that is not ice bound during winter months, and will have to compete in the worldwide LNG market with other proposed LNG projects, which do not require as large an initial investment for a gas pipeline connecting the gas source to the LNG facilities. The LNG project option would have the advantages that the shipping distance from Valdez to Japan is less than the shipping distances to market of most of the other projects, and its gas is a secure U.S. resource. Although large LNG markets exist in Pacific Rim countries, LNG prices have not been strong enough to date to support an ANS LNG project. Extensive efforts by commercial interests continue to show improvements in project economics and studies indicate that a window of opportunity for a ANS LNG market could develop in the 2005 time frame (Oil Daily, 1995a). 


\section{LNG AND GTL PRODUCT MARKETS}

This section contains a review of the Asian LNG market and the U.S. refined product markets, and a review of future supply/demand volumes and prices in these markets. The two options for utilizing North Slope gas described in Section 3 would produce different types of products that would be sold in different end user markets and different market locations. The LNG option would produce LNG that would be marketed in Japan, South Korea, and Taiwan. The GTL option would produce a refinery feedstock having a large concentration of material that would be refined to gasoline and distillate products (e.g., jet fuel, home heating oil, No. 2 fuel, or diesel fuel) and would be marketed to U.S. West Coast refineries or exported.

\subsection{U.S. West Coast Oil Product Markets}

The U.S. West Coast is a major market for oil products with most of the consumed products being produced by refineries located in the region. In 1994, the refineries in the region (PAD District V) ${ }^{\mathrm{a}}$ produced about 2.8 MMB/D of refined products to meet a demand of $2.7 \mathrm{MMB} / \mathrm{D}$ in the region. Gasoline was $49.5 \%$ and distillate was $29.0 \%$ of the total refined products demand (EIA, 1995b).

In assessing the value of a GTL product as a feedstock to a refinery, the primary variable is the average crude price. The value of a feedstock, such as GTL products, can be estimated from the average crude price and is based on the relative processing costs and value of the refined products.

The refined products of highest value are gasoline and distillates, which sell at higher prices than crude oil because of the processing cost to convert crude oil to these products. In Figure 4.1, prices of gasoline and No. 2 fuel oil (one of the distillate products) are plotted along with the average price of crude oil imported into the U.S. (EIA, 1995c). As can be seen, the prices of these products track the pattern of movements of crude oil prices. The wholesale gasoline price averages $\$ 8 / B B L$ higher than crude oil and No. 2 fuel oil price averages $\$ 6 / \mathrm{BBL}$ higher than crude oil. In addition, the products that are made in the Shell SMDS plant in Malaysia and the Exxon AGC-21 pilot project are higher value fuel products than those made from crude oil because of the zero sulfur, nitrogen, and aromatic content, which makes them ideal for meeting the new low-emission regulations for diesel, etc. (Eilers, 1990; Eisenberg, 1994). These products

a. Petroleum Administration for Defense District V (PAD District V) includes Alaska, Arizona, California, Hawaii, Nevada, Oregon, and Washington (EIA, 1995b). 
are expected to make excellent high value blending products for meeting the new California low-emission fuel regulations and thus could have a higher value than normal diesel and gasoline products. Shell reports that the high-quality distillates made in its Malaysia plant have been commanding premiums of $\$ 8$ to \$10/BBL over crude oil-derived distillate in the California market (Oil Daily, 1994d).

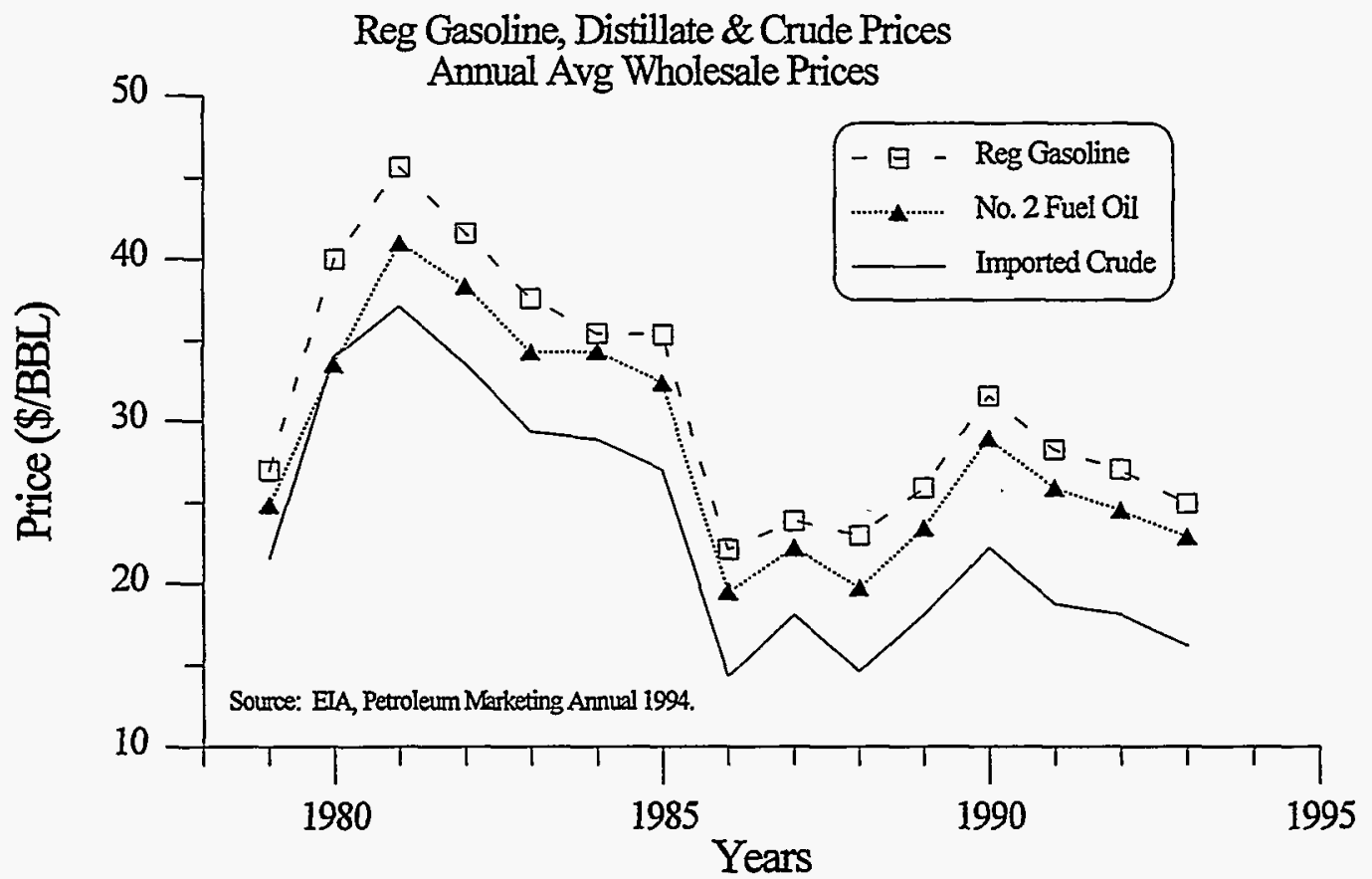

Figure 4.1. U.S. average annual wholesale prices for gasoline, No. 2 fuel oil, and imported crude oil in dollars of the day (EIA, 1995c).

GTL products envisioned in this study, would be expected to fit reasonably well into the West Coast refinery situation. The GTL product would arrive at the West Coast refineries mixed with Alaska crude oil. (However, if it is feasible to transport GTL products in TAPS as alternating slugs with the crude oil, the products would remain separate from the crude oil and be transported as hydrocarbon fuels that would not have to be separated from the crude oil in the refining process. The feasibility of this option was not evaluated in this study.) West Coast refineries were specifically designed for the Alaska crude and many of them are highly complex with a higher level of hydrocracking facilities than in most refining areas. The GTL product envisioned for this application contains high concentrations of straight chain paraffins. In the distillate boiling range, this feedstock makes attractive diesel fuel material, but the higher boiling paraffins are best converted to valuable products by hydrocracking. Thus, while any change in refinery feedstock requires some adaptation in refinery operation, the West Coast refinery market appears to be a reasonably good target market for GTL products from the processing and refinery product standpoint. 
At today's crude market prices and state of development, GTL projects look attractive only for a few producing locations, primarily remote locations where gas has a low market value as discussed by Hackworth (DOE, 1995). Even for low-value remote gas, the analyses by Hackworth indicate that increasing crude prices are needed to provide a reasonable return on GTL conversion facilities and provide a reasonably attractive wellhead price to producers. The EIA's 1995 forecast of oil prices is shown in Figure 4.2 (EIA, 1995). The EIA 1995 forecasts span the range of other published forecasts (see Table 4.1). To provide an additional comparison, a flat oil price of $\$ 18 / B B L$ is also used in this study. As shown in Figure 4.1, when shown in dollars of the day, crude oil prices have fluctuated for the last 10 years but have shown neither an upward or downward trend.

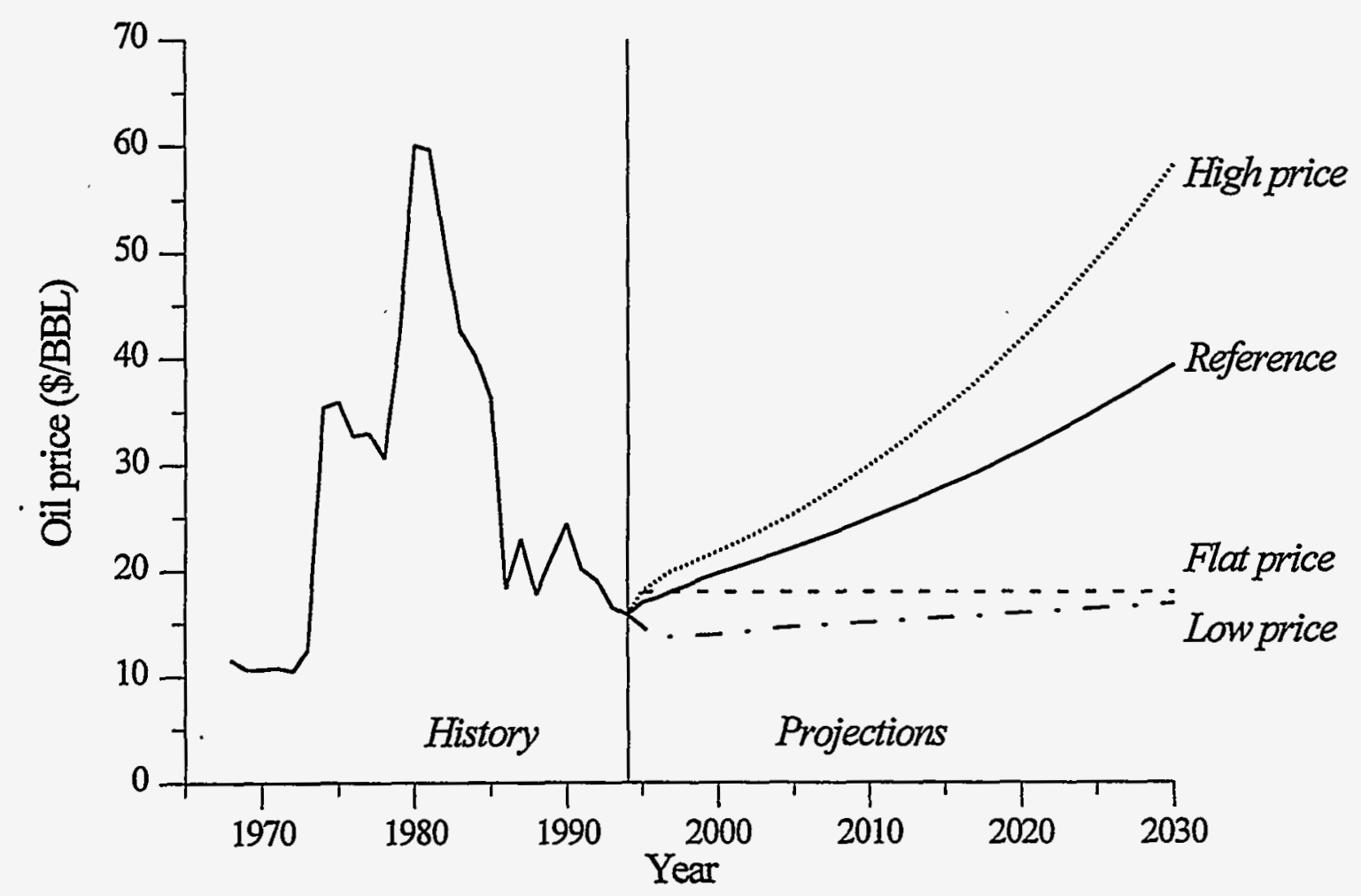

Figure 4.2. Historical world oil prices and world oil price forecasts in 1/1/95\$ (EIA, 1995).

\subsection{LNG Markets}

Natural gas that has been discovered in locations where there is little local demand has experienced great difficulty in building markets in distant major energy market areas. Over the last half-century, oil production in the Middle East has gained a major market share in the oil markets of Asia, Europe, and the U.S. In contrast, there has been little development and export of natural gas from the Middle East despite its large volume of discovered natural gas reserves (Table 4.2). 
Table 4.1. Comparative forecasts of world oil prices (EIA, 1995).

\begin{tabular}{lccc}
\hline & \multicolumn{3}{c}{ 1995 dollars per barrel } \\
\cline { 2 - 4 } Forecast & 2000 & 2005 & 2010 \\
\hline AE095 reference & 19.76 & 22.21 & 24.92 \\
AEO95 low price & 13.97 & 14.72 & 15.13 \\
AEO95 high price & 21.85 & 25.36 & 29.95 \\
DRI & 20.86 & 25.76 & 29.31 \\
WEFA & 19.58 & 21.26 & 22.30 \\
IEA & 23.94 & 29.14 & 29.14 \\
GRI & 19.40 & -25.62 & 15.62 \\
PEL & 16.65 & 26.35 & 26.35 \\
NRC & 25.25 & 24.23 & 26.68 \\
CEC & 21.99 & & \\
\hline
\end{tabular}

Table 4.2. World Gas Statistics (BP, 1995; OGJ, 1995i).

\begin{tabular}{lcrc}
\hline & $\begin{array}{c}\text { Reserves } \\
\text { (TCF) }\end{array}$ & $\begin{array}{c}\text { Production } \\
\text { (TCF) }\end{array}$ & $\begin{array}{c}\text { R/P } \\
\text { Ratio }\end{array}$ \\
\hline North America & 311 & 24.8 & 12.5 \\
Latin America & 189 & 2.5 & 76.1 \\
Western Europe & 216 & 8.4 & 25.8 \\
Former Soviet Union & 1976 & 23.7 & 83.4 \\
Middle East & 1594 & 4.5 & 354.5 \\
Africa & 341 & 2.6 & 131.0 \\
Asia and Australia & 350 & 7.0 & 49.7 \\
\hline TOTAL & 4978 & 73.5 & 67.7 \\
& & & \\
\hline
\end{tabular}

The natural gas reserves and/or resources, which are located far from major markets (usually referred to as remote gas), face a significant transportation disadvantage. To get to markets, remote gas must usually be liquefied either by conversion to LNG or by one of the chemical conversion processes (GTL) discussed in Section 3. To date, LNG has been the primary means used to move natural gas to distant markets. The LNG business has been built primarily around two geographical pairings; the North Africa to Europe trade and the Asia/Australia supply of Japanese markets. As Figure 4.3a and Figure 4.3b show, these two trades account for most of the current world LNG traffic. The Asia/Australia trade has experienced the most robust growth, growing at an average $7 \%$ per year between 1984 and 1995 . North African export has grown at $4 \%$ per year during the same period. 


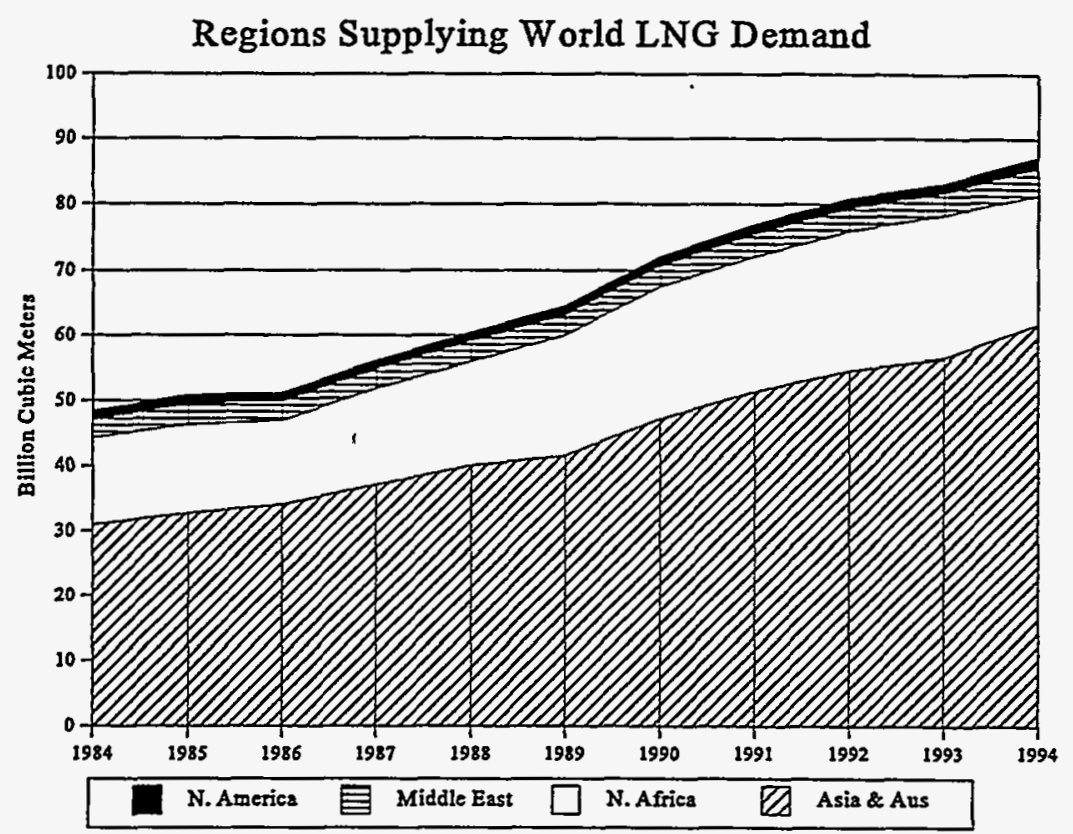

Figure 4.3a. LNG world supply volumes and regions (BP, 1995).

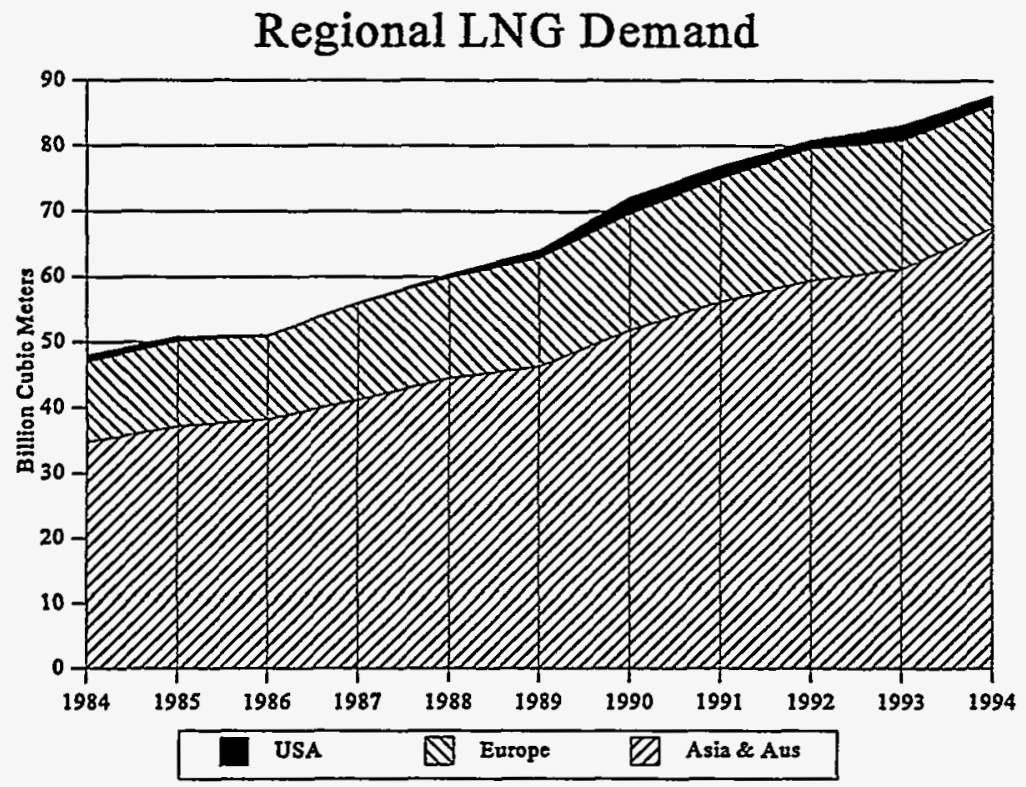

Figure 4.3b. LNG world regional demand (BP, 1995).

There has also been a small export volume ( $1.7 \%$ of world supply) from the production facility in southern Alaska, and from Abu Dhabi in the Middle East (4.9\% of world supply) (ADNR, 1995c). The Alaska and Abu Dhabi exports are marketed in Japan (BP, 1995). 
Japan is the largest LNG market representing 65\% of world demand in 1994. LNG demand in Japan has grown at a rather steady $5 \%$ per year over the past decade. Worldwide LNG consumption has increased 6.2\% per year between 1984 and 1994 (BP, 1995).

At the Eleventh International Conference \& Exhibition on Liquefied Natural Gas held July 3-6, 1995, a number of industry forecasters exchanged views on the future growth of LNG demand. Generally, the forecasts are for healthy LNG growth to continue, but at a slightly diminished growth rate. Forecasts by CEDIGAZ (Cornot-Gandolphe, 1995) and by consultant Malcolm Peebles (Peebles, 1995), see demand growing to 130 million metric tonnes per year (MMTPA) by the year 2010 as shown below in Table 4.3. Asian markets are seen as continuing to be the major LNG market representing two-thirds of the 2010 demand. Japan's share is forecasted to decline as demands in other Asian countries grow at a faster rate.

Table 4.3 World LNG demand forecast (after Cornot-Gandolphe, 1995).

\begin{tabular}{lccc} 
& 1994 & 2000 & 2010 \\
\cline { 2 - 4 } $\begin{array}{l}\text { LNG Demand } \\
\text { (MMTPA) }\end{array}$ & 65 & 90 & 130 \\
\hline
\end{tabular}

Historically, the delivered price of LNG has been strongly influenced by the price of crude oil, as shown in Figure 4.4 (BP, 1995). LNG prices rose almost in proportion to crude in 1978 and 1979. When world oil prices fell precipitously in 1986, LNG followed the downward path at a somewhat slower pace. In recent years, LNG has been selling at a price premium over crude delivered to the Japanese market. This may or may not continue in the future but the potential for development of power generation plants based on LNG as announced in 1994 by Tokyo Electric, suggests that an LNG market could develop that would not be as strongly tied to crude oil prices (Alaska Conservation Foundation, 1994).

Although there has historically been a significant correlation between crude oil and LNG prices, there are some important differences in the cost structures of crude versus LNG that have major impacts on who supplies which market and how supply contracts are written. When $\$ 20 /$ barrel crude oil is delivered to Japan, only about $\$ 0.70$ to $\$ 1.50$ of that $\$ 20$ goes for transportation with the producers at the plant gate receiving about $90 \%$ of the market price. By contrast, if LNG is delivered to Japan at $\$ 3.40 / \mathrm{MMBTU}$ (equivalent to $\$ 20 / \mathrm{BBL}$ on a BTU basis), the producer at the wellhead may only receive a small fraction of 


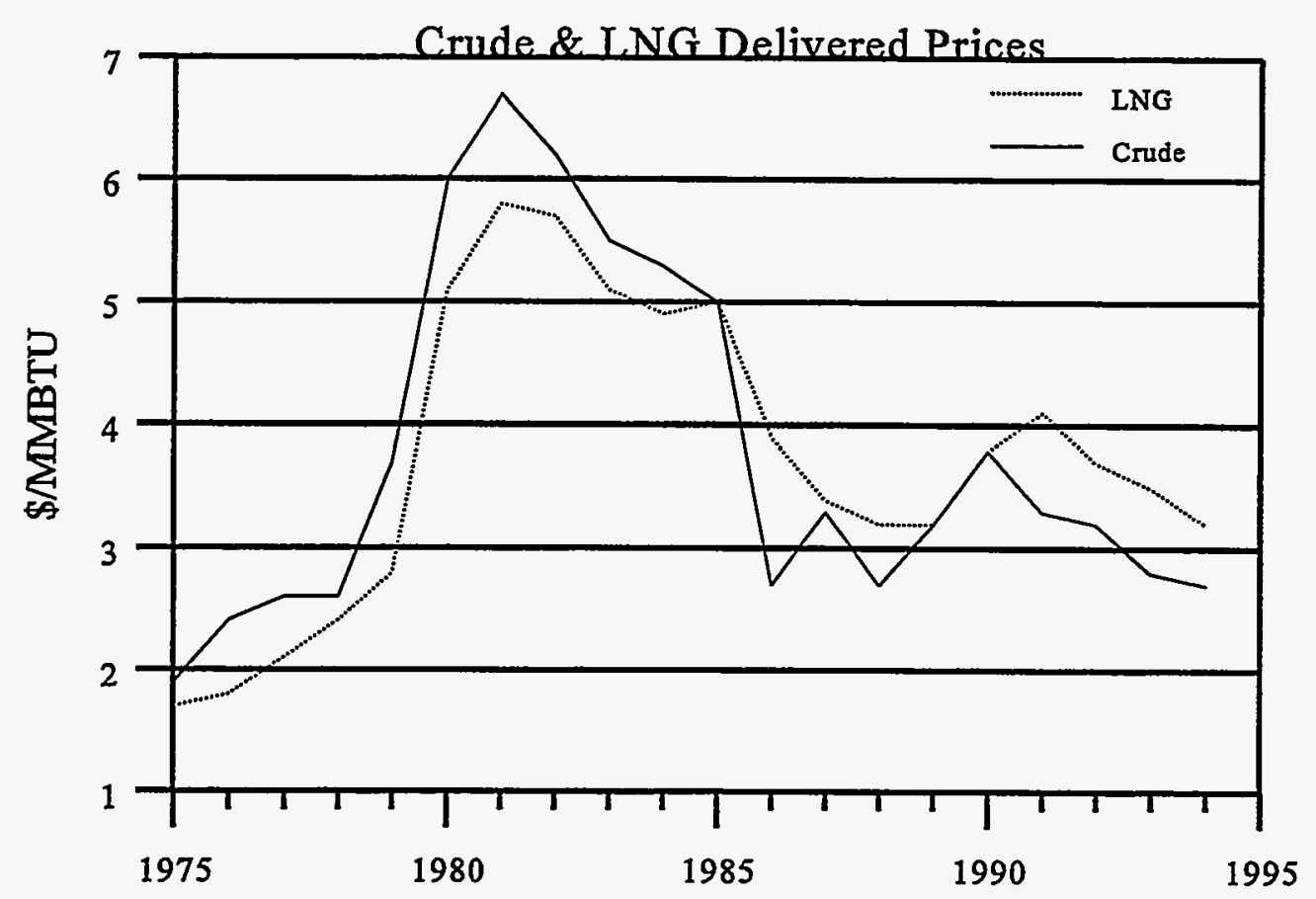

Figure 4.4. Historical prices for LNG and crude oil (BP, 1995)

the sale price (e.g., $5 \%$ to $25 \%$ ) with the balance being consumed by liquefaction and transportation costs. Cost breakdowns for liquefaction and transportation costs are discussed in detail in the papers presented at the Eleventh International Conference \& Exhibition on Liquefied Natural Gas (Cornot-Gandolphe, 1995; Hawkshaw, 1995).

Sellers and buyers of LNG are both well aware that the price of crude oil could drop to $\$ 10 / \mathrm{barrel}$ or, in tight market situations, could jump quickly to $\$ 40 /$ barrel and remain at that level for several years. Long-term LNG contracts take this into account by retarding the rise or decline in LNG prices during crude oil price spikes and collapses (Hawkshaw, 1995). Figure 4.5 is an illustration of a possible long-term LNG contract that is typical of historical contracts that allow the buyer and developer to share the risk of price fluctuations. Between a crude price of $\$ 14$ and $\$ 25 / \mathrm{BBL}$, the LNG price is adjusted proportionally for changes in the price of crude oil based on BTU content. However, if the crude oil price drops below $\$ 14 / B B L$, the LNG price declines only a fraction of the crude oil price decline. Conversely, if the crude oil price rises above $\$ 25 / \mathrm{BBL}$, the $L N G$ price increases only a fraction of the crude oil price increase.

Hawkshaw and Flower (1995) addressed the question of the supply sources for future demand. They presented a view that the supply sources for the future Asian market will be based on relative cost 


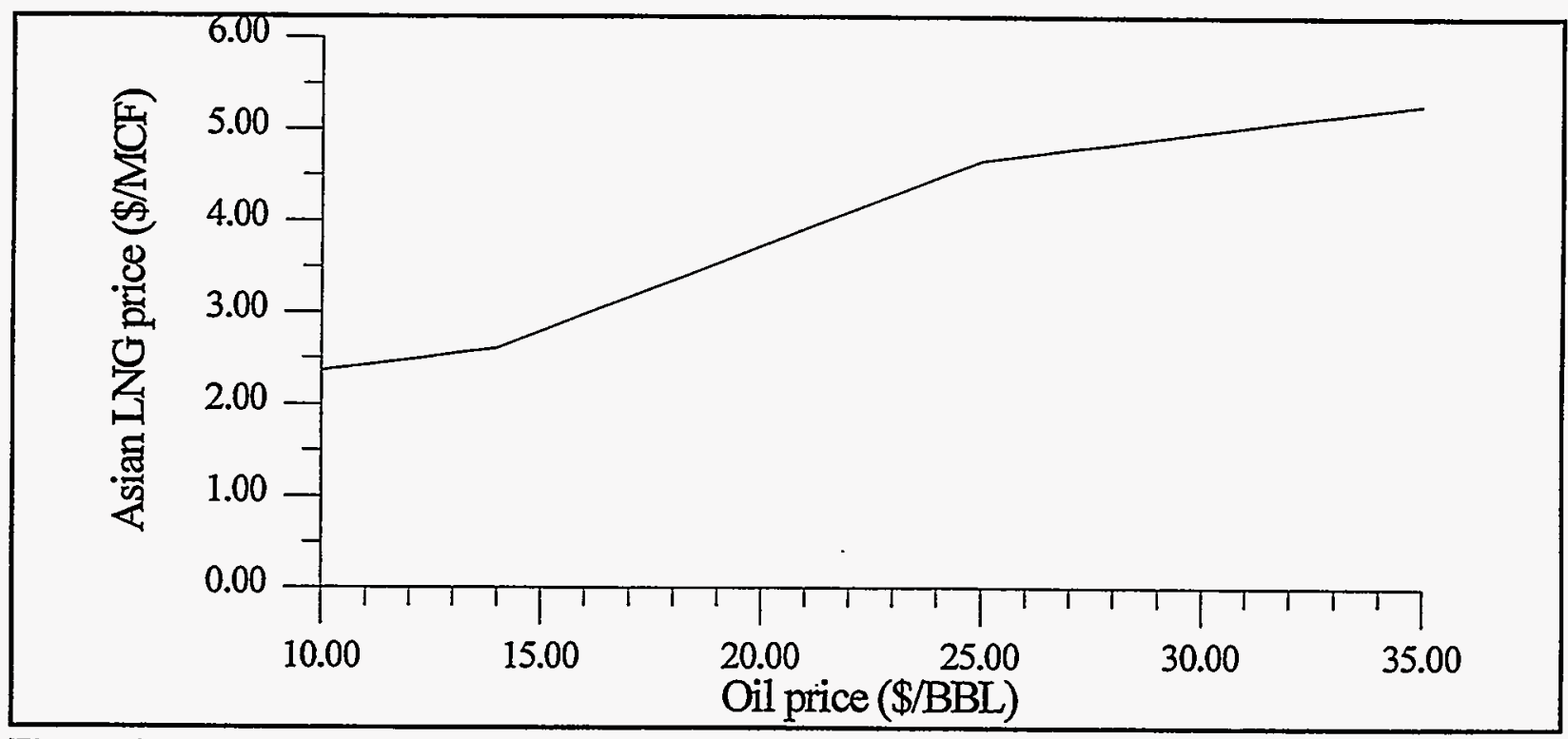

Figure 4.5. Example of relationship for a long-range LNG contract showing dependence on crude oil prices.

competitiveness. Figure 4.6 represents this assessment of cost of delivery from various supply sources. According to Hawkshaw and Flower, new supply would first come from expansion in Australia and Indonesia and from the grass roots projects in South East Asia. As shown, North Slope Alaska falls in the least cost competitive grouping. Viewed from a cost competitiveness basis, an LNG project for North Slope gas faces a major cost disadvantage because it must support a $\$ 6.6$ billion gas pipeline in addition to the liquefaction and LNG transportation cost. In contrast, YPC believes TAGS has better economics than any of the proposed LNG project according to the North Slope Natural Gas Pipeline Status Report published in 1994 by the Alaska Conservation Foundation; i.e., "Yukon Pacific modeling based on what they claim to be very conservative assumptions shows that TAGS has the best overall economics of any of the proposed projects (Qatar, Oman, New Guinea, Natuna Island, Sakhalin) vying to serve the post-2000 Asian LNG market." (Alaska Conservation Foundation, 1994, p. 5).

\subsection{Summary}

The prospects for utilization of North Slope natural gas are strongly tied to world crude prices. There has been steady growth in the Asian LNG market but the supply sources have been Asian and Australian gas located at comparatively short distances from the markets in Japan, Korea and Taiwan. Because crude prices have shown no sign of increasing in recent years and because GTL technology is only emerging to commercialization, there have been only a few GTL projects. The possible future price path for crude oil would not impact LNG and GTL options equally. A high crude price path would more 
favorably impact GTL than the LNG option. These market price impacts are described in detail in Section 5.

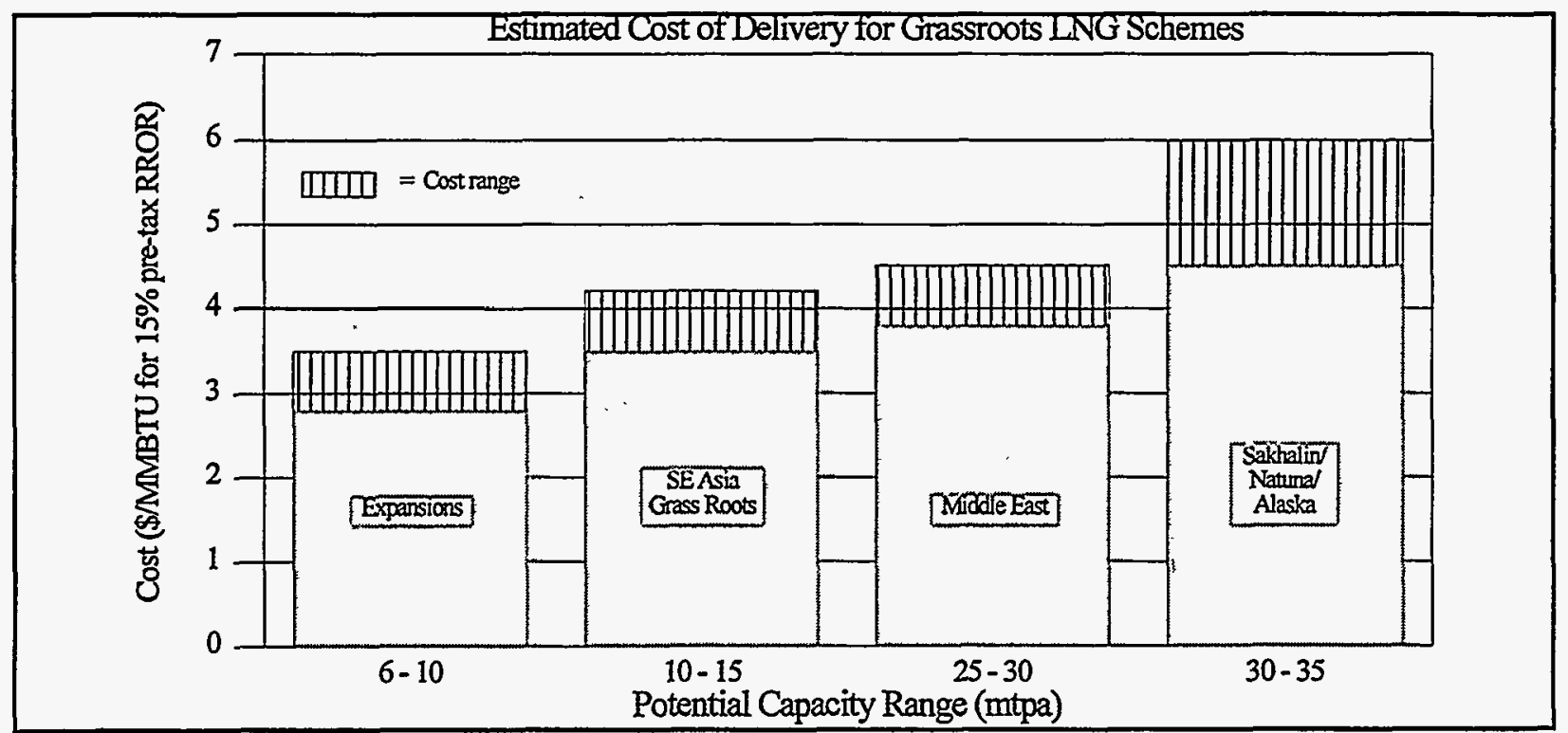

Figure 4.6. Estimated Pacific Rim delivery costs for LNG from various sources (Hawkshaw and Flower, 1995). 


\section{ECONOMIC ANALYSIS}

The economic evaluations of different methods of bringing ANS gas to market are described in this section. Because PBU and PTU are the only units with more than 1 TCF of proved gas reserves, they are the only units included in the evaluation of gas production and sales. It should be kept in mind that major gas sales from PBU could affect the oil production. The rate of oil (and converted liquids) production has a significant effect on TAPS tariffs, which influences the economics of all producing units on the North Slope.

Three different scenarios are considered for PBU and PTU.

1. No major gas sales: Continue the current mode of operations without major gas sales; i.e., continue to reinject gas from PBU, do not develop PTU, and sell only oil (crude oil, condensate, and NGLs).

2. LNG conversion: Major gas sales by $P B U$ and $P T U$ to a gas pipeline/LNG project modeled after the TAGS project proposed by Yukon Pacific Corporation with the following components:

- Construction and operation of an independently owned and operated gas pipeline/LNG plant, modeled after the proposed TAGS project, which purchases gas from PBU and PTU.

- PBU and PTU deliver gas to the LNG project gas conditioning plant on the North Slope.

3. GTL conversion: Major gas sales by PBU and PTU to a GTL conversion plant located on the North Slope at or near TAPS pump station No.1 (PS No. 1) with the following components:

- Construction and operation of an independently owned GTL conversion plant (including necessary gas conditioning facilities) located on the North Slope, which purchases gas from PBU and PTU. Converted liquid product will be transported to Valdez in TAPS along with the conventionally produced crude oil.

- $\quad$ PBU and PTU deliver gas to the GTL conversion plant. 
Figure 5.1 is a schematic diagram illustrating the gas and liquid flows from PBU for the LNG and the GTL conversion projects. It is assumed that all facilities outside the PBU boundary are independently owned and operated and are not part of the PBU facilities. It is possible that the gas conditioning plant could be owned by PBU and benefit from cost sharing with the existing PBU Central Gas Facility (CGF), which is currently processing 7.5 BCFPD of gas. However, the economics for both options assume the gas conditioning plant is built by the gas project developers.

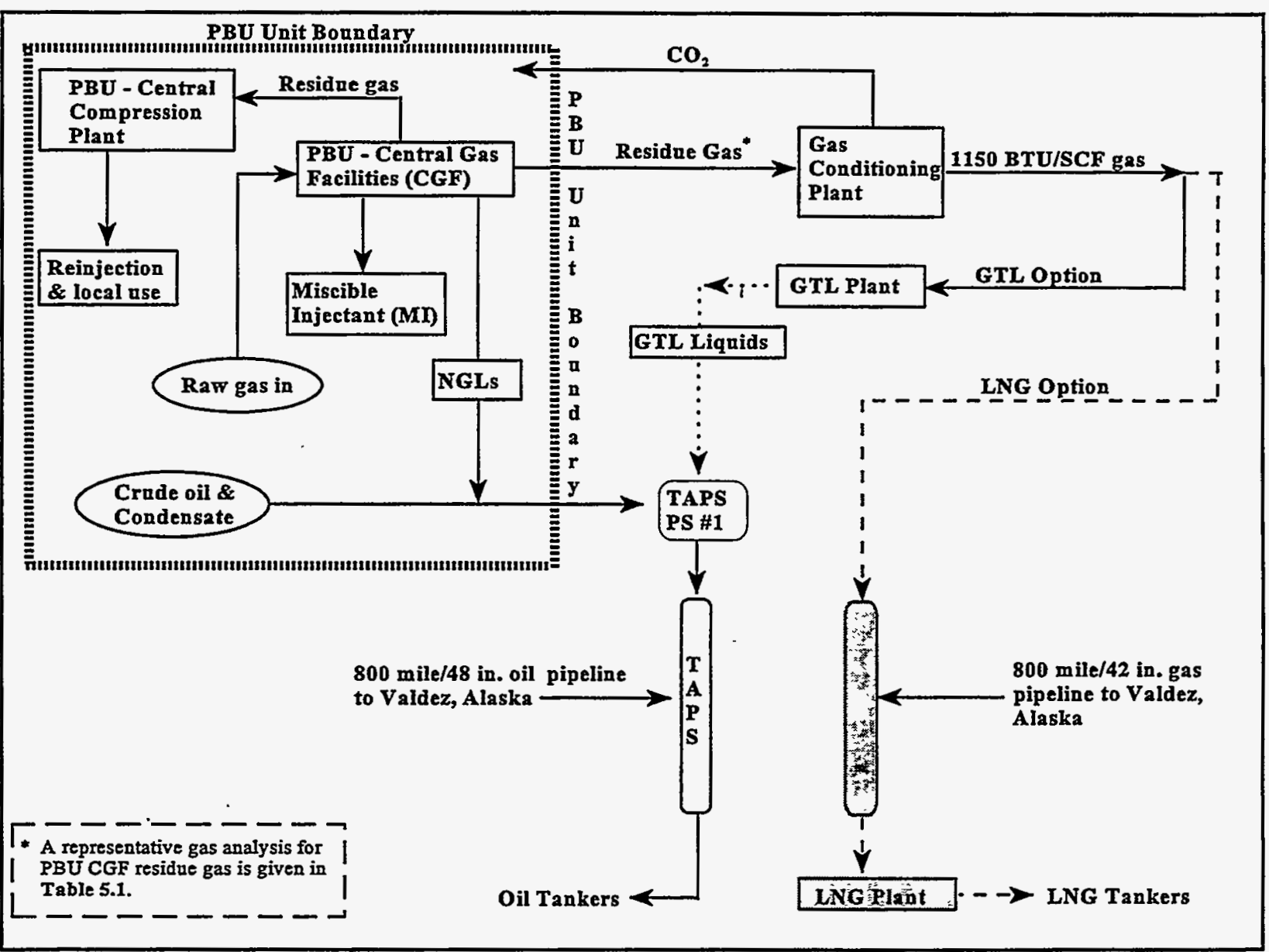

Figure 5.1. Schematic of gas and liquid flows from PBU for gas sales options.

The LNG project and the GTL plant are considered stand-alone entities that are separate from the gas producing units as well as the Trans Alaska Pipeline System (TAPS) operations and crude oil tanker delivery system. This enables the incremental investment required to market the presently unmarketable gas to be examined separately from the oil and gas extraction operations at PBU and PTU. PBU and PTU operations are examined separately to assess the effects of the gas projects on their economic value. 


\subsection{Comparative Analysis Framework}

A discounted cash flow economic model previously developed at the INEL specifically for Alaska oil and gas projects was revised and expanded as necessary to evaluate the gas sales projects as well as the historical and projected economics of the producing units (DOE, 1991; DOE, 1993a). The model is described in Appendix C.

All the input variables required to economically assess the options are subject to uncertainties in their final values. The sensitivity of the economic results to changes in the input variables is used to illustrate the effects of changes in the variables. Some of the variables, such as gas and oil production forecasts, TAPS and marine tariff schedules, and the gas conversion technology used to establish the baseline economic variables, are not changed over the life of the projects and are not included as variables in the sensitivity analysis. Also, it is historically clear that world crude oil price predictions are unreliable. To illustrate the effects that wide variations in crude oil price expectations and the risks that such uncertainty imposes on investors, two separate world crude oil price schedules are used in the evaluations. The base case evaluations and the sensitivity analyses use the DOE's Energy Information Administration 1995 reference oil price forecasts (AEO95), which contains about a $2.4 \%$ annual increase (in addition to inflation) in oil prices. To show the effect of a flat oil price scenario, results are presented for an \$18/BBL flat oil price and the base assumptions. Other input assumptions that are more subject to change from continued technology advancement, operator decisions, investor decisions, or government control, are included in the sensitivity analysis to evaluate the effects that conceivable changes in their values might have on the comparative economics of the gas conversion options or the producing units, or both. The base assumptions for all the variables are discussed below.

In addition to the net present value (NPV), discussed in Section 1.3, several other economic measures yield information about the relative value of the gas sales options. The measures examined include: (a) NPV 10 , (b) ANS gas market price that each project can support, (c) overall revenues and costs over the lives of the respective projects; (d) and taxes, royalty, and other financial yields to the State and federal governments.

As discussed in Appendix B.1.1.1, a 10\% discount factor is used for the analysis because the technological risks for LNG are low as the technology is in use at large scale around the world. GTL technology, on the other hand, is not as well established as LNG technology, but it is in use around the world 
on a smaller scale. However, a $10 \%$ discount rate is believed to be a reasonable assumption for a comparative analysis because, if advanced GTL technology is available by the time a final decision is made for the gas sales option, such improvement will have been demonstrated at plant scale, resulting in a relatively low technology risk. Individual companies will have internal financial and risk requirements based on their individual assessments and financial situations at the time of the decision making, which may be higher or lower than $10 \%$.

Among the other economic measures for the projects, the ANS gas price is of particular interest in that it shows what the revenue yield could be to the separate gas producing units from the marketing of gas after all incremental "marketing" costs, including LNG or GTL conversion operations, are covered. The ANS gas price is the fraction of the final product sale price that could be paid to the gas producing units (PBU and PTU). For the LNG scenario, the final product sale price is the price received for the LNG as it is sold for revaporization in Japan. For the GTL scenario, the final product sale price is the price paid for the converted, high-quality liquids by West Coast refineries. The ANS gas price is determined such that the stand-alone gas projects provide a $10 \%$ rate of return on investment for the LNG and GTL projects with the baseline assumptions for capital investments and operating and maintenance costs. This price represents the upper limit of the fraction of the gas product price that the projects could potentially pay and provide the gas project developers a $10 \%$ rate of return. This upper limit value is used in the analyses in this study, although it is expected that gas sales contracts will be based on some formula that would provide a sharing of these potential revenues between the gas project developers and the gas producing units. This fraction of the gas product price is termed the "gas product net back" in this report.

The gas product net back is of interest in that it provides information relative to the gas purchasing contracts that will have to be set up between the gas producers and the gas sales projects developers. However, it is not a definitive measure by itself for determining which gas sales option should be pursued, because it does not take into account all the revenues to the producers. This is particularly important relative to the GTL option where the gas product net back does not include the effects of the TAPS tariff reductions that accrue to the crude oil producers from the GTL liquids absorbing a portion of the TAPS operating and capital amortization costs.

\subsubsection{Fixed Economic and Technical Parameters}

The gas and oil production forecasts determine the volume and rates of gas and oil production for 
the project economic evaluations. The forecasts, although subject to normal uncertainties in forecasting, such as unpredictability of long-term reservoir performance, changes in technology, fluctuations in oil and gas prices, and modifications in taxing structure, have been extensively reviewed and are kept fixed throughout the evaluations. The gas conversion technologies are not varied except through the sensitivity of the variables such as capital costs, operating and maintenance $(O \& M)$ costs, and conversion efficiency. The gas and oil production volume and rate forecasts are described in Appendix A. The technologies for gas conversion are discussed in Section 3.3.

5.1.1.1 Gas Production Forecast. For comparison purposes, the amount and rate of gas production and sale to the LNG and the GTL projects are identical, beginning in 2005 from PBU and 2008 from PTU, and ending in 2036 for PBU and 2027 for PTU. The total production forecast for major gas sales from PBU and PTU used in this analysis is 25 TCF of hydrocarbon gas (see Table 2.3). Annual production rates are developed in Appendix A.2.2 and Appendix A.3.1 for PTU. After startup and buildup over a 5-yr period, the PBU daily production is 2.05 BCFPD, consistent with the level proposed by the TAGS LNG proposal used to develop the LNG option in this study. PBU total production is $21.8 \mathrm{TCF}$ over a 32-yr life. The PTU maximum gas sales rate is assumed to be 0.44 BCFPD and results in a 20-yr life for a total gas production of 3.18 TCF. The PTU portion of the project anticipates the desirability of PTU investment and production beginning after LNG or GTL operations have been started at PBU and being completed before PBU production ends.

5.1.1.2 Oil Production Forecast. The annual oil production forecasts of the North Slope oil operations are assumed to be the same for both gas sales options. For PBU, the ultimate oil production volume for a 2005 startup of both major gas sales options is reduced by $400 \mathrm{MMBO}$ (about $3 \%$ ) from the no major gas sales case forecast, as discussed in detail in Section 2.2.4. The oil production forecasts are described in detail for each of the currently developed North Slope fields and the undeveloped Point Thomson Unit in Appendix A. Other undeveloped fields are discussed but forecasts are not developed.

Under a GTL conversion sales option, the decrease in TAPS tariffs, resulting from the increased liquids transport through TAPS, may make it feasible to economically operate ANS oil fields longer than would be the case for the LNG option. However, the oil production forecasts used in this evaluation are the same for both gas sales options, except that the ultimate PTU condensate recovery is less for the LNG option than for the GTL option. This is because the economics of PTU condensate recovery under the LNG option do not benefit from the lower TAPS tariff resulting from the liquids produced in the GTL option. Hence, 
PTU condensate recovery under the LNG option reaches its economic limit earlier.

5.1.1.3 Technology for Gas Conversion. This analysis assumes that the LNG option will employ established physical conversion technology and will be supported by a gas conditioning plant, pipeline, and LNG tanker fleet similar to the TAGS project proposed by YPC (Alaska Conservation Foundation, 1994). The \$14 million, 14 million metric tonnes per annum (MMTPA) LNG project, as planned by YPC, includes an over-sized gas pipeline capable of delivering enough gas to support a 25 MMTPA project with added compressor stations, LNG plant capacity, and tankers. The 14 MMTPA project as proposed by YPC could be supplied by gas only from PBU at a rate of 2.05 BCFPD. To accommodate PTU production of $0.44 \mathrm{BCFPD}$ assumed in this analysis, the LNG conditioning and liquefaction plant, and tanker fleet are increased to accommodate $2.49 \mathrm{BCFPD}$ for a sales capacity of 17 MMTPA. LNG technology is described briefly in Section 3.3.4.

The GTL conversion technology assumed for this study is state-of-the-art Fischer-Tropsch (FT) chemical conversion, as discussed in Section 3.3.2. After conditioning of the gas purchased from the PBU and PTU, the gas is converted to synthesis gas $\left(\mathrm{CO}\right.$ and $\left.\mathrm{H}_{2}\right)$ and subsequently to a distillate-type, liquid hydrocarbon product, suitable for shipment with North Slope crude oil through TAPS and in crude oil tankers to refineries. The GTL plant capacity in this analysis is assumed to be sized for 2.49 BCFPD of clean, dry, $1150 \mathrm{BTU} / \mathrm{SCF}$ gas, identical with the LNG project, for comparison purposes.

\subsubsection{Variable Economic Parameters and Base Assumptions}

The remaining variables and the base case assumptions for their value are discussed below.

5.1.2.1 Crude Oil Price Forecast. The record of the last 20 years shows clearly the uncertainty of future oil price forecasts. However, the feasibility of not only gas sales options, but continued ANS oil operations, ultimately depends upon world oil prices remaining high enough to cover costs associated with development and operation of the projects. For the base case analysis, it is assumed that world oil prices would follow DOE's Energy Information Administration reference oil price forecast (AEO95), as discussed in Section 4.1 (EIA, 1995). These forecasts anticipate an average annual real oil price increase of approximately $2.4 \%$ per year over inflation through 2015 and beyond. In recent years, oil prices have fluctuated primarily in the $\$ 16$ to $\$ 20 / \mathrm{BBL}$ range as supplies have continued to be ample. Thus, for comparison purposes, the impact of prices remaining stagnant within this range was evaluated by also using 
an \$18/BBL (1995\$) flat oil price. These forecasts and the EIA high and low forecast were discussed in Section 4.1 and shown in Figure 4.2.

The oil price level is critical because wellhead oil price as well as GTL liquid and LNG sales values are a function of world oil prices. There are six components to wellhead oil price evaluation:

$$
\begin{aligned}
\text { Wellhead Oil Price } & =(\text { World Oil Price })-(\text { Marine Tariff })-(\text { TAPS Tariff }) \\
& -(\text { Alaskan Crude Oil Adjustment })-(\text { Field Tariff })-(\text { Quality Adjustment }) .
\end{aligned}
$$

The individual components in the wellhead oil price are defined in the following sections.

5.1.2.1.1 Marine Tariffs--Three years of history and the future estimated costs of shipping liquids from Valdez to West Coast and Gulf of Mexico delivery points are given in Figure 5.2. Factors considered in the estimate of marine tariffs include the assumption that there will be no shipments of ANS crude oil to Gulf of Mexico ports after 1998 because of the declining ANS crude oil production, the passage of the Alaska Export Bill in November 1995 allowing export of Alaskan crude (HOH, 1995), and the shorter haul from Alaska to the northern Pacific Rim. The increase in rates after 1999 results from the increased costs for replacement or retrofitting of existing single-hull ships with double-hull tankers (see Appendix B.1).

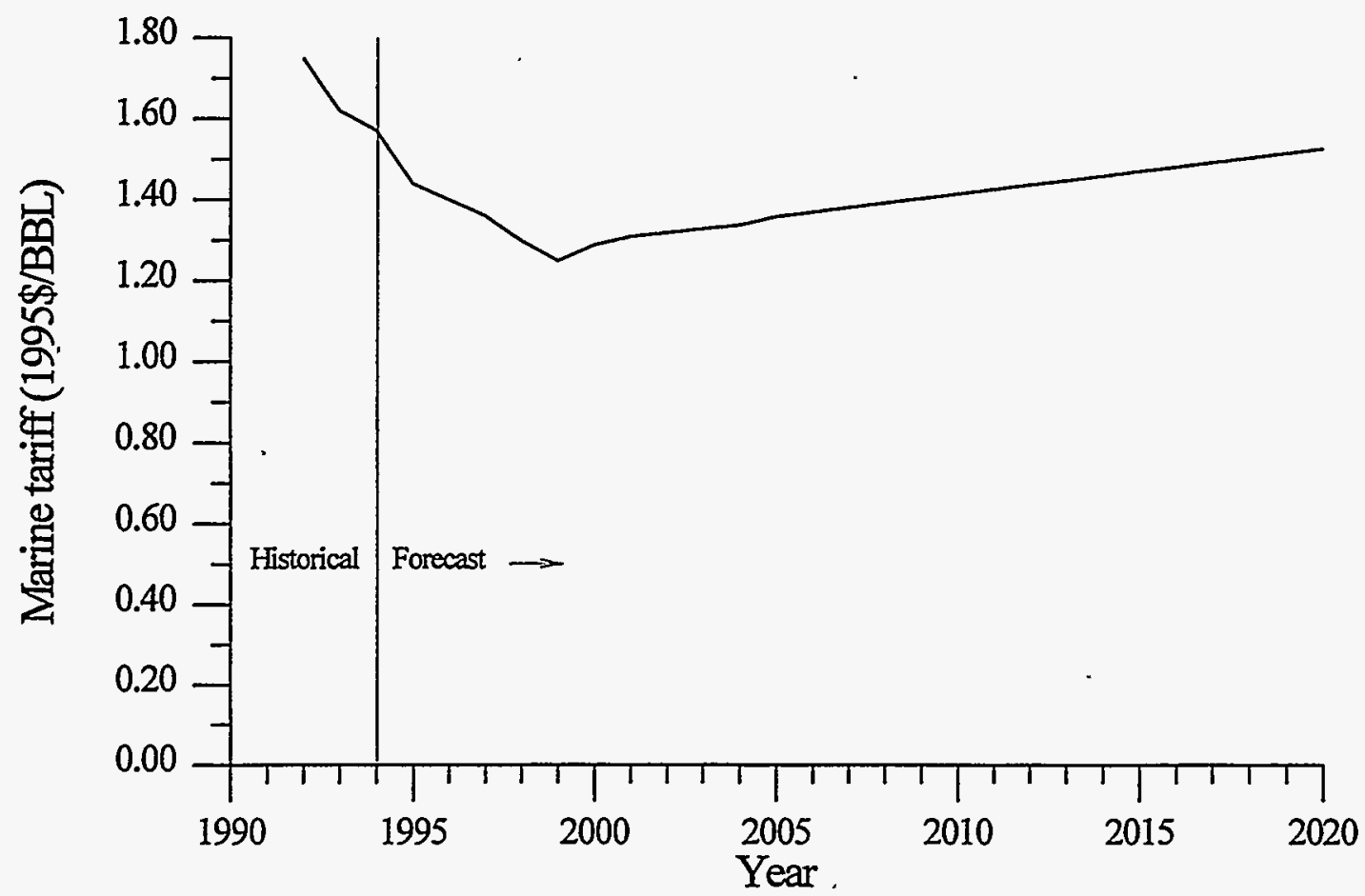

Figure 5.2. Average marine transportation costs to deliver crude oil from Valdez, AK to Lower 48. 
5.1.2.1.2 TAPS Tariffs--Separate TAPS tariff schedules were estimated for each of the three ANS gas production scenarios: no major gas sales, gas sales to a LNG project, and gas sales to a GTL project. Three years of history and the future TAPS tariff schedules for the three scenarios are given in Figure 5.3. TAPS tariffs per barrel of transported liquid remain fairly steady under the GTL conversion option over the project life. In contrast, there is a sharp increase under the LNG and no major gas sales options. The reason for this difference is that the liquid volume generated by the GTL option absorbs an increasing amount of TAPS operating costs as the ANS crude oil production declines. Additional details of the TAPS tariff outlook are described in Appendix B.1.1.

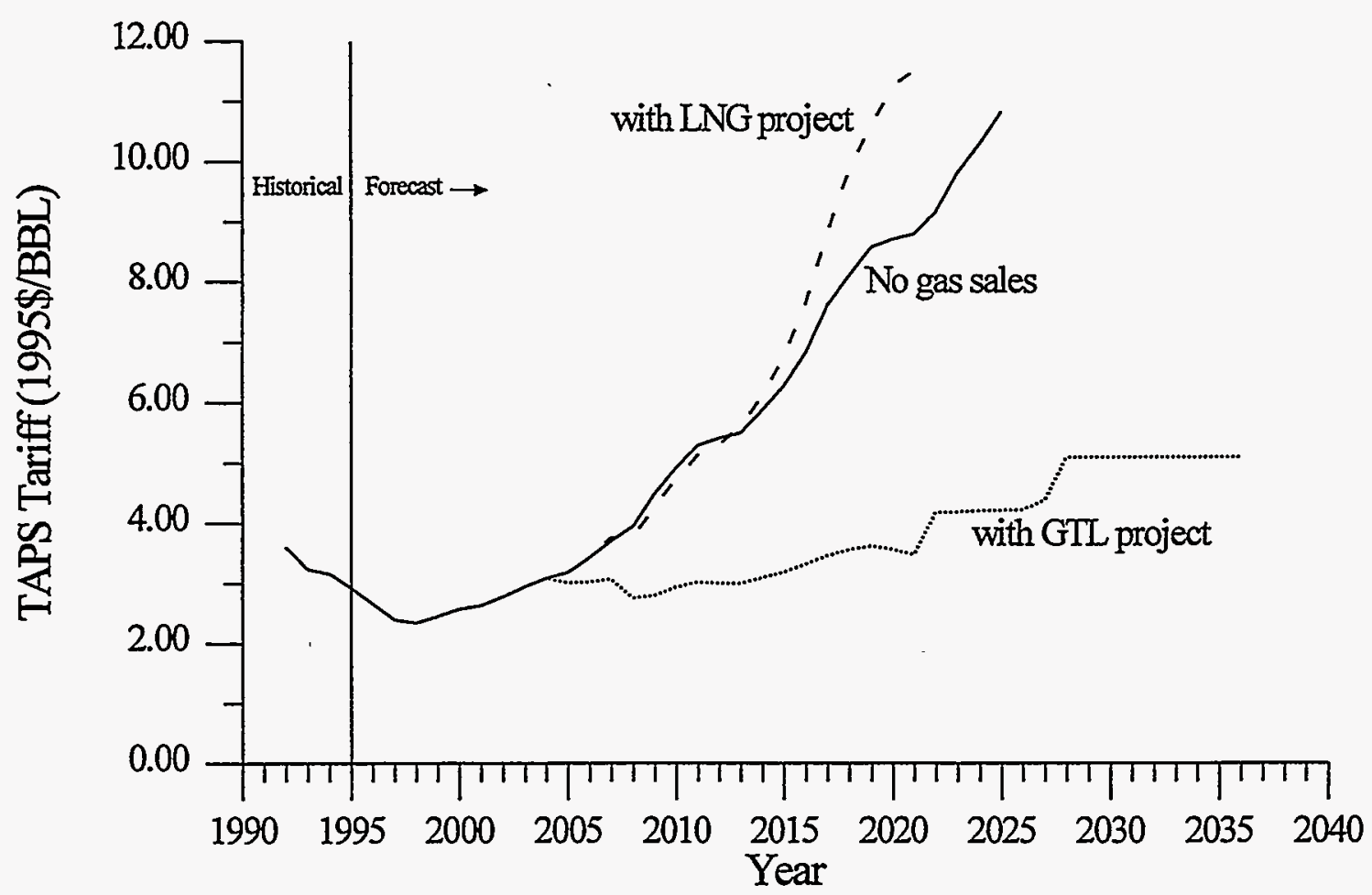

Figure 5.3. TAPS tariffs for three North Slope production scenarios.

5.1.2.1.3 Alaskan Crude Oil Adjustment--A deduction of $1.00 \$ / B B L$ is applied to the oil price forecasts shown in Figure 4.2, in determining ANS oil prices to account for gravity differences between ANS oil and "world" crude used to develop the price forecasts.

5.1.2.1.4 Field Pipeline Tariffs--A field pipeline tariff is charged against the oil and gas price of liquids delivered from any project through a common carrier pipeline to PS No. 1 or to the LNG or GTL project. This is applied in the PTU evaluations, but does not apply to PBU. Field tariffs are discussed 
in more detail in Appendix B.1.1.1.4.

5.1.2.1.5 TAPS Quality Adjustment--Effective December 1, 1993, the TAPS Quality Adjustment methodology was changed from a gravity-differential basis to a market-value basis. A market value differential is applied to each stream entering TAPS, such that delivered volumes with higher market values receive higher selling prices than those with lower market values (see Appendix B.1.1.1.5).

5.1.2.2 Gas Quality. The quality of the gas sold to both the LNG or the GTL project is assumed to have a heating value of $1150 \mathrm{BTU} / \mathrm{SCF}$ on a dry basis (State of Alaska, 1996). This BTU content exceeds typical U.S. pipeline specifications but provides an opportunity to sell ethane and propane that may not be possible to transport in TAPS because of vapor pressure limits. The principal raw gas impurity, $\mathrm{CO}_{2},(12 \%$ in PBU gas and 4\% in PTU gas) will be removed in the gas conditioning plants of the respective gas sales options. The quality of the LNG product is assumed to be equal to the input gas, $1150 \mathrm{BTU} / \mathrm{SCF}$, on regassification. Table 5.1 shows a typical composition of $\mathrm{PBU}$ gas on a dry basis before removal of $\mathrm{CO}_{2}$.

Table 5.1. Example composition for PBU CGF residue gas. ${ }^{a}$

\begin{tabular}{|c|c|}
\hline Component & Residue Gas Composition (vol\%) \\
\hline Methane & 76.2 \\
\hline Ethane & 6.4 \\
\hline Propane & 3.2 \\
\hline I-Butane & 0.3 \\
\hline n-Butane & 0.8 \\
\hline $\mathrm{C}_{5}^{+}$ & 0.1 \\
\hline $\mathrm{CO}_{2}$ & 12.6 \\
\hline $\mathrm{N}_{2}$ & 0.4 \\
\hline Total & 100.0 \\
\hline
\end{tabular}

5.1.2.3 Gas Product Price Estimates. Currently, the minor gas sales occurring on the North Slope are not considered representative of prices during major gas sales. The methodology used to estimate gas prices for the two major gas sales scenarios, sales to a gas pipeline/LNG plant and to a GTL plant, is described below.

a. Personal communication, Arco Alaska, Inc., May 1996. 
5.1.2.3.1 LNG Price--For this evaluation, it is assumed that the LNG produced will be sold to Japan and other Pacific Rim countries. Thus, the North Slope gas price for the LNG scenario is determined as follows:

$$
\text { North Slope gas price }=(L N G \text { price in Asia }) \times(\text { gas product net back }) .
$$

The LNG sale price in Asia is calculated as follows:

$$
\begin{aligned}
& L N G \text { price in Asia }=\frac{\text { World Oil Price } \times(1+\text { Asian } L N G \text { bonus })}{B T U \text { conversion for } L N G} ; \\
& \text { where: } B T U \text { conversion for } L N G=\frac{5.9 \frac{M M B T U}{B B L}}{1.15 \frac{M M B T U}{M C F}}=5.13 \frac{M C F}{B B L}, \\
& \text { Asian LNG bonus }=0.1(10 \%) .
\end{aligned}
$$

For example, the LNG sales value for the AEO95 reference oil price for 1995 of $\$ 17.04 / \mathrm{BBL}$ would be about $\$ 3.65 / \mathrm{MCF}$ (\$3.17/MMBTU).

5.1.2.3.2 GTL Price--The liquids produced from the GTL conversion plants are assumed to be high quality hydrocarbons with environmentally superior characteristics. For the base case analysis, the hydrocarbon liquid produced from the GTL plant receives a $\$ 5.00 / B B L$ premium price (see the discussion in Section 4.1 and Appendix B.1.2). The GTL conversion plant liquid product price at the plant gate on the North Slope is calculated as follows:

GTL Hydrocarbon Price $=($ World Oil Price $) \div($ Liquids Premium $)-($ Marine Tariff $)-($ TAPS Tariff $)$.

The gas prices for a GTL scenario are calculated as follows:

$$
\begin{aligned}
& \text { North Slope gas price }=\frac{\text { World Oil Price }+ \text { liquids premium }}{B T U \text { conversion for GTL }} \times \text { gas product net back; } \\
& \text { where: } B T U \text { conversion for GTL }=\frac{5.75 \frac{M M B T U}{B B L}}{1.15 \frac{M M B T U}{M C F}}=5.00 \frac{M C F}{B B L}
\end{aligned}
$$

For example, the GTL liquid product price at the GTL plant gate using the AEO95 reference oil price for 
1995 of $\$ 17.04 / \mathrm{BBL}$, $\$ 5.00 / \mathrm{BBL}$ premium, marine tariff of $\$ 1.44 / \mathrm{BBL}$, and TAPS tariff of $\$ 2.93 / \mathrm{BBL}$ would be about $\$ 17.67 / \mathrm{BBL}$ or a GTL plant gate, gas equivalent price of $\$ 3.53 / \mathrm{MCF}$.

5.1.2.3.3 Wellhead Gas Price--The wellhead gas price is equal to the North Slope gas price less any field pipeline tariffs.

5.1.2.4 Operating Costs. Operating costs may include, but are not limited to, the operating and maintenance costs of (a) facilities, (b) wells (including workovers), (c) material purchases, (d) shared facilities charges, and $(e)$ overhead costs.

5.1.2.4.1 Gas Producing Unit Operating Costs--Operating cost estimates are based on publicly available data, engineering judgement, and experience for the existing oil operations. In general, as oil production declines, more of the costs are attributed to the cost of producing the gas and less to the oil. The procedure used is described in Appendix A.2.2.1.5.

5.1.2.4.2 LNG Project Operating Costs--An empirical method (Appendix B.1.5.5), using $5 \%$ of cumulative inflated investments, is used to estimate O\&M costs. Total operating cost is the sum of O\&M costs and the gas purchase cost.

5.1.2.4.3 GTL Plant Operating Costs-Total operating cost is the sum of the gas purchase cost and an estimated $\$ 6.00$ per barrel of liquid output O\&M cost (see Appendix B.1.5.3).

5.1.2.5 Gas Conversion Efficiency. Conversion efficiency is determined on a thermal equivalency basis and is based on information available for each gas option. For LNG, this includes any gas losses and use as fuel in the gas conditioning plant, gas pipeline, LNG conversion plant, and LNG tarikers. For GTL, conversion efficiency refers to the BTU's in the product divided by the BTU's in the gas purchased from the producing units.

5.1.2.5.1 LNG Efficiency-The TAGS project assumes a daily input to the gas pipeline of 2.05 BCFPD to deliver the 14 MMTPA (the equivalent of $1.87 \mathrm{BCFPD}$ ) to the Pacific Rim, resulting in an overall thermal efficiency for the LNG project of $91 \%$ (Alaska Conservation Foundation, 1994). The base case LNG scenario in this analysis involves the purchase of 2.49 BCFPD from both PBU and PTU. With a $91 \%$ efficiency, this results in LNG sales of 17 MMTPA (2.27 BCFPD), a $21 \%$ increase in required 
capacity for LNG facilities over the 14 MMTPA project.

5.1.2.5.2 GTL Efficiency--An overall plant thermal efficiency of $60 \%$ is used in the GTL evaluations (see Section 3.3.2). This is 3 percentage points lower than the $63 \%$ design efficiency reported for Shell's Malaysia plant (Eilers, 1990). The 60\% efficiency assumption may be conservative but is used because actual data from Shell's plant is not publicly available.

5.1.2.6 Investment Requirements. Investments for all the projects are based on the available public information for each project.

5.1.2.6.1 Producing Unit Investments--Total future investments for oil and gas extraction projects are based on the history of active projects and public information. Detailed investment information is found in Appendix $\mathbf{A}$ for all oil and gas projects used in this study. For PBU, all investments are related to the recovery of oil and total $\$ 1,790$ million (1995\$), as discussed in Appendix A.2.1.2.3. Because so many facilities are already in place for the recycling of the produced gas at PBU, it is assumed that no additional investments will be required for major gas sales. The gas conditioning plant investment is included in the gas sales projects. Investments for development of PTU, discussed in Áppendix A.3.1.3.7, are estimated to be about $\$ 900$ million $(1995 \$)$.

5.1.2.6.2 LNG Investments--Public information available for this study placed the total project cost for the 14 MMTPA LNG operation proposed by YPC at $\$ 14$ billion in $1995 \$$ (Alaska Conservation Foundation, 1994). The LNG project option analyzed in this study has a capacity of 17 MMTPA to handle both PBU and PTU gas, as discussed in Section 5.1.1.4. Based on the additional equipment needed to reach this capacity from the 14 MMTPA TAGS project dimensions, the YPC capital costs are increased from $\$ 14$ to $\$ 16$ billion, about $14 \%$. Details of the LNG project investments is contained in Appendix B.1.7.3.

5.1.2.6.3 GTL Investments--Based on a recent study by Hackworth, et al. (DOE, 1995), the investment required for a 300 MBPD GTL conversion plant (or multiple smaller plants) located on the North Slope is estimated to be between $\$ 27,700$ and $\$ 39,900$ per daily barrel (DBL) of output. For an unproven plant installation investment on the North Slope, the upper end of this investment range, $\$ 40,000 / \mathrm{DBL}$ (1995\$), is assumed for the evaluation. The total investment of $\$ 12$ billion (1995\$) is scheduled over a 6-year period. A detailed discussion is contained in Appendix B.1.7.2. 
5.1.2.7 State and Federal Taxes. State and federal tax calculations and the methodology used in the economic model are discussed in Appendix C.1.1. State taxes include: (a) severance tax (based on well and field rates), (b) conservation tax $(\$ 0.004 / \mathrm{BBL}$ conservation tax rate and $\$ 0.05 / \mathrm{BBL}$ conservation surtax rate), (c) property or ad valorem tax (2\% of property tax base), (d) State income tax at an effective rate of $3 \%$, and (e) royalty, where royalty rates are set on a lease-by-lease basis. The average project royalty ranges from $12.5 \%$ to about $20.0 \%$ depending on the individual lease royalty rates within the project area (see Appendix B.1.10). Federal income taxes are assessed at 34\% as described in Appendix C.1.1.7.

5.1.2.8 Summary. The preceding paragraphs have summarized the base values of the variables needed to compare the feasibility of the three gas sales options for ANS gas: (a) no major gas sales (gas reinjected for pressure maintenance, enhanced oil recovery, etc.), (b) LNG conversion and sale, and (c) GTL conversion and sales. The next section presents the results of the economic assessment of these options using the variable assumptions described above.

\subsection{Baseline Economic Assessment}

The economic results, using the baseline assumptions, for the LNG and GTL projects and PBU and PTU with major gas sales are described in this section. All values are given in $1995 \$$ unless specifically stated otherwise. The North Slope gas price is adjusted for each scenario so that each gas sales option (LNG or GTL) earns a $10 \%$ rate of return $\left(\mathrm{NPV}_{10}=0\right)$. This provides the maximum possible income to $\mathrm{PBU}$ and PTU for the gas sold to the gas sales projects. The relative economic value of each gas sales option from the point of view of the producing units is determined by comparing the NPV ${ }_{10}$ of the producing units (PBU and PTU) under each option.

\subsubsection{LNG Project Economics}

A stand-alone LNG project consisting of a gas conditioning plant, a gas pipeline, a LNG conversion plant and associated facilities, and a LNG tanker fleet capable of handling gas from both PBU and PTU is evaluated. Baseline results from this gas sales option are summarized in Table 5.2. The estimated gas reserves and the LNG project facilities capacity are assumed to be sufficient for 32 years of LNG operations, as described in Section 5.1.1. Project investment is $\$ 16$ billion, total operating costs (gas purchase costs and O\&M costs) are about $\$ 65$ billion, and after-tax cash flow is over $\$ 31$ billion. The discounted cash flow for a $10 \%$ discount rate $\left(N P V_{10}\right)$ for the LNG project is zero because the evaluation of stand-alone gas projects sets the North Slope gas purchase price such that the projects earn a $10 \%$ rate of return. The gas product net 
back for the LNG project calculated in this manner is $28.1 \%$. Substantive LNG project investment begins in 2000 and is completed in 2008; major gas sales start in 2005 and end in 2036 for a 32-yr life (see Appendix B.1.7 - B.1.9). The impact of this scenario on the cash flow of PBU and PTU is discussed in Section 5.3.3.

Table 5.2. LNG project costs and net revenues (1995\$).

\begin{tabular}{||l|c|}
\hline Economic Factor & AEO95 Reference Oil Price \\
\hline \hline Project Life (2005 - 2036) & 32 yrs \\
\hline Investment (\$, millions) & 16,000 \\
\hline Total Operating Costs ${ }^{\text {(\$, millions) }}$ & 64,800 \\
\hline Rate of Return & $10.0 \%$ \\
\hline Gas Product Net Back & $28.1 \%$ \\
\hline After-Tax Cash Flow (\$, millions) & 31,500 \\
\hline a. Operating costs include O\&M costs and cost of gas purchased from the producers. \\
\hline
\end{tabular}

\subsubsection{GTL Project Economics}

A GTL plant capable of handling gas from both PBU and PTU is evaluated. Baseline results for the stand-alone GTL conversion plant, which includes facilities for any required gas conditioning as well as the conversion plant, as described in Section 3.3.2, are summarized in Table 5.3. The plant is enlarged at the PBU plant site to handle gas from PTU as it comes on line in 2008. Substantive investment begins in 2003 and is completed in 2007; the project life is the same as in the LNG case, 2005 to 2036 for a 32-yr life. The investment schedule is discussed in Appendix B.1.7.

Table 5.3. GTL project costs and net revenues (1995\$).

\begin{tabular}{||l|c|}
\hline Economic Factor & AEO95 Reference Oil Price \\
\hline \hline Project Life (2005 - 2036) & 32 yrs \\
\hline Investment (\$, millions) & 12,000 \\
\hline Total Operating Costs ${ }^{\mathrm{a}}$ (\$, millions) & 46,100 \\
\hline Rate of Return & $10.0 \%$ \\
\hline Gas Product Net Back & $15.1 \%$ \\
\hline After-Tax Cash Flow (\$, millions) & 20,900 \\
\hline a. Operating costs include O\&M costs and cost of gas purchased from the producers. \\
\hline
\end{tabular}


Like the LNG evaluation, the GTL plant also earns a $10 \%$ rate of return and the resulting gas product net back is $15.1 \%$. Total GTL investment is approximately $\$ 12$ billion, total operating costs are over $\$ 46$ billion over the project life with a resulting total cash flow of over $\$ 20$ billion in $1995 \$$.

\subsubsection{Economics for Prudhoe Bay Unit with Major Gas Sales}

Both the LNG and the GTL options -- under the baseline assumptions -- have significantly better after-tax cash flows than the no major gas sales option. For PBU, the only costs are operating costs to continue production of oil and gas. It is assumed that no additional investments are required at PBU to produce the gas for the gas sales options because of the gas handling facilities already in place (Section 5.1.2.6.1). Table 5.4 summarizes the baseline PBU economic results.

Table 5.4. Prudhoe Bay Unit economics - summary (1995\$).

\begin{tabular}{|c|c|c|c|}
\hline \multirow[b]{2}{*}{ Economic Factor } & \multicolumn{3}{|c|}{ PBU Cases (AEO95 Reference Oil Price) } \\
\hline & $\begin{array}{l}\text { No Major } \\
\text { Gas Sales }\end{array}$ & LNG Sales & GTL Sales \\
\hline $\begin{array}{l}\text { Remaining Oil Project Life }(1995 \text { - } 2025 \text { or } 2021) \\
\text { Gas Project Life }(2005 \text { - 2036) }\end{array}$ & $\begin{array}{r}31 \\
0\end{array}$ & $\begin{array}{l}27 \\
32\end{array}$ & $\begin{array}{l}27 \\
32\end{array}$ \\
\hline $\begin{array}{l}\text { Remaining Oil Reserves - billion BBL } \\
\text { Gas Reserves } \quad-\text { TCF (Sales) }\end{array}$ & $\begin{array}{l}4.2 \\
0\end{array}$ & $\begin{array}{r}3.8 \\
21.8\end{array}$ & $\begin{array}{r}3.8 \\
21.8\end{array}$ \\
\hline $\begin{array}{l}\text { Investments for oil production ( } \$ \text {, millions) } \\
\text { Investments for gas production ( } \$ \text {, millions) }\end{array}$ & $\begin{array}{r}1,790 \\
0\end{array}$ & $\begin{array}{r}1,790 \\
0\end{array}$ & $\begin{array}{r}1,790 \\
0\end{array}$ \\
\hline Gas Product Net Back (\%) & - & 28.1 & 15.1 \\
\hline $\begin{array}{l}\text { Revenue From Oil Sales ( } \$ \text {, millions) } \\
\text { Maximum Revenue From Gas Sales (\$, millions) } \\
\text { Total Oil and Gas Sales Revenue (\$, millions) }\end{array}$ & $\begin{array}{r}56,100 \\
\frac{0}{56,100}\end{array}$ & $\begin{array}{l}48,800 \\
31.500 \\
80,300\end{array}$ & $\begin{array}{l}51,300 \\
\frac{21,700}{73,000}\end{array}$ \\
\hline After-Tax Cash Flow (\$, millions) & 17,600 & 31,500 & 27,400 \\
\hline Discounted Cash Flow - $\mathrm{NPV}_{10}(\$$, millions $)$ & 8,600 & 11,100 & 10,400 \\
\hline Incremental $N P V_{10}(\$$, millions $)$ & 0 & 2,500 & 1,800 \\
\hline
\end{tabular}

On a net present value basis, both gas sales options show positive economics for PBU relative to the no major gas sales option. The oil revenue is higher for the no major gas sales option because it is assumed that withdrawal of gas for major gas sales starting in 2005 will reduce the ultimate oil recovery by $400 \mathrm{MMBO}$. Of the two gas sales options, oil revenues with the GTL option exceed those attainable in the 
LNG case by $\$ 2,500$ million because of the benefits of GTL liquids in reducing TAPS tariffs on all liquid products shipped through the line. Conversely, because the LNG project can support a higher ANS gas price than the GTL project, the gas revenue is $\$ 9,800$ million greater for the LNG option than for the GTL option. This difference is also shown by the gas market net back being $28.1 \%$ for the LNG option and $15.1 \%$ for the GTL option. Part of this gas revenue difference between the two options is offset by the oil revenue effects of the lower TAPS tariffs as shown by the increased revenue from oil sales for the GTL option, $\$ 51.3$ billion, compared to the $\$ 48.8$ billion for the LNG option. The LNG - GTL project difference narrows even more when examined in terms of discounted cash flow, the more critical measure of project value. The PBU $\mathrm{NPV}_{10}$ for the LNG scenario is $\$ 11.1$ billion. The GTL scenario, with PBU producing and selling oil and gas on the same schedule as the LNG project, has a NPV 10 of $\$ 10.4$ billion, a difference of $\$ 700$ million, or about $6 \%$.

Wellhead oil and gas prices for PBU are shown in Figure 5.4. The impact of the TAPS tariff reduction resulting from the increased liquid transport through TAPS from GTL liquids is dramatic as illustrated in the wellhead oil price portion of Figure $\mathbf{5 . 4}$.

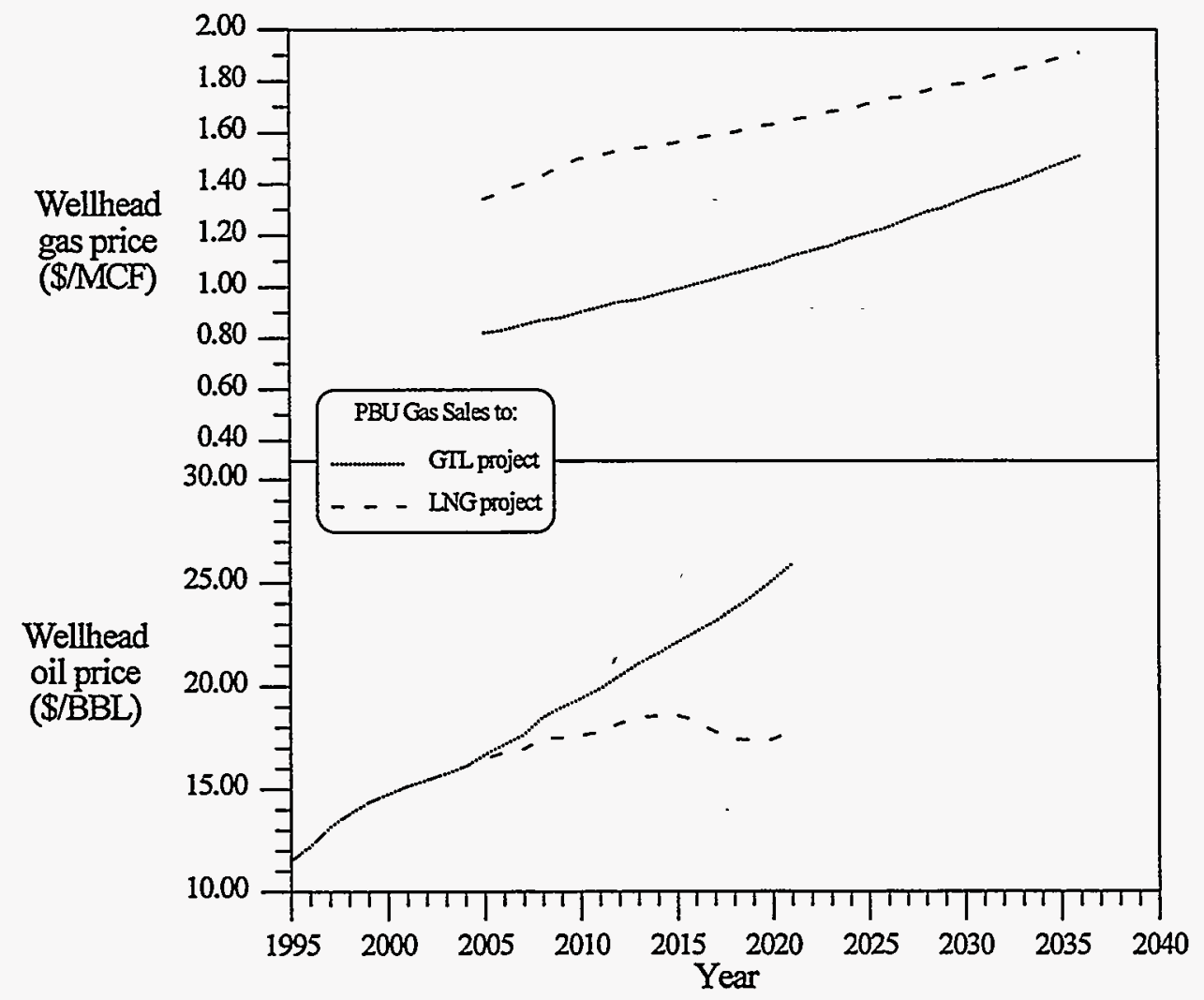

Figure 5.4. Wellhead gas and oil prices for the Prudhoe Bay Unit under LNG and GTL scenarios for the AEO95 reference oil price forecast (1995\$). 
5.2.4 Economics for Point Thomson Unit with Major Gas Sales. PTU lies 50 miles to the east of PBU and is presently undeveloped. Full field development costs must be incurred, including basic infrastructure and pipelines to the Prudhoe Bay Area, before liquids and gas sales can be realized. The same gas sales alternatives are evaluated for Point Thomson as for Prudhoe Bay: (a) sales to an LNG project, and (b) sales to a GTL plant located at Prudhoe Bay. The GTL plant module for PTU gas conversion is located in the Prudhoe Bay area because our analysis indicates that there is little economic advantage at either site, for the scenarios as set out in this study.

Results in Table 5.5 compare the two gas sales scenarios for PTU. Gas sales from PTU lag 3 years behind PBU to account for the assumed field development schedule. The economic value $\left(N_{P V}\right)$ of the TU development for gas sales to either gas sales option is almost the same, $\$ 350$ million for LNG and $\$ 330$ million for GTL in $1995 \$$.

Table 5.5. Point Thomson Unit economics - summary (1995\$).

\begin{tabular}{||l|c|c||}
\hline \multirow{2}{*}{ Economic Factor } & \multicolumn{2}{|c|}{$\begin{array}{c}\text { PTU Cases using AEO95 Reference Oil } \\
\text { Price }\end{array}$} \\
\cline { 2 - 3 } & LNG Sales & GTL Sales \\
\hline Remaining Oil Project Life (yrs) & 14 & 20 \\
Gas Project Life w/sales beginning in 2008 (yrs) & 20 & 20 \\
\hline Reserves - million BBL & 181 & 207 \\
\hline Investments at PTU (\$, millions) & 3.18 & 3.18 \\
\hline Gas Product Net Back (\%) & 900 & 900 \\
\hline Revenue from Condensate \& Oil Sales (\$, Millions) & 2,300 & 15.1 \\
Maximum Revenue from Gas Sales (\$, Millions) & 3,900 & 3,400 \\
Total Revenue (\$, millions) & 6,200 & 6,900 \\
\hline After Tax Cash Flow (\$, millions) & 2,300 & 2,300 \\
\hline Discounted Cash Flow - NPV 10 (\$, millions) & 350 & 330 \\
\hline
\end{tabular}

In the LNG sales scenario, PTU condensate is produced through 2021 and gas through 2027, while in the GTL sales scenario, PTU produces condensate 6 years longer, throughout the life of the GTL project (see Appendix A.3.1.3.5). This difference in condensate production life is a result of the shutdown of PBU oil production in 2021, which would cause a drastic increase in TAPS tariffs and the inevitable shutdown 
of TAPS. Without GTL production to adsorb a portion of TAPS operating costs after the end of PBU oil production in 2021, TAPS tariffs would become prohibitively high even if the pipeline could continue to be operated at such low throughput rates. Thus, condensate production would halt in 2021 under the LNG option but continue to completion under the GTL option. As a result, PTU produces 26 million barrels more condensate with gas sales to a GTL plant than under the gas pipeline/LNG scenario.

\subsubsection{State and Federal Government Revenue.}

The State of Alaska and the federal government both receive substantial revenues from each of the three producing scenarios under the base case (AEO95 Reference Oil Price). Tables 5.6 and 5.7 illustrate the potential future revenues collected by the State and federal governments under the three producing scenarios. The State receives income from royalty, severance taxes, property taxes, conservation taxes, and state income taxes where the federal government collects only income taxes (see Section 5.1.9). As shown in Table 5.6, Alaska revenue is about the same for both gas sales options. As shown in Table 5.7, federal income taxes are higher for the LNG option than for the GTL option. This results because the LNG project has an undiscounted after-tax cash flow of $\$ 31.5$ billion (1995\$) compared to the $\$ 20.9$ billion (1995\$) for the GTL project (Tables 5.2 and 5.3), even though both the LNG and the GTL project provide the same 10\% rate of return on investment in this evaluation. However, federal income taxes from the TAPS pipeline and the tanker operations are not included in the GTL option, which would tend to reduce the difference.

Table 5.6. State of Alaska revenues under three producing scenarios - summary (1995\$).

\begin{tabular}{||l|c|c|c|c|c||}
\hline \multirow{2}{*}{ Scenario } & \multicolumn{5}{c||}{ Revenues (\$, billions) } \\
\cline { 2 - 6 } & PBU & PTU & LNG project & GTL plant & Totals \\
\hline No Major Gas Sales & 20.6 & 0 & 0 & 0 & 20.6 \\
\hline Sales to LNG & 26.4 & 1.9 & 3.5 & 0 & 31.8 \\
\hline Sales to GTL & 24.2 & 1.9 & 0 & 4.8 & 30.9 \\
\hline
\end{tabular}

Table 5.7. Federal government revenues under three producing scenarios - summary (1995\$).

\begin{tabular}{||l|c|c|c|c|c||}
\hline \multirow{2}{*}{ Scenario } & \multicolumn{5}{c|}{ Revenues (\$, billions) } \\
\cline { 2 - 6 } & PBU & PTU & LNG project & GTL Plant & Totals \\
\hline No Major Gas Sales & 7.8 & 0 & 0 & 0 & 7.8 \\
\hline Sales to LNG & 14.9 & 1.2 & 17.8 & 0 & 33.9 \\
\hline Sales to GTL & 12.8 & 1.2 & 0 & 11.6 & 25.6 \\
\hline
\end{tabular}




\subsubsection{Baseline Economic Summary}

The aggregate of the economics of PBU and PTU gas sales show a likely NPV $_{10}$ to the gas producers of $\$ 11.5$ billion for the gas pipeline/LNG scenario, $\$ 10.7$ billion for the GTL conversion scenario, and $\$ 8.6$ billion if major gas sales are not undertaken (1995\$). Estimated baseline government revenues under the gas sales options for the State increase from the no major gas sales case by $54 \%$ with LNG sales and $50 \%$ with GTL sales and for the federal treasury by $435 \%$ and $330 \%$, respectively. These economic measures reflect the baseline assumptions discussed earlier in Section 5.2. However, before conclusions can be reached, the sensitivity of such economic results to shifts in economic parameter values must be considered.

\subsection{Sensitivity Analysis}

Analysis of the sensitivity of project economics to the variables used in the calculations is intended to determine which economic input factors are most important to the economic outcome of a given project. By knowing which variables cause the greatest change in project economics, efforts can be focussed to decrease critical costs, refine critical technology, or evaluate tax incentives, whichever the case may be. Plots showing which variables are most critical to the economics of the four stand-alone projects (PBU and PTU producing units, and LNG and GTL conversion projects) are used to delineate the importance of the respective variables. The calculated data used in constructing the plots are shown in Appendix D.

Each plot shows the effect of varying certain input values on project net present value $\left(\mathrm{NPV}_{10}\right)$. In the analyses, one variable at a time is changed. Variables analyzed include: (a) gas product net back fraction, (b) royalty rates, (c) State and federal income taxes, (d) GTL liquids premium, (e) field pipeline tariffs, (f) GTL plant efficiency, (f) investments, (g) operating costs, (h) gas usage for the LNG project, (I) the BTU content of the gas sold from the Units, and (j) the Asian LNG bonus. The oil price projection, AEO95 reference oil price, is kept constant in this analysis. A separate evaluation of the effects of a constant $\$ 18 / \mathrm{BBL}$ oil price is presented in Section 5.4.

Note that in the economic sensitivity analyses, operating and maintenance costs (op cost factor) are limited to the expenses of operating and maintaining project facilities, and do not include the cost of gas purchased. The cost of the gas feedstock is calculated directly from the gas product net back variable. Where applicable, State and federal taxes include severance, ad valorem, conservation, and income taxes. Although most of the input variables are changed by $\pm 30 \%$, some variables could easily range beyond $30 \%$ 
and others may have a smaller range. The $30 \%$ range displayed on the plots is not meant to imply any limit or possible range of variance.

\subsubsection{PBU and PTU Economic Sensitivity with Gas Sales to LNG Project}

The sensitivity of the economics of selling gas from PBU to a gas sales project (either a LNG project or a GTL project) can be readily seen through changes in the Unit's incremental revenues above those revenues generated if no gas had been sold. The incremental NPV $_{10}$ of PBU with gas sales to a LNG project is $\$ 2,500$ million for the base case discussed above. Figure 5.5 shows plots of the incremental $N_{P V} V_{10}$ values for PBU relative to the no major gas sales case as each of the six variables change. These data show that the amount of State and federal taxes is the most critical variable for PBU under this scenario. For example (see Figure 5.5), a $15 \%$ reduction in State and federal taxes increases the incremental project $N_{P V}$ by $\$ 1,500$ million to $\$ 4,000$ million. The other variables are less critical to overall project economics. (Note that the gas product net back variable, the gas BTU content variable, and the LNG bonus variable overlap in this figure and in Figure 5.6.

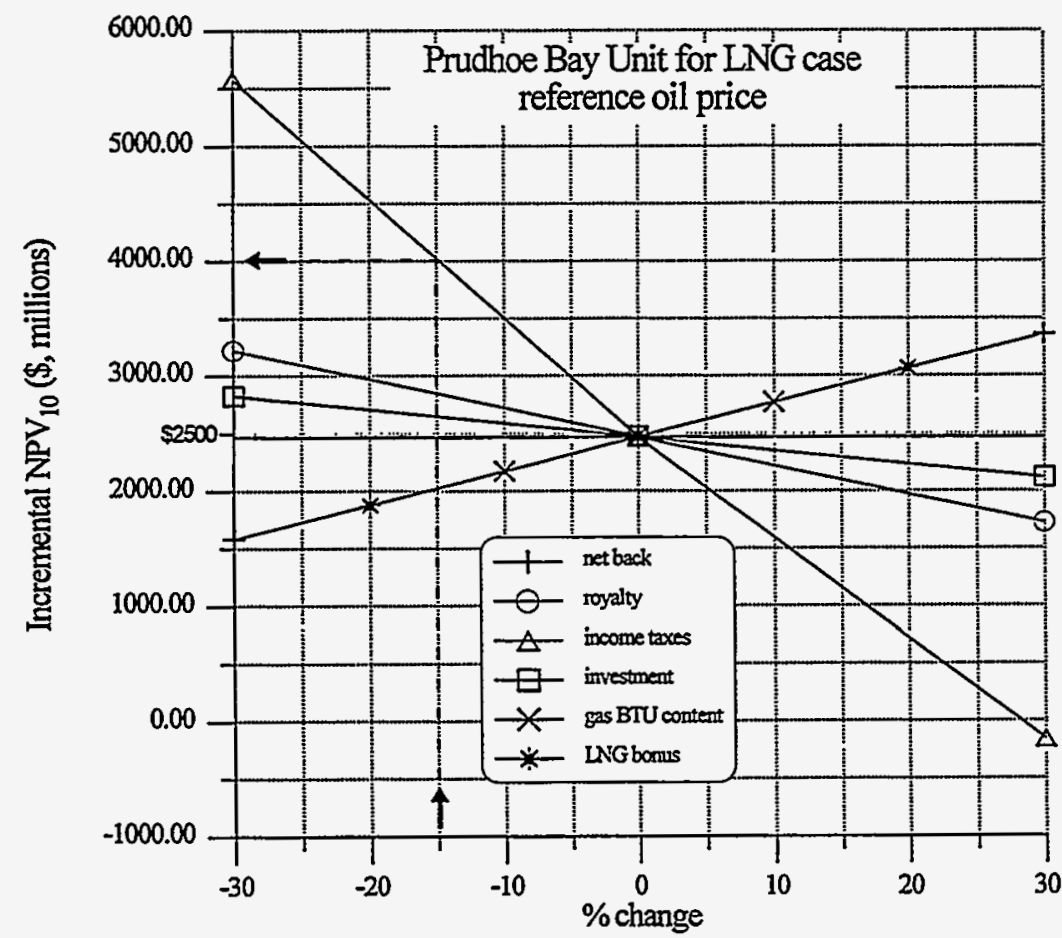

Figure 5.5. Variable sensitivity plot for Prudhoe Bay Unit with gas sales to a LNG project with illustration showing effect of lowering state and federal taxes by $15 \%$ - reference oil price forecast. 
The base $\mathrm{NPV}_{10}$ for PTU with gas sales to a $L N G$ project is $\$ 340$ million. The price received for the gas sold (gas product net back variable), the gas BTU content, and the LNG bonus are the most critical variables for PTU as shown in Figure 5.6. However, State and federal taxes and field investment are also critical variables for PTU under this scenario. Field pipeline tariffs and royalty rates play a less important role than the other variables analyzed.

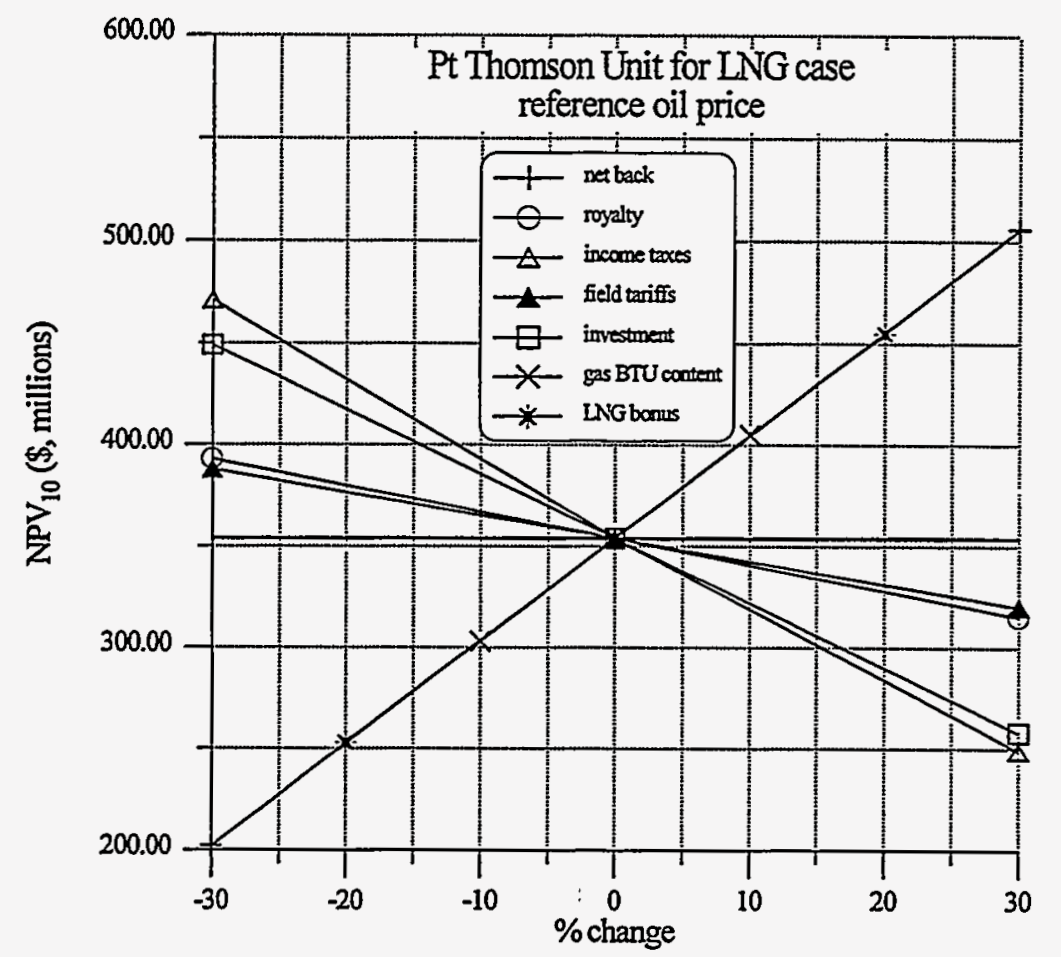

Figure 5.6. Sensitivity plot for Point Thomson Unit with gas sales to gas pipeline/LNG project - reference oil price forecast.

\subsubsection{PBU and PTU Economic Sensitivity with Gas Sales to a GTL Plant.}

Six variables were tested for economic sensitivity of the gas producing units for the GTL scenario. The variable most critical to both PBU and PTU economics under the GTL scenario is the combined State and federal taxes (see Figure 5.7 and Figure 5.8). The gas product net back, gas BTU content, and field investment are also very critical for PTU. The effects of varying the liquid premium were small for both PBU and PTU compared to the impact of other variables. 


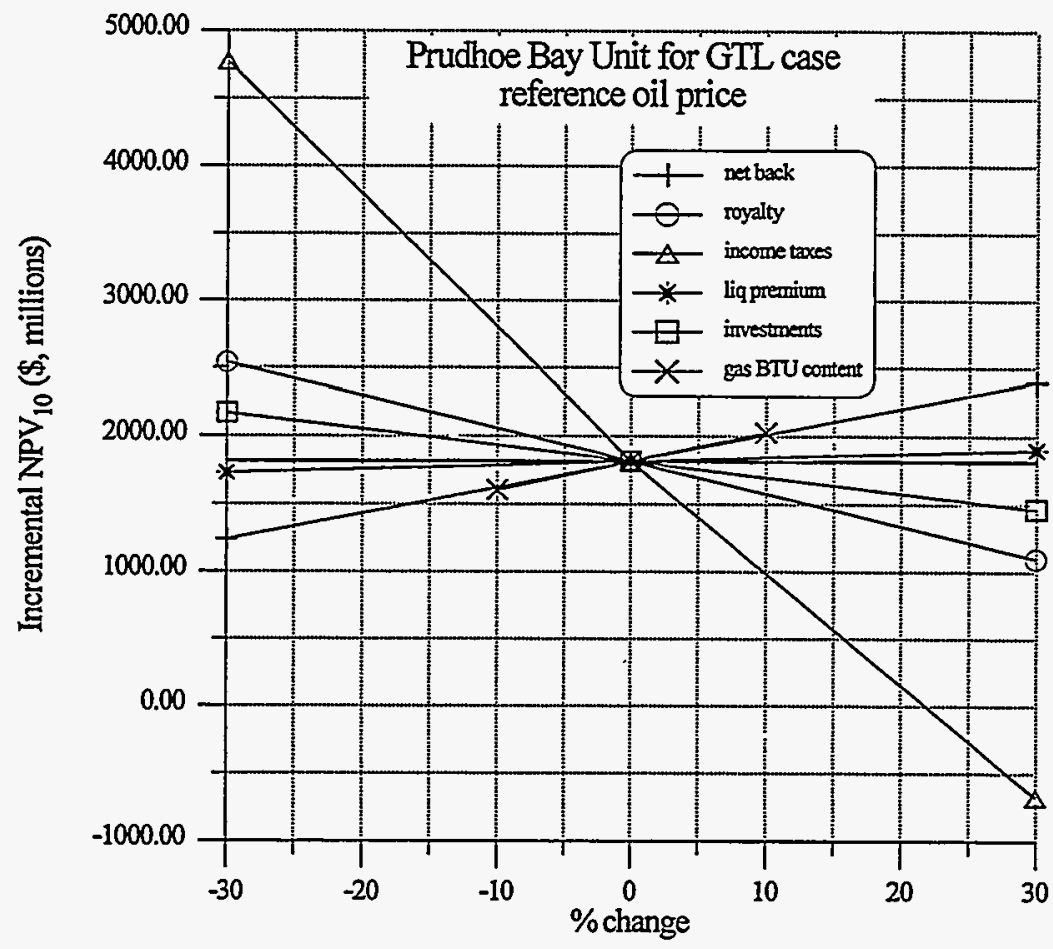

Figure 5.7. Variable sensitivity plot for Prudhoe Bay Unit with gas sales to GTL plant - reference oil price.

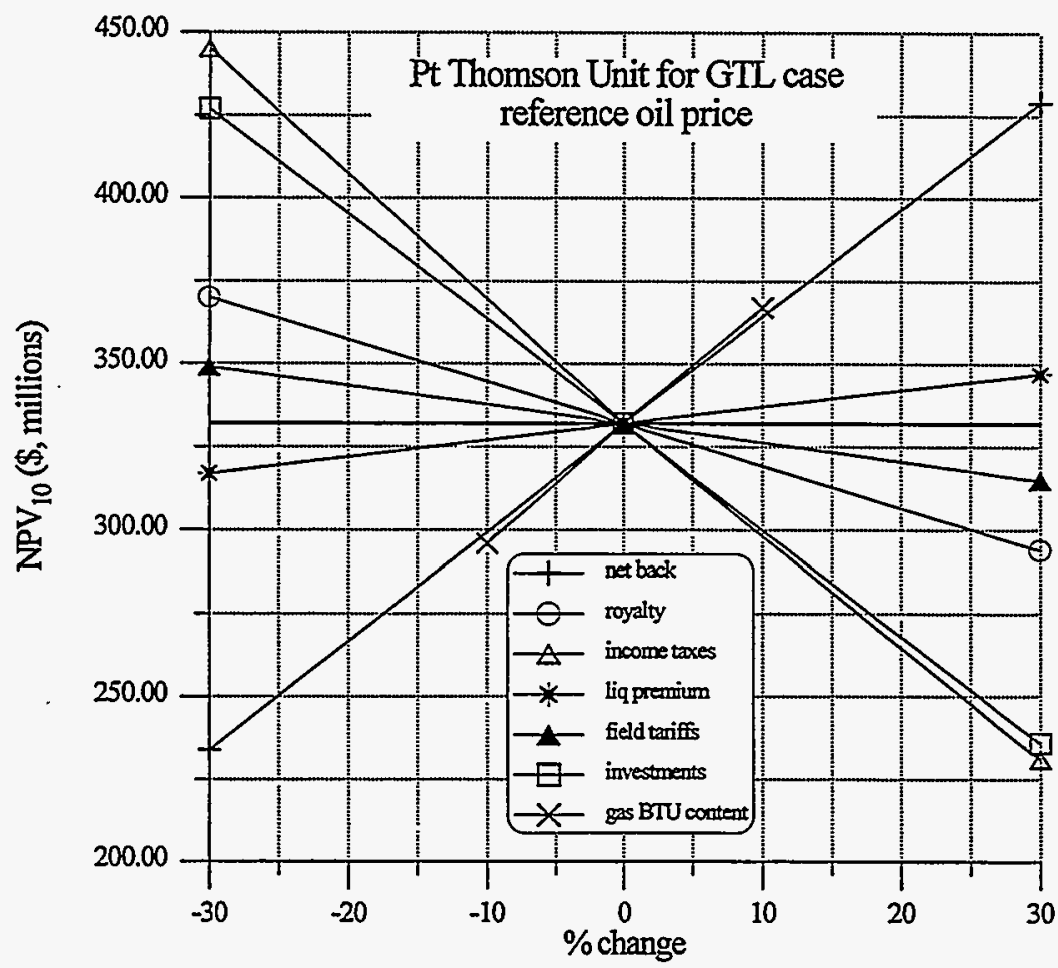

Figure 5.8. Variable sensitivity plot for PTU with gas sales to a GTL plant - reference oil price. 


\subsubsection{LNG Project Economic Sensitivity.}

Variables analyzed to determine LNG project sensitivity include: investment, operating costs, State and federal taxes, gas producer net back, shrinkage, gas BTU content, and Asian LNG bonus. Shrinkage is the percentage of the purchased gas lost due to fuel usage and process efficiencies.

Sensitivity analysis results, shown in Figure 5.9, indicate that the gas BTU content, the LNG bonus, and the project investment are the most critical variables to project economics. Net back fraction, state and federal taxes, operating costs, and shrinkage are important, but less critical to total project economics.

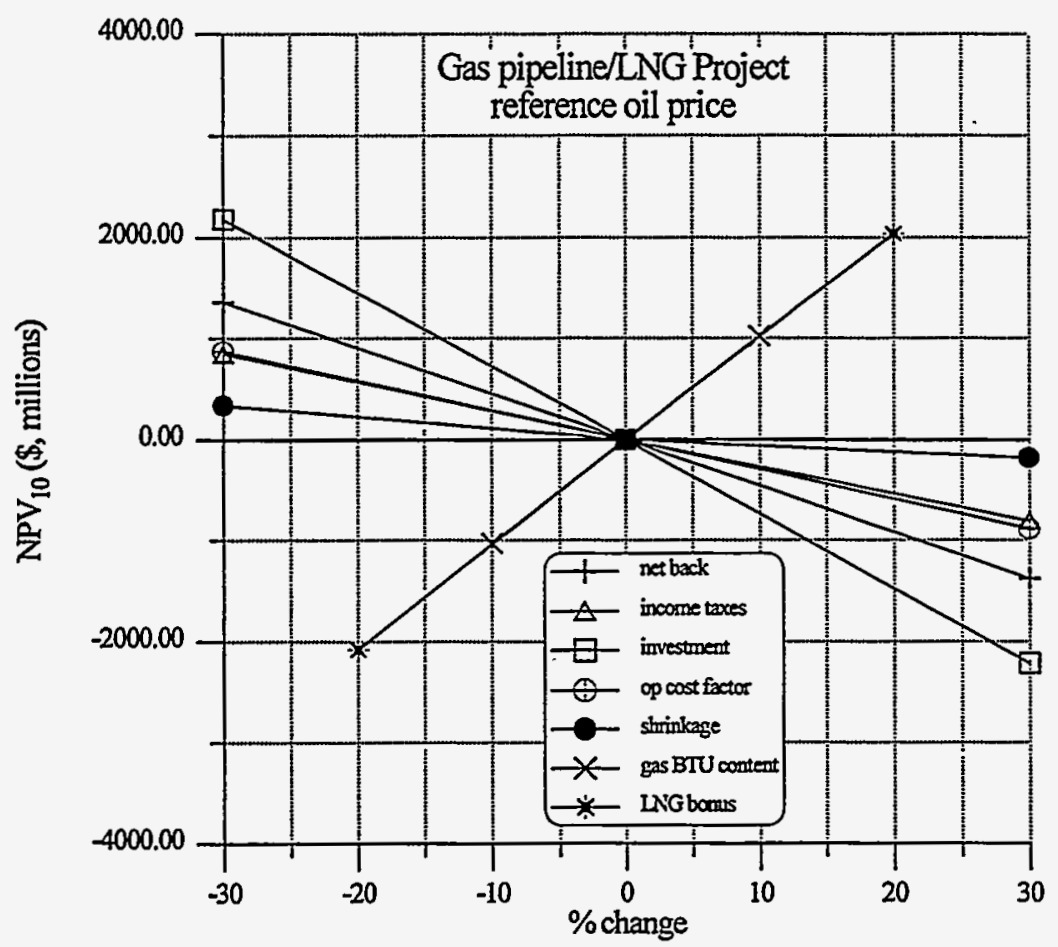

Figure 5.9. Variable sensitivity plot for LNG project showing effect of altering variables on project net present value - reference oil price.

\subsubsection{GTL Conversion Plant Economic Sensitivity.}

Variables analyzed to determine GTL project sensitivity include: operation and maintenance costs, liquid premium price, initial plant investment, state and federal taxes, GTL plant efficiency, gas product net back, and gas BTU content. The most critical variable in the GTL plant economics is the overall efficiency of gas usage and conversion as shown in Figure 5.10. Other important variables, listed in order of sensitivity, include plant investment, gas BTU content, net back fraction, O\&M costs (op cost factor), State 
and federal taxes, and liquid premium price.

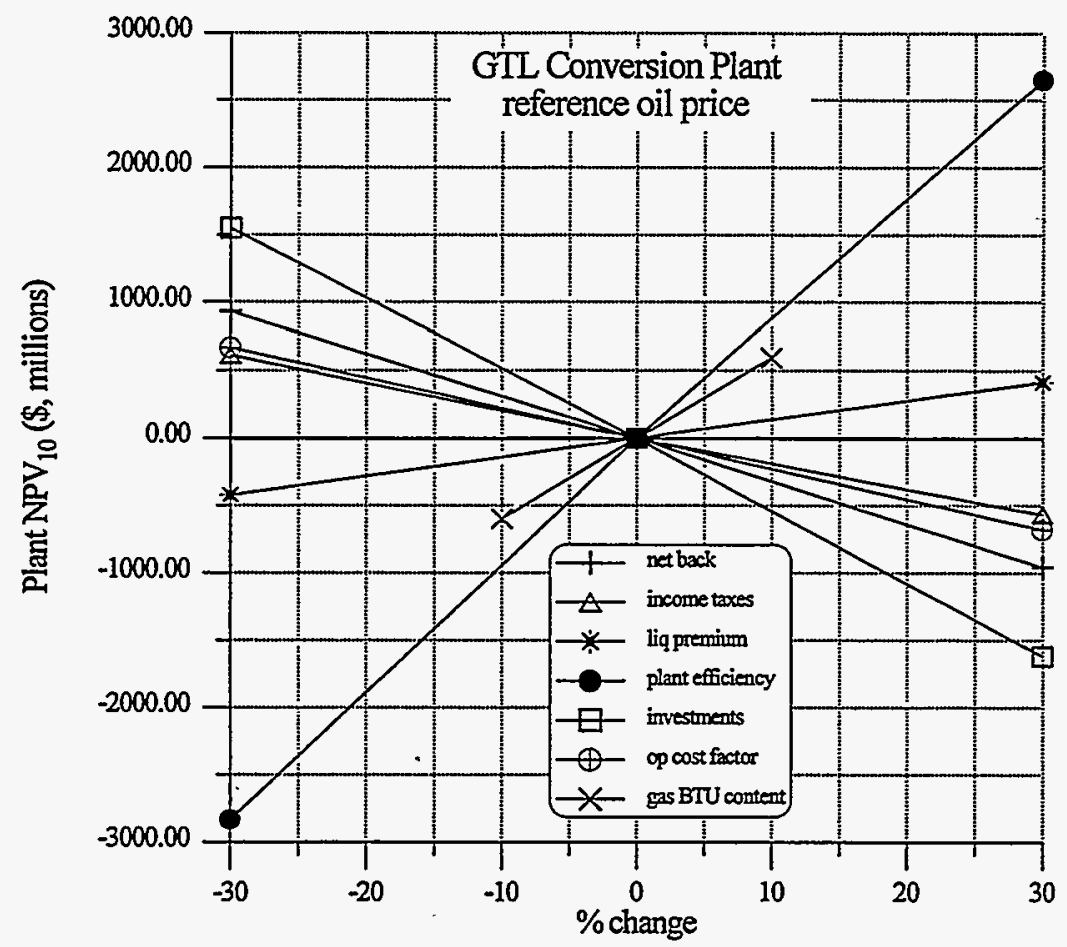

Figure 5.10. Variable sensitivity plot for GTL plant showing effect of changing input variables on the net present value of the plant - reference oil price.

\subsubsection{Summary Discussion.}

From this analysis it can be seen that a major cost driver for both the GTL and LNG conversion projects is initial investment costs. If this variable is successfully lowered or even held at the assumed value, both projects show acceptable rates of return for the reference oil price, while providing the Units a reasonable price for their gas. Of even greater significance to the GTL conversion project is plant efficiency. An increase in plant efficiency not only increases the profit stream by increasing liquid product sales volume, but the increased volume also decreases TAPS transportation costs for all transported liquids, providing a higher North Slope oil price than without GTL conversion. In the case of LNG, the delivered price as reflected by both the gas BTU content and the Asian bonus appear to be the most critical variables.

PBU is most affected by altering state and federal income taxes. For PTU, because it is less profitable, other variables come into play such as gas product net back fraction and field tariffs, as well as State and federal taxes and royalties. Because of its borderline economic status, government agencies are in a position to assist in improving the economic viability of the Point Thomson field. 


\subsection{Analyses Using the Flat Oil Price Forecast}

A flat oil price forecast of $\$ 18 / \mathrm{BBL}(1995 \$)$ is used to evaluate the gas sales scenarios for a much more conservative oil price forecast than the EIA 1995 reference oil price forecast. Using the $\$ 18 / \mathrm{BBL}$ flat oil price forecast, Point Thomson requires a gas product net back percentage much higher than either of the gas sales alternative projects can afford to offer to earn a 10\% rate of return. For PTU to be economical for the $\$ 18 / \mathrm{BBL}$ oil price, significant (and probably unreasonably large) changes in several of the input variables would be required. Therefore, the sensitivity analyses done with the $\$ 18 / \mathrm{BBL}$ flat oil price forecast include gas produced from PBU alone at 2.05 BCFPD, yielding LNG sales of 14 MMPTA and GTL liquid sales of $250 \mathrm{MBPD}$. The capital investments are reduced to the levels required for the reduced scale of the projects; i.e., $\$ 14$ billion for the LNG project and $\$ 10$ billion for the GTL project.

The same approach is used with the flat oil price forecast as with the reference oil price forecast: both the LNG and GTL projects are forced to a $10 \%$ rate or return by varying the gas product net back fraction. Any economic advantage of the two options then shows up in the evaluation of PBU economics and are presented in terms of incremental $N V_{10}$ relative to the no major gas sales case. However, for the $\$ 18 / \mathrm{BBL}$ flat oil price, neither of the two gas sales options can receive a $10 \%$ rate of return and return a positive incremental $\mathrm{NPV}_{10}$ to $\mathrm{PBU}$-- in other words, for both gas sales projects to receive a $10 \%$ rate of return with these input variables and the $\$ 18 / \mathrm{BBL}$ flat oil price, PBU would fare better by with the no major gas sales option.

Since it is necessary for both the gas projects and the PBU to provide reasonable rate of return, a breakeven flat oil price greater than $\$ 18 / \mathrm{BBL}$ is calculated such that both the gas producer and buyer earn a $10 \%$ rate of return. Thus, both the NPV ${ }_{10}$ of the gas sales projects and the incremental NPV ${ }_{10}$ for PBU were held to be equal to zero, which means the value of the projects to the PBU owners would be equal to the no major gas sales case. This is accomplished by varying the gas product net back fraction until both the gas producer (PBU) and the gas buyer (either the LNG project or the GTL project) earn a $10 \%$ rate of return on their respective projects. As shown in Figure 5.11, the breakeven flat oil price for the LNG scenario is $\$ 19.36 / \mathrm{BBL}$; while the breakeven flat oil price for the GTL scenario is slightly higher at $\$ 19.94 / \mathrm{BBL}$. 


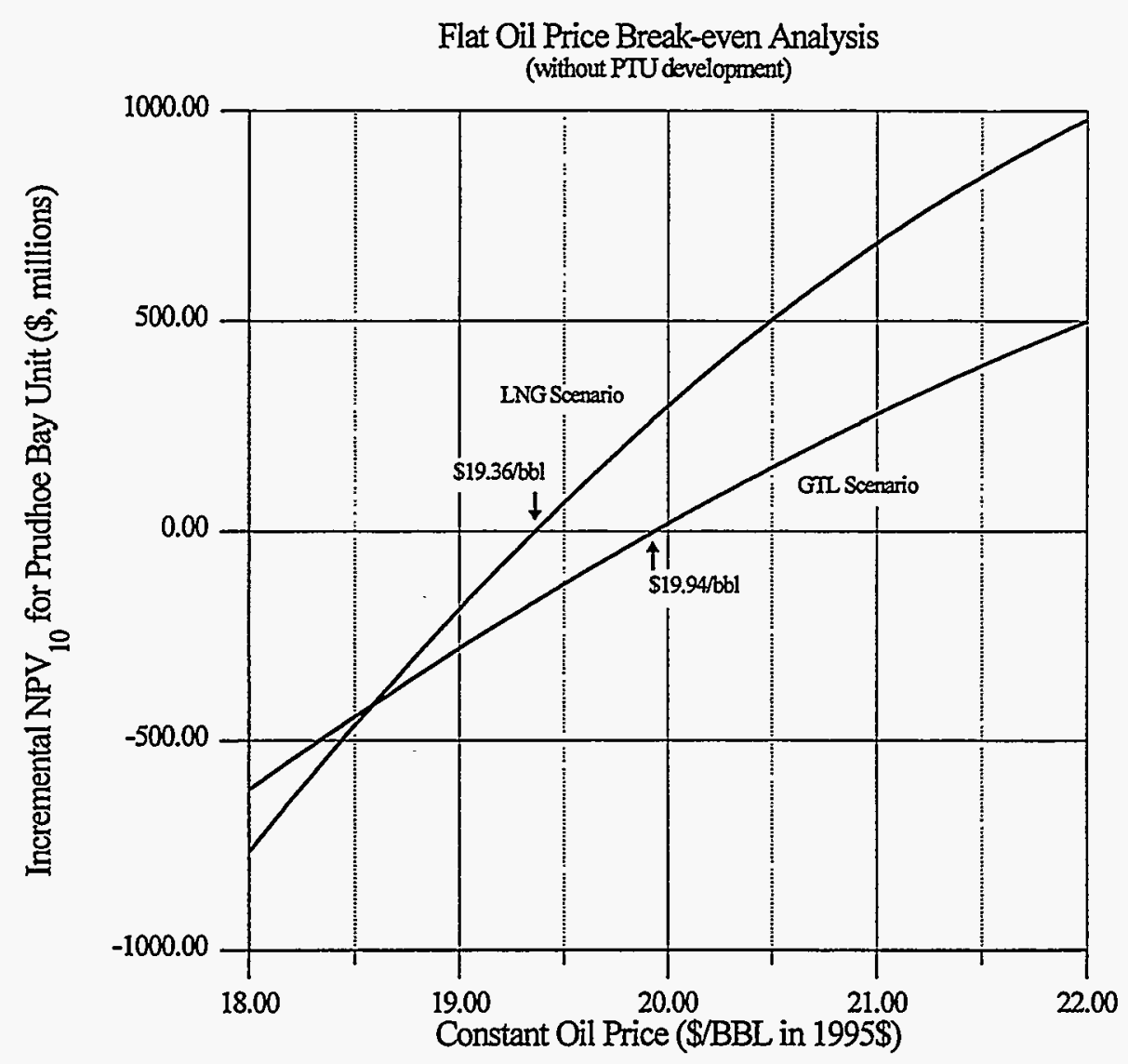

Figure 5.11. Analysis to determine the break-even $\left(\mathrm{NPV}_{10}=0\right)$ flat oil price for each gas sales scenario for PBU.

\subsection{Delaying Major Gas Sales Until 2010}

Currently, the gas from Prudhoe Bay is being used to recover oil from PBU as well as the Kuparuk River Unit. Starting major gas sales from Prudhoe Bay in the year 2005 reduces the amount of gas available for oil recovery operations and causes a reduction in oil produced from the PBU. It is estimated that $400 \mathrm{MMBO}$ of oil will be lost by starting major gas sales in 2005 (see Section 2.3.7.1). However, if the gas is not sold until a later date, the amount of lost oil recovery is reduced. By delaying major gas sales by 5 years, from 2005 to 2010 , it estimated that from zero to $200 \mathrm{MMBO}$ of oil recovery will be lost. ${ }^{2}$ For this sensitivity analysis, it is assumed that gas sales beginning in 2010 cause no negative impact on PBU recovery. The economic ramifications to PBU and to both gas sales alternatives of delaying the sale of gas until 2010 using the AEO95 reference oil price is as follows.

a. Estimate based on discussions with Arco Alaska, Inc. in August 1991 and March 1995. 
By delaying project start up until 2010 using the AEO95 reference oil price forecast, the incremental $\mathrm{NPV}_{10}$ of the LNG scenario decreases from $\$ 2500$ million to $\$ 2200$ million. The incremental $N V_{10}$ of the GTL scenario decreases from $\$ 1800$ million to $\$ 1700$ million as shown in Figure 5.12.

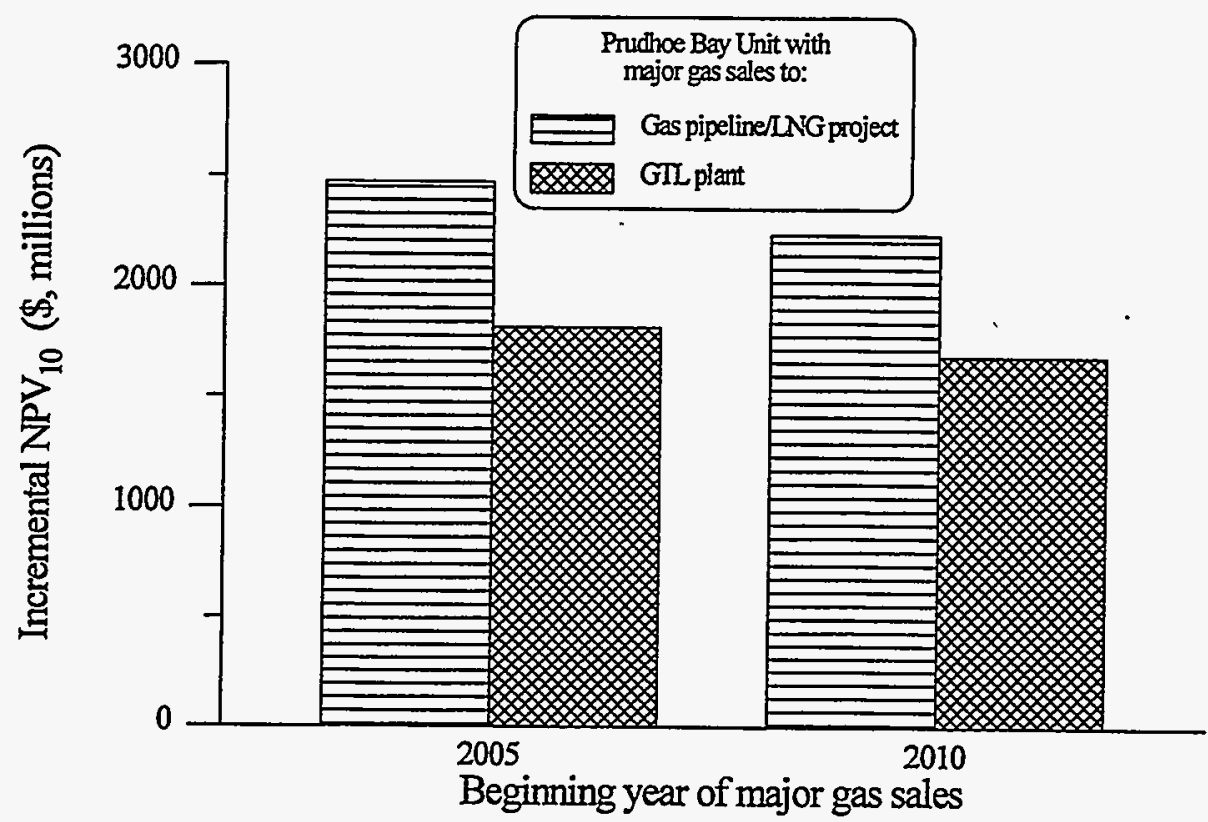

Figure 5.12. Effect of delaying major gas sales from PBU from 2005 to 2010 using AEO95 reference oil price.

\subsection{Summary of Economic Results}

The preceding sections summarize the analytical framework by which the three options for ANS gas can be compared. The projects and options were evaluated using a standard discounted cash flow analysis presented in terms of net present value $\left(\mathrm{NPV}_{10}\right)$. The $\mathrm{NPV}_{10}$ captures the sum, in 1995\$, of annual revenues less expenses and investments, adjusted for a discount rate that provides a $10 \%$ rate of return on investment. The $\mathrm{NPV}_{10}$ analysis required the following input information:

(a) Oil and gas recovery forecasts for all developed and producing ANS oil fields and a forecast for the undeveloped PTU to provide the expected pipeline flow for determination of TAPS tariff schedules.

(b) A determination of the technology that might be employed to transport and convert ANS gas to a transportable and marketable commodity. 
(c) A requirement that the gas sales option (LNG or GTL) provide a reasonable rate of return (assumed to be $10 \%$ ) as a stand-alone operation before any "gas product net back" could be calculated for payment to the gas producing units.

This delineation of production, gas utilization option technology, and investment return requirement was then followed by summaries of the key variables that influence the economic acceptability of each option. Baseline assumptions for the variables were:

(a) The EIA 1995 Reference Oil Price (AEO95) case was used for the baseline economics. This case assumes a future world oil price with a predicted real oil price increase of about $2.4 \%$ per year.

(b) The hydrocarbon composition and heating value of the ANS gas provided as feedstock to LNG or GTL options is assumed to remain consistent over the project life at $1150 \mathrm{BTU} / \mathrm{SCF}$.

(c) Final product sales price is a direct function of world oil prices, adjusted upwards for their special value and desirability as a fuel; in the case of LNG by a $10 \%$ Asian bonus and in the case of GTL liquids by $\$ 5 / \mathrm{BBL}$.

(d) Annual operating costs of each gas project are assumed to be $5 \%$ of total capital investments for the LNG project and \$6/BBL for the GTL project.

(e) Operation efficiencies relative to the conversion of feedstock gas to salable product is assumed to be $91 \%$ for $L N G$ and $60 \%$ for GTL.

(f) No additional investments are required to sell gas from PBU because of the extensive gas-handling facilities already in place at PBU for separation and reinjection of 7.5 BCFPD. The estimated capital investment required to develop PTU is $\$ 900$ million (1995\$).

(g) Excluding PTU development costs, the total investment requirements for the LNG project are adjusted upward from the $\$ 14$ billion (1995\$) publicly announced in 1994 by Yukon Pacific for its proposed 14 MMTPA LNG project, to $\$ 16$ billion (1995\$) for the 17 MMTPA LNG project required to accommodate concurrent gas sales from PBU and PTU at 2.49 BFCPD. For the GTL option to handle the same gas volume as the LNG option, the plant investment is $\$ 12$ billion (1995\$), based 
on $\$ 40,000 / \mathrm{DBL}$ of output capacity for a large scale (300 MBPD) state-of-the-art GTL operation in the Prudhoe Bay field area.

(h) Major gas sales from PBU, starting in 2005 and ramping up to 2.05 BCFPD in 5 years, will reduce PBU oil recovery by 400 million barrels oil (MMBO). PBU gas sales will end in 2036.

(i) Gas sales from PTU start in 2008 at $0.44 \mathrm{BCFPD}$, providing a peak rate of gas sales from PBU and PTU of 2.49 BCFPD. PTU gas sales end in 2027.

(j) Federal and State of Alaska taxes and other charges are assumed to remain as they are at this date. The effects of any changes or incentives that could be provided to encourage development of one or the other of the gas sales options from tax or royalty changes were evaluated in the sensitivity analysis in Section 5.3.

The baseline comparative calculations show that in spite of potential reductions in PBU recovery of as much as $400 \mathrm{MMBO}$ upon major gas sales, both LNG and GTL gas sales options have a greater payoffs than the option of not selling the gas and continuing to reinject until the oil recovery reaches an economic limit. It is not nearly as clear which gas sales option is more preferable, however. As shown in Table 5.8, while the NPV 10 for the producing units for the LNG option exceeds that of the GTL option by about 7\%, the total investment for LNG is $24 \%$ greater than required for GTL.

Table 5.8. Summary of gas sales options NPV's and investments.

\begin{tabular}{|c|c|c|}
\hline . & $\begin{array}{c}\text { NPV }_{10} \text { LNG Option } \\
\text { (1995\$, billions })\end{array}$ & $\begin{array}{c}\text { NPV }_{10} \text { GTL Option } \\
(1995 \$, \text { billions })\end{array}$ \\
\hline Prudhoe Bay Unit - No major gas sales & 8.6 & 8.6 \\
\hline Prudhoe Bay Unit & 11.1 & 10.4 \\
\hline Point Thomson Unit & 0.4 & 0.3 \\
\hline Total NPV 10 & 11.5 & 10.7 \\
\hline \multicolumn{3}{|c|}{ Total Investment (1995\$, billions) } \\
\hline Gas option investment & 16.0 & 12.0 \\
\hline Pt. Thomson development & 0.9 & 0.9 \\
\hline Total & 16.9 & 12.9 \\
\hline
\end{tabular}


Variables in these computations and how their change might effect the comparison of the two gas sales options were then examined. For the baseline assumptions, the results showed that neither option is economic, if oil prices remain at a flat $\$ 18 / \mathrm{BBL}$. Conversely, the results showed that the delay of gas sales by as much as 5 yrs has only a slight effect on profitability of both the LNG and GTL options, assuming product sales are not deterred by such delay. Of the variables examined, the State and federal tax burden appears to have the most effect on the economic feasibility of gas sales by the PBU and PTU. For the LNG project on a stand-alone basis, the Asian price bonus, gas feedstock quality, and total investment costs have the most impact on feasibility, while for the GTL project, plant efficiency and then total investment costs are the most critical variables. 


\section{DISCUSSION, CONCLUSIONS, AND RECOMMENDATIONS}

This section contains a discussion of the issues and the economic analysis performed in this study, the conclusions based on the analysis, and recommendations that interested industry, State of Alaska and federal parties may wish to pursue.

\subsection{Discussion}

Although there has been a high level of interest in developing a capability to bring the huge North Slope natural gas resource to market since the discovery of the giant Prudhoe Bay field, the urgency to develop the capability to sell the large, currently unmarketable, North Slope gas resources has increased in recent years as the steep decline in North Slope oil production has become more evident now that Prudhoe Bay has begun its inevitable decline. As described in Section 2.2.1, Prudhoe Bay and Point Thomson (a smaller, undeveloped gas/gas condensate field 50 miles east of Prudhoe Bay) contain about 25 TCF of the 26 TCF of the estimated saleable natural gas discovered on the North Slope. This is a highly significant resource (over 4 billion barrels of oil equivalent) addition to the estimated remaining recoverable reserves of about 6 billion barrels (as of January 1, 1995) from producing North Slope fields. In addition, to the known 26 TCF of saleable gas reserves, there may be twice as much remaining undiscovered recoverable gas in Northern Alaska according to the latest USGS estimate (USGS, 1995).

To date, the only use of the gas that is currently produced at Prudhoe Bay with the crude oil, aside from local ANS use and the extraction of NGLs for sale with the crude oil, has been for reinjection to enhance recovery of crude oil. The use of Prudhoe Bay gas for oil recovery is becoming less important and less valuable with the decline in oil production. Thus, the urgency is increasing to develop the capability to market the gas, and thereby extend the life of North Slope operations and continue the generation of employment and revenue for the State of Alaska and the nation.

The possibility of exporting the gas via a pipeline from the North Slope to a Valdez LNG plant, followed by tanker shipment to Asian buyers, has long been suggested and studied as an ANS gas sales option. This study, however, sought to assess the economic and technical feasibility of a second option, based on newer technology than that well-established for LNG. This option involves the chemical conversion of gas to a distillate-type hydrocarbon liquid (GTL) that could be transported and sold with 
continuing ANS crude oil production via the existing TAPS and tanker fleet.

\subsubsection{Study Approach}

Before the feasibility of the GTL option could be assessed, as well as compared with the LNG option, an updated outlook for prospective oil production from producing ANS reservoirs had to be developed and an assessment of the gas conversion technology that might be deployed under each option also had to be made.

Without the speculative assumption of additional large oil finds, the introduction of unheralded new inexpensive oil extraction technology, or the development of known but marginal ANS oil reservoirs (the currently known reservoirs are not sufficient to offset or reverse the decline in Prudhoe Bay production), it is believed that ANS oil production will continue to decline. ANS oil production peaked in 1988 at 2.0 million barrels per day, declined to 1.4 million barrels per day in 1995, and will continue to decline based on the production outlook for the currently developed and known undeveloped fields. This decline is paced by the Prudhoe Bay field, which has produced almost 9 billion barrels of oil (about 70\% of its estimated 13 billion barrels of reserves) since the start of production in 1977 and whose inevitable depletion is now clearly evident. ANS oil production could end abruptly between 2009 and 2016 with a shutdown of TAPS, if TAPS operations becomes prohibitively expensive (or technically impossible) to continue (see Section 1.4.1 for a discussion of TAPS minimum flow limits).

Prospective gas conversion technology was then examined for both the more established physical conversion to LNG, and the less well established GTL chemical conversion to liquid hydrocarbons. We investigated not only state-of-the-art GTL technology, but also examined the most promising technology advancements known to DOE researchers that conceivably could have application on the North Slope. In spite of proponent optimism that such cost-cutting technology could be ready for application on a large scale by the time of decision making on ANS gas sales, about 4 to 7 years (consistent with investment lead time requirements and gas owner indications that the window of opportunity for major gas sales will be after 2005), a conservative approach to the analysis demanded such advancements not be factored into this assessment. Thus, this assessment assumes that state-of-the-art Fischer-Tropsch GTL technology, reflective of Shell's Middle Distillate Synthesis plant that has been operating in Malaysia since 1993, would be employed in a GTL option for ANS gas sales. Likewise, the LNG option for the gas assumes LNG conversion technology as planned and reported by Yukon Pacific Corporation in 1994. 


\subsubsection{Gas Sales - Base Economics}

Based on the ANS oil and gas production outlook and the conversion technology base, coupled with the assumption that output from either of the options would be marketable at premium prices (a $10 \%$ Asian fuel bonus and a $\$ 5 / B B L$ premium for clean-burning diesel fuel from GTL conversion liquids), an analytical comparison of the two options was performed. Both options were sized to handle a similar volume of gas on a daily basis beginning in 2005, consistent with the 2.05 BCFPD planned by Yukon Pacific Corporation to handle PBU gas, but adjusted upwards to a capacity of 2.49 BCFPD to accommodate PTU production, which would be completed well before PBU production ends in 2036.

Results of the economic model employed showed (in 1995\$) that after all expenses and allowing only a $10 \%$ rate of return on the incremental investment for preparing and transporting the gas to market for the respective gas sales options, the LNG option would yield an $\$ 11.5$ billion net present value $\left(N_{P V}\right)_{10}$ ), while the GTL option could be expected to yield a $\$ 10.7$ billion $N_{P V}$, or about $7 \%$ less. The total incremental investments required for these yields, however, would be $24 \%$ greater for the LNG option than for the GTL option, $\$ 16.9$ billion compared to $\$ 12.9$ billion.

\subsubsection{Gas Sales - Economic Variables}

These results are a synthesis of the base assumptions developed to complete the assessment. Changes in one or more of these assumptions could significantly alter these financial results.

In considering the LNG option, there are a large number of would be LNG suppliers in the world seeking to fill the expected LNG demand growth from gas-short Asian nations. Many of these suppliers are thought to have smaller capital outlays (not having the necessity of building an 800 -mi gas pipeline as is required at the start for the Alaskan LNG project), and it is quite possible the LNG project's Asian fuel bonus and its base LNG price will be less than anticipated, thereby reducing the LNG base economics. It is also possible, as more large LNG projects are designed and built around the world, that cost-saving measures will be found that would improve the LNG base economics.

Likewise, for the GTL option, conversion efficiency might prove to be closer to the $57 \%$ level of the older South African plants rather than to the plant design level of $63 \%$ efficiency for Shell's newer plant, thereby reducing the GTL base economics. In contrast, the target efficiency of 70 to $75 \%$ for the advanced 
GTL technology under development may prove out in time to be ready for the rapid GTL deployment envisioned (or for major portions of the development, if such GTL development is phased in more slowly), thereby improving the GTL base economics.

Clearly, the base economics of both of the gas sales options could be seriously impacted if, for example: investment cost contingencies associated with Alaska's climate, remoteness, and related factors prove to be underestimated; or such stand-alone projects as LNG and GTL require a greater than $10 \%$ rate of return to attract investors; or if world oil prices prove to be substantially lower than the DOE EIA reference oil price forecast (neither LNG nor GTL were found to be financially feasible at an \$18/BBL fiat oil price in this study's sensitivity analysis).

\subsection{Conclusion}

At this point in time, if the assumptions for the economic variables are valid -- and, we believe they are valid based on the public information available to us -- both the LNG and the GTL options are economically promising and warrant consideration in the decision making process, but it is not possible to conclude that one option is significantly better than the other.

This evaluation, however, does answer the specific question it was directed to address, namely: Is GTL conversion a feasible alternative for bringing ANS natural gas to market? The conclusion from this assessment is that state-of-the-art GTL conversion technology appears to be feasible and could be deployed within a meaningful time frame to sustain ANS and TAPS oil operations for 20 or more years beyond what might be anticipated without GTL.

Placing the issue of GTL feasibility aside, this ANS gas utilization assessment is not expected to be the last of what has been a number of studies focused on the marketing of Alaska's large, and potentially much larger, remote natural gas reserve. Alaskans face difficult gas development and marketing decisions in the near future, and need to develop the most complete understanding of the options possible. This is particularly so with respect to likely requests for State tax incentives and other actions that might be desired to move private commitments forward. 


\subsection{Recommendations}

To assist in responding to such requests and other decisions that must be made to implement the sale of ANS gas, this report concludes with a number of recommended follow-up analyses that interested industry, State and federal parties may wish to pursue in a timely manner:

1. Existing Infrastructure Savings-The economics of both of the options could benefit through the utilization of portions of the infrastructure existing at Prudhoe Bay and along the TAPS pipeline. These possibilities should be examined on a site-specific basis, not only for a GTL plant that would be built on the North Slope, but also for the LNG gas pipeline and prospective Valdez liquefaction and shipping facilities. (YPC reports that basic engineering and design have been completed, but it is likely that further engineering and design involving the Prudhoe Bay operators and Alyeska Pipeline Service Company will lead to additional refinements.)

2. Specific Cost Estimates--More precise, process- and site-specific cost estimates of the LNG and GTL options should be developed because of the important sensitivity of the economics of both of these options to capital costs in particular. These estimates should incorporate the latest in technologies and designs, attempting also to provide sufficient detail on the cost impact of technology advances possible within a meaningful timeframe.

3. TAPS Tariff Impact on Future Oil Production--A more complete assessment is desirable concerning the effect of reduced TAPS tariffs, anticipated from the envisioned GTL product volumes, on future ANS oil production from all existing fields and potential developments. The several dollar per barrel reduction suggested by this study could be important in determining how long selected ANS reservoirs might continue to produce, and could affect whether non-producing reservoirs might be brought on line.

4. Optimization of GTL Product Composition--To better refine the operating cost and price estimates of proposed GTL operations, technical assessments should be directed to delineating potential liquid product compositions with respect to: (a) feasible process chemistry, (b) methods of TAPS shipment (mixed with the crude or stored and batched separately, similar to oil product pipelines), (c) crude and GTL product separation and refining process(es) required to obtain to ultimate GTL product value, and (d) other factors as appropriate. 
5. ANS Cost Factors--A clearer picture should be developed of the cost penalties associated with capital construction and facility operation in the arctic climate and remote location of the ANS. This should be done for both GTL and LNG options and should also examine general Lower 48 and Alaskan capital and operating cost differences to provide the most reliable cost estimates for gas sales decision making.

6. Gas Sales Benefit to Alaska--The potential economic benefits of each gas commercialization option on the various regions and overall State should be assessed in detail to aid in decision making. Such examination might include: (a) an analysis of the types and aggregate of manufacturing and labor components for construction and operation of each gas option and the resulting stimulation of State and local economic development, (b) direct and indirect local employment to be generated (and saved or extended, if such be the case), and (c) gross and net revenues to State and local jurisdictions through prevailing or alternative tax schedules, etc.

7. Alternative GTL Development Schedule--The GTL option does not have to be developed at the pace required for the LNG project (resulting from the requirement to build the pipeline up front). The development scale was chosen to match the proposed TAGS LNG scale, pace, and scope in an attempt to make the obvious comparisons between the two options as comparable as possible. Hence, it would be useful to consider a slower development of GTL that could take advantage of the learning curve associated with deployment of new technology to lower costs and potentially take advantage of advanced GTL technology in the later modules for improved conversion efficiencies. Slower, incremental development would also reduce the magnitude of the capital outlays required in the early years and allow them to be offset by the increased profits from GTL sales. Such a development scenario increases the possibility of constructing more of the plant modules in Alaska and pacing the development over a long period of time to sustain higher employment and infrastructure levels within the State. 


\section{APPENDIX A}

\section{STATUS OF NORTH SLOPE DEVELOPMENT AND PRODUCTION}

\section{A.1 Overview}

This section includes an update of the status of the currently producing fields on the North Slope and a review of the status of the recent and planned developments that provide the basis for conclusions concerning the effects that major gas sales could have on oil recovery and provides a basis for evaluating the effects a viable gas-to-liquids technology could have on the future of the North Slope resources.

The known gas resource on the North Slope is currently being used very effectively for enhancing oil recovery in the Prudhoe Bay field and other fields. ARCO received approval from the Alaska Oil and Gas Conservation Commission in September 1995 to institute a miscible gas injection project in the Kuparuk River Unit, the second highest producing rate field in the U.S. (AOGCC, 1995b). ARCO proposes to use miscible injectant derived from the gas in the Prudhoe Bay Unit in this project. Hence, it is necessary to know the status and plans for oil recovery from the North Slope in any consideration of gas resource development and sales.

Recent decisions by British Petroleum (BP) and other companies to aggressively pursue development of satellite fields around the Prudhoe Bay Unit (PBU) infrastructure, the purchase by BP of the Milne Point Unit from Conoco, and announced plans to pursue development of Badami, are examples of potential that exists for North Slope development. The policy change by the State of Alaska to allow the commissioner of the Department of Natural Resources to change the royalty and severance tax on field on the North slope to encourage development is a sign that the State is willing to pursue a more aggressive approach to North Slope development.

\section{A.2 Producing Fields}

\section{A.2.1 Prudhoe Bay Unit - Oil Production}

The Prudhoe Bay field, the largest oil field in North America, is located adjacent to the Beaufort Sea coastline about 200 mi east of Point Barrow (see Figures 2.1 and 2.2). 
The field was discovered in 1968 when oil and gas were tested in the Prudhoe Bay State No. 1. Hydrocarbons are present in three Permo-Triassic sand intervals, the Ivishak sandstone of the Sadlerochit Group, Sag River, and Shublik, with the Ivishak the most prolific. OOIP is about 23 billion BBL oil. OGIP is about $46 \mathrm{TCF}$. Of this volume, $30 \mathrm{TCF}$ is in the gas cap and the remainder is in solution in the oil rim.

The Prudhoe Bay field was unitized in 1977 and the Permo-Triassic participating area (PBU) was placed on production in June 1977. Total liquids recovery (oil, condensate, and NGL) from PBU was 8.822 billion BBL oil through December 1994. Production has declined from a peak average rate of about 1,600 MBPD during 1987 to an average of 1,057 MBPD during December 1994 (see Figure A.1).

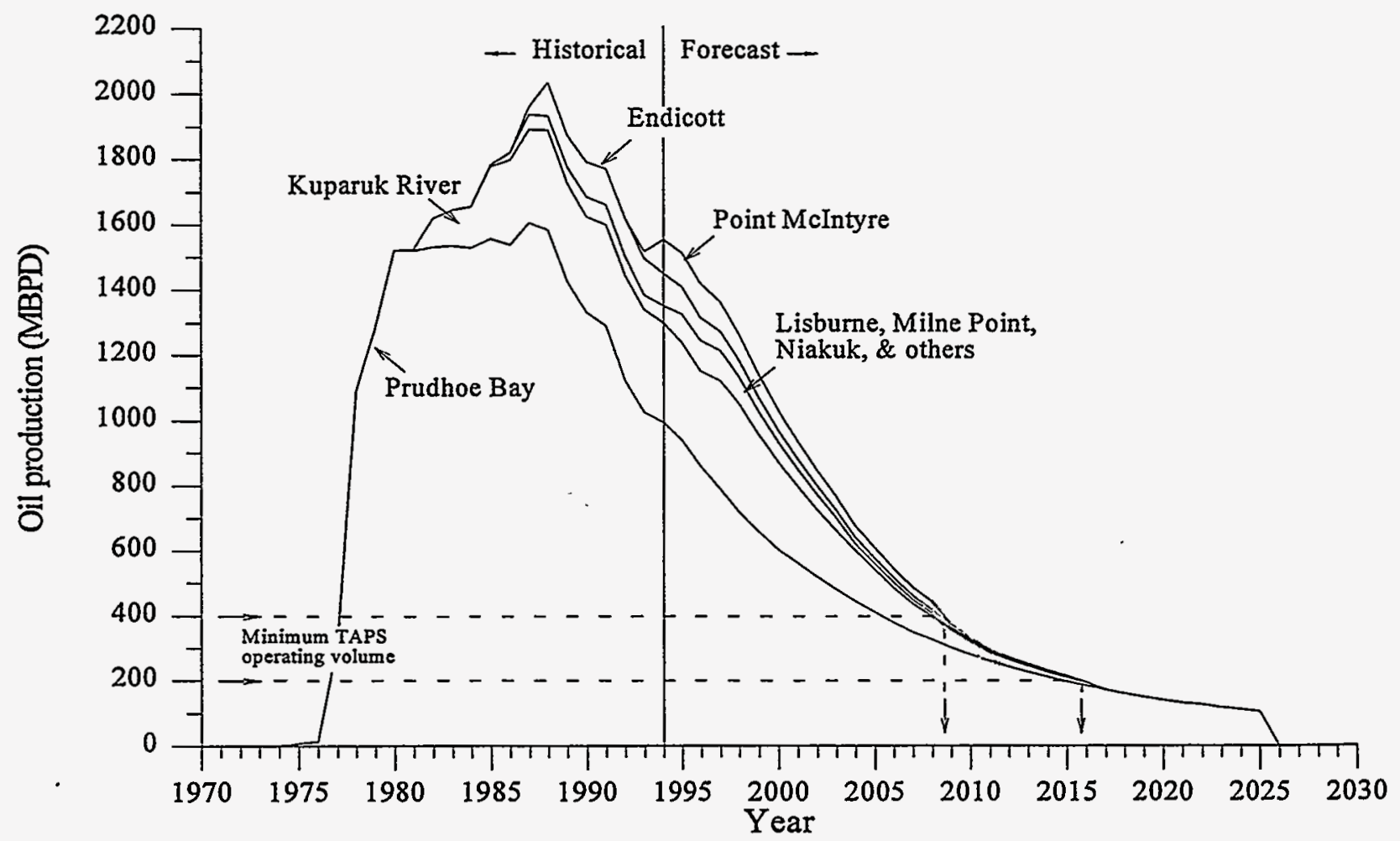

Figure A.1. The Alaska North Slope historical production and production forecast at the Energy Information Administration (EIA) Reference Oil Price (economically recoverable oil).

Total recovery estimates range from 12.2 to about 12.9 billion BBL oil, which is between $53 \%$ and $56 \%$ of OOIP, (ADNR, 1995c; AOGCC, 1992; DOE, 1993). The possibility of recovering over 13 billion BBL oil of crude oil in addition to condensate and NGL recoveries has been suggested (Platts, 1993). This higher recovery requires drilling of wells in addition to those included in current operating plans. 
A.2.1.1 Development Plan. Current PBU development plans (ADNR, 1994j) are consistent with previous plans to enhance ultimate recovery through continuation of infill well drilling, well workovers and redrills, and expansion of the Prudhoe Bay miscible gas project (PBMGP) in the Sadlerochit and Sag River, and continued development in the Eileen West End area. These plan's include:

- Continue drilling and redrill programs with six rigs.

- Expansion of PBMGP will potentially include about 110 additional miscible injection (MI) wells.

- In the Eileen area, waterflood (WF) and MI development may commence in 1996. Peripheral area development is planned for 1996. Expansion of WF/MI will be evaluated in 1998.

A.2.1.2 Input Data - No Major Gas Sales. Published information and field production history are the basis for most PBU input data. Recent reports to the ADNR and the Alaska Oil and Gas Conservation Commission (AOGCC) (AOGCC, 1991; ADNR, 1991; ADNR, 1992f; ADNR, 1993f; ADNR, 1994j; ADNR, 19940) were also used in development of the forecasts of recoveries and costs used in this study.

A.2.1.2.1 Recoverable Oil--The ultimate recoverable reserves forecast in the previous DOE publication (1993) was about 12.9 billion BBL oil (oil, condensate, and NGLs). Public records (ADNR, 1995; AOGCC, 1992) list ultimate reserve volumes of from 12.2 billion BBL oil to 12.6 billion BBL oil. Any of these reserves volumes are reasonable. A recent suggestion (Platts, 1993) that reserves might exceed 13 billion BBL oil are not substantiated at present. The ultimate reserve volume from the previous DOE publication (1993) is revised to 13 billion BBL oil by addition of the anticipated sale of 100 MMBBLS of NGLs to the Kuparuk River Unit as reported in Petroleum Information Corporation (PIC, 1994a) (see Appendix A.2.4.2.2). It is assumed that this NGL volume is in addition to those volumes currently being utilized (i.e., fuel, sales, or MI production). The excess NGLs are blended with the gas being reinjected into the gas cap. Remaining reserves at 1/1/95 are about 4.2 billion BBL oil (oil, condensate, and NGLs) with cumulative recovery of about 8.8 billion BBL oil as of 1/1/95 (ADNR, 1995c).

A.2.1.2.2 Production Forecast--PBU production is continuing to decline but the rate of decline is not yet clearly established. The extensive efforts to increase recovery throughout the life of the PBU have been highly successful. However, future efforts are not expected to have significant mitigating effects on the decline rate. 
The expansion of existing facilities; the expansion of the PBMGP; and the drilling, redrilling and workover of wells and their expected impact on production rate were considered in development of the production forecast needed to recover the estimated future recovery. The production average of $992 \mathrm{MBPD}$ during the first quarter of 1995 was slightly lower than the yearly average of 1,026 MBPD for 1994 . Production was curtailed in 1994 during the expansion of gas handling facilities. It is too early to determine the effect of this expansion on the production rate. Monthly production rates during 1993, 1994, and the first quarter of 1995 indicate production is continuing to decline. The production forecast is patterned after that in the previous DOE publication (1993). Modifications were made to reflect current production volumes and anticipated results of current unit plans. The volume of NGLs assumed to be sold to KRU (see Appendix A.2.4.2.2) are not included in the production forecast, but are treated as a separate outside sales in the evaluation. The production forecast prepared represents the estimated volumes being delivered to PS No. 1. The production forecast, with a productive life through 2025 is given in Table A.1.

Table A.1. PBU production forecast.

\begin{tabular}{||c|c||c|c|c|c||}
\hline YEAR & MBPD & YEAR & MBPD & YEAR & MBPD \\
\hline \hline 1995 & 940 & 2006 & 380 & 2017 & 172 \\
\hline 1996 & 860 & 2007 & 350 & 2018 & 160 \\
\hline 1997 & 790 & 2008 & 326 & 2019 & 150 \\
\hline 1998 & 720 & 2009 & 302 & 2020 & 140 \\
\hline 1999 & 660 & 2010 & 280 & 2021 & 132 \\
\hline 2000 & 605 & 2011 & 260 & 2022 & 126 \\
\hline 2001 & 563 & 2012 & 243 & 2023 & 117 \\
\hline 2002 & 520 & 2013 & 227 & 2024 & 111 \\
\hline 2003 & 482 & 2014 & 212 & 2025 & 105 \\
\hline 2004 & 446 & 2015 & 198 & & \\
\hline 2005 & 412 & 2016 & 185 & & \\
\hline
\end{tabular}

A.2.1.2.3 Investments--Estimates of future investments are based on the most current unit plans (ADNR, 1994j; Platts, 1993). Review of the future investments in the previous DOE publication indicated that some adjustments were needed. The cost to drill wells is assumed to be unchanged at $\$ 2.2$ million (1995\$) and is used in the evaluation. The investment schedule is shown on Table A.2. 
Table A.2. PBU drilling and investment schedüle.

\begin{tabular}{||c|c|c|c|c||}
\hline & Drilling & \multicolumn{3}{|c|}{ Investments (1995\$, millions) } \\
\hline Year & No. Wells & Wells & Facilities & Total \\
\hline 1995 & 50 & 110 & 535 & 645 \\
\hline 1996 & 50 & 110 & 210 & 320 \\
\hline 1997 & 50 & 110 & 210 & 320 \\
\hline 1998 & 40 & 88 & 73 & 161 \\
\hline 1999 & 30 & 66 & 96 & 162 \\
\hline 2000 & 20 & 44 & 24 & 68 \\
\hline 2001 & 10 & 22 & 0 & 22 \\
\hline 2001 & 10 & 22 & 0 & 22 \\
\hline 2003 & 10 & 22 & 0 & 22 \\
\hline 2004 & 10 & 22 & 0 & 22 \\
\hline 2005 & 10 & 22 & 0 & 22 \\
\hline \hline Total & 290 & 639 & 1,148 & 1,786 \\
\hline
\end{tabular}

A.2.1.2.4 Operating Costs--Operating costs are estimated by using a cost per barrel of total fluid (BTF) produced. The water cut versus percent recovery data used in the previous DOE publication (1993) was revised after review of the recent PBU oil and water production data. The revised data are shown in Table A.3 and in graphical form on Figure A.2. No public data were found concerning operating costs for PBU. The operating cost factor used in the previous DOE publication (1993) was $\$ 1.03 / \mathrm{BTF}$ in $1 / 1 / 92$ dollars. That cost factor, $\$ 1.098 / \mathrm{BTF}$ in $1 / 1 / 95$ dollars, is used in PBU evaluations.

A.2.1.2.5 TAPS Tariff-PBU oil sales will be subject to a TAPS tariff as listed in Table B.3 of Appendix B.1.1.1.2.

A.2.1.2.6 Future Producers--The number of future active producing wells is required for annual severance tax calculations. The Set A equations listed in Appendix C.1.1.6 are used to project the decline of future active producing wells for PBU. 
Table A.3. PBU Percent Water Cut and Percent Recovery Data.

\begin{tabular}{||c|c||}
\hline Recovery-\% & Water Cut-\% \\
\hline 0.0 & 0.0 \\
\hline 4.4 & 0.0 \\
\hline 10.7 & 0.9 \\
\hline 16.7 & 2.6 \\
\hline 28.6 & 7.5 \\
\hline 42.8 & 20.0 \\
\hline 52.6 & 33.5 \\
\hline 60.0 & 44.0 \\
\hline 70.0 & 59.0 \\
\hline 80.0 & 70.0 \\
\hline 90.0 & 79.0 \\
\hline 102.0 & 80.0 \\
\hline
\end{tabular}

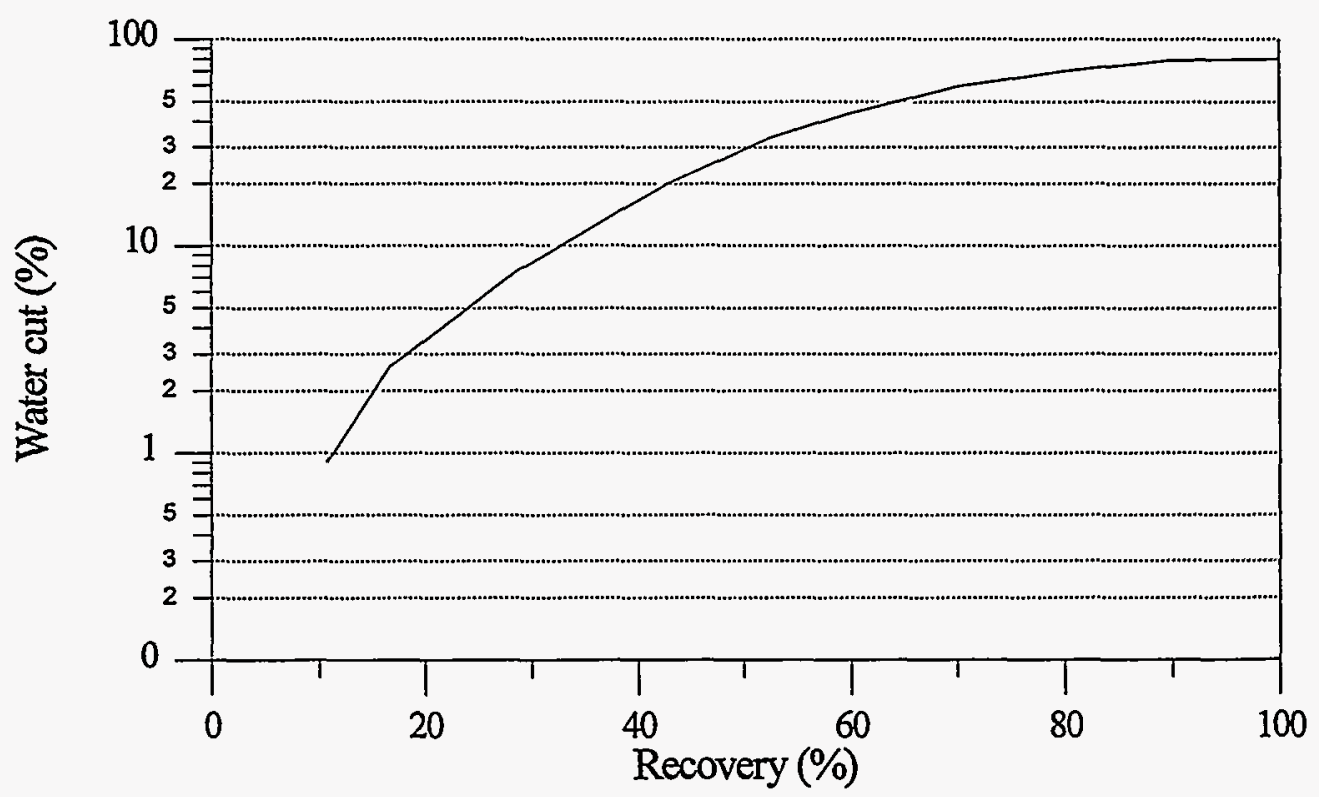

Figure A.2. PBU Permo-Triassic percent water cut versus percent recovery curve.

A.2.1.3 Summary. The PBU Permo-Triassic oil pool, the largest in the United States, has experienced declining production since a peak of about 1.6 MMBO per day during 1987. There are no 
development or production enhancement projects that can arrest the decline in production that had reached about 1.0 MMBO per day in December 1994. The oil pool is still expected to recover more than $50 \%$ of OOIP. The estimate of future recoverable liquids as of $1 / 1 / 95$ is 4,200 MMBBLS (oil, condensate and NGLs) including the sale of NGLs to KRU.

\section{A.2.2 Prudhoe Bay - With Gas Sales to an LNG Project.}

Under major gas sales to an independently owned LNG system there are some changes in the operation of PBU. Oil recovery may be less than that discussed in Appendix A.2.1 due to more rapid reservoir pressure decline; the loss in oil recovery is dependent on the start-up date of major gas sales. ${ }^{a}$ The estimated loss in recovery ranges from 0.9 billion BBL oil with start of gas sales in 2000 to no loss with start-up in 2015. Currently, the earliest anticipated start-up date is 2005 with lost reserves being about 0.4 billion BBL oil. A start-up date of 2005 is used in the evaluation.

A.2.2.1 Input Data - Gas Sales to LNG Project. Based on the start-up of major gas sales in 2005, some of the PBU economic parameters discussed in Appendix A.2.1 require modification, and a gas production forecast and gas pricing determination are needed. Economic parameters that are modified are listed below along with the sections where they are discussed for the no major gas sales scenario.

- $\quad$ Recoverable oil (Appendix A.2.1.2.1)

- $\quad$ Production forecast-oil (Appendix A.2.1.2.2)

- Operating costs (Appendix A.2.1.2.4)

- Investments (Appendix A.2.1.2.3)

- TAPS tariff (Appendix B.1.1.1.2)

A.2.2.1.1 Recoverable Oil--The assumed loss of 0.4 billion BBL oil of PBU oil recovery (oil, condensate, and NGLs) reduces future recovery from about 4.2 billion BBL oil (Appendix A.2.1.2.1) to about 3.8 billion $\mathrm{BBL}$ oil.

A.2.2.1.2 Oil Production Forecast--The loss of oil recovery as a result of major gas sales in 2005 is assumed to commence in 2007 at low volumes and increase over time. The revised production

a. ARCO Alaska, Inc., personal communication, March 7, 1995. 
schedule resulted in a shortening of the oil recovery period by 4 years. The revised PBU oil forecast is given in Table A.4.

Table A.4 PBU production forecast - with major gas sales.

\begin{tabular}{||c|c||c|c|c|c||}
\hline Year & MBPD & Year & MBPD & Year & MBPD \\
\hline 1995 & 940 & 2004 & 446 & 2013 & 180 \\
\hline 1996 & 860 & 2005 & 412 & 2014 & 163 \\
\hline 1997 & 790 & 2006 & 380 & 2015 & 145 \\
\hline 1998 & 720 & 2007 & 340 & 2016 & 128 \\
\hline 1999 & 660 & 2008 & 308 & 2017 & 115 \\
\hline 2000 & 605 & 2009 & 278 & 2018 & 102 \\
\hline 2001 & 563 & 2010 & 250 & 2019 & 95 \\
\hline 2002 & 520 & 2011 & 226 & 2020 & 85 \\
\hline 2003 & 482 & 2012 & 205 & 2021 & 80 \\
\hline
\end{tabular}

A.2.2.1.3 Production Forecast-Gas--Based on available data, the net hydrocarbon gas available for sale is determined as follows:

$$
\begin{array}{ll}
\text { Recoverable gas volume: } \quad \text { Gas Cap, } 30.0 \mathrm{TCF} * 0.80 \mathrm{RF} & =24.0 \mathrm{TCF} \\
\text { Oil Rim, } 16.0 \mathrm{TCF} * 0.60 \mathrm{RF} & =9.6 \mathrm{TCF} \\
\quad \text { Total } & =33.6 \mathrm{TCF} \\
\text { Total lease use, local sales, and shrinkage (estimated) } & =8.8 \mathrm{TCF} \\
\text { Net gas produced (includes } \mathrm{CO}_{2} \text { ) } & =24.8 \mathrm{TCF} \\
\text { Net hydrocarbon gas available for sale (after } \mathrm{CO}_{2} \text { removal) } & =21.8 \mathrm{TCF}
\end{array}
$$

A 2005 start-up of major gas sales is assumed and the rate is ramped up at 20\%/yr over a 5-yr period to a maximum assumed sales rate of 2.05 billion cubic feet per day (BCFPD) in 2009. The gas production forecast to recover the total estimated recoverable gas of 21.8 TCF is given in Table A.5 and has a project life of 32 yrs. It is assumed that PBU will be capable of delivering the forecasted volumes throughout the project life without a falloff in the last few years of production because of the high productivity of PBU wells. It is also assumed that if other sources of gas are available for delivery to the LNG system, those volumes will not reduce the sales from PBU.

A.2.2.1.4 Gas Price--Gas prices paid to PBU are based on a gas product net back share of 
the sale price of LNG in Asian markets. The LNG total project retains enough of the Asian sale price to give the project an assumed 10\% rate of return on investment, as discussed in Section 5.2 and Appendix B.1.3.

Table A.5. PBU gas sales forecast - with $L N G$ project.

\begin{tabular}{||c|c||c|c||c|c||c|c||}
\hline Year & BCFPD & Year & BCFPD & Year & BCFPD & Year & BCFPD \\
\hline \hline 2005 & 0.41 & 2013 & 2.05 & 2021 & 2.05 & 2029 & 2.05 \\
\hline 2006 & 0.82 & 2014 & 2.05 & 2022 & 2.05 & 2030 & 2.05 \\
\hline 2007 & 1.23 & 2015 & 2.05 & 2023 & 2.05 & 2031 & 2.05 \\
\hline 2008 & 1.64 & 2016 & 2.05 & 2024 & 2.05 & 2032 & 2.05 \\
\hline 2009 & 2.05 & 2017 & 2.05 & 2025 & 2.05 & 2033 & 2.05 \\
\hline 2010 & 2.05 & 2018 & 2.05 & 2026 & 2.05 & 2034 & 2.05 \\
\hline 2011 & 2.05 & 2019 & 2.05 & 2027 & 2.05 & 2035 & 2.05 \\
\hline 2012 & 2.05 & 2020 & 2.05 & 2028 & 2.05 & 2036 & 0.28 \\
\hline
\end{tabular}

A.2.2.1.5 Operating Costs--PBU operation, with major gas sales, will go from oil-only sales (except for minor sales of gas to TAPS and for local use) to eventually gas-only sales. To simplify project economic evaluations, operating costs are determined differently for the three phases of operation: (1) oilonly sales, (2) gas and oil sales, and (3) gas-only sales.

During the oil-only phase, PBU operating costs are determined by the method discussed in Appendix A.2.1.2.4.

During the oil and gas phase, operating costs are based on the following:

- The gas operating cost in the first year of gas sales is assumed to be $5 \%$ of the operating cost in the last year of oil-only sales.

- The gas operating cost determined for the first year of gas sales is used in subsequent years of oil and gas sales after applying a $2.5 \%$ per year escalation. This escalation is to account for the relative increase in gas production that occurs as the oil rate declines.

- The total operating cost for PBU continues to be determined by the method discussed in 
Appendix A.2.1.2.4, until oil sales cease.

- The oil operating cost is the difference between total operating cost and the gas operating cost.

When oil sales cease to be economical, gas operations are assumed to pay all PBU operating costs. PBU operating costs are assumed to be less during gas-only operations than during both oil and gas sales. It is recognized that certain fixed costs will be incurred even though the very large oil operations are shut down. This operating cost is assumed to be $50 \%$ of the oil-only operating cost during the last year of oil and gas operations. The total operating cost for the first year of gas-only operations is the sum of the assumed fixed cost and the gas operating cost as determined above. The determination of future PBU operating costs are shown schematically in Figure A.3.

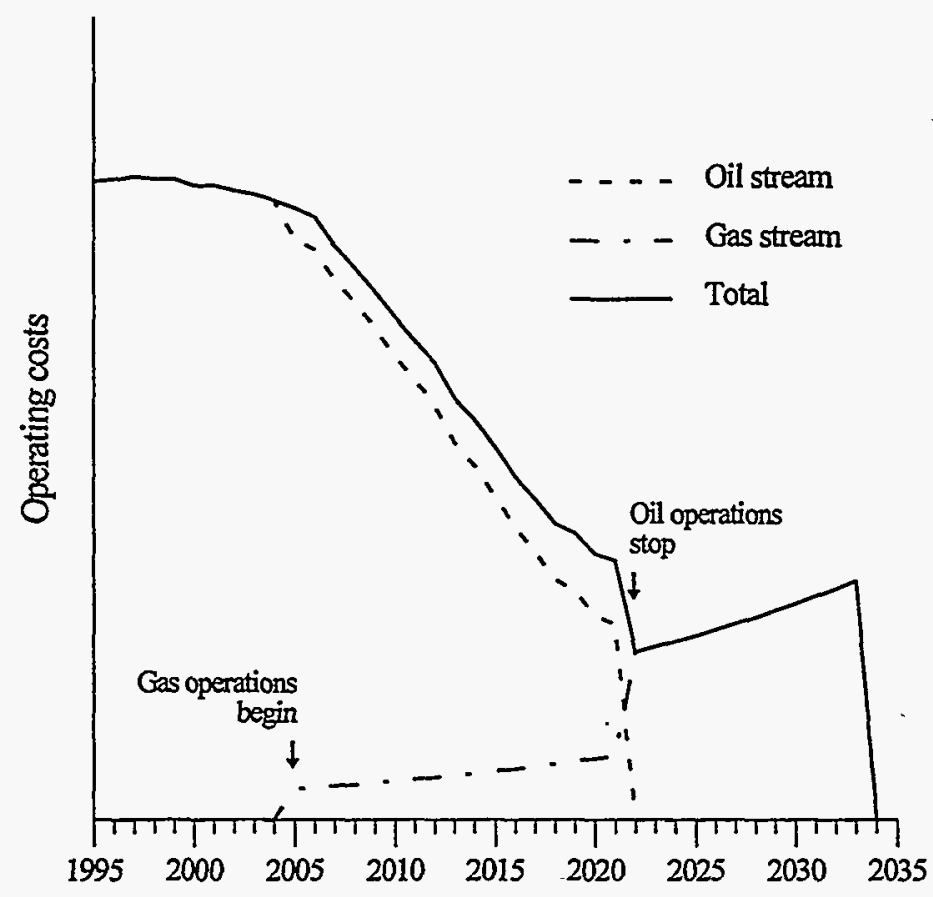

Figure A.3. Curve illustrating the determination of future PBU operating costs.

A.2.2.1.6 Investments-As a result of the facilities in place to handle the 7.5 BCFPD of gas being recycled (e.g., gas conditioning, compression, wells, and lines), it is assumed that no additional investments are required at $\mathrm{PBU}$ for major gas sales.

A.2.2.1.7 TAPS Tariff-A revised TAPS tariff is determined for 2005 and subsequent years 
using the revised PBU oil production schedule given in Table A.4. TAPS tariff calculation is discussed in Appendix B.1.1.1.2.

A.2.2.2. Summary. Results of the economics evaluation of the LNG scenario are summarized in Section 5.2.

\section{A.2.3 Prudhoe Bay Unit - With Gas Sales to a GTL Project}

Under major gas sales for conversion of natural gas to liquid hydrocarbons, it is assumed that gas is sold to an independently owned conversion plant. Although GTL technology is not economically proven at the scale required for effective North Slope operations (see Section 3), it is assumed for comparative economics that initial start-up of a gas-to-liquid conversion plant occurs in 2005.

As discussed in Appendix A.2.2 for the LNG project, reduced oil recovery of 0.4 billion BBL oil will also occur in this operating scenario. The produced gas forecast developed in Appendix A.2.2 is used in this evaluation.

A.2.3.1 Input Data - Gas Sales to GTL Plant. All economic parameters discussed in Appendix A.2.2 for major gas sales are adopted except for gas prices and TAPS tariffs. These two parameters are discussed below.

A.2.3.1.1 Gas Price-GTL Plant--Gas prices paid to PBU are a gas product net back share of the liquid sales value that would result in a $10 \%$ rate of return on investment for the GTL plant owners. The gas product net back share is related to gas volumes on a BTU basis. Details of this method are in Appendix B.1.3.2.

A.2.3.1.2 TAPS Tariff--A revised TAPS tariff is determined for 2005 and later years using the revised PBU oil production forecast (Table A.4) and the volumes of converted hydrocarbon liquids given in Table B.12 from PBU and PTU gas sales. The TAPS tariff calculation is discussed in Appendix B.1.1.1.2.

A.2.3.2 Summary. Details of the economics of the GTL scenario are summarized in Section 5. Results shown in Table A.6 compare PBU operations under the three scenarios. As a result of reduced 
effectiveness of field recovery systems with the removal of large volumes of gas from the reservoir, both gas sales scenarios reduce oil recovery by 400 million barrels from the case without major gas sales.

Table A.6. Prudhoe Bay Unit economics - summary (1995\$).

\begin{tabular}{|c|c|c|c|}
\hline \multirow[b]{2}{*}{ Economic Factor } & \multicolumn{3}{|c|}{ PBU Cases (AE095 Reference Oil Price) } \\
\hline & $\begin{array}{l}\text { No Major } \\
\text { Gas Sales }\end{array}$ & LNG Sales & GTL Sales \\
\hline $\begin{array}{l}\text { Remaining Oil Project Life (1995 - } 2025 \text { or 2021) } \\
\text { Gas Project Life (2005 - 2036) }\end{array}$ & $\begin{array}{r}31 \\
0\end{array}$ & $\begin{array}{l}27 \\
32\end{array}$ & $\begin{array}{l}27 \\
32\end{array}$ \\
\hline $\begin{array}{l}\text { Remaining Oil Reserves - billion BBL } \\
\text { Gas Reserves } \quad \text { - TCF (Sales) }\end{array}$ & $\begin{array}{l}4.2 \\
0\end{array}$ & $\begin{array}{r}3.8 \\
21.8\end{array}$ & $\begin{array}{r}3.8 \\
21.8\end{array}$ \\
\hline $\begin{array}{l}\text { Investments for oil production ( } \$ \text {, millions) } \\
\text { Investments for gas production ( } \$ \text {, millions) }\end{array}$ & $\begin{array}{r}1,790 \\
0\end{array}$ & $\begin{array}{r}1,790 \\
0\end{array}$ & $\begin{array}{r}1,790 \\
0\end{array}$ \\
\hline Gas Product Net Back (\%) & - & 28.1 & 15.1 \\
\hline $\begin{array}{l}\text { Revenue From Oil Sales (\$, millions) } \\
\text { Maximum Revenue From Gas Sales (\$, millions) } \\
\text { Total Oil and Gas Sales Revenue (\$, millions) }\end{array}$ & $\begin{array}{r}56,100 \\
56,100\end{array}$ & $\begin{array}{l}48,800 \\
31,500 \\
80,300\end{array}$ & $\begin{array}{l}51,300 \\
21,700 \\
73,000\end{array}$ \\
\hline After-Tax Cash Flow (\$, millions) & 17,600 & 31,500 & 27,400 \\
\hline Discounted Cash Flow - $\mathrm{NPV}_{10}(\$$, millions $)$ & 8,600 & 11,100 & 10,400 \\
\hline Incremental $\mathrm{NPV}_{10}(\$$, millions $)$ & 0 & 2,500 & 1,800 \\
\hline
\end{tabular}

\section{A.2.4 Kuparuk River Unit}

The Kuparuk River field is located west of and adjacent to PBU. It was discovered by Sinclair and BP in 1969 in the Ugnu State No. 1 well. The Kuparuk River Unit was formed in 1981 with ARCO as unit operator. The unit covers about 200 square miles. The KRU and the Kuparuk Participating Area (KPA) are shown on Figure A.4. KPA production began in December 1981 from two members of the Kuparuk River formation of Lower Cretaceous Age.

$\mathrm{ARCO}$ and $\mathrm{BP}$ hold major interests in the unit along with minor interest owners Amoco, Chevron, Exxon, Mobil, and Unocal. All leases carry a $12.5 \%$ royalty and five leases along the northern border also carry a net profit interest. 


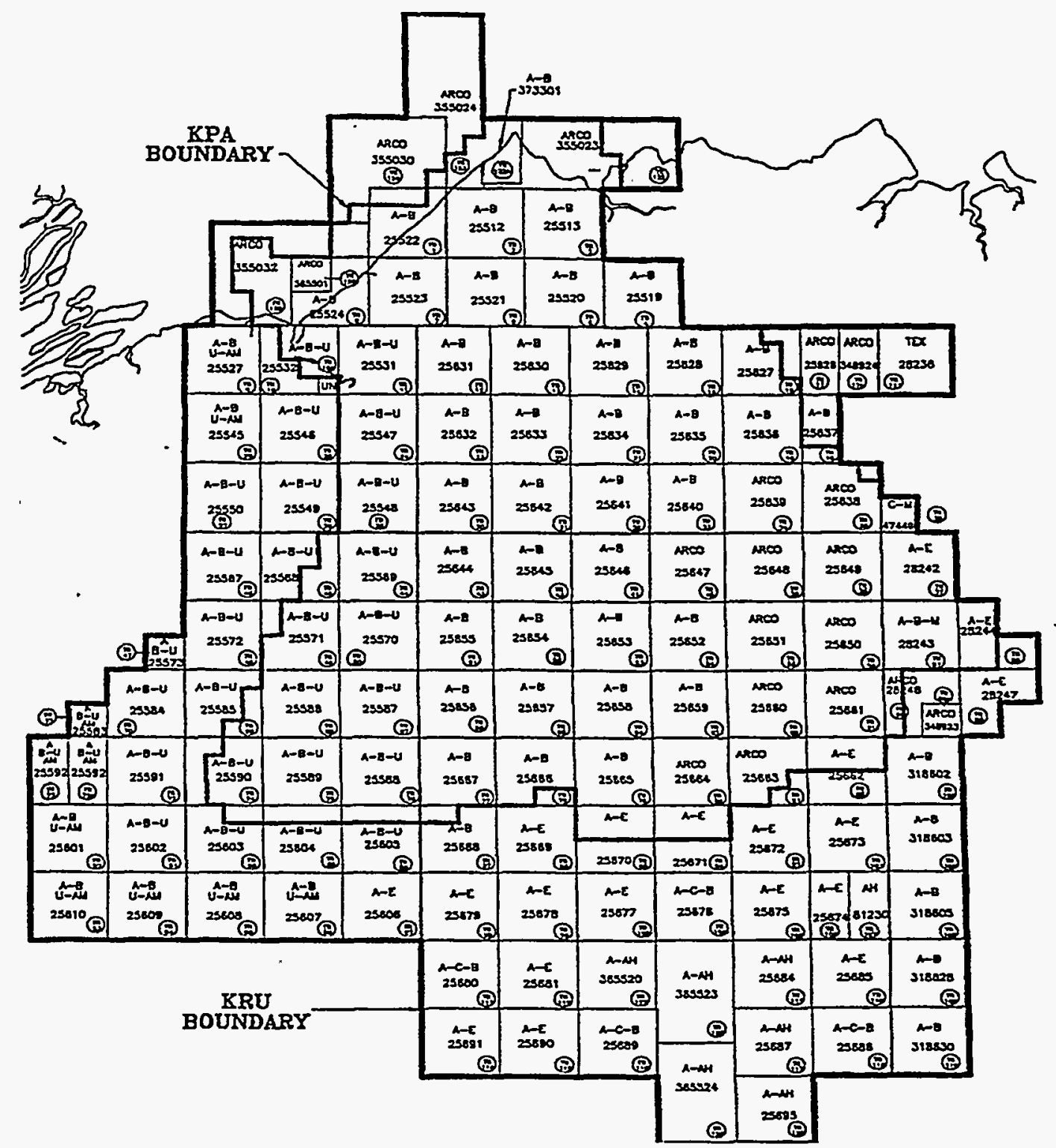

Figure A.4 KRU and KPA outline. ${ }^{\mathrm{a}}$

a. Alaska Department of Natural Resources, personal communication, December 1992.

Production from KPA during 1994 averaged $306 \mathrm{MBPD}$ (including oil and NGL) with 1,185 MMBO cumulative production as of $1 / 1 / 95$ (AOGCC, 1994c). Remaining recovery from KPA as of $1 / 1 / 95$ is estimated to be 1,131 MMBO for an ultimate recovery of 2,316 MMBO. In addition, it is estimated that 33 MMBBLS of injected offsite NGL (used as enriched gas injectant) will be recovered. 
A.2.4.1 Development Plans. According to the 1994 Update to the Unit Plan of Development (POD) for the Kuparuk River Unit (ADNR 1994m), future development drilling will continue to focus on peripheral and infill drilling. Future development drilling opportunities include expansions to the periphery of approximately 12 existing drill sites, development of 2 new drill sites, and selective 80 -acre infill drilling at most drill sites. Expansion of immiscible water-alternating-gas from 15 drill sites to 20 drill sites during the next 2 years is planned. Conceptual plans include a large scale enriched gas injection (LSMI) project at 10 to 15 existing drill sites.

Based on the discouraging results of delineation drilling in the southern and southeastern portions of the field, no additional development is planned for these areas at this time.

No major central facility expansions are planned beyond those related to the enhanced oil recovery process.

Portions of KRU contain shallow, oil-bearing reservoirs. Three of these (Colville, West Sak, and Ugnu) have been the object of evaluation to determine their commercial potential. Colville and West Sak have greater near-term development potential than Ugnu, which has potential only in the long-term.

A.2.4.2 Input Data. Evaluation input data are developed using history, current development plans, published information, and personal communications.

A.2.4.2.1 Recoverable Oil--Ultimate KPA recovery was listed as 2,130 MMBO in the previous DOE publication (1993). This estimate did not include any incremental recovery from the LSMI project discussed in Appendix A.2.4.1. It is assumed that the LSMI project will be approved (PIC, 1994a) and is included in this analysis. The revised production forecast results in a remaining recovery of $971 \mathrm{MMBO}$ (herein referred to as the KPA production forecast, meaning that it excludes LSMI production) and $160 \mathrm{MMBO}$ of LSMI production for a total remaining recovery of 1,131 MMBO and an ultimate recovery of 2,316 MMBO. In addition, it is estimated that $33 \mathrm{MMBBLS}$ of the injected offsite NGLs used in the LSMI project is recovered along with the KPA production.

A.2.4.2.2 Production Forecast--Actual KPA production for 1992, 1993, and 1994 (AOGCC, 1992a; AOGCC, 1993j; AOGCC, 1994c) was greater than forecasted in the previous DOE publication (1993). However, the actual 1992, 1993, and 1994 annual average production results in a decline 
that ties in well to the previous DOE publication (1993) KRU forecast starting at 1/1/95. With the exception of the LSMI project, no significant new information is available to indicate or to justify revision of the previous forecast beyond 1995. Therefore, the production forecast from the previous DOE publication (1993) is used in this analysis for 1995 and later years for KPA production (excluding LSMI). For the KPA production forecast, the 1994 annual average production rate of $306 \mathrm{MBPD}$ is declined at $2 \%$ through 1997 , 11\% from 1998 through 2003, and 17\% thereafter. This forecast, Table A.7, results in remaining recoverable oil of $971 \mathrm{MMBO}$ as of 1/1/95.

A separate incremental forecast is developed for the LSMI project using the following assumptions:

- LSMI injection is initiated in 1996 and injected at a constant rate over 10 years.

- 4 billion BBL oil OOIP.

- $4 \%$ of OOIP recovered by LSMI ( $2 \%$ to $5 \%$ recovery is typical for recovery processes of this type).

- One-third of the injected offsite NGL is recovered and sold along with KRU oil production.

- 20 year production life with production response starting in 1997.

- The purchase cost of offsite NGL used in the previous DOE (1993) publication of $\$ 1$ billion (1992\$), escalated to $\$ 1.066$ billion (1995\$) is adopted for this publication and allocated on a barrel of injected offsite NGL basis.

- NGL purchase price is about $70 \%$ of the TAPS PS No. 1 price for PBU crude oil, resulting in 100 MMBBLS of offsite NGL purchased for the project.

The LSMI oil production forecast is developed by starting the production in 1997, ramping-up to 1998 , and then declined at $17 \%$ per year to recover $160 \mathrm{MMBO}$ ( $4 \%$ of OOIP) over 20 years. The LSMI NGL production forecast is developed by ramping-up NGL production for 5 years starting in 1997, then declined at $15 \%$ per year to recover 33 MMBBLS of NGL over 20 years. The LSMI oil and NGL production forecasts are combined into a single LSMI production forecast (Table A.7) and results in remaining recovery of $193 \mathrm{MMBO}$. The KPA forecast and the LSMI forecast (which includes LSMI NGL production) are combined into the single Total KPA production forecast shown in Table A.7.

A.2.4.2.3 Investments--According to information contained in the 1994 POD (ADNR, $1994 \mathrm{~m}$ ), the scope of future development has been reduced from that considered for the previous DOE publication (1993). Development drilling, facility (new drill sites), and facility capacity expansion plans have each been reduced in scope. It is assumed that LSMI project investment will be minimal. 
Table A.7. KPA production forecast.

\begin{tabular}{|c|c|c|c|}
\hline Year & $\begin{array}{c}\mathrm{KPA} \\
\text { (MBPD) }\end{array}$ & $\begin{array}{c}\text { LSMI } \\
\text { (MBPD) }\end{array}$ & $\begin{array}{c}\text { TOTAL KPA } \\
\text { (MBPD) }\end{array}$ \\
\hline 1995 & 299 & 0 & 299 \\
\hline 1996 & 292 & 0 & 292 \\
\hline 1997 & 285 & 47 & 332 \\
\hline 1998 & 260 & 72 & 332 \\
\hline 1999 & 235 & 63 & 298 \\
\hline 2000 & 210 & 57 & 267 \\
\hline 2001 & 185 & 50 & 235 \\
\hline 2002 & 165 & 42 & 207 \\
\hline 2003 & 145 & 35 & 180 \\
\hline 2004 & 125 & 30 & 155 \\
\hline 2005 & 105 & 25 & 130 \\
\hline 2006 & 85 & 21 & 106 \\
\hline 2007 & 71 & 17 & 88 \\
\hline 2008 & 57 & 15 & 72 \\
\hline 2009 & 43 & 12 & 55 \\
\hline 2010 & 30 & 10 & 40 \\
\hline 2011 & 18 & 8 & 26 \\
\hline 2012 & 14 & 7 & 21 \\
\hline 2013 & 12 & 6 & 18 \\
\hline 2014 & 10 & 4 & 14 \\
\hline 2015 & 8 & 4 & 12 \\
\hline 2016 & 7 & 3 & 10 \\
\hline
\end{tabular}

The number of future wells to be drilled during 1995 through 1997 is reduced from 154 wells in the previous DOE publication (1993) to 116 for this analysis. The $\$ 2.2 \mathrm{MM} /$ well (1992\$) estimate used in the previous DOE publication (1993), escalated to $\$ 2.3 \mathrm{MM} /$ well (1995\$), is used in this analysis. 
Facility costs are reduced by three southern and southeastern drill sites and by the facility capacity expansions considered in the previous DOE publication (1993). Facility expansion costs are reduced 50\% after backing out one new drill site per year. The drill site cost of $\$ 8 \mathrm{MM} / \mathrm{drill}$ site (1992\$) from the previous DOE (1993) publication is used in this analysis. The facility costs used in the previous DOE publication (1993) are reduced by an additional $\$ 20.4$ million $(1992 \$)$ for this analysis. Drilling and facility investment schedules are shown in Table A.8.

Table A.8. KPA drilling and investment schedule

\begin{tabular}{||c|c|c|c|c||}
\hline \multirow{2}{*}{ Year } & \multirow{2}{*}{$\begin{array}{c}\text { Drilling } \\
\text { No. Wells }\end{array}$} & \multicolumn{3}{|c|}{ Investment - 1995\$, millions } \\
\cline { 3 - 5 } & & \multicolumn{1}{|c|}{ Wells } & Facilities & Total \\
\hline \hline 1995 & 40 & 92.0 & 116.2 & 208.2 \\
\hline 1996 & 40 & 92.0 & 116.2 & 208.2 \\
\hline 1997 & 36 & 82.8 & 74.2 & 157.0 \\
\hline 1998 & 0 & 0 & 21.7 & 21.7 \\
\hline 1999 & 0 & 0 & 21.7 & 21.7 \\
\hline 2000 & 0 & 0 & 21.7 & 21.7 \\
\hline Total & 116 & 266.8 & 371.7 & 638.5 \\
\hline
\end{tabular}

A.2.4.2.4 Operating Costs--In the previous DOE publication (1993), operating costs were determined using a cost per BTF. Total fluid production was based on a relationship between water cut and percent of ultimate recovery using past production history. Current water cut versus cumulative recovery is reasonably close to the predicted relationship used in the previous DOE publication (1993); therefore, that relationship is adopted for this analysis (Figure A.5).

The cost per BTF used in the previous DOE publication (1993) of \$1.27/BTF (1992\$), adjusted for inflation to $\$ 1.35 / \mathrm{BTF}(1995 \$$ ), is used to calculate operating cost in this analysis.

The MI costs to KPA for expansion of the WAG project at KPA from the previous DOE publication (1993) of $\$ 1$ billion (ARCO 1991a), escalated to $\$ 1.066$ billion (1995\$) allocated on a barrel of injected offsite NGL basis, is added to the operating cost in this publication as the offsite NGL costs to KPA for the LSMI project. 


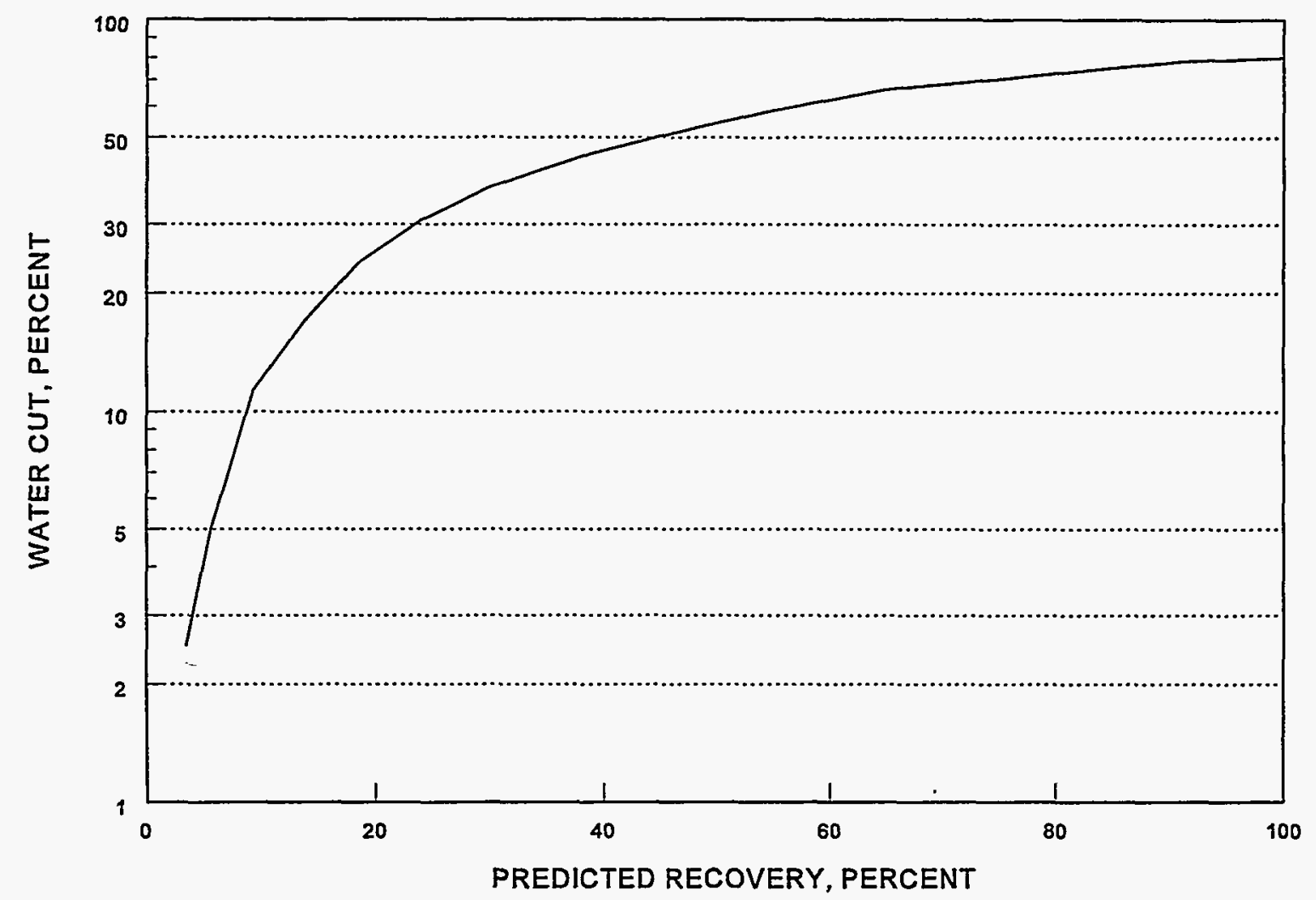

Figure A.5. KRU water cut versus cumulative production as percent of ultimate production.

A.2.4.2.5 Kuparuk Pipeline Tariff--The pipeline tariff listed in the previous DOE publication (1993) of \$0.19/BBL (1995\$) is used in this analysis (see Appendix B.1.1.1.4).

A.2.4.2.6 Future Producing Wells--The number of future active producing wells, required for annual severance tax calculations from the Set B equations in Appendix C.1.1.6 is used for this analysis.

A.2.4.3 Summary. The KRU Kuparuk field began production in 1981. As of June 1994, 754 wells were active in the KPA. There were 42 developed drill sites; including 22 drill sites under waterflood, 15 drill sites under immiscible WAG, and three drill sites under LMSI. It is assumed that a large scale enriched gas injection project will be approved and that the project will be started in early 1996. Annual average production for 1994 was $306 \mathrm{MBPD}$. Cumulative production through 1/1/95 was 1,185 MMBO. Remaining recovery as of $1 / 1 / 95$ is estimated to be $1,131 \mathrm{MMBO}$, including $160 \mathrm{MMBO}$ of incremental LSMI production, for an ultimate recovery of $2,316 \mathrm{MMBO}$. In addition it is estimated that $33 \mathrm{MMBBLS}$ of the 
injected offsite NGL as part of the LSMI project will be recovered along with KPA production, for a total remaining recovery of $1,164 \mathrm{MMBBLS}$.

Analysis using the four price forecasts listed in Table B.1, Appendix B.1.1 show that all of the forecasted liquids can be economically recovered using the EIA reference and high oil price forecasts. About $340 \mathrm{MMBO}$ of forecasted recovery is lost under the low price case scenario. The evaluation results are given in Table A.9. About 50 MMBBLS is lost using the flat oil price.

Table A.9. KPA economics.

\begin{tabular}{|c|c|c|c|c|}
\hline \multirow{2}{*}{ Economic Factor } & \multicolumn{4}{|c|}{ Oil Price Forecasts } \\
\hline & $\begin{array}{l}\text { AEO95 } \\
\text { Low }\end{array}$ & $\begin{array}{c}\text { AE095 } \\
\text { Reference }\end{array}$ & $\begin{array}{c}\text { AEO95 } \\
\text { High }\end{array}$ & $\begin{array}{l}\text { Flat Oil Price } \\
\text { S18/BBL }\end{array}$ \\
\hline Remaining Project Life - yrs & 8 & 22 & 22 & 15 \\
\hline $\begin{array}{r}\text { Remaining Reserves - MMBBLS }{ }^{\mathrm{a}} \\
- \text { TCF (Sales) }\end{array}$ & $\begin{array}{c}825 \\
0\end{array}$ & $\begin{array}{c}1,164 \\
0\end{array}$ & $\begin{array}{c}1,164 \\
0\end{array}$ & $\begin{array}{c}1,113 \\
0\end{array}$ \\
\hline Investments - as spent ( $\$$, millions) & 663 & 663 & 663 & 663 \\
\hline Operating Costs - as spent ( $\$$, millions) & 3,615 & 6,811 & 7,009 & 6,126 \\
\hline Cash Flow - NPV 10 (1995\$, millions) & 432 & 2,347 & 3,150 & 1,732 \\
\hline
\end{tabular}

\section{A.2.5 Duck Island Unit}

The Endicott reservoir, the productive zone of the Endicott Participating Area (Endicott) of the Duck Island Unit (DIU) (Figure A.6), was discovered in 1978 by the Sohio (BP) Sag Delta No. 4 well. The field is located 10 miles east of the Prudhoe Bay Unit in offshore waters of the Beaufort Sea off the Sagavanirktok River delta in water depths ranging from 2 to 14 feet and was the world's first arctic offshore commercial oil field. Production is from the Kekiktuk formation of Mississippian age and was initiated in October 1987 from two man-made gravel islands connected to the mainland by a breached causeway.

During 1989, BP Exploration tested the Sag Delta No. 9 well to evaluate the development potential of the Sag Delta North accumulation in a separate fault block north of the Endicott Kekiktuk reservoir. The well was originally drilled as a wildcat well from Endeavor Island, a gravel-filled drilling island connected 
by a bridge to the main Endicott production island. In 1991, BP Exploration applied to the State of Alaska

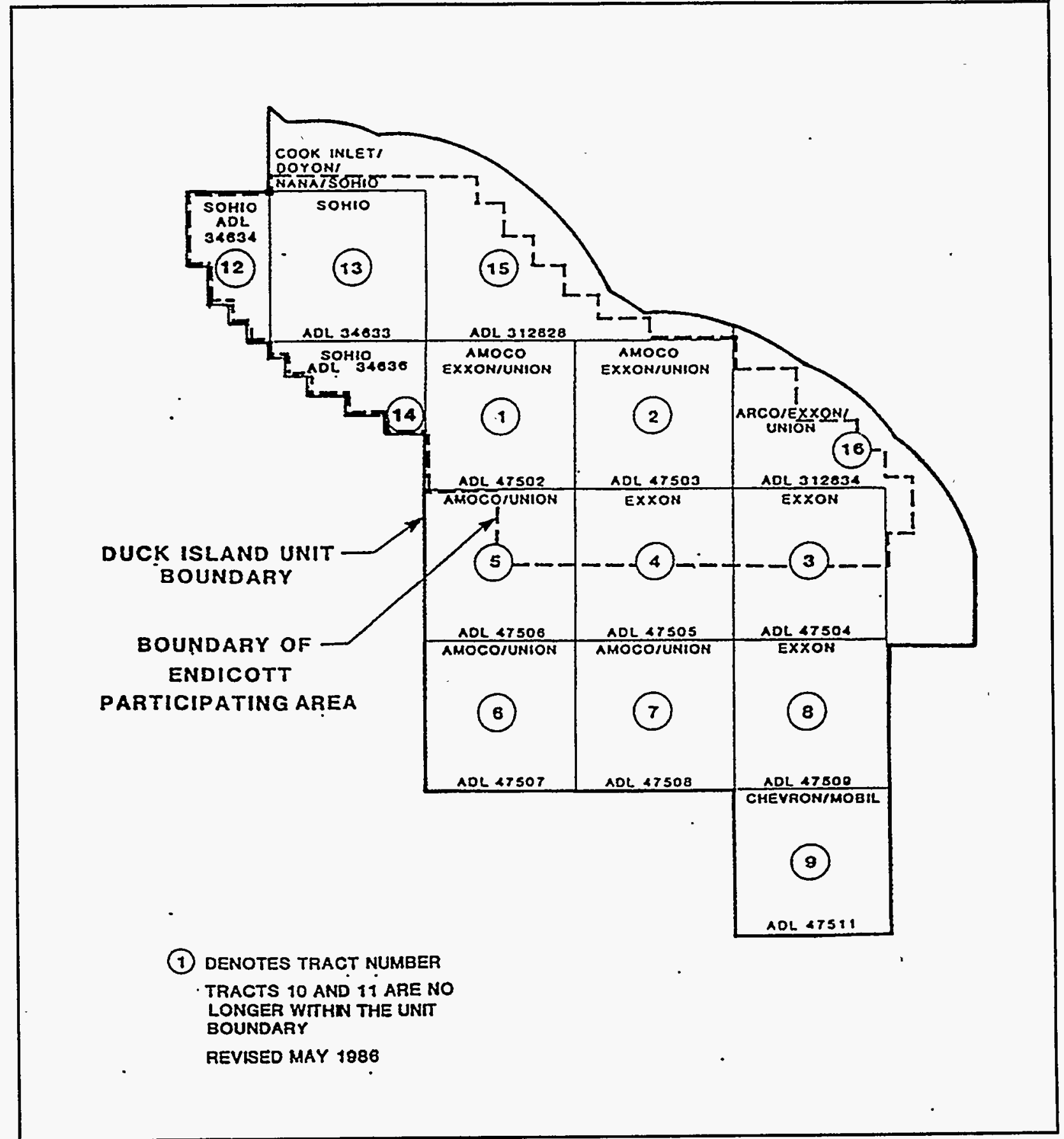

Figure A.6. Endicott Participating Area of the Duck Island Unit (AOGCC 1986).

for the formation of the Sag Delta North Participating Area (SDNPA) as a new participating area of the DIU (Figure A.7) to develop and produce the Alapah (Mississippian carbonate) and the Ivishak (Permo-Triassic sandstone) reservoirs. SDNPA production is commingled downhole with production from the Ivishak and Alapah reservoirs and produced through the Endicott production facilities. 


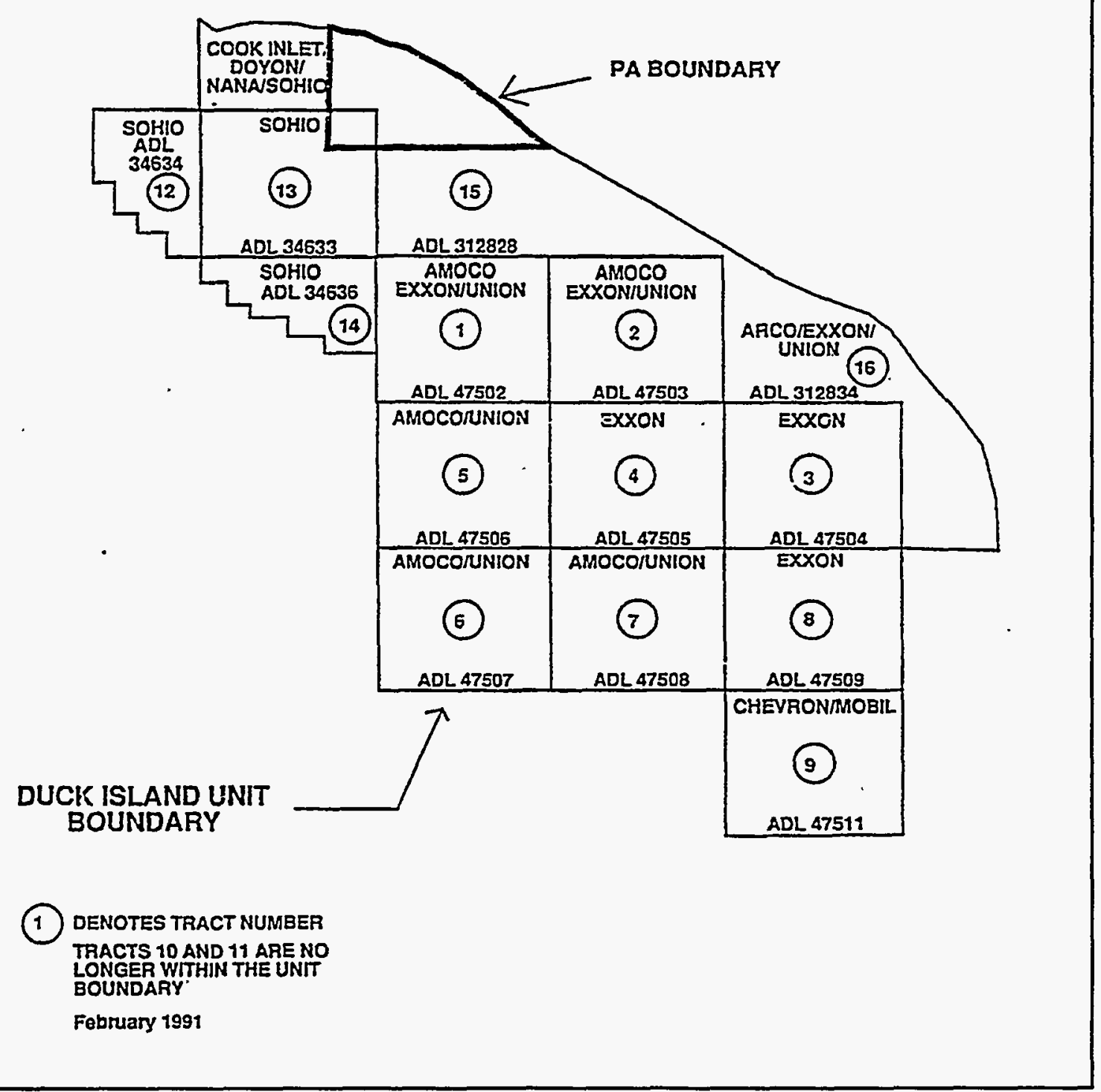

Figure A.7. Sag Delta North Participating Area (AOGCC 1991a).

Production from the Endicott pool during 1994 averaged 97 MBPD (including oil and NGL) with 278 MMBO cumulative production as of $1 / 1 / 95$ (AOGCC, 1994c). Remaining recovery from the Endicott pool as of $1 / 1 / 95$ is estimated to be $194 \mathrm{MMBO}$ for an ultimate recovery of $472 \mathrm{MMBO}$.

Production from the SDNPA Ivishak pool during 1994 averaged 1.019 MBPD (including oil and NGL) with 6.5 MMBO cumulative production as of $1 / 1 / 95$ (AOGCC, 1994c). Remaining recovery from the SDNPA Ivishak pool as of $1 / 1 / 95$ is estimated to be $0.4 \mathrm{MMBO}$ for an ultimate recovery of $6.9 \mathrm{MMBO}$. 
The combined production from the Endicott pool and SDNPA during 1994 averaged 98 MBPD (including oil and NGLs) with a combined cumulative recovery of $284.5 \mathrm{MMBO}$ as of $1 / 1 / 95$. The combined remaining recovery from Endicott and SDNPA as of 1/1/95 is estimated to be 194.4 MMBO for a combined ultimate recovery of 478.9 MMBO.

A.2.5.1 Development Plans. According to the Endicott Reservoir Plan of Development (ADNR, 1995a) and the Sag Delta North Plan of Development (ADNR, 1995b) the development plans for Endicott and SDNPA, from the previous DOE publication (1993) are still valid and thus remain unchanged.

A.2.5.2 Input Data. Input data are developed using history, current development plans, published information, and personal communications.

A.2.5.2.1 Recoverable Oil--Ultimate recovery for the Endicott pool of 416 MMBO was used in the previous DOE publication (1993). That estimate was based on forecasted 1994 average annual production of 71.9 MBPD whereas production actually averaged 97 MBPD for 1994. Assuming an annual decline of $15 \%$ from 1994 production, the remaining recovery at 1/1/95 from the Endicott pool is now estimated to be $194 \mathrm{MMBO}$ for the ultimate recovery of $472 \mathrm{MMBO}$ adopted for this analysis. Additional production history is needed before further revision should be considered.

No additional development has occurred in SDNPA since the previous DOE publication (1993) and the water cut has increased to $89 \%$. Assuming an annual decline rate of $40 \%$ from 1994 production, the remaining recovery at 1/1/95 from SDNPA is now estimated to be $0.4 \mathrm{MMBO}$ for the ultimate recovery of 6.9 MMBO. Production history is limited and this ultimate recovery value is slightly lower than the previous DOE publication (1993) estimate. Actual production for 1992, 1993, and 1994 has been lower than the previous forecast. The revised ultimate recovery of 6.9 MMBO is adopted for this analysis.

The combined remaining recovery from the Endicott pool and SDNPA is now estimated to be 194.4 MMBO for the combined ultimate recovery of 478.9 MMBO.

A.2.5.2.2 Production Forecast--The Endicott and the Sag Delta North production forecasts have been combined for the total DIU production forecast used for the economic evaluations in this analysis as shown in Table A.10. The Endicott production forecast was developed using a $15 \%$ annual decline rate from the 1994 average annual production rate of 97 MBPD for 1995 and later years. The Sag Delta North 
production forecast was developed using a $40 \%$ annual decline rate, consistent with the previous DOE publication (1993), from the 1994 average production rate of 1.019 MBPD for 1995 and later years.

Table A.10. Endicott and Sag Delta North production forecast (MBPD).

\begin{tabular}{|c|c|c|c|}
\hline Year & Endicott & Sag Delta North & Total DIU \\
\hline 1995 & 82.4 & 0.6 & 83.0 \\
\hline 1996 & 70.1 & 0.4 & 70.5 \\
\hline 1997 & 59.6 & 0.2 & 59.8 \\
\hline 1998 & 50.6 & 0.0 & 50.6 \\
\hline 1999 & 43.0 & 0.0 & 43.0 \\
\hline 2000 & 36.6 & 0.0 & 36.6 \\
\hline 2001 & 31.1 & 0.0 & 31.1 \\
\hline 2002 & 26.4 & 0.0 & 26.4 \\
\hline 2003 & 22.5 & 0.0 & 22.5 \\
\hline 2004 & 19.1 & 0.0 & 19.1 \\
\hline 2005 & 16.2 & 0.0 & 16.2 \\
\hline 2006 & 13.8 & 0.0 & 13.8 \\
\hline 2007 & 11.7 & 0.0 & 11.7 \\
\hline 2008 & 10.0 & 0.0 & 10.0 \\
\hline 2009 & 8.5 & 0.0 & 8.5 \\
\hline 2010 & 7.2 & 0.0 & 7.2 \\
\hline 2011 & 6.1 & 0.0 & 6.1 \\
\hline 2012 & 5.2 & 0.0 & 5.2 \\
\hline 2013 & 4.4 & 0.0 & 4.4 \\
\hline 2014 & 3.8 & 0.0 & 3.8 \\
\hline 2015 & 3.2 & 0.0 & 3.2 \\
\hline
\end{tabular}

A.2.5.2.3 Investments-With the completion of the Endicott Causeway Breach Project in 1994, the majority of investments have been made. Future investment, adjusted for inflation, is assumed to remain unchanged from the investment schedule set forth in the previous DOE publication (1993), using the techniques set forth in that publication.

The investment schedule (Table A.11) for this analysis has been developed using the following assumptions: 
- $\quad$ Endicott well costs are $\$ 3.2$ million (1995\$) per well.

- $\quad$ Two wells per year will be drilled during 1995 and 1996.

- Facility investments are $\$ 5.4$ million (1995\$) per year.

- $\quad$ Facility investments will be made during 1995 and 1996.

Table A.11. Endicott drilling and investment schedule.

\begin{tabular}{||c|c|c|c|c||}
\hline \multirow{2}{*}{ Year } & \multirow{2}{*}{$\begin{array}{c}\text { Drilling } \\
\text { No. Wells }\end{array}$} & \multicolumn{3}{|c|}{ Investment - \$, millions (1995\$) } \\
\cline { 3 - 5 } & & Wells & Facilities & Total \\
\hline 1995 & 2 & 6.5 & 5.4 & 11.9 \\
\hline 1996 & 2 & 6.5 & 5.4 & 11.9 \\
\hline Total & 4 & 13.0 & 10.8 & 23.8 \\
\hline
\end{tabular}

A.2.5.2.4 Operating Costs--Operating costs are based on a cost factor per BTF using a water cut versus percent cumulative recovery relationship to forecast total produced fluid. The cost per barrel factor, adjusted for inflation, from the previous DOE publication (1993) is used for this analysis.

The cost per barrel factor used in the previous DOE publication (1993) was $\$ 1.50 / B T F(1992 \$)$. Adjusted for inflation, the operating cost factor is $\$ 1.60 / \mathrm{BTF}$ (1995\$), and is used in this analysis.

Production performance during 1994 indicates the water cut versus percent cumulative recovery is consistent with the relationship developed in the previous DOE publication (1993) (Figure A.8). That relationship is used in this analysis.

A.2.5.2.5 Pipeline Tariff--Endicott liquids (including Sag Delta North liquids) are delivered to TAPS PS No. 1 through a separate 26-mile common carrier pipeline. The pipeline tariff calculated for the DIU from the previous DOE publication (1993) was $\$ 0.76 / \mathrm{BBL}(1992 \$)$. A new pipeline tariff, adjusted for increased volumes, is \$0.68/BBL (1995\$) (see Appendix B.1.1.1.4) and is used in this analysis.

A.2.5.2.6 Future Producers--The number of future active producing wells is determined using the Set B equations of Appendix C.1.1.6. 


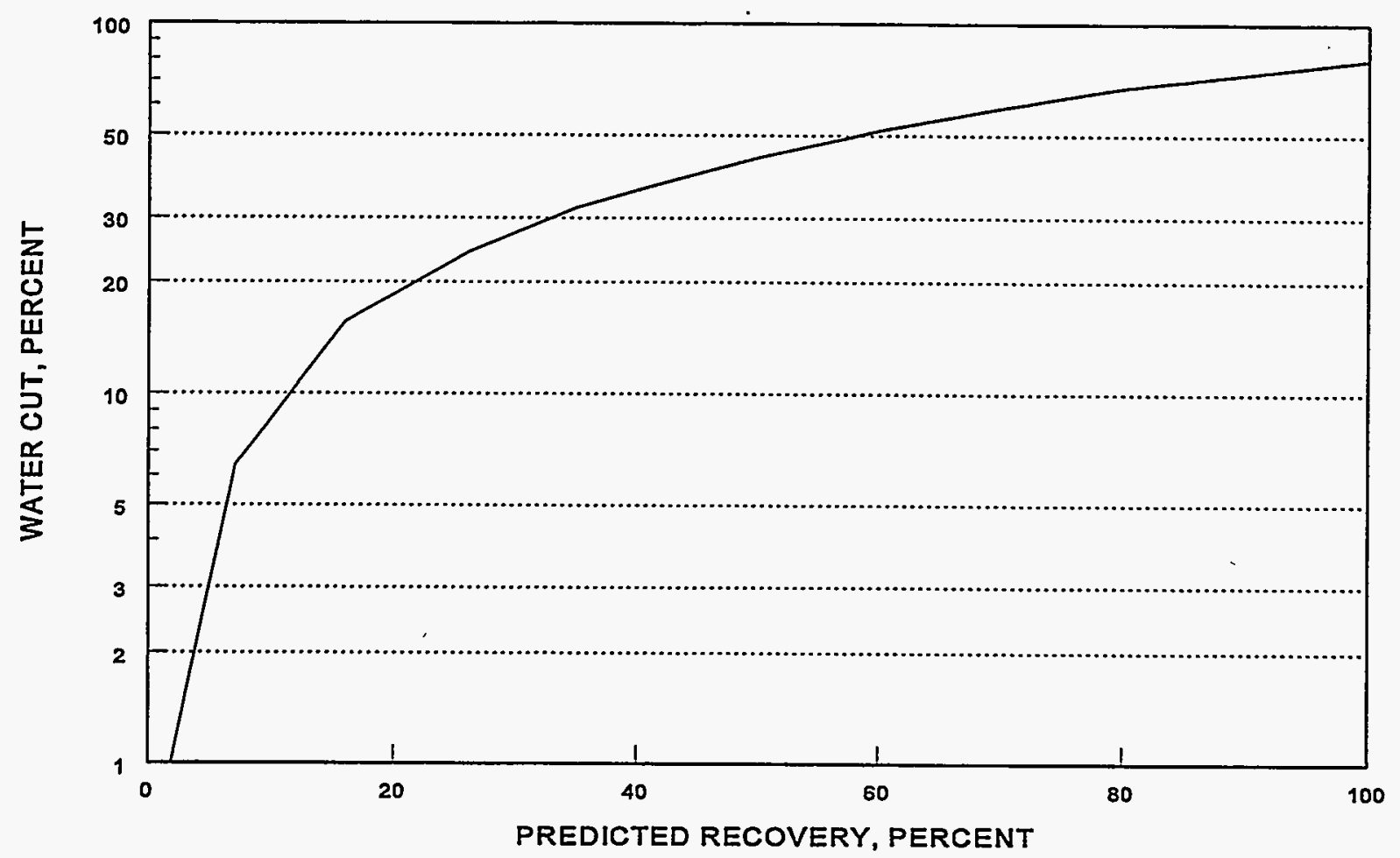

Figure A.8. Endicott formation - percent water cut versus percent recovery.

A 2.5.2.7 Net Profits Interest--Two leases in the DIU have net profits interests (NPI) in addition to a $20 \%$ royalty, the remaining eight leases have a $12.5 \%$ royalty only. The estimated NPI share used in the previous DOE publication (1993) to reflect the State of Alaska and industry share of revenue is adopted for this analysis. The NPI share is estimated to be $14 \%$ (ADNR, 1995c) of income before federal income tax. That percentage factor, for simplicity, is used over the remaining project life for this analysis.

A.2.5.3 Summary. Endicott, the world's first commercial arctic offshore oil field, began production in 1987. Sag Delta North began production in 1991 through the Endicott production facilities. Both Endicott and Sag Delta North are separate participating areas within DIU. As of February 1995, a total of 98 Endicott development wells and five Sag Delta North wells have been drilled. Endicott production (including Sag Delta North production) peaked at $124 \mathrm{MBPD}$ in 1992 and has declined to an annual average of $98 \mathrm{MBPD}$ for 1994. Combined Endicott and SDNPA cumulative production through 1/1/95 was 284.5 MMBO. Combined Endicott and SDNPA remaining recovery as of 1/1/95 is estimated to be 194.4 MMBO for an ultimate recovery of $478.9 \mathrm{MMBO}$.

Analysis using the four price forecasts listed in Table B.1, Appendix B.1.1 show that all of the 
forecasted liquids can be economically recovered using the EIA reference and high oil price forecasts. About 160 MMBBLS of forecasted recovery is lost using the low price case forecast as shown in Table A.12. Using the flat oil price, lost recovery is estimated at about 25 MMBBLS

Table A.12. DIU economics.

\begin{tabular}{|c|c|c|c|c|}
\hline \multirow{2}{*}{ Economic Factor ${ }^{2}$} & \multicolumn{4}{|c|}{ Oil Price Forecasts } \\
\hline & $\begin{array}{c}\text { AEO95 } \\
\text { Low }\end{array}$ & $\begin{array}{c}\text { AEO95 } \\
\text { Ref. }\end{array}$ & $\begin{array}{c}\text { AEO95 } \\
\text { High }\end{array}$ & $\begin{array}{c}\text { Flat Oil } \\
\text { Price }\end{array}$ \\
\hline Remaining Project Life - yrs & 1 & 21 & 21 & 11 \\
\hline $\begin{array}{ll}\text { Remaining Reserves } & - \text { MMBBLS } \\
& - \text { TCF (Sales) }\end{array}$ & $\begin{array}{c}30.2 \\
0\end{array}$ & $\begin{array}{c}194.4 \\
0\end{array}$ & $\begin{array}{c}194.4 \\
0\end{array}$ & $\begin{array}{c}167.4 \\
0\end{array}$ \\
\hline Investments - as spent ( $\$$, millions) & 12 & 24 & 24 & 24 \\
\hline Operating Costs - as spent ( $\$$, millions) & 120 & 1,237 & 1,237 & 956 \\
\hline Cash Flow - NPV $10(1995 \$$, millions $)$ & 20 & 336 & 487 & 252 \\
\hline
\end{tabular}

\section{A.2.6 Milne Point Kuparuk Participating Area.}

The Milne Point Kuparuk Participating Area is a participating area within the Milne Point Unit (MPU). The MPU, which lies 30 miles northwest of PBU and adjacent to the Kuparuk River Unit, consists of the Milne Point Kuparuk Participating Area (MPKPA), the Schrader Bluff Participating Area (SBPA), and the Northwest Milne Point area (NWMP) (Figure A.9). Each participating area will be covered in separate sections with this section covering MPKPA.

The Kuparuk sandstone is the producing formation of the MPKPA. The Kuparuk zone was first discovered in 1969 by the Sinclair East Ugnu No. 1 well. MPU was unitized in 1979 and production from the MPKPA began in 1985. Production from MPKPA was shut-in in January 1987, due to low oil prices, and restarted in April 1989. BP Exploration Alaska Inc. (BP) acquired Conoco's interest in MPU and became operator in 1994.

Production from MPKPA during 1994 averaged 15.3 MBPD with 39.6 MMBO cumulative production as of 12/31/94 (AOGCC, 1994c). Remaining recovery from MPKPA as of 1/1/95 is estimated 


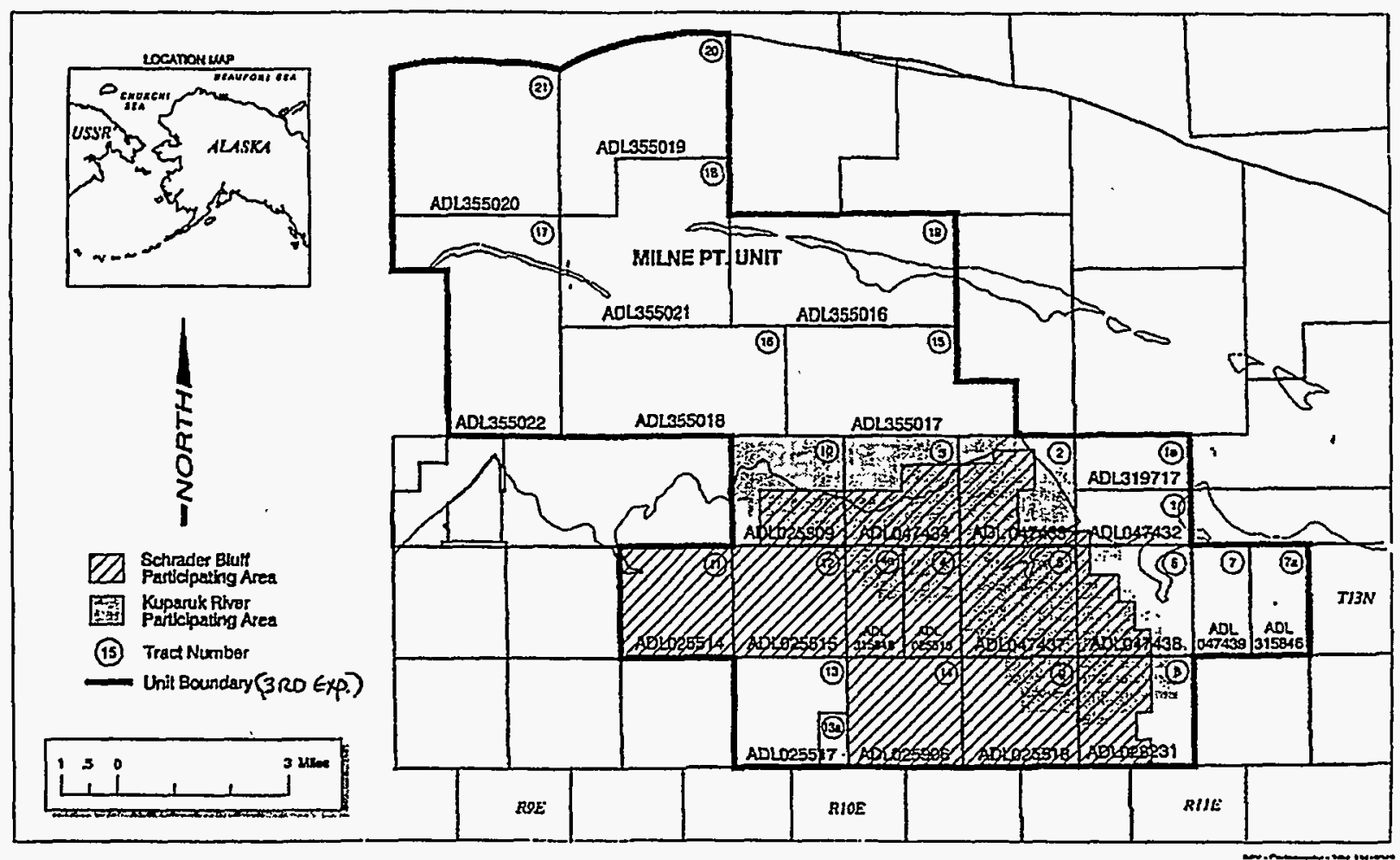

Figure A.9. MPKPA of the Milne Point Unit (ADNR, 1994.).

to be 97.8 $\mathrm{MMBO}$ for an ultimate recovery of 137.4 MMBO.

A.2.6.1 Development Plans. Development plans for MPU have changed significantly since the previous DOE publication (1993). Current plans are to conduct limited additional development drilling for MPKPA with 17 new producing wells and 7 injection wells into the Kuparuk formation planned during 1995 (ADNR, 1994s; Alaska Journal of Commerce, 1995b). Plans for development drilling beyond 1995 are contingent up the results of the 1995 development drilling program. Current plans are to expand MPKPA processing facility capacity from 30 MBBLS per day to 53 MBBLS per day by the end of 1995 (ADNR, 1994s). The MPKPA processing facilities are being shared with SBPA and will be shared with NWMP when it begins production.

Additional potential, "best case scenario", exists to increase MPU production to as much as 100 MBPD by the year 2000 with an increase in ultimate recovery to possibly as much as $600 \mathrm{MMBO}$ (Anchorage Daily News, 1995c). No information is available to indicate which field or fields this estimate is attributed to. 
A.2.6.2 Input Data. Input data are developed using history, current development plans, published information, and personal communications. The additional potential referred to in Appendix A.2.6.1 is not included in this evaluation.

A.2.6.2.1 MPKPA Recoverable Oil--Ultimate recovery from the MPKPA of 62.5 MMBO was carried in the previous DOE publication (1993). Actual annual production for 1992, 1993, and 1994 was approximately $2,500 \mathrm{BOPD}$ lower than forecasted. The remaining forecast was based on no additional development drilling beyond 1993. Current development drilling plans call for drilling 17 additional producing wells in 1995. Assuming an annual decline of $12 \%$ per year from 1994 production plus production from 16 additional wells, each with an initial rate of $1.2 \mathrm{MBPD}$ declined at $12 \%$ per year, the remaining recovery at $1 / 1 / 95$ is estimated to be $97.8 \mathrm{MMBO}$ for the ultimate recovery of $137.4 \mathrm{MMBO}$.

A.2.6.2.2 MPKPA Production Forecast--The MPKPA production forecast shown in Table A.13 was developed using the procedure described in Appendix A.2.6.2.1.

Table A.13. MPKPA production forecast

\begin{tabular}{|c|c||}
\hline Year & (BOPD) \\
\hline 1995 & 30,856 \\
1996 & 30,856 \\
1997 & 27,153 \\
1998 & 23,895 \\
1999 & 21,028 \\
2000 & 18,504 \\
2001 & 16,284 \\
2002 & 14,330 \\
2003 & 12,610 \\
2004 & 11,097 \\
2005 & 9,765 \\
2006 & 8,593 \\
2007 & 7,562 \\
2008 & 6,655 \\
2009 & 5,856 \\
2010 & 5,153 \\
2011 & 4,535 \\
2012 & 3,991 \\
2013 & 3,512 \\
2014 & 3,090 \\
2015 & 2,720 \\
\hline
\end{tabular}


A.2.6.2.3 MPKPA Investments--Seventeen development producing wells and seven injection wells are currently planned (Alaska Journal of Commerce, 1995b) to be drilled from existing pads in 1995. Development drilling beyond 1995 is contingent upon the results of the 1995 drilling program. The only investments forecasted are those associated with drilling the 24 wells currently planned and expansion of the MPKPA processing facility capacity from 30 MBBLS per day to 53 MBBLS per day. Using the operator's North Slope infrastructure and experience it is assumed that each well can be drilled at a cost of $\$ 2.0 \mathrm{MM} /$ well (1995\$). It is assumed that production facility costs, in addition to the production facility expansion costs, of $\$ 2.0$ million (1995\$) per year would be invested for three years.

The operator expects to invest $\$ 220$ million (1995\$) over a 3-year period for MPU development, including \$120 million (1995\$) during 1995 and 1996 for MPKPA processing facility capacity expansion and NWMP development. ${ }^{2}$ It is assumed that $\$ 100$ million (1995\$) will be spent for MPKPA and SBPA development and that $\$ 43$ million (1995\$) will be invested for NWMP development, excluding MPKPA processing facility expansion. It is assumed that MPKPA will make the investment in the processing facility capacity expansion and charge SBPA and NWMP a facility sharing fee for that investment. The MPKPA processing facility capacity expansion from 30 to $60 \mathrm{MBOPD}$ is assumed to cost a total of $\$ 77$ million (1995\$) with $80 \%$ being spent in 1995 and the remainder in 1996. The MPKPA drilling and investment schedule is shown in Table A.14.

Table A.14. MPKPA drilling and investment schedule

\begin{tabular}{|c|c|c|c|c|}
\hline \multirow{2}{*}{ Year } & \multirow{2}{*}{$\begin{array}{c}\text { Drilling } \\
\text { No. Wells }\end{array}$} & \multicolumn{3}{|c|}{ Investment - 1995\$, millions } \\
\cline { 3 - 5 } & 24 & Wells & Facilities & Total \\
\hline 1995 & 0 & 48 & 63.6 & 111.6 \\
\hline 1996 & 0 & 0 & 17.4 & 17.4 \\
\hline 1997 & 24 & 0 & 2.0 & 2.0 \\
\hline Total & & 48 & 83.0 & 131.0 \\
\hline
\end{tabular}

A.2.6.2.4. MPKPA Operating Costs--It is expected that the operator can reduce total operating costs from the operating costs used in the previous DOE publication (1993) as a results of their North Slope infrastructure and experience. A $\$ / B T F$ operating cost factor is assumed to be $\$ 1.54 / \mathrm{BTF}$

a. BP Exploration (Alaska) Inc., personal communication, March 20, 1995. 
(1995\$) which includes $\$ 0.55 / \mathrm{BTF}(1995 \$)$ for well workover cost plus $\$ 0.07 / \mathrm{BTF}$ (1995\$) for lease maintenance operating cost plus $\$ 0.92$ (1995\$) for processing facility operating cost. The total operating cost of $\$ 1.54 / \mathrm{BTF}(1995 \$)$ is used in this analysis and is applied to the MPKPA BTF production.

Estimates of MPKPA total fluid volumes are determined using a relationship of water cut versus percent of ultimate recovery. The 1994 water cut versus percent cumulative recovery is reasonably consistent with the MPU model water cut versus percent cumulative recovery relationship developed in the previous DOE publication (1993). That relationship (Figure A.10), with slight modification, is used in this analysis.

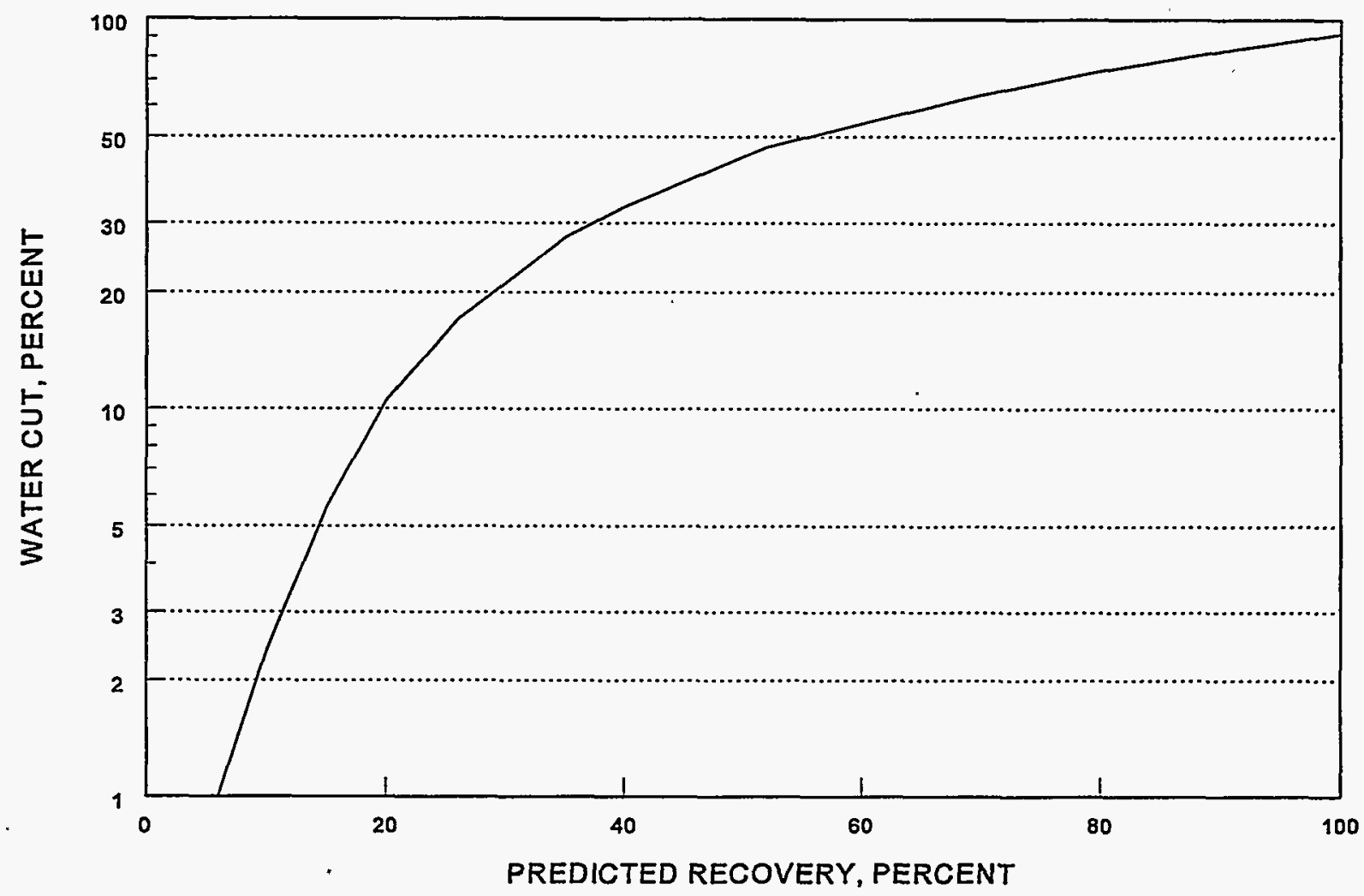

Figure A.10. MPU - model data of percent water cut versus percent of ultimate recovery.

A.2.6.2.7 Future Producing Wells--The number of future active producing wells is determined using the Set B equations from Appendix C.1.1.6.

A.2.6.3 Summary. Production from MPKPA of the MPU began in November 1985, but was shut-in between January 1987 and April 1989 due to low oil prices. Current development plans are to conduct 
limited development drilling and continued waterflood of the formation. Current plans are to expand the MPKPA processing facility capacity from 30 to 60 MBOPD. The MPKPA processing facilities are being shared with SBPA and NWMP. Average annual production from MPKPA for 1994 was 15.3 MBPD from 37 producing wells. Cumulative production as of $12 / 31 / 94$ was $39.6 \mathrm{MMBO}$. Remaining recovery as of $1 / 1 / 95$ is estimated to be 97.8 for an ultimate recovery of $137.4 \mathrm{MMBO}$.

Analysis using the four price forecasts listed in Table B.1, Appendix B.1.1 show that all of the forecasted liquids can be economically recovered using the EIA reference and high oil price forecasts. About $22 \mathrm{MMBO}$ recovery is lost in the flat oil price scenario, and none of the recoverable oil is economically recovered using the EIA low price forecast. The evaluation results are given in Table A.15.

Table A.15. MPKPA economics.

\begin{tabular}{|c|c|c|c|c|}
\hline \multirow{2}{*}{ Economic Factor ${ }^{2}$} & \multicolumn{4}{|c|}{ Oil Price Forecasts } \\
\hline & $\begin{array}{c}\text { AEO95 } \\
\text { Low }\end{array}$ & $\begin{array}{c}\text { AE095 } \\
\text { Ref. }\end{array}$ & $\begin{array}{c}\text { AEO95 } \\
\text { High }\end{array}$ & $\begin{array}{c}\text { Flat } \\
\text { Oil Price }\end{array}$ \\
\hline Remaining Project Life - yrs & 0 & 21 & 21 & 10 \\
\hline $\begin{array}{ll}\text { Remaining Reserves } & \text { - MMBBLS } \\
& - \text { TCF (Sales) }\end{array}$ & $\begin{array}{l}0 \\
0\end{array}$ & $\begin{array}{c}97.8 \\
0\end{array}$ & $\begin{array}{c}97.8 \\
0\end{array}$ & $\begin{array}{c}75.4 \\
0\end{array}$ \\
\hline Investments - as spent (\$, millions) & 0 & 133 & 133 & 133 \\
\hline Operating Costs - as spent ( $\$$, millions) & 0 & 803 & 803 & 418.4 \\
\hline Cash Flow - NPV 10 (1995\$, millions) & 0 & 160.7 & 235 & 113.7 \\
\hline
\end{tabular}

\section{A.2.7 Schrader Bluff Participating Area.}

The Schrader Bluff Participating Area (SBPA) is a participating area within the MPU (Figure A.9). The Schrader Bluff Sands, correlating to the lower Ugnu sands and to an eastern extension of the West Sak sands of the KRU to the southwest and sometimes referred to as West Sac or Ugnu sands, were first encountered in 1969 by the Sinclair East Ugnu No.1 well. The Schrader Bluff sands were also encountered in Chevron's Kavearak Point well the same year. The State approved the pool rules for the Schrader Bluff pool in 1990 and production was started from the Schrader Bluff sands in 1991. 
Production from SBPA during 1994 averaged 3.0 MBPD with 4.0 MMBO cumulative production as of 1/1/95 (AOGCC, 1994c), Remaining recovery from SBPA as of 1/1/95 is estimated to be $34.0 \mathrm{MMBO}$ for an ultimate recovery of 38.0 MMBO.

A.2.7.1 Development Plans. Development plans for MPU have changed significantly since the previous DOE publication (1993). Current plans are to increase Schrader Bluff well production and conduct limited additional development drilling for SBPA. These development plans include:

- Increase Schrader Bluff average well production from currently $200 \mathrm{BOPD}$ per well to $500 \mathrm{BOPD}$ per well through improved gravel filter technology (Anchorage Daily News, 1995c; Alaska Journal of Commerce, 1995b).

- Drill six new Schrader Bluff formation development wells and two water source wells in 1995 (ADNR, 1994s; Alaska Journal of Commerce, 1995b).

- Depending on the results of the 1995 MPKPA and SBPA drilling program, as many as 12 additional MPU development wells are planned for 1996 (Anchorage Daily News, 1995c). It is assumed that these will be SBPA development wells.

- Depending on the results of the SBPA development drilling program, the potential exists to construct a maximum of seven new MPU drilling pads, one per 4 square miles (Alaska Journal of Commerce, 1995b). It is assumed that these pads will be for SBPA development.

A.2.7.2 Input Data. Input data are developed using history, current development plans, published information, and personal communications.

A.2.7.2.1 SBPA Recoverable Oil--Ultimate recovery from the SBPA of 209.5 MMBO carried in the previous DOE publication (1993) was based on an extensive development drilling program, adding 44 wells during 1992 through 1994 and 252 producing wells from 1995 through 2012. The scope of SBPA development drilling has been significantly reduced from the assumptions used in the previous publication. Eleven development wells were drilled between 1992 and 1994, six development wells are planned for 1995, and 12 development wells are tentatively planned for 1996. It was assumed that the per well production rates will be increased to $500 \mathrm{BOPD}$, that 15 producing wells existed from 1994, that six producing wells would be drilled in 1995, and that 12 producing wells would be drilled in 1996 . The SBPA annual production rate was prorated with NWMP annual production rate such that total MPU production was less than or equal to the expanded MPKPA production facility capacity of 53 MBBLS per day. The 1997 
SBPA annual production rate was declined at $15 \%$ per year (Table A.16). The remaining recovery at 1/1/95 is estimated to be $34.0 \mathrm{MMBO}$ for the ultimate recovery of $38.0 \mathrm{MMBO}$.

Table A.16. SBPA production forecast

\begin{tabular}{|c|c||}
\hline Year & (BOPD) \\
\hline 1995 & 10,500 \\
1996 & 11,382 \\
1997 & 13,286 \\
1998 & 11,293 \\
1999 & 9,599 \\
2000 & 8,159 \\
2001 & 6,935 \\
2002 & 5,898 \\
2003 & 5,011 \\
2004 & 4,259 \\
2005 & 3,620 \\
2006 & 3,077 \\
\hline
\end{tabular}

A.2.7.2.2 SBPA Investments--Investments of $\$ 120$ million (1995\$) are planned over the next 3 years (Anchorage Daily News, 1995a, Anchorage Daily News, 1995c) for MPU development (assumed for drilling wells). Development plans call for the drilling of eight SBPA wells in 1995 and 12 more SBPA wells in 1996. Utilizing the operators North Slope infrastructure and experience, it is assumed that each well can be drilled for $\$ 2.0 \mathrm{MM} /$ well (1/1/95). It is assumed that additional production facility costs will be $\$ 2.0$ million per year for 1995,1996 and 1997 . The SBPA drilling and investment schedule is shown in Table A.17.

Table A.17. SBPA drilling and investment schedule

\begin{tabular}{||c|c|c|c|c||}
\hline \multirow{2}{*}{ Year } & \multirow{2}{*}{$\begin{array}{c}\text { Drilling } \\
\text { No. Wells }\end{array}$} & \multicolumn{3}{|c||}{ Investment - 1995\$, millions } \\
\cline { 3 - 5 } & & Wells & Facilities & Total \\
\hline 1995 & 8 & 16 & 2.0 & 18.0 \\
\hline 1996 & 12 & 24 & 2.0 & 26.0 \\
\hline 1997 & 0 & 0 & 2.0 & 2.0 \\
\hline Total & 20 & 40 & 6.0 & 46.0 \\
\hline
\end{tabular}


A.2.7.2.3 SBPA Operating Costs--It is expected that the operator will be able to lower operating costs due to it's North Slope infrastructure and experience and by application of revised production technology. The \$/BTF basic operating cost is assumed to be $\$ 0.62 / \mathrm{BTF}(1995 \$$ ) and is used as the SBPA operating cost in addition to the facilities cost sharing fee paid by SBPA to MPKPA.

The facilities cost sharing fee paid by SBPA to MPKPA from the previous DOE publication (1993) of $\$ 1.24 / \mathrm{BTF}$ (1992\$), adjusted for inflation to $\$ 1.32 / \mathrm{BTF}$ (1995\$) is used in this analysis and is applied to the SBPA BTF production. It is assumed that this cost includes $\$ 0.92 / \mathrm{BTF}$ incremental shared facility operating cost and $\$ 0.40 / \mathrm{BTF}$ shared facility access fee based on the cost savings to SBPA.

The total fluid production, BTF, used to determine SBPA operating cost and cost sharing fee is determined from the MPU model water cut versus percent cumulative recovery relationship (Figure A.10), slightly modified to reflect SBPA production characteristics.

A.2.7.2.4 Field Pipeline Tariff--The pipeline tariff of \$0.90/BBL (1995\$) discussed in Appendix A.2.6.2.6 is used in the SBPA analysis.

A.2.7.2.5 Future Producing Wells--The Set B equations in Appendix C.1.1.6 are used to estimate future annual producing wells.

A.2.7.3 Summary. The Schrader Bluff pool, which correlates to the lower Ugnu sands and upper West Sak sands, began producing in 1991. Cumulative production as of 1/1/95 was 4.0 MMBO. Remaining recovery as of $1 / 1 / 95$ is $34.0 \mathrm{MMBO}$ for an ultimate recovery of $38.0 \mathrm{MMBO}$. Development plans for SBPA have been revised significantly by the operator since 1994 .

Analysis using the four price forecasts listed in Table B.1, Appendix B.1.1 show that all of the forecasted liquids can be recovered using the EIA reference and high case price forecasts. About $8 \mathrm{MMBO}$ is lost using the flat oil price scenario and none of the forecasted liquids are economically recovered using the EIA low price forecast as shown in Table A.18.

\section{A.2.8 Northwest Milne Point Area.}

The Northwest Milne Point Area (NWMP), a currently undeveloped northwestern area of MPU, is 
Table A.18. SBPA economics.

\begin{tabular}{|c|c|c|c|c|}
\hline \multirow{2}{*}{ Economic Factor ${ }^{2}$} & \multicolumn{4}{|c|}{ Oil Price Forecasts } \\
\hline & $\begin{array}{c}\text { AEO95 } \\
\text { Low }\end{array}$ & $\begin{array}{c}\text { AE095 } \\
\text { Ref. }\end{array}$ & $\begin{array}{c}\text { AEO95 } \\
\text { High } \\
\end{array}$ & $\begin{array}{c}\text { Flat } \\
\text { Oil Price }\end{array}$ \\
\hline Remaining Project Life - yrs & 4 & 12 & 12 & 7 \\
\hline $\begin{array}{ll}\text { Remaining Reserves } & \text { - MMBBLS } \\
& - \text { TCF (Sales) }\end{array}$ & $\begin{array}{c}17 \\
0\end{array}$ & $\begin{array}{c}34 \\
0\end{array}$ & 34 & $\begin{array}{c}26 \\
0\end{array}$ \\
\hline Investments - as spent ( $\$$, millions) & 47.2 & 47.2 & 47.2 & 47.2 \\
\hline Operating Costs - as spent ( $\$$, millions) & 49.3 & 180.1 & 180.1 & 98.8 \\
\hline Cash Flow - NPV 10 (1995\$, millions) & -29.6 & 33.5 & 59.4 & 21.5 \\
\hline
\end{tabular}

a proposed participating area within the MPU (Figure A.9). The NWMP Kuparuk sand accumulation was encountered by Conoco's NW Milne No. 1 well, drilled in 1992. 3-D seismic data and three more exploratory wells in NWMP have extended the Milne Point Unit structure into this offshore area (AOGCC 1994d). The four exploratory wells encountered oil bearing sands stratigraphically equivalent to the MPKPA Kuparuk River sand. The operator plans to initiate development activities at NWMP in 1995.

Production from the NWMP is expected to begin by the end of 1995 . Ultimate recovery from the undeveloped NWMP is estimated to be $37.7 \mathrm{MMBO}$ based on a limited amount of available information. The NWMP accumulation is estimated to contain $70 \mathrm{MMBO}$ to $80 \mathrm{MMBO}$ (Alaska Journal of Commerce, 1995b).

A.2.8.1 Development Plans. The previous DOE publication (1993) did not address development of the NWMP. Current development plans (ADNR 1994s; Alaska Journal of Commerce, 1995b) include:

- Expand MPU facility capacity from currently $30 \mathrm{MBBLS}$ per day to $53 \mathrm{MBBLS}$ per day by the end of 1995 .

- Complete construction of F Pad for development of NWMP and connect to MPU production facilities by the end of $1995 .^{2}$

- Drill 10 development wells from F Pad at NWMP in 1995.

a. BP Exploration (Alaska) Inc., personal communication, March 20, 1995. 
- Begin NWMP production by the end of 1995.

A.2.8.2 Input Data. Input data are developed using history, current development plans, published information, and personal communications.

A.2.8.2.1 NWMP Recoverable Oil--The previous DOE publication (1993) did not address the NWMP as there were no plans at that time to develop this accumulation. For this analysis, it was assumed that NWMP wells would be produced at an initial rate of $1200 \mathrm{BOPD}$ per well. It was assumed that production at that rate would occur for half of the first year (1995). The production is prorated with SBPA to 53 MBBLS per day excess capacity above MPKPA production. Production is declined at $15 \%$ per year. The ultimate recovery is estimated to be 37.7 MMBO from the production schedule shown in Table A.19. This recovery is $47 \%$ of the 80 MMBO estimated for the NWMP accumulation by (Alaska Journal of Commerce, 1995b).

Table A.19. NWMP production forecast

\begin{tabular}{|c|c|}
\hline \hline Year & (BOPD) \\
\hline 1995 & 7,800 \\
1996 & 10,762 \\
1997 & 12,561 \\
1998 & 11,054 \\
1999 & 9,727 \\
2000 & 8,560 \\
2001 & 7,533 \\
2002 & 6,629 \\
2003 & 5,833 \\
2004 & 5,133 \\
2005 & 4,517 \\
2006 & 3,975 \\
2007 & 3,498 \\
2008 & 3,078 \\
2009 & 2,709 \\
\hline
\end{tabular}

A.2.8.2 NWMP Investments--It is estimated that each of the 10 wells planned for 1995 will cost $\$ 3.1 \mathrm{MM} /$ per well (1995\$), that F Pad will cost $\$ 8.0$ million (1995\$) to construct in 1995 , and that additional production facility costs are $\$ 2.0$ million (1995\$) for 1996 and 1997 . The NWMPU drilling and investment schedule is shown in Table A.20. 
Table A.20. NWMP drilling and investment schedule

\begin{tabular}{||l|l|l|l|l||}
\hline \multirow{2}{*}{ Year } & \multirow{2}{*}{$\begin{array}{l}\text { Drilling } \\
\text { No. Wells }\end{array}$} & \multicolumn{3}{|c|}{ Investment - 1995\$, millions } \\
\cline { 3 - 5 } & 10 & Wells & Facilities & Total \\
\hline 1995 & 0 & 31.0 & 8.0 & 39.0 \\
\hline 1996 & 0 & 0 & 2.0 & 2.0 \\
\hline 1997 & 0 & 0 & 2.0 & 2.0 \\
\hline Total & 10 & 31.0 & 12.0 & 43.0 \\
\hline
\end{tabular}

A.2.8.2.3 NWMP Operating Costs--It is assumed that the NWMP per barrel of total fluid operating costs are similar to MPKPA operating cost of \$0.62/BTF (1995\$) and is used as the NWMP basic operating cost in addition to the facility cost sharing fee paid by NWMP to MPKPA.

The NWMP will pay to MPKPA a facilities cost sharing fee. It is estimated that this cost sharing fee is the same as that paid by SBPA. Therefore, the NWMP cost sharing fee is $\$ 1.32 / B T F(1995 \$)$ in this analysis and is applied to the NWMP BTF production. The total fluid production, BTF, used to determine NWMPU operating cost and cost sharing fee is determined from the MPU model water cut versus percent cumulative recovery relationship (Figure A.10), slightly modified to reflect the NWMP anticipated production characteristics.

A.2.8.2.4 Field Pipeline Tariff--The field pipeline tariff of \$0.90/BBL (1995\$) assumed for MPKPA in Appendix A.2.6.2.6 is used in the NWMP analysis.

A.2.8.2.5 Future Producing Wells--The Set B equations in Appendix C.1.1.6 are used to estimate future annual producing wells.

A.2.8.3 Summary. Plans are to develop the NWMP accumulation from a gravel pad (F Pad) located at No Point with connections to existing MPU production facilities. A total of 10 wells are currently planned. Ultimate recover is estimated to be $37.7 \mathrm{MMBO}$ with production beginning by the end of 1995 .

Analysis using the four price forecasts listed in Table B.1, Appendix B.1.1 show that all of the forecasted liquids can be economically recovered using the EIA reference and high case price forecasts. 
About 6.5 MMBO recovery is lost using the flat oil price scenario, and about 10.5 MMBO is lost using the EIA low price forecast case. The evaluation results are given in Table A.21.

Table A.21. NWMP economics.

\begin{tabular}{|c|c|c|c|c|}
\hline \multirow{2}{*}{ Economic Factor ${ }^{2}$} & \multicolumn{4}{|c|}{ Oil Price Forecasts } \\
\hline & $\begin{array}{l}\text { AEO95 } \\
\text { Low }\end{array}$ & $\begin{array}{l}\text { AEO95 } \\
\text { Ref. }\end{array}$ & $\begin{array}{l}\text { AEO95 } \\
\text { High }\end{array}$ & $\begin{array}{c}\text { Flat } \\
\text { Oil Price }\end{array}$ \\
\hline Remaining Project Life - yrs & 8 & 15 & 15 & 10 \\
\hline $\begin{array}{ll}\text { Remaining Reserves } & \text { - MMBBLS } \\
& - \text { TCF (Sales) }\end{array}$ & $\begin{array}{c}27.2 \\
0\end{array}$ & $\begin{array}{c}37.7 \\
0\end{array}$ & $\begin{array}{c}37.7 \\
0\end{array}$ & $\begin{array}{c}31.2 \\
0\end{array}$ \\
\hline Investments - as spent ( $\$$, millions) & 43.6 & 43.6 & 43.6 & 43.6 \\
\hline Operating Costs - as spent ( $\$$, millions) & 92 & 208.9 & 208.9 & 125.6 \\
\hline Cash Flow - NPV 10 (1995\$, millions) & 3.1 & 63.7 & 92.3 & 46 \\
\hline
\end{tabular}

\section{A.2.9 Lisburne Participating Area}

The Lisburne Participating Area (LPA) of the Prudhoe Bay Unit produces from the Lisburne group which is subdivided into the Alapah of Mississippian age and the overlying Wahoo of Pennsylvanian age. The Lisburne pool was discovered in 1968 by the ARCO/Humble (Exxon) Prudhoe Bay State No. 1 well, the discovery well for the shallower Prudhoe Bay field. The State approved formation of the LPA of PBU in 1986 (Figure A.11). The LPA is located in the northeastern corner of PBU.

A.2.9.2 Input Data--Input data are developed using history, current development plans, published information, and personal communications.

A.2.9.2.1 Production Forecast--The Alapah production forecast has been combined with Lisburne production forecast for the LPA production forecast shown in Table A.22. Remaining recovery from LPA is estimated to be $40.0 \mathrm{MMBO}$ as of $1 / 1 / 95$. Recovery to date is $115.1 \mathrm{MMBO}$. The 1994 average annual production rate was declined at $12 \%$ per year. This decline results in an estimated ultimate recovery of $155.1 \mathrm{MMBO}$. 


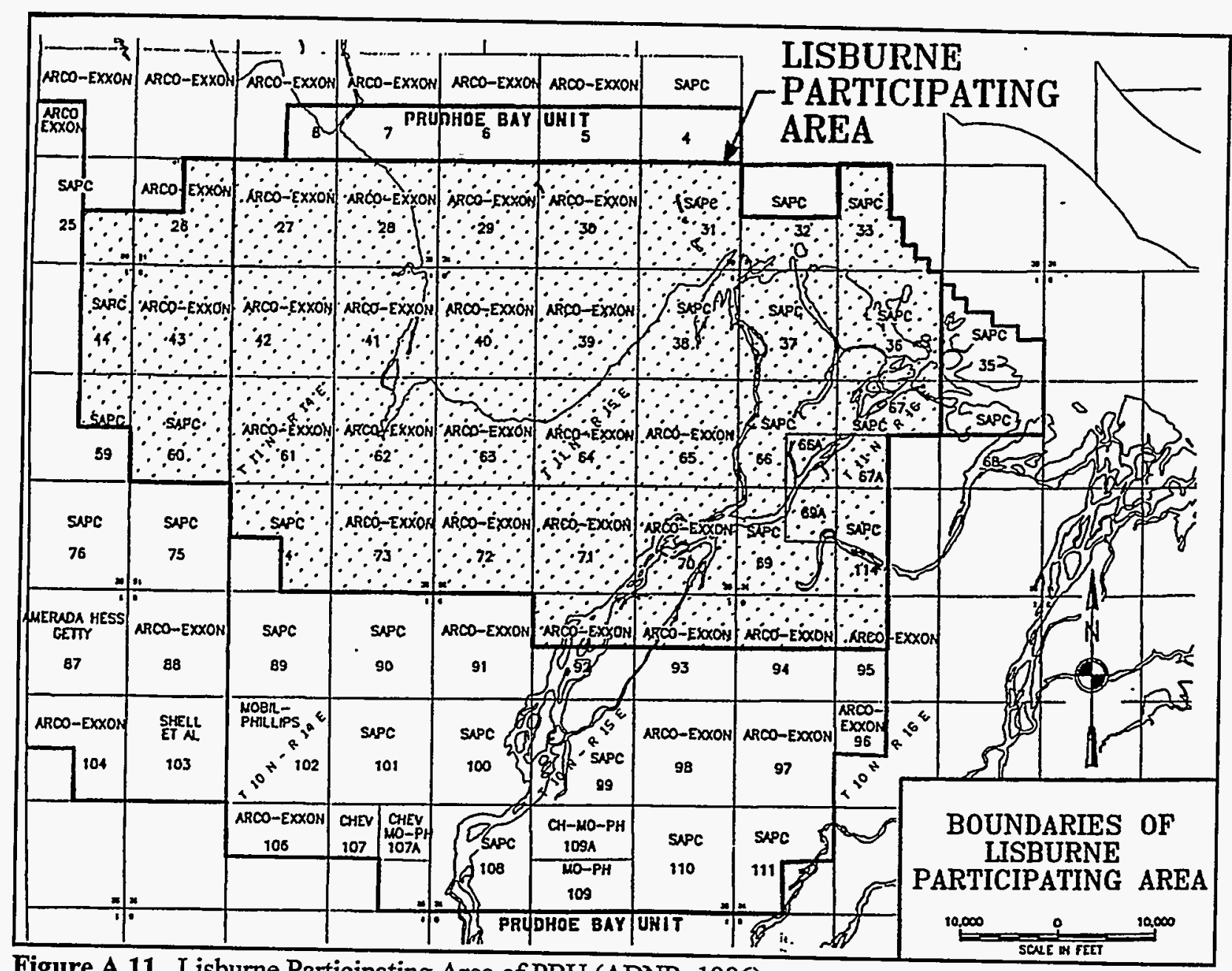

Figure A.11. Lisburne Participating Area of PBU (ADNR, 1986).

Table A.22. LPA production forecast

\begin{tabular}{|c|c|}
\hline Year & (MBPD) \\
\hline 1995 & 19.3 \\
1996 & 17.0 \\
1997 & 14.9 \\
1998 & 13.2 \\
1999 & 11.5 \\
2000 & 10.2 \\
2001 & 8.9 \\
2002 & 7.9 \\
2003 & 6.8 \\
\hline
\end{tabular}


A.2.9.2.2 Investments--Future development of the LPA appears to be limited and no future development wells are currently planned. The LPA drilling and investment schedule is shown in Table A.23.

Table A.23. LPA drilling and investment schedule.

\begin{tabular}{||c|c|c|c|c||}
\hline \multirow{2}{*}{ Year } & \multirow{2}{*}{$\begin{array}{c}\text { Drilling } \\
\text { No. Wells }\end{array}$} & \multicolumn{3}{|c|}{ Investment - 1995\$, millions } \\
\cline { 3 - 5 } & & Wells & Facilities & Total \\
\hline \hline 1995 & 0 & 0 & 2.0 & 2.0 \\
\hline 1996 & 0 & 0 & 1.0 & 1.0 \\
\hline Total & 0 & 0 & 3.0 & 3.0 \\
\hline
\end{tabular}

A.2.9.2.3 Operating Costs--The operating cost used in the previous DOE publication (1993) of $\$ 1.50 / B T F(1992 \$)$, adjusted for inflation to $\$ 1.60 / B T F(1995 \$)$ is used in this analysis and applied to LPA BTF to determine LPA operating cost.

The water cut relationship used in the previous DOE publication (1993) is used in this analysis to determine LPA BTF.

The LPA processing facilities and some infrastructure components are being used by Point McIntyre Participating Area (PMPA), Niakuk Participating Area (NPA), West Beach Participating Area (WBPA), and North Prudhoe Bay State Participating Area (NPBSPA) under a facilities sharing arrangement. The incremental cost to operate the LPA facilities due to the use by the other PAs is added to the LPA operating cost. Seventy $\%$ of the cost sharing fee that LPA receives from each of these other PAs is added to the LPA operating cost as an estimate of that incremental cost.

A.2.9.2.4 Facilities Cost Sharing--The cost sharing fee paid to LPA by PMPA, NPA, WBPA, and NPBSPA is included as income to LPA and is subject to State and federal income taxes, but is not subject to royalty or State production taxes.

A.2.9.2.5 Field Pipeline Tariff--Lisburne pipeline tariff has been revised as information indicates that Niakuk did not buy into the LPA pipeline (ADNR, 1991g) and for a revised throughput of 564.56 MMBBL. The initial Lisburne pipeline investment is estimated at $\$ 43.29$ million (1992\$), adjusted 
for inflation to $\$ 46.16$ million (1995\$). The resulting revised total Lisburne pipeline cost, with no Niakuk buy-in, is $\$ 53.16$ million (1995\$). The revised Lisburne pipeline tariff is $\$ 0.32 / \mathrm{BBL}$ (1995\$) (see Appendix B.1.1.1.4) and is used in this analysis.

A.2.9.2.6 Future Producing Wells--The Set B equations in Appendix C.1.1.6 are used to estimate the future active producing wells.

A.2.9.3 Summary. Production from the Lisburne field began in 1986. As of November 1994, a total of 87 Lisburne wells had been drilled, of which 48 are producing. Annual average production for 1994 was 21.8 MBPD. Cumulative production as of $1 / 1 / 95$ was $115.1 \mathrm{MMBO}$. Remaining recovery as of 1/1/95 is estimated to be $40.0 \mathrm{MMBO}$ for an ultimate recovery of 155.1 MMBO.

Analysis using the four price forecasts listed in Table B.1, Appendix B.1.1 show that all of the forecasted liquids can be economically recovered using the ELA reference and high oil price forecasts. About 12.3 MMBO of forecasted recovery will be lost using the flat oil price scenario, and about 16.9 MMBO will be lost using the EIA low oil price forecast. The life of LPA is extended beyond the life of economic oil recovery as a result of the facility sharing fee income collected at LPC. The evaluation results are given in Table A.24.

Table A.24. LPA economics (1995\$).

\begin{tabular}{|c|c|c|c|c|}
\hline \multirow{2}{*}{ Economic Factor ${ }^{2}$} & \multicolumn{4}{|c|}{ Oil Price Forecasts } \\
\hline & $\begin{array}{c}\text { AEO95 } \\
\text { Low }\end{array}$ & $\begin{array}{c}\text { AEO95 } \\
\text { Ref. }\end{array}$ & $\begin{array}{c}\text { AE095 } \\
\text { High }\end{array}$ & $\begin{array}{c}\text { Flat } \\
\text { Oil Price }\end{array}$ \\
\hline $\begin{array}{l}\text { Remaining Project Life - yrs } \\
\text { - Due to LPA production only } \\
\text { - With LPC sharing income }\end{array}$ & $\begin{array}{l}4 \\
7 \\
\end{array}$ & $\begin{array}{c}9 \\
14\end{array}$ & $\begin{array}{c}9 \\
14\end{array}$ & $\begin{array}{c}5 \\
10\end{array}$ \\
\hline $\begin{array}{c}\text { Remaining Reserves - MMBBLS } \\
\text { - TCF (Sales) }\end{array}$ & $\begin{array}{c}13.3 \\
0\end{array}$ & $\begin{array}{c}40 \\
0\end{array}$ & $\begin{array}{c}40 \\
0\end{array}$ & $\begin{array}{c}27.7 \\
0\end{array}$ \\
\hline Investments - as spent ( $\$$, millions) & 3 & 3 & 3 & 3 \\
\hline Operating Costs - as spent ( $\$$, millions) & 856 & 1,473 & 1,473 & 1,168 \\
\hline Cash Flow $-\mathrm{NPV}_{10}(1995 \$$, millions $)$ & 74 & 200 & 231 & 156 \\
\hline
\end{tabular}




\section{A.2.10 Point McIntyre}

Point McIntyre was discovered in February 1989 and was one of the largest oil field discovered in the United States during the decade of the 1980's. Hydrocarbons have been tested in the Cretaceous Seabee and Kuparuk River Sand formations. The Kuparuk is the main productive horizon. A more complete discussion of Point McIntyre is given in the previous DOE publication (1993).

The accumulation lies mostly offshore in Prudhoe Bay, located about 10 miles north of TAPS PS No. 1 (Figure 1.2). The Prudhoe Bay Unit was expanded to include all the acreage within the Point McIntyre productive area (ADNR, 1992n).

Point McIntyre is a separate participating area within the Prudhoe Bay unit. Development of the PMPA commenced during 1993 by the drilling of 15 wells (AT 1992). Total investment to develop PMPA will be reduced by the sharing of facilities owned by the Lisburne participating area (ADNR, 1992n).

A.2.10.1 Input Data. Evaluation input data are developed using published information, early production performance and empirical relationships.

A.2.10.1.1 Recoverable Oil--Estimated recovery volumes for Point McIntyre vary from a low of about $340 \mathrm{MMBO}$ (AOGCC, 1993b), to a high of about $450 \mathrm{MMBO}$ (ADNR, 1995c). These recovery volumes range from about $42.5 \%$ to $56.3 \%$ of OOIP. Production performance may justify the higher reserve estimate, however the lower estimate, $340 \mathrm{MMBO}$, is used in this Point McIntyre evaluation.

A.2.10.1.2 Investments--Estimates of future investments and the schedule of these investments are based on the most current unit plans and published industry estimates of total investments (Anchorage Daily News, 1994; AOGCC, 1993b; Anchorage Times, 1992). An estimated development cost of $\$ 764.5$ million (1995\$) is used as the investment required under the facilities sharing agreement with LPA (Anchorage Daily News, 1994). The cost to drill wells in the previous DOE publication (1993) is used in this evaluation and is $\$ 3.25$ million in $1995 \$$. With no published data available, it is assumed that about $60 \%$ of the total investment was spent in the first two years of operation. The drilling and investment schedules for PMPA are given in Table A.25. 
Table A.25. PMPA drilling and investment schedule.

\begin{tabular}{||c|c|c|r|r||}
\hline & Drilling & \multicolumn{3}{|c|}{ Investments (1995\$, millions) } \\
\hline \hline Year & No. Wells & Wells & \multicolumn{1}{|c|}{ Facilities } & \multicolumn{1}{c|}{ Total } \\
\hline 1995 & 12 & 39.0 & 64.0 & 103.0 \\
\hline 1996 & 11 & 35.8 & 42.1 & 77.9 \\
\hline 1997 & 9 & 29.3 & 21.3 & 50.6 \\
\hline 1998 & 8 & 26.0 & 6.4 & 32.4 \\
\hline 1996 & 6 & 19.5 & 6.4 & 25.9 \\
\hline 2000 & 3 & 9.8 & 6.0 & 15.8 \\
\hline Total & 49 & 159.4 & 146.4 & 305.8 \\
\hline
\end{tabular}

A.2.10.1.3 Production Forecast--The Point McIntyre production forecast is based on the following:

- $\quad$ Published information (AOGCC, 1993b; ADNR, 1995c)

- Production history to date (AOGCC, 1993j; AOGCC, 1994c)

- Production decline rate of about $12 \%$

- Peak production rate over 3-year period.

Cumulative production through December 1994 is about 45.7 MMBO. The remaining reserves of 294.3 MMBO are forecasted to be recovered over a 14-year period. The PMPA production forecast is given in Table A.26.

Table A.26 PMPA production forecast.

\begin{tabular}{||c|c||c|c|}
\hline Year & MBPD & Year & MBPD \\
\hline 1995 & 104.0 & 2002 & 47.5 \\
\hline 1996 & 104.0 & 2003 & 42.0 \\
\hline 1997 & 91.0 & 2004 & 37.0 \\
\hline 1998 & 81.0 & 2005 & 33.0 \\
\hline 1999 & 71.0 & 2006 & 29.0 \\
\hline 2000 & 62.0 & 2007 & 25.8 \\
\hline 2001 & 54.0 & 2008 & 25.0 \\
\hline
\end{tabular}


A.2.10.1.4 Operating Costs-Operating costs are divided between field operating costs and facilities sharing costs (ADNR 1992n). Field operating costs are based on a BTF cost factor and a water-cut relationship to determine total fluid produced. The smoothed Milne Point Unit model results (Figure A.10) are used for PMPA. As operating cost estimates are not in public records, the following assumptions are used:

- $\$ 1.00 / \mathrm{BBL}$ oil for well workovers

- $\$ 0.50 / \mathrm{BBL}$ oil for maintenance and repairs

- $\quad \$ 0.25 / \mathrm{BBL}$ oil for field expenses.

To relate these assumptions to total fluid production, it is assumed that $732 \mathrm{MMBBLS}$ of water will be produced during recovery operations. This results in a field operating cost of \$0.55/BTF (1995\$) and is used in the PMPA evaluation.

A.2.10.1.5 Point McIntyre Facilities Sharing Fees-PMPA production and injection fluids are processed through the LPA facilities and there are various facilities sharing fees. There is a charge of $\$ 2.00 / \mathrm{BBL}$ of hydrocarbons produced. This charge totals $\$ 680 \mathrm{MM}$, and is applied to the annual oil production volumes in the evaluations.

For simplification, the following sharing fees are estimated on a BTF basis.

- $\quad$ \$0.17/BBL water handling cost. This will apply to the estimated $723 \mathrm{MMB}$ water produced and a to reservoir voidage fill volume of 510 MMBBLS of water. The voidage fill volume is assumed as 1.5 BBL water/1.0 BBL oil produced. This results in a total water handling cost of \$209.61 MM. On a BTF basis, this is $\$ 0.20 / \mathrm{BTF}(1995 \$)$.

- A share of the LPC operating costs is assumed at $\$ 1.00 / \mathrm{BBL}$ oil or a total of $\$ 340 \mathrm{MM}$. On a BTF basis this charge is $\$ 0.32 / \mathrm{BTF}(1995 \$)$.

The total facilities cost sharing fee paid by Point McIntrye is $\$ 0.52 / \mathrm{BTF}$ (1995\$) plus the hydrocarbon charge of $\$ 2.00 / \mathrm{BBL}$ oil produced. 
A.2.10.1.6 Field Pipeline Tariff--A tariff of $\$ 0.32 / B B L$ is used in the PMPA evaluation (see Appendix B.1.1.1.4).

A.2.10.1.7 Future Producers--The Set B equations in Appendix C.1.1.6 is used to estimate future annual producers.

A.2.10.2 Summary. The Point McIntyre Field was discovered in 1989. The Prudhoe Bay Unit was expanded to include Point McIntyre acreage as a new participating area. Initial development and production began in 1993. The development was made more attractive by the utilization of excess LPA facilities capacity. Ultimate reserves are estimated at $340 \mathrm{MMBO}$.

Analysis using the four price forecasts in Table B.1, Appendix B.1.1 show that all of the forecasted liquid can be economically recovered using the EIA reference and high oil price forecasts. Using the EIA low oil price forecast, PMPA loses about $87 \mathrm{MMBO}$. About $40 \mathrm{MMBO}$ are lost using the flat oil price scenario. The evaluation results are given in Table A.27.

Table A.27 PMPA economics.

\begin{tabular}{|c|c|c|c|c|}
\hline \multirow{2}{*}{ Economic Factor } & \multicolumn{4}{|c|}{ Oil Price Forecasts } \\
\hline & $\begin{array}{c}\text { AEO95 } \\
\text { Low }\end{array}$ & $\begin{array}{c}\text { AEO95 } \\
\text { Reference }\end{array}$ & $\begin{array}{l}\text { AEO95 } \\
\text { High }\end{array}$ & $\begin{array}{l}\text { Flat Oil Price } \\
\text { \$18/BBL }\end{array}$ \\
\hline Remaining Project Life - yrs & 7 & 14 & 14 & 10 \\
\hline $\begin{array}{r}\text { Remaining Reserves - MMBBLS } \\
- \text { TCF (Sales) }\end{array}$ & $\begin{array}{c}207 \\
0\end{array}$ & $\begin{array}{c}294 \\
0\end{array}$ & $\begin{array}{c}294 \\
0\end{array}$ & $\begin{array}{c}254 \\
0\end{array}$ \\
\hline Investments - as spent (\$, millions) & 282 & 282 & 282 & 282 \\
\hline Operating Costs - as spent ( $\$$, millions) & 879 & 1,929 & 1,929 & 1,309 \\
\hline Cash Flow -NPV 10 (1995\$, millions) & 175 & 649 & 867 & 532 \\
\hline
\end{tabular}

\section{A.2.11 Niakuk}

The Niakuk oil pool was discovered in early 1985 , by the drilling of Niakuk No. 5. Production is from the Kuparuk River sand formation. The oil pool is within the Prudhoe Bay Field (AOGCC 1994) and 
is located offshore north of Heald Point (Figure 2.2).

After efforts to develop Niakuk from an offshore gravel island were abandoned, the development of the field by directional drilling from a pad on Heald Point was initiated in 1993 (Alaska Journal of Commerce, 1993). Production began in April 1994, at about 12 MBPD. Production averaged about 15 MBPD during January 1995 (AOGCC, 1995). Peak rate of about 23 MBPD is expected by January 1996 (AOGCC, 1993h). Production is processed through the LPC (AOGCC, 1993h).

A.2.11.1 Development Plan. Future development plans include the Alapah formation (AOGCC, 1993h; ADNR, 1991g). The Alapah is included in the evaluation. Consideration will be given to development of a potential Kuparuk River oil accumulation north of the Niakuk pool (AOGCC, 1993h). A potential extension of the Kuparuk River reservoir to the west has apparently been proven and may be included in the development area (AOGCC, 1994).

Initial development is in the Kuparuk formation from a 20-well drilling pad on Heald Point. In January 1995, there were seven producers and no injectors (AOGCC, 1995). Current development plans include about 10 wells producing for 1 year. At that time, about April 1995, four or five of these wells will be converted to water injectors (AOGCC, 1995a). Ultimate development plans may include a total of nine producers and five injectors for the Niakuk Kuparuk reservoir (AOGCC, 1994). The potential reserves of the north accumulation are not included in the evaluation.

Production is processed through the LPC and excess gas above lease use are injected into the Lisburne gas cap. Pressured water for enhanced oil recovery will be obtained from PBU (AOGCC, 1993h).

A.2.11.2 Input Data. The evaluation data are developed using production history, current development plans and published information.

A.2.11.2.1 Recoverable Oil--Current estimates of OOIP for the Kuparuk River formation is 137.4 MMSTB. Original gas-in-place is estimated at 90.9 billion cubic feet (BCF) (AOGCC, 1993h). Anticipated ultimate recovery under waterflood operations is about $40 \%$ of OOIP or 54 MMBO (AOGCC, 1993h; Anchorage Daily News, 1994a). This recovery volume is adopted for evaluation.

Estimates of OOIP for the Alapah are not available. Per well recovery of $1.75 \mathrm{MMBO}$ used in the 
previous DOE publication (1993) is adopted for this evaluation. Ultimate recovery from the Alapah in Niakuk is about 5.0 MMBO, with development commencing in 1997.

A.2.11.2.2 Investments-The previous DOE publication (1993) used total development costs of $\$ 186$ million (1992\$), with some facilities. sharing at LPC and a buy-in of the LPA oil sales line. Since then the estimated total cost for of the project has been reduced to $\$ 130$ million (1993\$) (Alaska Journal of Commerce, 1993) and later to $\$ 110$ million (1994\$) (Alaska Daily News, 1994a). The $\$ 110$ million (1994\$) is adopted for evaluation. The investment total in $1995 \$$ is $\$ 112.4 \mathrm{MM}$. Funds are not included for a buy-in of the LPA pipeline as current information indicates this did not occur (ADNR, 1991g; AOGCC, 1993h). It is assumed that technical advances have reduced drilling costs to $\$ 3.88$ million (1995\$) from the $\$ 6.15$ million (1992\$) used in the previous DOE publication (1993).

Alapah development costs are assumed to be for drilling wells only and the cost to drill Kuparuk River wells is used for the Alapah wells.

It is assumed that seven Kuparuk wells were drilled prior to 1/1/95 (AOGCC, 1995) and that about $90 \%$ of the facilities investments were spent prior to $1 / 1 / 95$. The estimated future investments for the Kuparuk River and Alapah developments are given in Table A.28.

Table A.28. Niakuk drilling and investment schedule.

\begin{tabular}{||l|l|l|l|l|l||}
\hline \multirow{2}{*}{ Year } & \multicolumn{2}{|c|}{ Wells } & \multicolumn{2}{c|}{ Investments - 1995\$, millions } \\
\cline { 2 - 7 } & Kuparuk & Alapah & Wells & Facilities & Total \\
\hline 1995 & 7 & 0 & 27.2 & 5.6 & 32.8 \\
\hline 1996 & 0 & 0 & 0 & 0 & 0 \\
\hline 1997 & 0 & 2 & 7.8 & 0 & 7.8 \\
\hline 1998 & 0 & 1 & 3.9 & 0 & 3.9 \\
\hline Total & 7 & 3 & 38.9 & 5.6 & 44.5 \\
\hline
\end{tabular}

A.2.11.2.3 Production Forecasts-Published information indicate a productive life of 15 years for the Kuparuk River (Alaska Journal of Commerce, 1993; Alaska Daily News, 1993). Peak oil rate is expected to be between $20 \mathrm{MBPD}$ and $25 \mathrm{MBPD}$ (ADNR, 1991g; Alaska Daily News, 1994a). The State has limited the oil rate to $23 \mathrm{MBPD}$ (AOGCC, 1994), and that rate is used in the evaluation. A Kuparuk 
River production forecast was provided to the state in October 1993 (AOGCC, 1993h). The Kuparuk forecast is determined using a 2 year peak rate of $23 \mathrm{MBPD}$ and a decline rate of about $17 \%$ per year over a 9 year life. The production rate forecast for the Alapah is patterned after the forecast developed in the previous DOE publication (1993).

The individual production forecasts for the Kuparuk River sands and the Alapah, and the total project forecast are given in Table A.29. Total volume forecasted is about 56.0 MMBO. With cumulative production of about 3.4 $\mathrm{MMBO}$, ultimate recovery totals $59.4 \mathrm{MMBO}$.

Table A.29. Niakuk production forecast (MBPD)

\begin{tabular}{||l|l|l|l||}
\hline Year & Kuparuk & Alapah & Total \\
\hline \hline 1995 & 18.5 & 0 & 18.5 \\
\hline 1996 & 23.0 & 0 & 23.0 \\
\hline 1997 & 23.0 & 0.5 & 23.5 \\
\hline 1998 & 19.1 & 2.5 & 21.6 \\
\hline 1999 & 15.8 & 2.5 & 18.3 \\
\hline 2000 & 13.1 & 2.5 & 15.6 \\
\hline 2001 & 10.9 & 2.1 & 13.0 \\
\hline 2002 & 9.0 & 1.8 & 10.8 \\
\hline 2003 & 7.5 & 1.6 & 9.1 \\
\hline
\end{tabular}

A.2.11.2.4 Operating Costs-In the previous DOE publication (1993), operating costs were divided between field costs (well operation, maintenance, and well workovers) and cost sharing fees for use of the LPC facilities. Both operating costs were based on a BTF cost factor, using the Milne Point Unit model water cut relationship (Figure A.10) to determine total fluid produced.

The operating cost factor of \$1.13/BTF (1995\$) (DOE 1993) was determined by using estimated reductions in facilities costs due to sharing in LPA facilities. Recent information indicates the LPA operator is performing some of the maintenance and other day-to-day operations (Anchorage Daily News, 1993), and a reduction of the operating cost factor is made. However, well workover costs of $\$ 18.85$ million (1995\$) (DOE 1993) are not reduced. The previous operating cost without well workovers is $\$ 1.07 / B T F$ (1995\$). 
It is assumed that the Niakuk operator will incur only $25 \%$ or $\$ 0.27 / \mathrm{BTF}$ of this well workover cost. The well workover cost related to a total produced fluid volume of $236 \mathrm{MMBBLS}$ is $\$ 0.08 / \mathrm{BTF}$. The total of these two cost factors gives a revised operating cost of $\$ 0.35 / \mathrm{BTF}(1995 \$)$ that is used in the evaluation.

A.2.11.2.5 Facilities Sharing Fees-The provisions for Niakuk to share in the LPA facilities are not known. The facilities sharing fees for Niakuk are patterned after the cost sharing agreement between Point McIntyre and the LPC (ADNR, 1992n), that sets out various individual fees. There is a charge of $\$ 2.00 / \mathrm{BBL}$ for hydrocarbons processed. This charge is applied to the annual produced oil volumes, and for Niakuk, totals about $\$ 118$ million (1995\$).

For simplification, the following sharing fees are estimated on a BTF basis:

- $\$ 0.17 / \mathrm{BBL}$ water handling costs. This is applied to the estimated 177 million barrels of water (MMBW) water produced and a reservoir voidage fill volume of $89 \mathrm{MMBW}$. Voidage fill is assumed at 1.5 BBL of water per 1.0 BBL oil produced. This results in a total water handling cost of $\$ 45.2 \mathrm{MM}$. On a BTF basis, this is $\$ 0.19 / \mathrm{BTF}(1995 \$)$.

- $\$ 1.00 / \mathrm{BBL}$ oil for a share of facilities operating costs, including gas handling, gas lift, maintenance and repairs. On a BTF basis this is $\$ 0.25 / \mathrm{BTF}(1995 \$)$.

- Assume the reduction of $\$ 0.81 / B T F$ in Niakuk operating costs resulting from the LPA's performance of field operations, less the above sharing fees, will apply as a facilities sharing cost.

The facilities sharing fee on a BTF basis totals $\$ 0.81 /$ BTF $(1995 \$$ ) and is used in the evaluation.

A.2.11.2.6 Future Producers-The Set B equations in Appendix C.1.1.6 is used to forecast future annual producers.

A.2.11.2.7 Field Pipeline Tariff-Niakuk oil production is shipped to PS No. 1 through the Lisburne pipeline. The estimated tariff used in the evaluation is $\$ 0.32 / B B L$ (1995\$) (see Appendix B.1.1.1.4).

A.2.11.3 Summary. The Niakuk oil pool was discovered in 1985. Production is from the Kuparuk 
River sand formation. The oil pool is within the Prudhoe Bay Unit and is located offshore north of Heald Point. Initial plans to develop from an offshore island were abandoned in 1991. Later plans to develop from a shore site were initiated. Final plans included utilizing excess processing capacity at LPC. With engineering improvements, the total cost to develop Niakuk, including the Alapah, was reduced from about $\$ 200$ million (1995\$) estimated in the previous DOE publication (1993), to the current estimate of $\$ 123.7$ million (1995\$) total investment. The estimated remaining recoverable oil volume is $55.6 \mathrm{MMBO}$ (proven reserves).

Analysis using the four price forecasts listed in Table B.1, Appendix B.1.1 show that all of the forecasted liquids can be economically recovered using the EIA reference and high oil price forecast. About $18 \mathrm{MMBO}$ are lost using the ELA low oil price forecast. The project loses about $7 \mathrm{MMBO}$ when the flat oil price scenario is used in the project economics. The evaluation results are shown in Table A.30.

Table A.30 Niakuk economics.

\begin{tabular}{|c|c|c|c|c|}
\hline \multirow{2}{*}{ Economic Factor ${ }^{2}$} & \multicolumn{4}{|c|}{ Oil Price Forecasts } \\
\hline & $\begin{array}{c}\text { AEO95 } \\
\text { Low }\end{array}$ & $\begin{array}{c}\text { AE095 } \\
\text { Reference }\end{array}$ & $\begin{array}{c}\text { AEO95 } \\
\text { High }\end{array}$ & $\begin{array}{c}\text { Flat Oil Price } \\
\text { \$18/BBL }\end{array}$ \\
\hline Remaining Project Life - yrs & 5 & 9 & 9 & 7 \\
\hline $\begin{array}{r}\text { Remaining Reserves - MMBBLS } \\
\text { - TCF (Sales) }\end{array}$ & $\begin{array}{c}38.3 \\
0\end{array}$ & $\begin{array}{c}55.6 \\
0\end{array}$ & $\begin{array}{c}55.6 \\
0\end{array}$ & $\begin{array}{c}48.7 \\
0\end{array}$ \\
\hline Investments - as spent ( $\$$, millions) & 45.6 & 45.6 & 45.6 & 45.6 \\
\hline Operating Costs - as spent ( $\$$, millions) & 161.2 & 378 & 378 & 259 \\
\hline Cash Flow - NPV 10 (1995\$, millions) & 18.6 & 100 & 146 & 93 \\
\hline
\end{tabular}

\section{A.2.12 Other Fields}

The West Beach and North Prudhoe Bay State are two small PAs within PBU. Currently each has one producing well. These two PAs are discussed in the following sections.

A.2.12.1 West Beach Participating Area. WBPA is located offshore, north of the Lisburne Production Center. WBPA became effective during 1993 (AOGCC, 1993c), with initial production from 
the Kuparuk River sand formation in April 1993. Cumulative recovery, from WBPA No. 4, totaled about 1.25 MMBBLS (oil and NGLs), through (12/31/95) (AOGCC, 1994c).

A.2.12.1.1 Recoverable Oil-Estimates of OOIP in the Kuparuk formation range from 12 to $65 \mathrm{MMBO}$ (AOGCC, 1993). Potential wells for recovery ranging from 1 for the lower OOIP volume to 12 wells if the upper OOIP volume is proven. Information indicates a very minor gas cap is present (AOGCC,1993a). Based on performance to date, future recovery from Well No. 4 is estimated at about $0.620 \mathrm{MMBO}$ (oil and NGLs) over the next four years. Ultimate recovery is about 1.87 MMBO or about $15 \%$ of OOIP (of $12 \mathrm{MMBO}$ ). That is a reasonable recovery for primary operation only.

A.2.12.1.2 Current Operations-All produced fluids are processed through LPC facilities (AOGCC, 1993). Excess gas is injected into the Lisburne gas cap (AOGCC 1993a). No details of the facilities sharing arrangement with LPC are available, however, it is assumed such fees would be similar to those set out for Point McIntyre (ADNR, 1992n).

A.2.12.1.3 Future Plans-At present, there are no published plans for additional development nor have any additional wells been permitted through February 1995 (AOGCC, 1995).

A.2.12.1.4 Summary-Ultimate recovery from WPBA No. 4 is expected to total about 1.87 MMBO. Based on available information, it is concluded that further development of the WBPA would result in marginal economics. Lacking information on future development plans, it is assumed that further development will not occur.

Because of the small amount of future reserves (0.620 MMBO), WBPA is not included in the economics evaluations of producing North Slope fields. Its exclusion will have a minimal effect on the study results.

A.2.12.2 North Prudhoe Bay State Participating Area. NPBSPA is located on the Prudhoe Bay shoreline north of the Lisburne Production Center. NPBSPA became effective in 1994 (ADNR, 1994p). However, initial production began in October 1993, to aid in determining the potential of the Ivashak, Sag River, and Shublik reservoirs. Production is from North Prudhoe Bay State No. 3.

A.2.12.2.1 Recoverable Oil-Cumulative production through 12/31/94 totaled about 
1.2 MMBO, however, monthly history is incomplete and difficult to analyze (AOGCC, 1994c). An indicated OOIP of 12.13 MMB is given in the Tract Participation Table presented in the application to form the participating area (ADNR, 1994p). Other information indicates an OOIP of 12 MMBO and an OGIP of 31 BCF (AOGCC, 1994c). Expected ultimate recovery (\% of OOIP) is not available. An assumed 35\% recovery factor gives total recovery of about 4.2 MMBO. This recoverable oil volume is adopted for this study and results in future recoverable oil of about 3.0 MMBO.

A.2.12.2.2 Current Operations-All Produced fluids are processed through LPC facilities (ADNR, 1994p). Excess gas is injected into "another Greater Point McIntyre Area reservoir" (ADNR, 1994p), which is assumed to be the Lisburne gas cap. No information is available on the facilities sharing agreement with LPC, however, it is assumed sharing fees are similar to those set out for Point McIntyre (ADNR, 1992n).

A.2.12.2.3 Future Plans-At present there no published plans for additional development at NPBSPA, nor have any additional wells been permitted through February 1995 (AOGCC 1995).

A.2.12.2.4 Summary-Ultimate recovery for NPBSPA is estimated to total about 4.2 MMBO (oil and NGLs). Based on available information, it is believed that further development of the NPBSPA would result in marginal economics. Lacking information on future development plans, it is assumed that further development will not occur.

Because of the small amount of future reserves (3.0 MMBO), NPBSPA is not included in the economic evaluations of producing North Slope fields. Its exclusion will have a minimal effect on the study results.

\section{A.2.13 Summary of Producing Fields.}

The Prudhoe Bay field was discovered in 1968, with initial production occurring in 1977. Since then an additional 9 oil pool have been developed for production in the immediate area, with the most recent being Niakuk in 1994. Annual average production peaked in 1988 at just over 2 MMBOPD, when PBU production began to decline. The other developed oil pools were not large enough - in comparison - to offset the decline at PBU. The ten active projects on the North Slope produced about 1,700 MBOPD at the start of 1995. Cumulative ANS recover of oil, condensate, and NGLs totaled about 10,500 MMBBLS at 12/31/94. 
Future recoverable oil, at 1/1/95, is estimated at about 6,100 MMBBLS through 2025. The historic and projected oil production from the developed fields on the North Slope is shown in Figure A.1.

Project evaluations show that all of the forecasted liquid hydrocarbons can be economically recovered using the EIA reference and high oil price forecasts. The use of the EIA low oil price scenario results in a reduction of about $2,200 \mathrm{MMBO}$ recovery and the shortening of the producing life to 2006 . The use of the flat oil price scenario results in a reduction of about $370 \mathrm{MMBO}$ with a productive life through 2015. This demonstrates the sensitivity of ANS oil production to oil pricing, and also to the obvious need to discover and develop potential ANS reserves before the PBU and TAPS infrastructures are lost.

The composite North Slope production forecasts for the case without major gas sales, with major gas sales, and with a GTL converted liquids sales case are shown in Figures 2.3, 2.4, and 2.9, respectively. As indicated by the analysis and discussion in this section, the interest and commitment to the North Slope area continues to be high. However, it is clear that without additional development and new discoveries, the existing fields will reach the lower limits of TAPS operation in 2009 for a minimum throughput rate of 400 MBOPD and in 2016 for a minimum of $200 \mathrm{MBOPD}$. The effects of an economic GTL conversion technology on maintaining the viability of the North Slope oil production capability is clearly demonstrated in Figure 2.9.

\section{A.3 Fields with Development Potential}

The North Slope has many discovered, but undeveloped fields with resources totaling over 1 billion BBL oil and 4 TCF gas. They range from very small fields to large fields with billions of barrels of liquids in place and 3 TCF gas. Oil fields included are West Sak, Ugnu, Fish Creek, Umiat, Simpson, Gwydyr Bay, Northstar, Hammerhead, Colville Delta, Sandpiper, Badami, Kuvlum, Sourdough, and Cascade (see Figure 2.1). Gas fields included are Meade, Wolf Creek, Gubik, Square Lake, Kavik, Kemik, Point Thomson/Flaxman Island, and Walakpa (see Figure 2.1 and Figure 2.2) (Bird, 1990; AOGR, 1995e; OGJ, 1995c; ADNR, 1995c).

Although these fields are small by North Slope standards, they would most likely have been developed if located in the Lower 48. However, with the apparent cooperation between the State and operators, combined with the State of Alaska's need for additional revenues, and the declining North Slope production, several of the marginal oil fields are getting renewed study for development possibilities 
(AOGR, 1995e). Development of the more promising of these resources, could extend the life of the North Slope producing properties, which would allow more time for additional oil exploration and potential development, as well as, allowing time for the development of a gas sales scenario.

It is probable that most, if not all, of the gas resource accumulations were discovered by exploration efforts looking for oil. Based on gas discoveries to date, it is likely that many more gas accumulations could be discovered that might allow facilities sharing arrangements similar to those currently being employed in the PBU area.

Several of the more prominent oil and gas resource accumulations are discussed in the following sections. The first discussion is for the Point Thomson Unit (PTU), which contains the second largest gas resource on the ANS.

\section{A.3.1 Point Thomson Unit}

The Point Thomson Unit (PTU) covers a gas condensate field about $50 \mathrm{mi}$ east of TAPS PS No. 1. The unit contains about 83,800 acres, much of which is offshore (Figure 2.2). Discussions are apparently in progress on possible contraction of the unit area; however, the outcome of these discussions is not known at this time (ADNR, 1994t). [A detailed description of the Point Thomson field is contained in the previous DOE publication (1993)]. Early estimates of PTU reserves carried by the ADNR (1991a) were 5 TCF gas and $300 \mathrm{MMBBLS}$ of oil and condensate. The possibility of a reduced reservoir size was mentioned in a letter from the unit operator to the ADNR (1991e). The current reserve estimates for the PTU carried by the ADNR (1995c) are 3 TCF gas and 200 MMBBLS of oil and condensate. The Alaska Department of Revenue (ADOR) does not include major North Slope gas sales in their Spring 1995 forecast of revenue (ADOR, 1995).

A.3.1.1 Date of Initial Production. The date of initial production is unknown. A number of articles have been published that discuss sale of North Slope gas with possible dates of first gas sales varying from 1997, at the earliest, to beyond 2010 at the latest (Anchorage Times, 1991a; Anchorage Times, 1991b; Anchorage Times, 1991c; Anchorage Daily News, 1992). The date of first gas sales from PTU is dependent on gas sales from PBU or some large undiscovered gas field with PBU-size reserves to justify a gas sales market. Any gas sales scenario is dependent on an end-point market willing to pay a price to justify the total project. The following assumptions are made concerning the development of PTU. 
1. Gas is sold in the PBU area for transport to an LNG plant at Valdez for shipment to Asian markets or to a GTL plant that is expanded to handle PTU gas as well as the PBU gas.

2. A gas sales system is completed by 2005 (Anchorage Daily News, 1992).

3. PBU gas becomes available during the year 2005. A ramp-up of 5 years is used for gas sales to reach $2.05 \mathrm{BCF} / \mathrm{D}$.

4. PTU development begins in 2002 with first production about 2008.

A.3.1.2 Evaluation Data. Public data are used where available; otherwise, best judgement estimates are made. Well and test information are used extensively.

A.3.1.3 Reservoir Volume. The reserves carried by the ADNR (1995c) are used as a guide in developing the base case.

A.3.1.3.1 Reservoir Area-To obtain an independent estimate of field reserves an approximate field size is required and used to determine the number of wells for field development. Information obtained from the exploratory wells in the Point Thomson area is used to estimate a possible reservoir limit boundary. This limit is shown by the solid line on Figure A.12 and contains 23,800 acres.

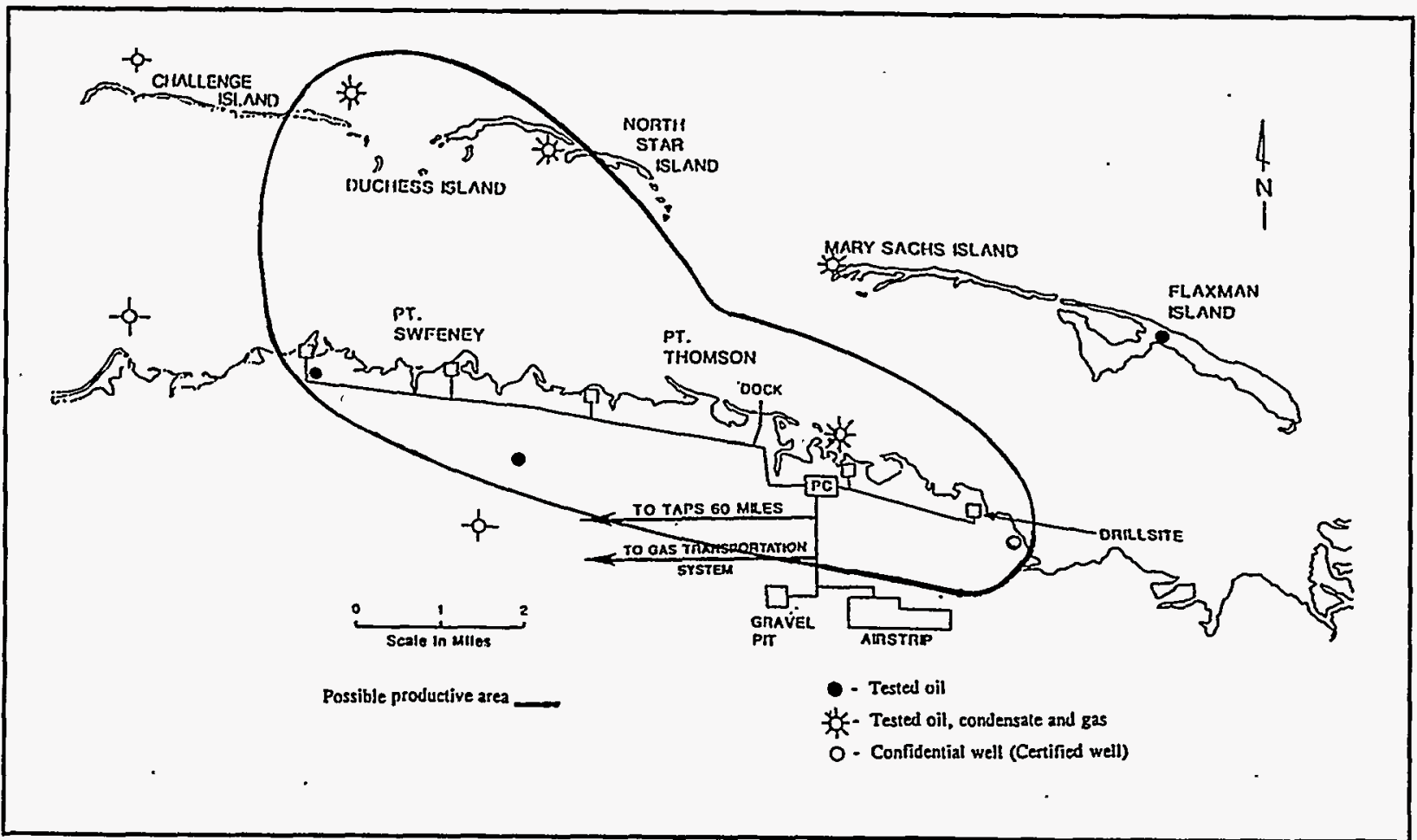

Figure A.12 PTU possible reservoir limit. 
A.3.1.3.2 Development Plan. One possible gas sales development scenario is based on the reservoir area of 23,800 acres. This scenario assumes the area can be drained from 32 wells drilled from onshore pads. The five onshore drillsites are connected to a central processing center (Figure A.13). Two pipelines are required, one for liquid sales to TAPS PS No. 1, and the other to a gas sales point in the Prudhoe Bay field area. Figure A.14 shows a possible sales pipeline and main road corridor. Figure A.14 also shows the five major river crossings that the pipelines and road would encounter.

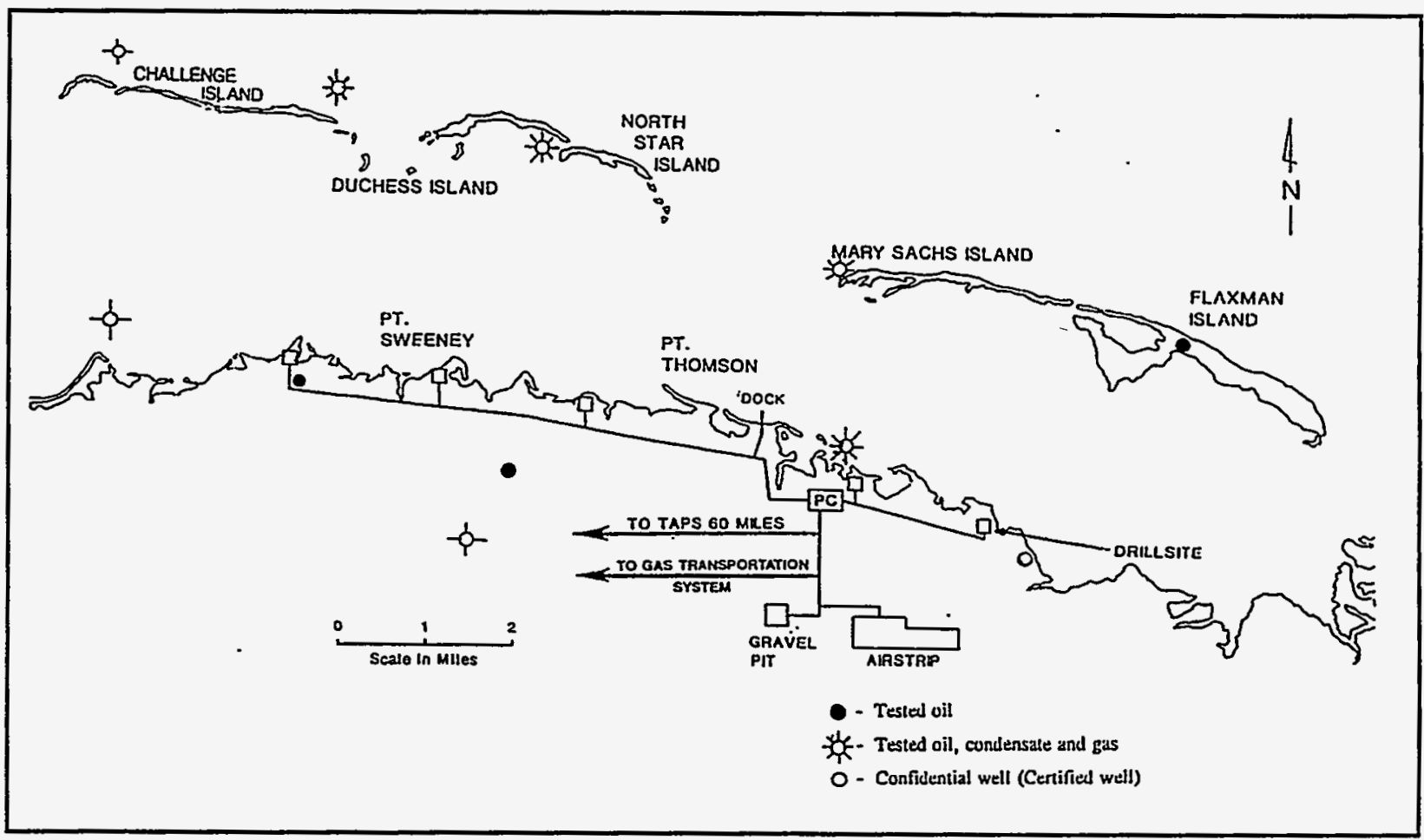

Figure A.13. PTU possible development plan for gas sales.

A.3.1.3.3 Reservoir Parameters-The following reservoir parameters are used to determine gas volumes (ADNR, 1988; USGS, 1987).

- $\mathrm{S}_{\mathrm{w}}=35 \%($ Assumed)

- $h=110 \mathrm{ft}$ (The Pt. Thomson sand is up to $300 \mathrm{ft}$ thick. Two hundred feet is assumed as the average thickness. The Flaxman sand is $70 \mathrm{ft}$ thick in one well, but is limited to the northern area. In determining net pay, $70 \mathrm{ft}$ is assigned to $1 / 4$ of the productive area. Pre-Mississippian sand is present in two wells; therefore, $5 \mathrm{ft}$ is assigned to $1 / 20$ of productive area. A net-to-gross ratio of 0.50 is assumed, resulting in an average pay thickness of about $110 \mathrm{ft}$.)

- $\phi=20 \%$ (Varies by zone: Pt. Thomson - 5 to $25 \%$, Flaxman $>20 \%$, Pre-Mississippian - No record. An average of $20 \%$ is assumed for all zones.) 


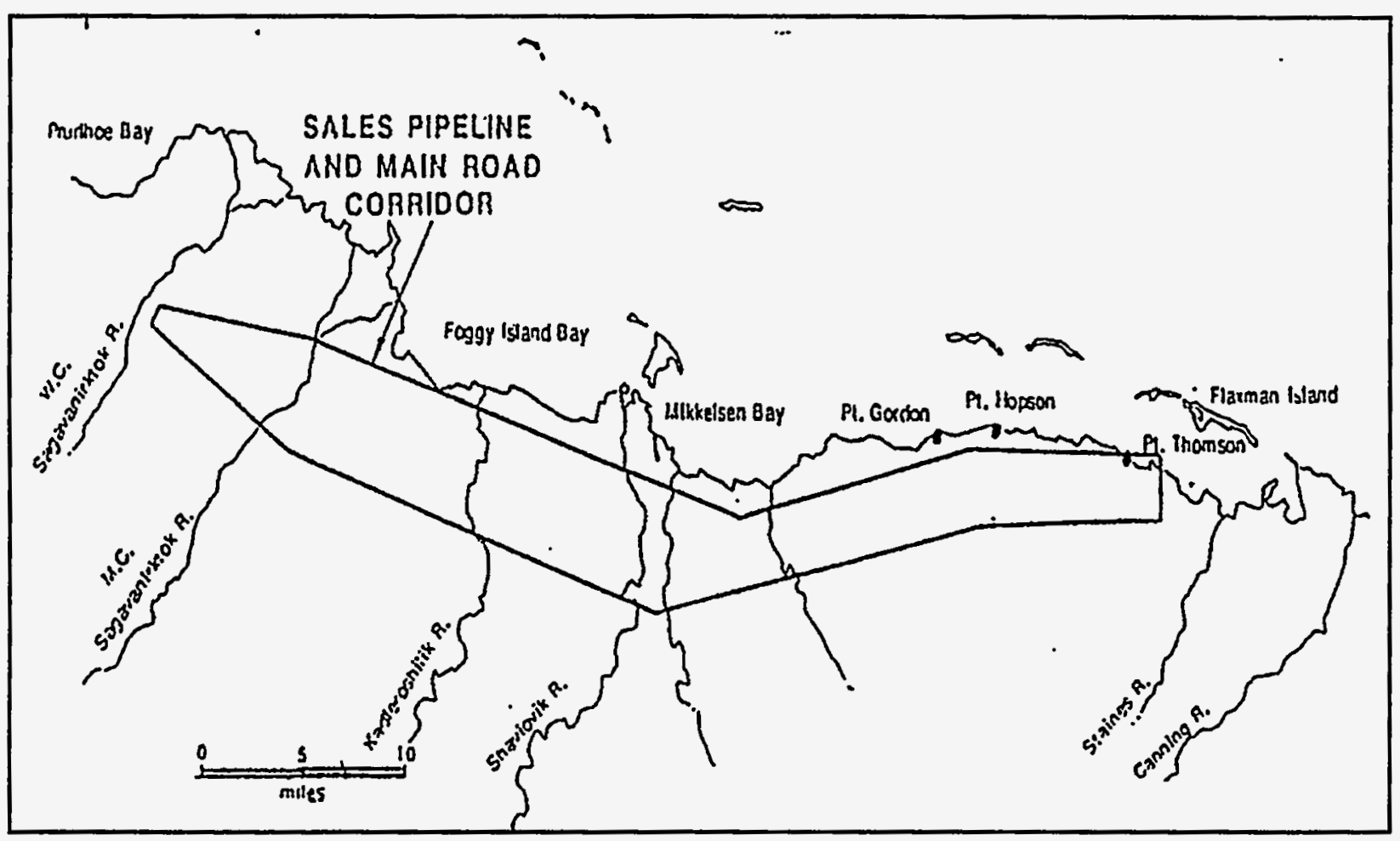

Figure A.14. PTU possible sales pipelines and main road corridor.

- $\mathrm{A}=23,800$ acres

- $\quad$ Reservoir temperature $\left(\mathrm{T}_{\mathrm{r}}\right)=238^{\circ} \mathrm{F}$ or $698^{\circ} \mathrm{R}$

- $\quad$ Reservoir pressure $\left(\mathrm{P}_{\mathrm{r}}\right)=10154.7$ PSIA

- $\quad$ Gas gravity $=0.8$ (Assumed)

- $\quad$ Gas compressibility at surface $\left(Z_{\mathrm{s}}\right)=1.0$

- Gas compressibility at reservoir conditions $\left(\mathrm{Z}_{\mathrm{s}}\right)=1.45$ (Assumed)

- $\quad$ Surface pressure $\left(\mathrm{P}_{\mathrm{s}}\right)=14.7$ PSIA

- Surface temperature $\left(\mathrm{T}_{\mathrm{s}}\right)=60^{\circ} \mathrm{F}$ or $520^{\circ} \mathrm{R}$

- $\mathrm{RF}=70 \%$.

A.3.1.3.4 Recoverable Gas--The volume of the reservoir occupied by gas, the volume of that gas at surface conditions, and the estimated recoverable hydrocarbon gas volume using the 23,800 -acre reservoir are as follows: 
(1) Reservoir gas volume, $\mathrm{G}_{\mathrm{r}}=14.83 \mathrm{TCF}$

(2) Gas volume at surface conditions, $\mathrm{G}_{\mathrm{s}}=5.26 \mathrm{TCF}$

(3) Recoverable gas (including $\mathrm{CO}_{2}+$ liquids), $\mathrm{G}_{\mathrm{p}}=3.68 \mathrm{TCF}$

(4) $\mathrm{G}_{\mathrm{p}}=3.54 \mathrm{TCF}$ w/o $\mathrm{CO}_{2}($ at $4 \%){ }^{\mathrm{a}}$

Based on available and assumed data, the net gas available for sales is determined as follows:

- Gas-in-place (DOE, 1995)

$=5.26 \mathrm{TCF}$

- Recoverable wet gas volume (70\% RF)

$=3.68 \mathrm{TCF}$

- $\quad$ Estimated lease use and shrinkage (10\%)

$=0.37 \mathrm{TCF}$

- $\mathrm{CO}_{2}$ removal (4\%)

$=0.13 \mathrm{TCF}$

- Net hydrocarbon gas available for sale

$=3.18 \mathrm{TCF}$

A.3.1.3.5 Recoverable Hydrocarbons-The volumes estimated in Appendix A.3.1.3.4 are wet gas. The wet gas is reduced for shrinkage from condensate removal and by adjusting for the reservoir occupied by the oil column. With an assumed $10 \%$ reduction, the revised gas reserve is in close agreement with reserve estimate of $3 \mathrm{TCF}$. The States' current reserves estimates of $3 \mathrm{TCF}$ and $200 \mathrm{MMBBL}$ condensate are used as guides in this evaluation.

A.3.1.3.6 Production Forecasts-A possible gas sales scenario is for a maximum production rate of 500 million cubic feet per day (MMCFPD) of wet gas. It is assumed that $60 \mathrm{MMCFPD}$ accounts for fuel, liquid shrinkage, and $\mathrm{CO}_{2}$ removal. The $\mathrm{CO}_{2}$ volume is $20 \mathrm{MMCFPD}$, using a $4 \% \mathrm{CO}_{2}$ concentration. A maximum sustainable dry gas sales rate of 440 MMCFPD is assumed starting in 2008. Gas sales can be continued for 19 yrs at 440 MMCFPD and with a reduction to 350 MMCFPD in the 2027 to match the estimated gas available for sale of 3.18 TCF for a 20 -yr life. It is assumed that PTU will be capable of delivering gas at the assumed gas sales rate without a falloff in the last few years of production.

The average oil rate for five drillstem tests (DSTs) is about 650 BOPD (ADNR, 1988; USGS, 1987). It is assumed that oil production averages $400 \mathrm{BOPD} /$ well for the first year and goes on decline at about $20 \% / y r$. The last year of oil recovery will be 2013 . This results in oil recovery of $12.8 \mathrm{MMBO}$.

a. Exxon Company U.S.A., personal communication, September 12, 1991. 
Information on liquid recovery is very limited. Both oil and condensate are produced with the gas. It is assumed that the $40^{\circ} \mathrm{API}$ condensate and oil mixture can be stabilized to meet TAPS specifications. Based on DST results, the condensate yield could be between 40 and 80 BBLS/per million cubic feet (MMCF) (ADNR 1988, USGS 1987). An initial condensate ratio of 70 BBLS/MMCF of wet gas is assumed in forecasting condensate rates. The estimated condensate production profile follows curve $\mathrm{C}$ of Figure A.15. A peak condensate ratio of about $80 \mathrm{BBLS} / \mathrm{MMCF}$ is reached in years 5 and 6 before declining to about 18.0 BBLS/MMCF in 2027. This rate forecast results in a recoverable volume of condensate of 194.2 MMBBLS over the 20-yr life. Hence, the potentially recoverable oil and condensate is 207.0 MMBBLS. The oil, condensate, and the gas forecasts are given in Table A.31. All 207.0 MMBBLS is recovered for the GTL option; however, for the LNG option, no liquids are sold after 2021 because of the shutdown of PBU oil production in 2021 (see Table A.4) resulting in a drastic increase in TAPS tariffs. This causes the PTU oil and condensate total recovery to be reduced to 181.4 MMBBLS.

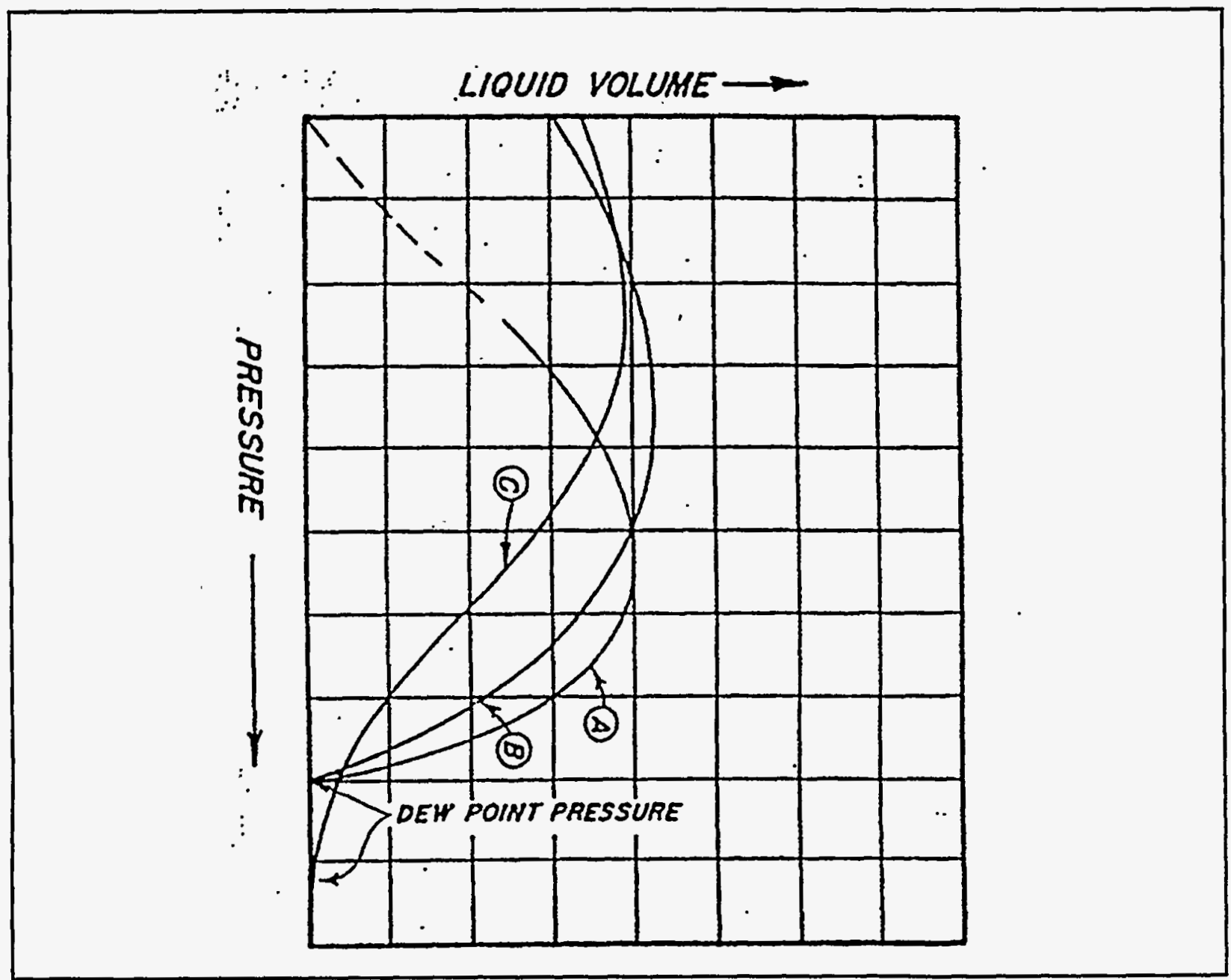

Figure A.15. Curves illustrating several types of liquid behavior of condensate systems (Standing, 1977). 
Table A.31. PTU production forecasts.

\begin{tabular}{|c|c|c|c|c|c|c|}
\hline \multirow{2}{*}{ Year } & \multicolumn{2}{|c|}{ Condensate } & \multirow{2}{*}{$\begin{array}{c}\text { Oil } \\
\text { (MBPD) }\end{array}$} & \multirow{2}{*}{$\begin{array}{c}\text { Sales } \\
\text { Liquids } \\
\text { (MBPD) }\end{array}$} & \multicolumn{2}{|c|}{ Gas } \\
\hline & $\begin{array}{c}\text { Ratio } \\
\text { (BBL/MMCF) }\end{array}$ & $\begin{array}{c}\text { Recoverable } \\
\text { (MBPD) }\end{array}$ & & & $\begin{array}{c}\text { Wet Gas } \\
\text { (MMCE/D) }\end{array}$ & $\begin{array}{c}\text { Gas Sales } \\
(\mathbf{M M C F / D )} \\
\end{array}$ \\
\hline 2008 & 71.1 & 35.53 & 9 & 44.53 & 500 & 440 \\
\hline 2009 & 77.6 & 38.80 & 8 & 46.80 & 500 & 440 \\
\hline 2010 & 79.5 & 39.75 & 6 & 45.75 & 500 & 440 \\
\hline 2011 & 80.0 & 40.00 & 5 & 45.00 & 500 & 440 \\
\hline 2012 & 79.9 & 39.95 & 4 & 43.95 & 500 & 440 \\
\hline 2013 & 78.2 & 39.10 & 3 & 42.10 & 500 & 440 \\
\hline 2014 & 75.8 & 37.90 & 0 & 37.90 & 500 & 440 \\
\hline 2015 & 72.0 & 36.00 & 0 & 36.00 & 500 & 440 \\
\hline 2016 & 67.5 & 33.75 & 0 & 33.75 & 500 & 440 \\
\hline 2017 & 61.9 & 30.95 & 0 & 30.95 & 500 & 440 \\
\hline 2018 & 54.2 & 27.10 & 0 & 27.10 & 500 & 440 \\
\hline 2019 & 48.2 & 24.10 & 0 & 24.10 & 500 & 440 \\
\hline 2020 & 41.5 & 20.75 & 0 & 20.75 & 500 & 440 \\
\hline 2021 & 36.7 & 18.35 & 0 & 18.35 & 500 & 440 \\
\hline 2022 & 30.9 & 15.45 & 0 & 15.45 & 500 & 440 \\
\hline 2023 & 28.1 & 14.05 & 0 & 14.05 & 500 & 440 \\
\hline 2024 & 24.7 & 12.35 & 0 & 12.35 & 500 & 440 \\
\hline 2025 & 22.0 & 11.00 & 0 & 11.00 & 500 & 440 \\
\hline 2026 & 20.0 & 10.00 & 0 & 10.00 & 500 & 440 \\
\hline 2027 & 18.0 & 7.20 & 0 & 7.20 & 400 & 350 \\
\hline
\end{tabular}

A.3.1.3.7 Investments--Methods to estimate investments for production facilities and field pipelines are discussed in the following section.

A.3.1.3.7.1 Facilities Investments-Facilities investments are estimated using a facility cost factor of $\$ 16,210 / \mathrm{BBL}$ (1995\$) of peak rate of production as discussed in Appendix B.1.7.1.1. The peak 
rate is determined by converting the produced wet gas volume to equivalent barrels using an assumed factor of 13.5:1. Because PTU is at a remote location, the facilities cost is increased by a factor of 1.2. The facilities investment estimated by this approach is $\$ 720.4$ million (1995\$). The estimated cost to drill and complete development wells in an overpressured reservoir, from an onshore drilling pad is about $\$ 4.83$ million (1995\$). The total number of wells is estimated using the area within the dashed line on Figure A.12. Spacing of 740 acres/well is assumed. This results in 32 wells for this scenario.

The facilities investment includes onshore facilities, pads, field roads and pipelines, causeway to a dock, airstrip, separation and treatment facilities, and compression (as needed for sales and for $\mathrm{CO}_{2}$ disposal). The assumed investment schedule spans 6 to 7 years of which about 2 years are for environmental impact statement preparation ( $\$ 2.8$ million in 1995\$) and approval followed by 4 to 5 years for design, construction, shipping, installing facilities and pipelines, and for drilling wells. Twenty producing wells are drilled and completed by the date of initial sales with the remaining 12 wells drilled over the next 2 years. The resulting investment schedule is shown in Table A.32.

Table A.32. PTU drilling and investment schedule.

\begin{tabular}{||c|c|c|c|c|}
\hline \multirow{2}{*}{ Year } & Wells & \multicolumn{3}{|c|}{ Investments - 1995\$, millions } \\
\cline { 2 - 5 } & No. & Wells & Facilities & Total \\
\hline 2002 & 0 & 0 & 2.8 & 2.8 \\
\hline 2003 & 0 & 0 & 0 & 0 \\
\hline 2004 & 0 & 0 & 17.2 & 17.2 \\
\hline 2005 & 5 & 24.2 & 255.6 & 279.8 \\
\hline 2006 & 7 & 33.8 & 222.4 & 256.2 \\
\hline 2007 & 8 & 38.6 & 222.4 & 261.0 \\
\hline 2008 & 6 & 29.0 & 0 & 29.0 \\
\hline 2009 & 6 & 29.0 & 0 & 29.0 \\
\hline Totals & 32 & 154.6 & 720.4 & 875.0 \\
\hline
\end{tabular}

A.3.1.3.7.2 Pipeline Investments--This development scenario requires both a gas and liquids line. To simplify the economic evaluation, it is assumed an outside concern will build and operate both lines. The estimated cost to construct the gas and oil pipelines to the Prudhoe Bay area is determined using data from 
Han-Padron (MMS, 1985). Assumptions used in this estimate are:

- $75 \%$ of the lines are below ground.

- One haul road is constructed.

- A reduction of $25 \%$ is realized in the investment for the smaller line when two lines are constructed simultaneously.

- The liquid line connects to the Endicott pipeline at the closest point.

- The gas sales line is south of the PBU central gas facility.

The estimated cost to construct the liquids line is $\$ 130.2$ million (1995\$) and the gas line is estimated to cost \$154.8 million (1995\$). Tariffs for the throughput volumes are discussed in Appendix A.3.1.3.9.

A.3.1.3.8 Operating Costs-There are no published estimates of operating costs for PTU. The method using a cost per barrel of total fluid and water-cut percentages related to ultimate recovery are not applicable at PTU because it is primarily a depleting gas condensate reservoir. An empirical method is used to estimate PTU operating costs (Appendix B.1.5.1). Cumulative inflated investment and a 5\% factor are used to determine annual operating costs. Because all wells are required for deliverability throughout the project life, operating costs are not reduced in late project years.

A.3.1.3.9 Field Pipeline Tariffs-The PTU development scenario assumed for this evaluation, requires that both a gas and a liquids sales line be built and pipeline tariffs charged.

A.3.1.3.9.1 Liquids Line--The PTU liquids pipeline is connected to the Endicott pipeline. A separate and revised field pipeline tariff is calculated for both the PTU liquids pipeline and for the Endicott pipeline for the increased throughput. A tariff is calculated separately for the PTU liquids pipeline segment using the formula in Appendix B.1.1.1.4, a pipeline cost of $\$ 130.2$ million (1995\$) and a liquids throughput volume of 181.4 MMBBLS for the LNG option and 207 MMBBLS for the GTL option. The tariffs for the PTU liquids pipeline segment are \$2.40/BBL for the LNG option and \$2.11/BBL for the GTL option.

It is assumed the closest tie-in point is located about mid-way on the Endicott pipeline or about 12 miles from PS No. 1. Using the currently estimated Endicott pipeline tariff of $\$ 0.68 / \mathrm{BBL}(1995 \$)$ for a throughput of 470.6 MMBO (Appendix B.1.1.1.4) the adjusted tariff after adding the PTU liquids sales 
volume of $207 \mathrm{MMBBLS}$, is $\$ 0.24 / \mathrm{BBL}(1995 \$)$. That tariff is applicable only to the Point Thomson liquids.

The total field tariff for PTU liquids is the sum of these two tariffs or $\$ 2.64 / \mathrm{BBL}$ for the LNG option and $\$ 2.35 / \mathrm{BBL}$ for the GTL option.

A.3.1.3.9.2 Gas Line--The PTU gas pipeline is connected to a central plant owned by the gas purchaser. The tariff is calculated by using the formula in Appendix B.1.1.1.4 with a gas pipeline cost of $\$ 154.8$ million (1995\$) and the gas sales volume of 3.18 TCF. The tariff is $\$ 0.16 / \mathrm{MCF}(1995 \$)$ for both LNG and GTL options.

A.3.1.3.10 Gas Sales Price-The gas sales price is determined by the method discussed in Appendix B.1.3 for both the LNG and the GTL options.

A.3.1.3.11 Royalty Rate-The majority of tracts carry $12.5 \%$ royalty, six tracts carry high NPIs or sliding scale royalty. An average royalty of $14.25 \%$ is assumed.

A.3.1.3.12 TAPS Tariff--TAPS tariffs are determined as discussed in Appendix B.1.1.1.2 for the LNG and GTL options. For the GTL option, this includes the addition of the liquid sales stream from the Prudhoe Bay area GTL plant to the producing fields oil production streams.

A.3.1.4 Summary. The Point Thomson field is a gas condensate resource in a deep overpressured reservoir that is located mostly offshore. It is not located close to the PBU infrastructure, but is 50 miles east of TAPS PS No. 1. It does not appear that development of Point Thomson for sales of liquids alone is economically feasible (ADNR, 1994t). In addition to the technical problems associated with developing a deep overpressured offshore field using highly deviated wells, the size of the resource is still questionable (ADNR, 1994t). Current estimates of recoverable gas reserves is $3.18 \mathrm{TCF}$.

The estimated Point Thomson reserve volume will not, by itself, justify the development of facilities for sale of North Slope gas. Sales from the much larger PBU gas cap, or a similar size gas reserve, will be required to justify any sales scenario. The earliest this might occur from PBU is about 2005 (Appendix A.2.2). However, before any gas sales can occur from the North Slope, a gas market must be available that will provide a purchase price for the gas that can justify development of the gas resources and the required infrastructure and facilities. In addition, the Point Thomson project faces the construction of field delivery 
lines to the Prudhoe Bay area that will encounter five major river crossings and be in the coastal plain. The impact of these conditions will not be determined until environmental assessments are conducted.

It is assumed that initial startup of a sales to a gas sales project (LNG or GTL) occurs in 2008. PTU oil, condensate, and gas production forecasts were given in Table A.31. The project life for PTU for both gas sales projects is 20 years. However, liquid production stops in 2021 for the LNG option due to the loss of PBU oil production that would result very high transportation tariffs and an almost certain shutdown of TAPS under even the most optimistic assumptions about TAPS shutdown rates. The liquid sales forecast for the GTL option continues for the full 20-yr life of gas sales and produces $26 \mathrm{MMBO}$ more liquids than in the LNG sales case. The annual gas and converted liquid sales volumes are shown in Table B.12.

Results in Table A.34 compares the two gas sales scenarios for the PTU. PTU gas sales lag 3 years behind PBU to account for the assumed field development schedule. The economic results are about the same for either gas sales option for PTU. The economic results are discussed in Section 5.2.4.

Table A.34. Point Thomson Unit economics - summary (1995\$).

\begin{tabular}{||l|c|c||}
\hline \multirow{2}{*}{ Economic Factor } & \multicolumn{2}{|c|}{ PTU Cases using AEO95 Reference Oil } \\
& \multicolumn{2}{|c|}{ Price } \\
\cline { 2 - 3 } & LNG Sales & GTL Sales \\
\hline Remaining Oil Project Life (yrs) & 14 & 20 \\
Gas Project Life w/sales beginning in 2008 (yrs) & 20 & 20 \\
\hline Reserves - million BBL & 181 & 207 \\
\hline Investments at PTU (\$, millions) & 3.18 & 3.18 \\
\hline Gas Product Net Back (\%) & 900 & 900 \\
\hline Revenue from Condensate \& Oil Sales (\$, Millions) & 2,300 & 15.1 \\
Maximum Revenue from Gas Sales (\$, Millions) & 3,900 & 3,400 \\
Total Revenue (\$, millions) & 6,200 & 2,900 \\
\hline After Tax Cash Flow (\$, millions) & 2,300 & 6,300 \\
\hline Discounted Cash Flow - NPV (\$, millions) & 350 & 2,300 \\
\hline
\end{tabular}




\section{A.3.3 West Sak Oil Pool}

The West Sak oil pool is located within the KRU, MPU and PBU (small part) unit boundaries, at depths between 2000 and $4500 \mathrm{ft}$ (See Figure 2.2). A detailed history and economic evaluation of West Sak is contained in the 1993 DOE publication (1993). Based on that evaluation, development of West Sak does not appear to be economic under current recovery technology and current oil prices (Anchorage Daily News, 1995a)

With about 16 billion barrels of original oil in place (OGJ, 1995c), the potential is large, but depends on improved technology and higher oil prices. The operator has announced renewed efforts to determine what research should be done to determine if the field is worth developing (Anchorage Daily News, 1995a). Three aspects of the study are reduction of drilling cost, improving completion techniques, and enhanced oil recovery processes. If after completion of these efforts, development is still not commercial, the operator intends to see if there are steps the State (reduced royalty and/or reduced taxes) and federal government (federal assistance program) will take to improve development economics (OGJ, 1995c).

Because of the uncertainties associated with this complicated field, no projection of field development can be made and therefore, no economic evaluation is included in this study.

\section{A.3.4 Badami Field}

Badami was discovered in 1990 . The discovery well tested at the rate of 4,250 BOPD. A confirmation well was drilled in 1992 and two additional wells were drilled in 1995 (OGJ, 1995c). Badami is located about 35 miles east of Prudhoe Bay (See Figure 2.1) and may contain about 150 MMBO recoverable reserves (Alaska Journal of Commerce, 1995c). No information is publicly available on the formation or depth. Most of the reservoir is located offshore under Mikkelsen Bay and, if further drilling confirms the resource to contain at least $100 \mathrm{MMBO}$ recoverable reserves, development could occur from an onshore drilling pad. Current plans call for a total of 60 wells, of which, 40 are for production, 18 are for water injection, and two are for gas injection (Alaska Journal of Commerce, 1995).

Current plans include efforts to reduce total project investments from an initial estimate of $\$ 780$ million (1995\$) to about $\$ 320$ million (1995\$) (AOGR, 1995m). Initially, produced fluid was to be shipped to Endicott for processing through an elevated pipeline. Revised planning uses a 27.9-mile, below 
ground, pipeline to move chilled oil to an Endicott pipeline tie-in. The estimated cost of the below ground pipeline is $\$ 50$ million (1995\$) or a savings of about $\$ 130$ million (1995\$) from an elevated line with four river crossings (OGJ, 1995c). The 20-inch pipeline is designed for a minimum 25 year life and would carry in excess of the potential 50 MBOPD from Badami. This would allow production from other possible accumulations to be shipped to PS No. 1 (Alaska Journal of Commerce, 1995).

One other requirement for development was taking steps to reduce operating costs below the best experienced on the North Slope. A crew of 12 would operate the field and there would be no permanent road connecting Badami to Prudhoe Bay (OGJ, 1995c). No other published information is available on the aspect of field operations where additional reductions might be effected (Alaska Journal of Commerce, 1995).

The operator has approached the state to change the way state royalties are determined to encourage development of this potential resource. The average royalty over the Badami leases is about $15 \%$ and could impact the development. A proposed sliding scale royalty scheme is being given consideration by the state (Alaska Journal of Commerce, 1995; Anchorage Daily News, 1995b).

The operator's approach could shorten the time between discovery and development by 3 years and allow development as early as 1997 (OGJ, 1995c). However, efforts to confirm the reservoir size are not complete and Badami is not included in the economic evaluation.

\section{A.3.5 Kuukpik Unit}

The Kuukpik unit is an exploratory unit in the Colville River delta area comprised of about 90,000 acres. It shares a common unit boundary with the northwest edge of KRU (PIC, 1992).

Exploratory efforts have been conducted in and around the unit area for several years and are continuing (ADNR, 1992d; ADNR, 1994m; PIC, 1992; Anchorage Daily News, 1995a). These efforts include geophysical programs and exploratory drilling. To date nine wells have been drilled, of which six have been reported as testing hydrocarbons. Only one well has been reported as a dry hole (PIC, 1992; ADNR 1992d). Oil recovery from two wells showed a gravity range of 21 to $32^{\circ}$ API (ARCO, 1992). Total depth of the wells is believed to be between 9,000 and 10,500 $\mathrm{ft}(\mathrm{ADNR}, 1992 \mathrm{e})$. No data are ávailable on the formation or the intervals tested. The reported depth is consistent with the Kuparuk River sand formation in nearby projects. 
Exploratory efforts are continuing as the operator has recently drilled two additional wells in the Colville area (AOGCC, 1994c). The goal is to develop sufficient reserves to justify a stand-alone processing facility to be utilized by several accumulations in the area. Current results indicate no single accumulation is of sufficient size to justify the cost of development alone (ADNR, 1994n).

Kuukpik is not included in the economic evaluation.

\section{A.3.6 Thetis Island Unit}

The Thetis Island unit is located adjacent to the northeast boundary of the Kuukpik unit. No information is available on the results of drilling the Thetis Island No. 1. Recent exploratory efforts include a geophysical program between Thetis Island No. 1 and the Kalubik No. 1 (a Kuukpik unit well), and well information trades with the Kuukpik unit (ADNR, 1992d).

Thetis Island could be an extension of the accumulation trend discovered within the Kuukpik unit; however, additional information is required to determine the potential of any hydrocarbon accumulation in the Thetis Island unit.

\section{A.3.7 Kuvlum Field}

The Kuvlum Field is located in federal waters, 60 miles northeast of Prudhoe Bay (see Figure 2.1). Discovery was made in 1992 and initially was believed to contain up to 6 billion BBL oil recoverable reserves with 1 billion BBL oil as the minimum threshold for development. The field development would require expensive pipelines and other equipment to deal with crushing ice floes in the area. Additional drilling revealed potential geological and producing problems of such magnitude, that most of the original owners decided to abandon the prospect. The field, although a sizable accumulation, was described as not commercial as a stand alone project (OGJ, 1995c). One owner acquired the interests of all other owners with the belief the oil prices would rise sufficiently to make Kuvlum worthwhile to develop (Anchorage Daily News, 1995e; AOGR, 1955g).

The operator was expected to submit a development plan in early 1995 (AOGR, 1995c).

Kuvlum is not included in the economic evaluation. 


\section{A.3.8 Cascade Oil Pool}

The Cascade oil pool was discovered in March 1993 by the drilling of Cascade No. 1 to a total depth of $10,109 \mathrm{ft}$ in the original hole and to $9,175 \mathrm{ft}$ in the sidetracked hole. The Kuparuk River formation flowed at a sustained rate of $1720 \mathrm{BPD}$. The Kuparuk sand resource accumulation is located southeast of MPU between PBU, KRU, and MPU (OGJ, 1995c). At present, there are two wells in the oil pool. ${ }^{2}$ Expectations are that the operator will request expansion of Milne Point participating area to include the Cascade discovery (Platts, 1995b).

Plans indicate development will be from a new pad, $\mathrm{K}$ pad, and include a 3.3-mi road and a 3.8 mile raised pipeline to the MPU E pad. Development from $\mathrm{K}$ pad will be in two 20 well phases. Initial development work is expected to begin by mid-year 1995, with a one rig drilling program in late 1995. Potential production from this resource could be from 10 to $15 \mathrm{MBPD}$ and 5 to $10 \mathrm{MCFD}$ gas. It is expected that Cascade production will be processed through MPU facilities, and could begin as early as the second quarter of 1996 (OGJ, 1995c).

Until additional data is available, economics cannot be determined, and Cascade is not included in the economic evaluation.

\section{A.3.9 Northstar Unit}

The Northstar Unit (NU) is located in state and federal waters about 6 miles north of MPU (see Figure 2.2). The Northstar/Seal Island field was discovered in 1982 with oil recovery from the Sadlerochit formation (Permo-Triassic). Estimated recoverable resource is between 100 and 200 MMB) (AOGR, 1995e; OGJ, 1995c). A more complete discussion of NU is found in the previous DOE publication (1993).

The operator does not plan any additional delineation drilling, but hopes to have the field on production by about the year 2000 . If development does occur, the produced fluids may be processed through MPU facilities in an effort to reduce investment costs (AOGR, 1995e; OGJ, 1995c).

\section{A.3.10 Sandpiper Unit}

a. BP Exploration (Alaska) Inc., Personal communication, March 20, 1995. 
The Sandpiper field is located about 11 miles northwest of NU in federal waters (see Figure 2.1). The field was discovered in 1986 when the discovery well flowed oil and gas from the Sadlerochit formation (OGJ, 1995c). The potential resource may be as large as $150 \mathrm{MMBO}$ (AOGR, 1995e). If NU is developed, then Sandpiper's chance of being developed is enhanced.

\section{A.3.11 Summary of Fields with Potential}

None of the fields with potential are expected to be brought on line in the near future unless: a gas market is developed (Point Thomson), a breakthrough in enhanced oil recovery technology is achieved (West Sak), exploratory efforts prove sufficient reserves to justify development under current oil prices (Badami, Kuukpik unit, and Thetis Island unit) or if oil prices increase sufficiently to allow economical development of potential resources (this would apply to all fields with potential). Other actions that could encourage the development of marginal fields could include the reduction of State and federal revenue requirements through such steps as royalty reductions and reduced taxes.

\section{A.4 Summary}

ANS oil production started in 1977 with the startup of PBU, peaked at just over 2 MMBOPD in 1988, and averaged about 1.7 MMBOPD from ten active producing fields at the end of 1994 (Figure A.12). Cumulative ANS recovery (including crude oil, condensate, and NGL) totaled 10.5 billion BBL oil at the end of 1994. Remaining recoverable oil reserves from the ten developed fields at the beginning of 1995, using the EIA reference oil price forecast, is estimated to be 6.1 billion BBL oil without a major gas sales. The annual production forecasts for the developed fields and for the undeveloped field, PTU, are summarized in Table A.36.

Cumulative ANS net gas production (gas, including $\mathrm{CO}_{2}$, produced and not reinjected) totaled 2.4 BCF at the end of 1994. Remaining potential net gas production at the beginning of 1995 is estimated to be $38 \mathrm{TCF}$, including $26 \mathrm{TCF}$ (after $\mathrm{CO}_{2}$ removal, lease usage and local sales, and shrinkage) potential net major gas sales volumes available. However, the ultimate volume of gas sold at the economic limits of the producing fields is estimated to be 25 TCF (including 21.8 TCF from PBU and 3.18 TCF from PTU). With major ANS gas sales, remaining recoverable oil reserves are estimated to be 5.7 billion BBL oil (including 0.4 billion BBL oil reduction in PBU reserves due to the impact of major gas sales on oil recovery) and it is estimated that PTU could add another 0.2 billion BBL oil of potentially recoverable oil 
for a total of 5.9 billion BBL oil. Developing GTL conversion technology has the potential of utilizing ANS gas resources to produce an additional $300 \mathrm{MBPD}$ of high quality hydrocarbon liquids which could be blended into TAPS along with produced oil and could potentially produce a total of 2.8 billion BBLS of converted hydrocarbon liquids.

Discovered, but undeveloped ANS oil and gas fields (including PTU) are estimated to contain over 1.0 BBLS and 4 TCF of potentially recoverable oil and gas. Several of these undeveloped fields are being reviewed for possible future development, but it is unlikely that at current oil and gas market conditions very many of these undeveloped fields will ever be brought on production, unless a major gas sales market develops or production economics improve dramatically. Current estimates of undiscovered ANS resources are 7 billion BBL oil and 64 TCF of gas (USGS, 1995). ANS exploration activities have been greatly curtailed in recent years due to current oil and gas market conditions and exploration activity restrictions. Unless exploration activities produce positive results before the shutdown of TAPS (estimated to occur in the 2009 to 2016 timeframe), it is unlikely that any of these undiscovered resources will ever be recovered. 
Table A.36. Summary ANS production forecasts.

\begin{tabular}{|c|c|c|c|c|c|c|}
\hline Year & Prudhoe Bay & Kuparuk & $\begin{array}{l}\text { Lisburne, } \\
\text { M.P., } \\
\text { Niakuk, and } \\
\text { others }\end{array}$ & Endicott & Pt McIntyre & Pt. Thomson \\
\hline 1995 & 940.0 & 299.0 & 89.4 & 83.0 & 104.0 & 0.0 \\
\hline 1996 & 860.0 & 292.0 & 94.8 & 70.5 & 104.0 & 0.0 \\
\hline 1997 & 790.0 & 332.0 & 92.9 & 59.8 & 91.0 & 0.0 \\
\hline 1998 & 720.0 & 332.0 & 82.3 & 50.6 & 81.0 & 0.0 \\
\hline 1999 & 660.0 & 298.0 & 70.9 & 43.0 & 71.0 & 0.0 \\
\hline 2000 & 605.0 & 267.0 & 61.6 & 36.6 & 62.0 & 0.0 \\
\hline 2001 & 563.0 & 235.0 & 53.2 & 31.1 & 54.0 & 0.0 \\
\hline 2002 & 520.0 & 207.0 & 46.0 & 26.4 & 47.5 & 0.0 \\
\hline 2003 & 482.0 & 180.0 & 39.7 & 22.5 & 42.0 & 0.0 \\
\hline 2004 & 446.0 & 155.0 & 20.8 & 19.1 & 37.0 & 0.0 \\
\hline 2005 & 412.0 & 130.0 & 18.0 & 16.2 & 33.0 & 0.0 \\
\hline 2006 & 380.0 & 106.0 & 15.6 & 13.8 & 29.0 & 0.0 \\
\hline 2007 & 350.0 & 88.0 & 11.1 & 11.7 & 25.8 & 0.0 \\
\hline 2008 & 326.0 & 72.0 & 9.7 & 10.0 & 25.0 & 44.5 \\
\hline 2009 & 302.0 & 55.0 & 8.6 & 8.5 & 0.0 & 46.8 \\
\hline 2010 & 280.0 & 40.0 & 5.2 & 7.2 & 0.0 & 45.8 \\
\hline 2011 & 260.0 & 26.0 & 4.5 & 6.1 & 0.0 & 45.0 \\
\hline 2012 & 243.0 & 21.0 & 4.0 & 5.2 & 0.0 & 44.0 \\
\hline 2013 & 227.0 & 18.0 & 3.5 & 4.4 & 0.0 & 42.1 \\
\hline 2014 & 212.0 & 14.0 & 3.1 & 3.8 & 0.0 & 37.9 \\
\hline 2015 & 198.0 & 12.0 & 2.7 & 3.2 & 0.0 & 36.0 \\
\hline 2016 & 185.0 & 10.0 & 0.0 & 0.0 & 0.0 & 33.8 \\
\hline 2017 & 172.0 & 0.0 & 0.0 & 0.0 & 0.0 & 31.0 \\
\hline 2018 & 160.0 & 0.0 & 0.0 & 0.0 & 0.0 & 27.1 . \\
\hline 2019 & 150.0 & 0.0 & 0.0 & 0.0 & 0.0 & 24.1 \\
\hline 2020 & 140.0 & 0.0 & 0.0 & 0.0 & 0.0 & 20.8 \\
\hline 2021 & 132.0 & 0.0 & 0.0 & 0.0 & 0.0 & 18.4 \\
\hline 2022 & 126.0 & 0.0 & 0.0 & 0.0 & 0.0 & 15.5 \\
\hline 2023 & 117.0 & 0.0 & 0.0 & 0.0 & 0.0 & 14.1 \\
\hline 2024 & 111.0 & 0.0 & 0.0 & 0.0 & 0.0 & 12.4 \\
\hline 2025 & 105.0 & 0.0 & 0.0 & 0.0 & 0.0 & 11.0 \\
\hline 2026 & 0.0 & 0.0 & 0.0 & 0.0 & 0.0 & 10.0 \\
\hline 2027 & 0.0 & 0.0 & 0.0 & 0.0 & 0.0 & 7.2 \\
\hline
\end{tabular}


A-72

a 


\section{APPENDIX B}

\section{ECONOMIC ANALYSIS}

The technical and economic parameters that are used in the economic evaluations of North Slope gas utilization scenarios are defined and described in this section. These technical and economic parameters are also used to determine the economics of continued operation of the currently producing projects and other potential developments on the North Slope.

The analyses for currently producing fields and other potential developments are discussed in Appendix A. The treatment of taxes, royalty rates, and other economic variables used in the analyses are discussed and the financial model is described in Appendix $\mathbf{C}$.

\section{B.1 Definitions and Assumptions of Technical and Economic Parameters}

The technical and economic parameters used in the evaluation of continued oil operations, and operations with major gas sales, either through an LNG project or a GTL project, are discussed in this section. These parameters, as appropriate, are also used in the evaluation of currently producing projects.

\section{B.1.1 Oil Prices}

Several oil price forecasts are available for use. Three Energy Information Administration (EIA) Annual Energy Outlook (AEO) oil price cases; low, reference, and high scenarios, are discussed in "Annual Energy Outlook 1995," (EIA, 1995). An oil price projection is also discussed in a Gas Research Institute (GRI) publication, "1995 Policy Implications of the GRI Baseline Projection of U.S. Energy Supply and Demand in 2010." The GRI oil price projection, which is more conservative than the EIA reference base, shows little real growth through 2010.

To present a range of oil price sensitivities, the three EIA oil price scenarios (AEO95) are used in the evaluations. To further test oil price sensitivity, a no-growth, flat oil price (FOP) of $\$ 18.00 / \mathrm{BBL}$ $(1 / 1 / 95 \$)$ is assumed. This is based on the year-end 1994 North Slope crude price of about $\$ 16.70 / \mathrm{BBL}$ $(1 / 1 / 95)$ (rounded to $\$ 17.00 / \mathrm{BBL}$ ), which is assumed to be the delivered price in the Lower 48 states. A 
quality differential of $\$ 1.00 / \mathrm{BBL}$ is used to relate the North Slope crude price with prices for better quality oil sources. As discussed in Appendix B.1.1.1.3, this price reduction is applied to all oil price forecasts in the project evaluations.

The four oil price forecasts are shown graphically in 1995 constant dollars in Figure B.1 and in detail in Table B.1.

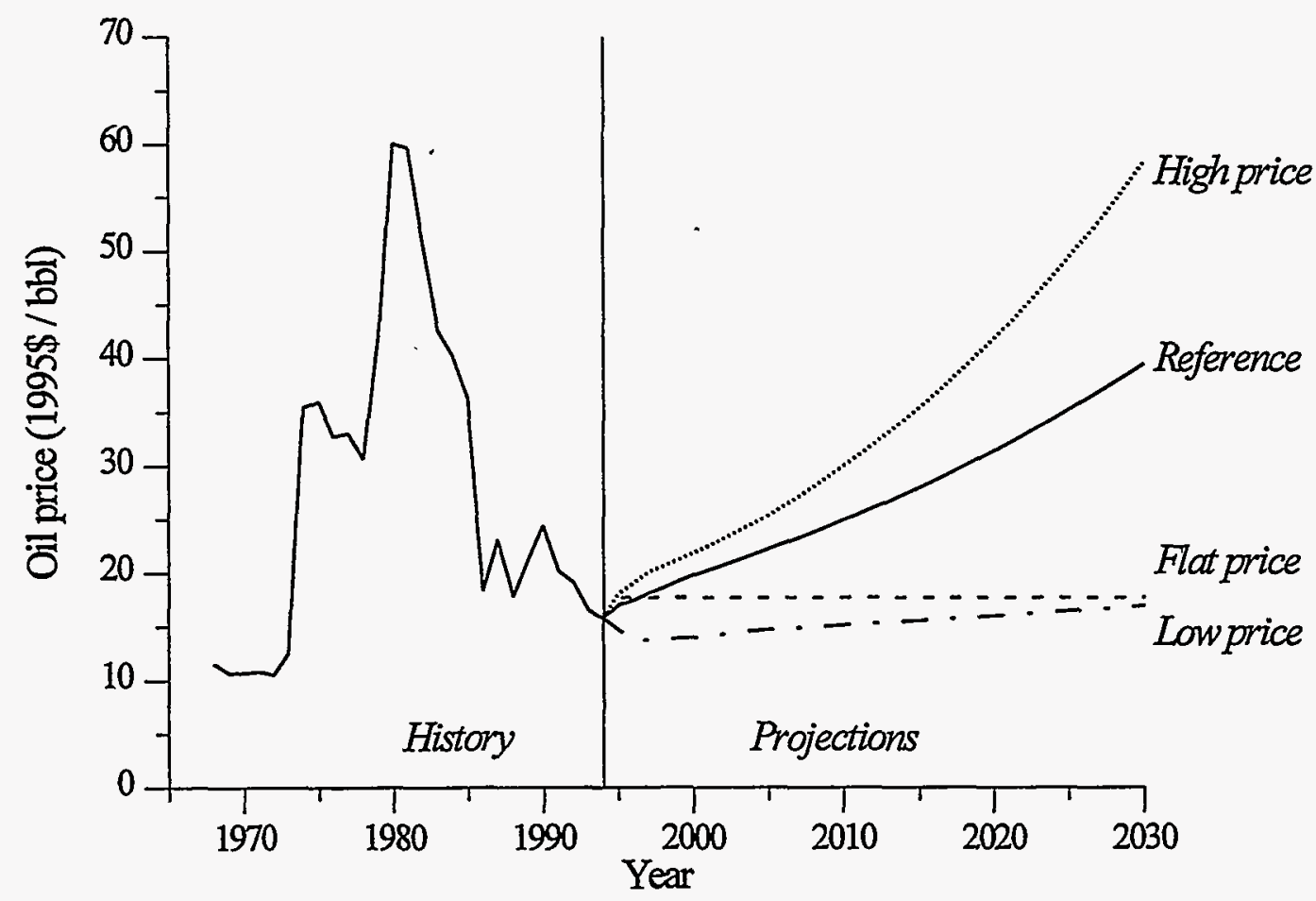

Figure B.1. Historical world oil prices and world oil price assumptions (EIA 1995).

Table B.1. World oil price cases (\$/BBL, constant 1/1/95\$).

\begin{tabular}{||l|c|c|c|c|c|c||}
\hline Year & 1995 & 2000 & 2005 & 2010 & 2015 & 2020 \\
\hline AEO95 High & 18.08 & 21.85 & 25.36 & 29.95 & 35.36 & 41.76 \\
\hline AEO95 Reference & 17.04 & 19.76 & 22.21 & 24.92 & 27.95 & 31.35 \\
\hline AEO95 Low & 14.72 & 13.97 & 14.72 & 15.13 & 15.56 & 16.00 \\
\hline Flat oil price & 18.00 & 18.00 & 18.00 & 18.00 & 18.00 & 18.00 \\
\hline
\end{tabular}


B.1.1.1 Wellhead Oil Price. The following definitions are used to calculate wellhead oil price:

$\begin{array}{lll}\text { - Wellhead price } & = & \text { World Oil Price - Oil Net Back } \\ \text { Oil Net Back } & = & \text { Marine Tariff }+ \text { TAPS Tariff + Alaskan Crude Differential } \\ & \text { Adjustment + Field Tariff }+ \text { Quality Adjustment }\end{array}$

The individual components in the oil net-back deductions are discussed in the following section.

B.1.1.1.1 Marine Tariffs-The crude oil, GTL plant hydrocarbon liquids, condensate, and NGL mixture is shipped from Valdez to West Coast and Gulf of Mexico delivery points. At present, about $15 \%$ of ANS crude is shipped to delivery points in the gulf of Mexico. Estimates of future marine transportation costs include consideration of:

- Double-hull tanker requirements

- The age of the tanker fleet transporting Alaskan crude

- The change in the West Coast demand for Alaskan crude

- The declining volume of Alaskan crude to be shipped

- Approval to export Alaskan crude.

In 1991, the Alaska Department of Revenue (ADOR) completed a study of tanker rates for North Slope crude (ADOR, 1991). The State of Alaska's mid-range marine tariff schedule in constant 1/1/1992\$ was adopted for the 1993 DOE study (DOE, 1993). A review of the marine tariff rates shown in the ADOR Fall 1994 and Spring 1995 Revenue Source Books (ADOR, 1994a, ADOR, 1995) reveal that the projected rates vary from year to year but are within $10 \%$ of those determined in the 1993 DOE study.

A forecasted decrease in near-term tanker rates is primarily a result of phasing out of crude shipments to points other than the U.S. West Coast by the year 2000. With export of Alaskan crude approved in November 1995 (HOH, 1995), and decline in ANS production, shipments to the Gulf of Mexico area are expected to end. However, the timing is uncertain and, although it could occur in mid-1996, it is assumed that shipments to the Gulf of Mexico will phase out by the end of 1998 . The later increase in rates results from the increased costs of constructing new double-hull tankers or to retrofit existing single hull ships. The projected rates in the previous DOE study (1993) are adopted for this study after revising the rates from 1996 through 1999 to account for issues described above. 
The yearly schedule of marine tariffs is developed as follows:

- Data points between 1999 and 2005 are obtained by interpolation.

- Data points after 2005 are obtained by using a straight line extrapolation.

The schedule in constant $1 / 1 / 1995 \$$ is given in Table B.2.

Table B.2. Marine transportation costs, Valdez to Lower $48(\$ / B B L) .{ }^{a}$

\begin{tabular}{|c|c||}
\hline Fiscal Year & Marine Tariff (constant $1 / 1 / 1995 \$)^{b}$ \\
\hline 1995 & 1.44 \\
\hline 1996 & 1.40 \\
\hline 1997 & 1.36 \\
\hline 1998 & 1.30 \\
\hline 1999 & 1.25 \\
\hline 2000 & 1.29 \\
\hline 2005 & 1.36 \\
\hline \multicolumn{2}{|l|}{} \\
\hline $\begin{array}{l}\text { a. Average cost of West Coast/Gulf Coast delivery mix. } \\
\text { b. } 1 / 1 / 1992 \$ \text { values from DOE 1993 inflated at 2.2\% per year. }\end{array}$ \\
\hline
\end{tabular}

Three years or history and the future estimated cost of shipping liquids from Valdez to West Coast and Gulf of Mexico delivery points are shown in Figure B.2.

B.1.1.1.2 TAPS Tariffs-TAPS tariffs are determined individually by TAPS owner companies according to a 1985 settlement agreement between the owners and the State. A brief discussion of the method used to calculate TAPS tariff follows. A more complete discussion on TAPS tariffs can be found in Section 3.2.5.1 of the $1991 \mathrm{DOE}$ publication (1991). Simplifying assumptions are:

- Single ownership of pipeline

- Total throughput goes to Valdez

- Minor investments after 1995

- Operating expenses adjusted to current level; currently about $\$ 700$ million/yr (Platts, 1992) 


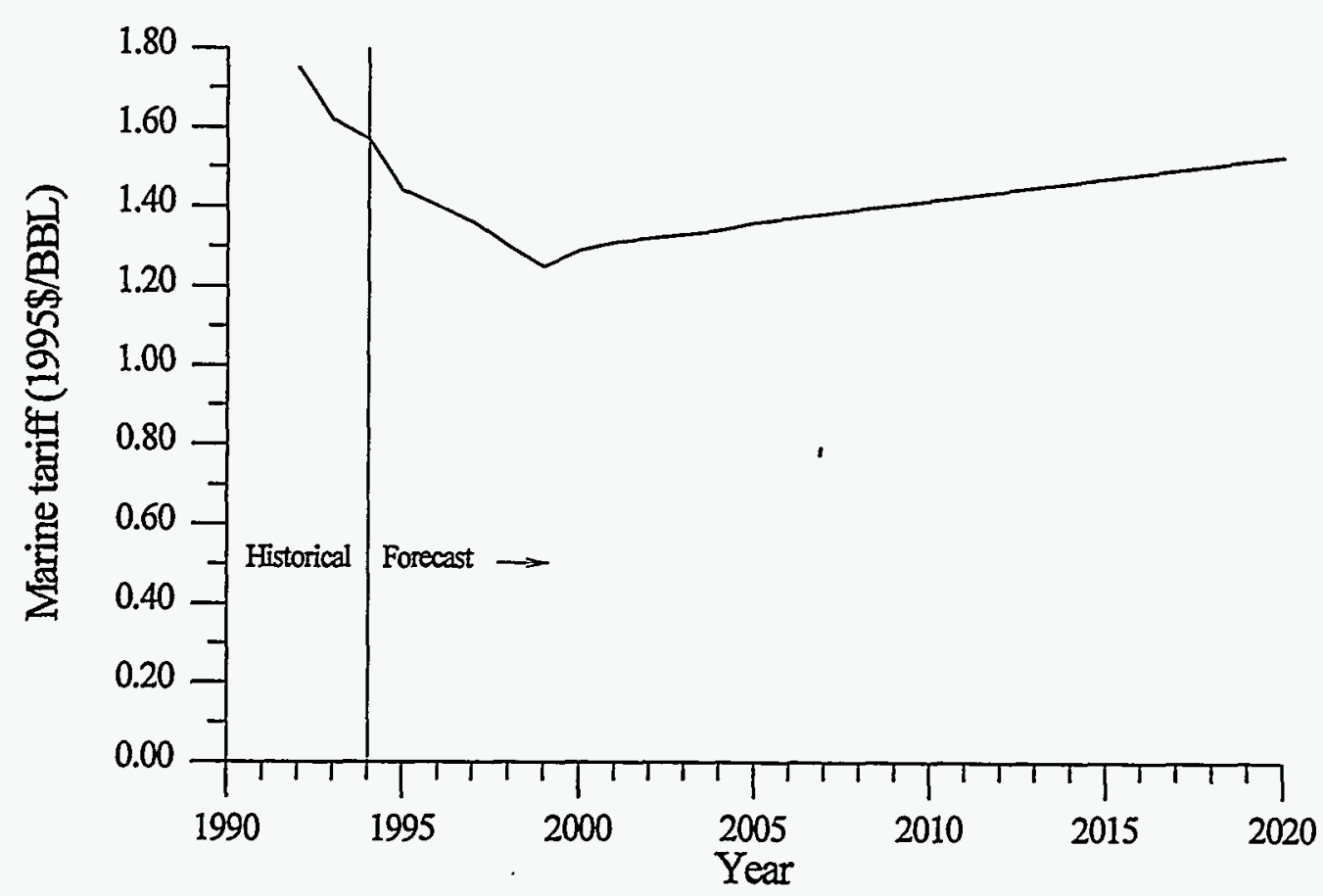

Figure B.2. Average marine transportation costs to deliver crude oil from Valdez, AK to lower 48 .

- Operating expenses are cut by $1 / 3$ by $12 / 31 / 96^{a}$

- Operating expenses are cut by another $30 \%$ by 2021 as more pump stations are demobilized

- Pipeline owners after-tax margin is limited to an inflation adjusted \$0.35/BBL (\$1983\$) (FERC, 1985; ADOR, 1995) This is \$0.53/BBL (1/1/95\$) of hydrocarbons shipped during 1995.

- Simplified depreciation

- Net carry-overs are zero

- State and federal income taxes remain at current level

- Field production volumes reduced by a factor to account for fuel usage and losses.

The method results in an estimated annual total revenue requirement (ATRR) necessary for TAPS owners to receive the allowed return on their investment. A base TAPS tariff schedule was prepared using updated information, including the current production forecasts of North Slope field rates for the active fields shown in Figure 1.1. The TAPS tariff schedule, for currently producing fields in $1 / 1 / 95 \$$, is given in Table B.3.

a. Alyeska Pipeline Service Co., "Facing The Future, Commitment, Challenge, Change," Remarks by James B Hermiller, January 6, 1992.

b. The after-tax margin is adjusted annually, beginning in 1983, using the Consumer Price Index for all Urban Consumers (CPI-U) (http://www.stls.frb.org/fred/data/cpi/cpiaucsl). 
Revised TAPS tariff schedules are determined and used when different liquid streams are delivered to TAPS PS No.1 under the two major gas sales scenarios. The revised TAPS tariff schedules for the two major gas sales scenarios and the base TAPS tariff schedule, are shown in Figure B.3.

Table B.3. TAPS tariff schedule for currently producing fields (1/1/95\$).

\begin{tabular}{||c|r||c|c||c|c||c|c||c|c||}
\hline Year & \$/BBL & Year & \$/BBL & Year & \$/BBL & Year & \$/BBL & Year & \$/BBL \\
\hline \hline 1995 & 2.93 & 2002 & 2.78 & 2009 & 4.49 & 2016 & 6.83 & 2023 & 9.81 \\
\hline 1996 & 2.66 & 2003 & 2.95 & 2010 & 4.92 & 2017 & 7.61 & 2024 & 10.29 \\
\hline 1997 & 2.39 & 2004 & 3.09 & 2011 & 5.29 & 2018 & 8.10 & 2025 & 10.83 \\
\hline 1998 & 2.34 & 2005 & 3.18 & 2012 & 5.41 & 2019 & .8 .58 & & \\
\hline 1999 & 2.45 & 2006 & 3.43 & 2013 & 5.50 & 2020 & 8.71 & & \\
\hline 2000 & 2.57 & 2007 & 3.70 & 2014 & 5.88 & 2021 & 8.79 & & \\
\hline 2001 & 2.63 & 2008 & 3.94 & 2015 & 6.27 & 2022 & 9.16 & & \\
\hline
\end{tabular}

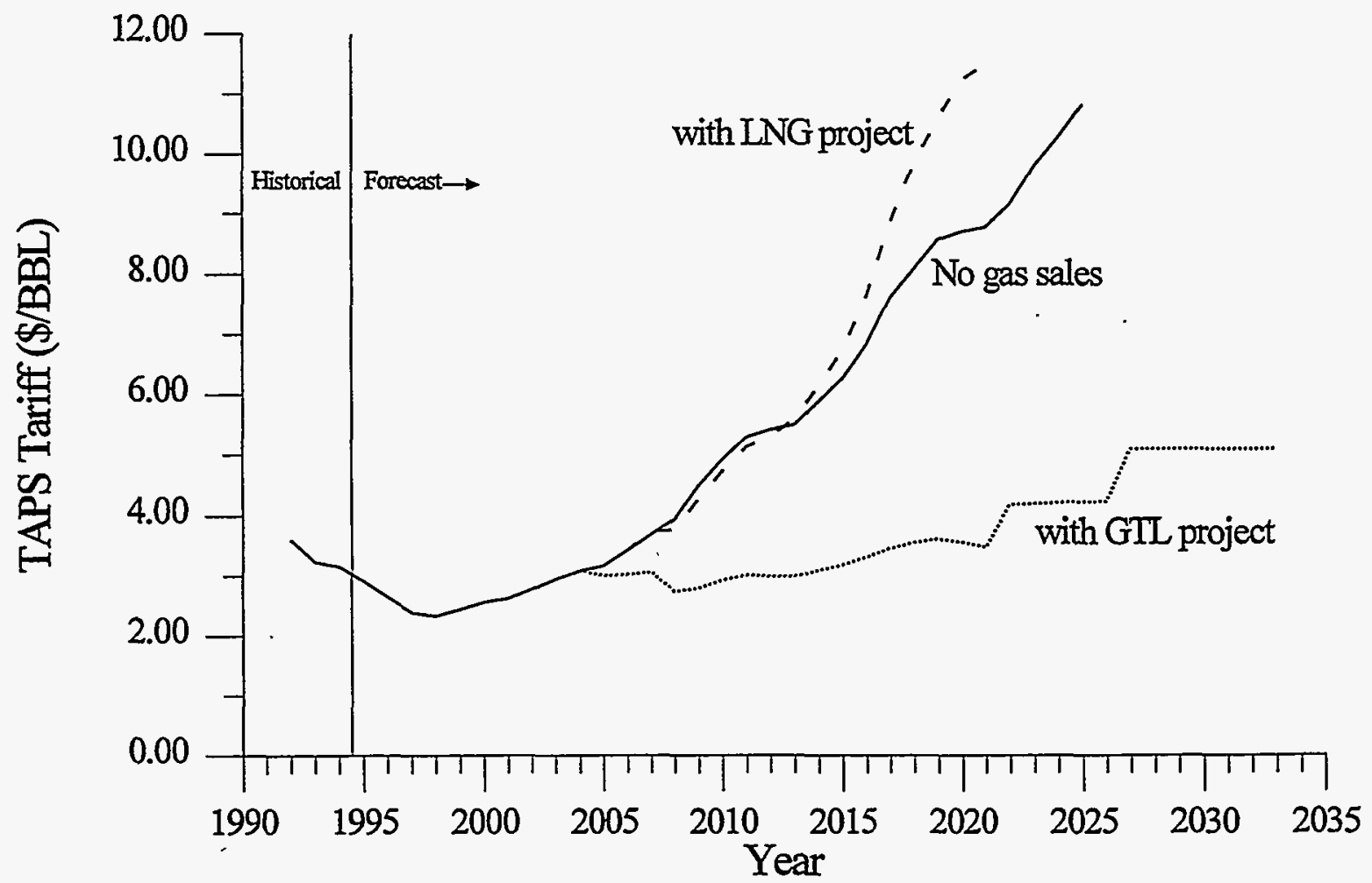

Figure B.3. TAPS tariffs for three North Slope production scenarios (1/1/95\$). 
In the LNG scenario the decrease in TAPS tariff from 2007 through 2011 results from increased TAPS throughput from Point Thomson production. The increase in TAPS tariffs after 2011 results from decreased TAPS throughput due to lower production rates projected from PBU during gas sales to an LNG project. The large decrease in TAPS Tariffs under the GTL scenario beginning in 2005, is a result of the increased throughput of this scenario. As an example of the effect on wellhead prices under the three different production scenarios, estimated PBU wellhead oil prices are shown in Figure B.4.

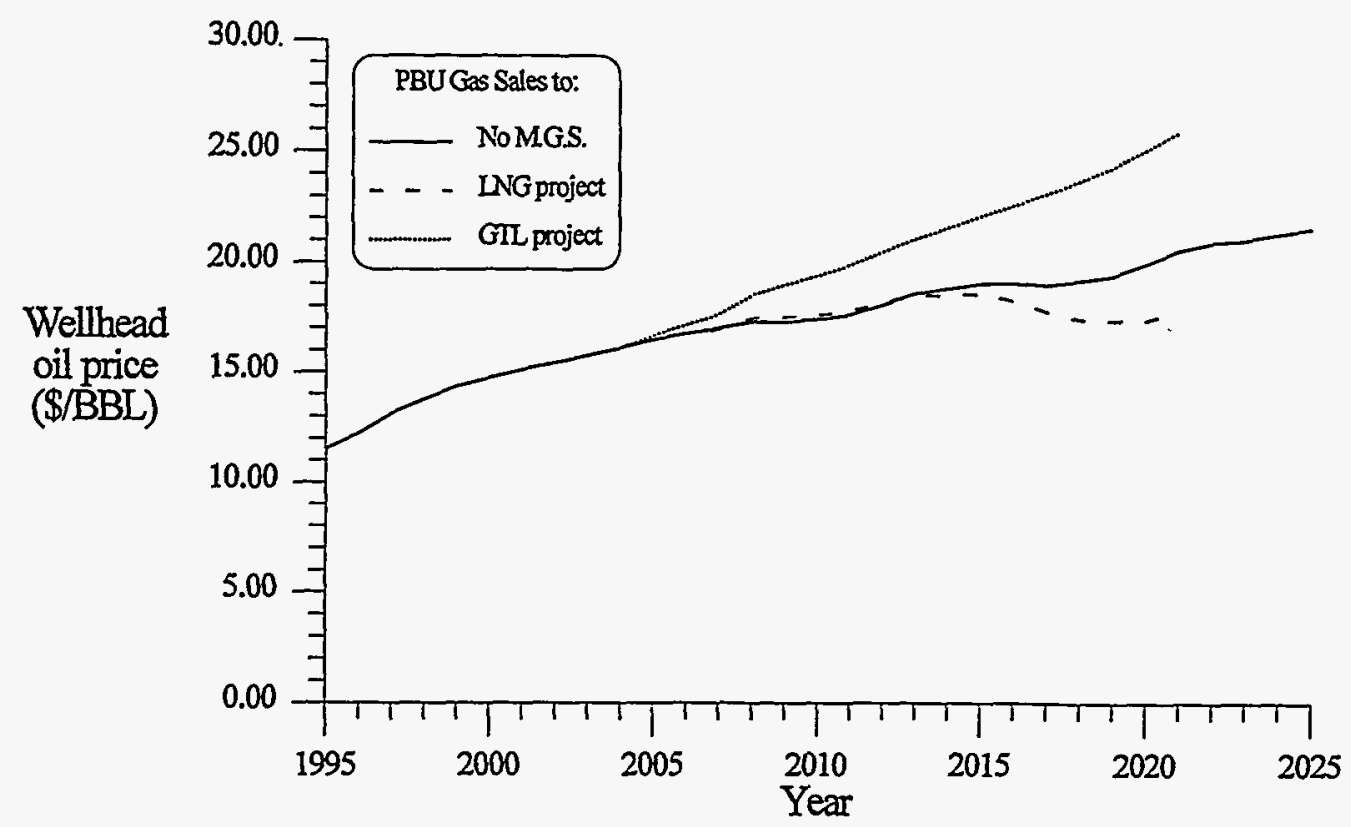

Figure B.4. PBU wellhead liquid prices in $1995 \$$ under different production scenarios.

B.1.1.1.3 Alaskan Crude Oil Adjustment-ANS crude mix receives a lower price than the "world" crude used to develop the crude oil price forecasts (See Table B.1). This is primarily due to the lower assumed 28 degree API gravity of the ANS crude mix as compared to the average of about 31 degree API for the mix of imported crudes (OJG 1995f). At present, this differential in price is about $\$ 1.00 / B B L$. It is assumed that this differential will be in effect throughout the evaluation period of any project evaluated. A $\$ 1.00 / B B L$ deduction is applied to the oil price schedules given in Table B.1.

B.1.1.1.4 Field Tariffs-PS No. 1 is located near the center of PBU (see Figure B.5). The producers deliver crude oil (a mixture of oil, condensate, and NGLs) to PS No. 1 for shipment to pipelines. When a producer transports crude through a field pipeline to PS No. 1, a field tariff is paid to the pipeline owners. If the pipeline tariff is known, it is used. When the development of a new field is evaluated, the cost of the pipeline to deliver crude to PS No. 1 or to an existing field pipeline is estimated and a field pipeline tariff determined. 


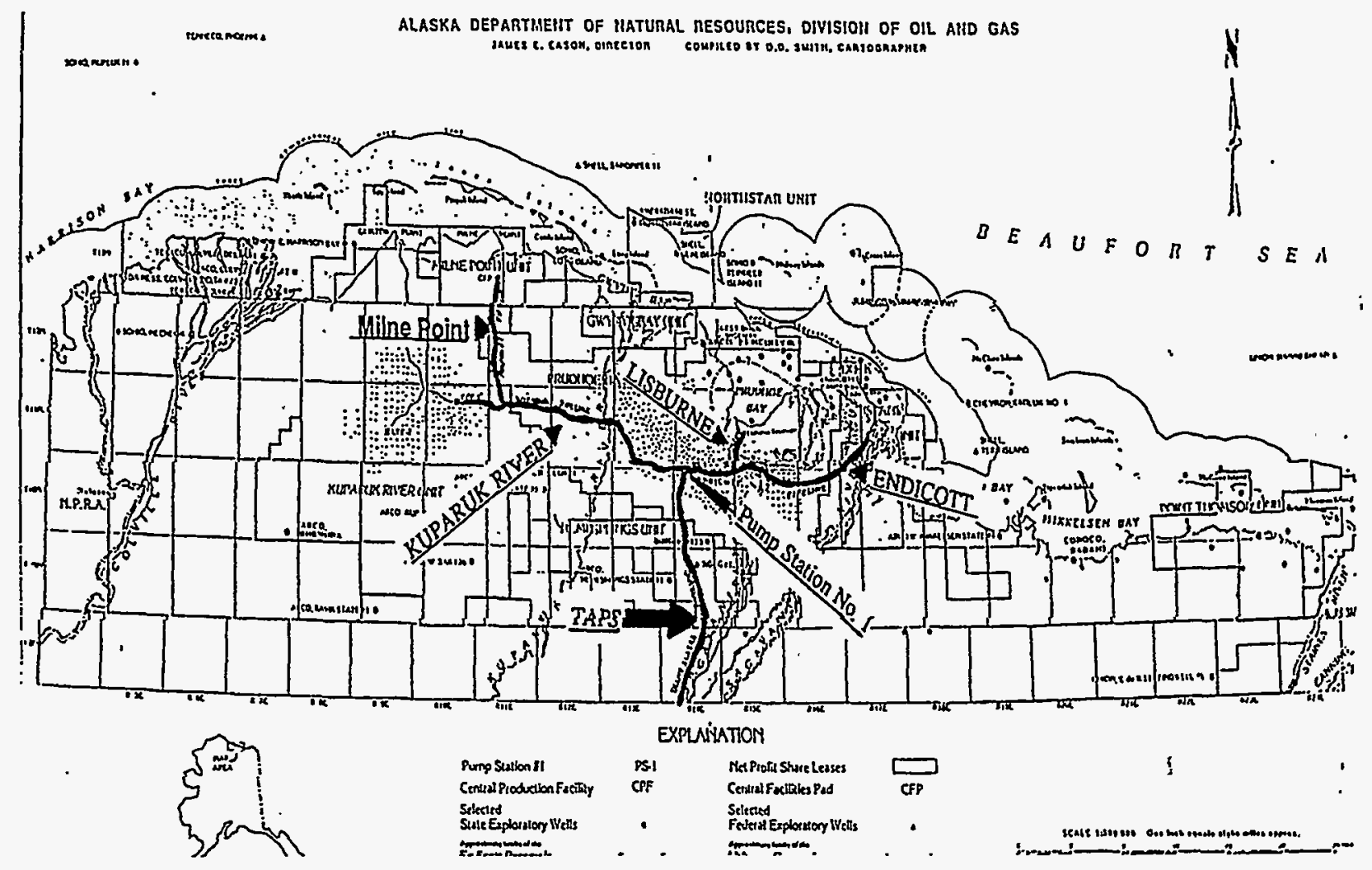

Figure B.5 North Slope Unit map showing field pipelines (from ADNR, 1995c).

A field pipeline tariff is estimated, as follows, for each field where the tariff is unknown. ${ }^{a}$

Tariff $=\frac{\text { Cost of pipeline, haul road and pump stations }(1 / 1 / 95 \$)}{\text { Total volume to be transported (BBL) }} \times 3.35=\$ / B B L(1 / 1 / 95 \$)$

Pipeline construction costs presented by Young (1986) and the National Petroleum Council (NPC) (1981) are used for each field pipeline situation. For the PTU gas pipeline, the same formula is used with the total gas volume in MCF to yield a \$/MCF tariff estimate.

Field pipeline tariffs applicable to currently producing projects are give in Table B.4.

B.1.1.1.5 TAPS Quality Adjustment--Effective December 1, 1993, the TAPS Quality Adjustment methodology was changed from a gravity-differential basis to a market-value basis. The market a. Alaska Department of Natural Resources, personal communication, May 1990. 
Table B.4 Field Pipeline Tariffs (\$/BBL, 1/1/95\$).

\begin{tabular}{|c|c|}
\hline Project & Tariff \\
\hline \hline KRU & 0.19 \\
\hline MPU & 0.90 \\
\hline DIU & 0.68 \\
\hline LPA & 0.32 \\
\hline PMPA & 0.32 \\
\hline Niakuk & 0.30 \\
\hline
\end{tabular}

value of each hydrocarbon stream being delivered to TAPS at PS No.1 is compared to the market value of the blended stream of all hydrocarbon streams being delivered to TAPS at PS No. 1. The market value of each lighter-end component and heavier-end distillation cut in a stream is volume weighted to determine that product's market value. The market value differential of each component is then applied to the delivered stream such that delivered streams with higher market values receive a higher selling price than delivered streams of lower market value.

The market value of each stream depends on the stream's composition, the then current market value of each of those components, and the volume of each component being blended into PS No. 1. To simplify this method, the delivered hydrocarbon's API gravity is used to estimate the market value. Generally, a product's market value increases as API gravity increases up to an intermediate API gravity due to the higher refinery value of lighter gasoline and diesel distillates and then decreases at very high API gravity due to the lower refinery value of very light NGLs. A general approximation of the market value to API gravity relationship (Figure B.6) is applied to each product's API gravity to determine that product's TAPS Quality Adjustment.

\section{B.1.2 GTL Hydrocarbon Pricing}

The liquids sales prices for the GTL scenario are based on the manufacture of a high quality hydrocarbon liquid that will be compatible with the crude oil delivery streams from the current and future producing fields, such as liquids in the 200 to $600^{\circ} \mathrm{F}$ boiling range (gasoline to distillate range). The exact specifications for the hydrocarbon liquid product will be determined by the characteristics of the total crude mix being delivered to TAPS at GTL plant startup and the characteristics, capabilities, and economics of the 


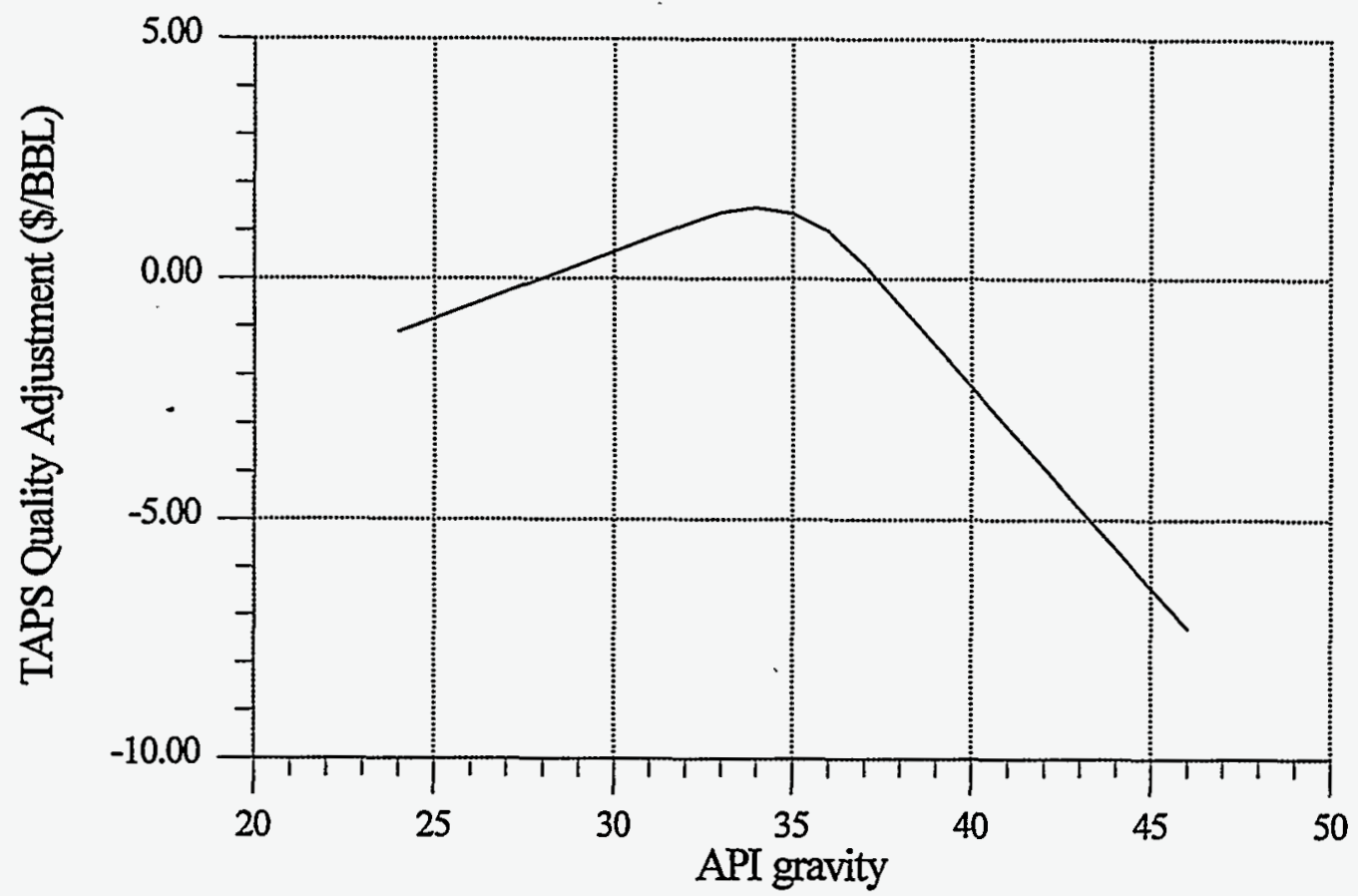

Figure B.6. TAPS Quality Adjustment for North Slope liquid product.

GTL process. These liquids will ostensibly have zero sulfur and require a minimum of refining to process them to high quality transportation fuels. Based on the value of gasoline and distillate relative to benchmark crude oils, as published in the Oil and Gas Journal, the differential value is about $\$ 6$ to $\$ 7 / B B L$. For the base case analysis, it is assumed the hydrocarbon liquid from the GTL plant will yield a \$5.00/BBL (1/1/95\$) premium price above the price forecasts in Appendix B.1.1 The TAPS Quality Adjustment (Appendix B.1.1.1.5) and the \$1.00/BBL Alaskan Crude Oil Adjustment (Appendix B.1.1.1.3) are not applied to the GTL products as they are to the ANS crude. The wellhead oil prices are determined by adding the premium to the price forecasts in Appendix B.1.1 and deducting only the transportation costs discussed in Appendix B.1.1.1. The effect of changing this premium is evaluated in the sensitivity analysis.

\section{B.1.3 Gas Prices}

Currently, only minor gas sales are occurring on the North Slope, and are not considered representative of prices during major gas sales. The actual gas prices will be determined by economic conditions at the time of sales. Gas prices are determined for two major gas sales scenarios: sales to a gas pipeline/LNG plant system and sales to a GTL plant. These forecasts are discussed in the following sections. 
B.1.3.1 Gas Prices - LNG Scenario. Currently, Cook Inlet gas is being sold in Japan as LNG. The possibility that North Slope gas may be sold in Asian markets is well known. For this evaluation, it is assumed that the LNG produced will be sold to Japan and other Pacific Rim countries. LNG prices in the Asian market are tied to the average price of a "basket" of imported liquid hydrocarbons. Because gas is a cleaner burning fuel, the LNG price at various times has received a bonus over crude oil. It is assumed that the bonus is $10 \%$ greater than the world oil price. The world oil price forecasts in Table B.1 are assumed to be representative of the "basket-of crude" price forecasts in Asia. Thus, the North Slope gas price for the LNG scenario is determined as follows:

North Slope gas price $=(L N G$ price in Asia $) \times($ gas product net back $)$.

LNG sale price in Asia is calculated as follows:

$L N G$ price in Asia $=\frac{\text { World Oil Price } \times(1+\text { Asian } L N G \text { bonus })}{B T U \text { conversion for } L N G} ;$

where: $B T U$ conversion for $L N G=\frac{5.9 \frac{M M B T U}{B B L}}{1.15 \frac{M M B T U}{M C F}}=5.13 \frac{M C F}{B B L}$,

Asian LNG bonus $=0.1(10 \%)$.

With changing world oil prices LNG prices determined by this method could reach high or low levels that would be inconsistent with existing LNG price levels. To offset this effect, the above calculation is modified for oil prices below $\$ 14 / \mathrm{BBL}(1 / 1 / 95 \$)$ and above $\$ 25 / \mathrm{BBL}(1 / 1 / 95 \$)$. Yearly oil price above $\$ 25 / \mathrm{BBL}$ are modified as follows:

Modified oil price $=\$ 25 / B B L+\frac{\text { world oil price } / B B L-\$ 25 / B B L}{3}$

Yearly oil prices below \$14/BBL (1/1/95\$) are modified as follows:

Modified oil price $=\$ 14 / B B L+\frac{\text { world oil price } / B B L-\$ 14 / B B L}{3}$

An example of the resulting Asian LNG prices for changes in world oil price are shown in Figure B.7. 


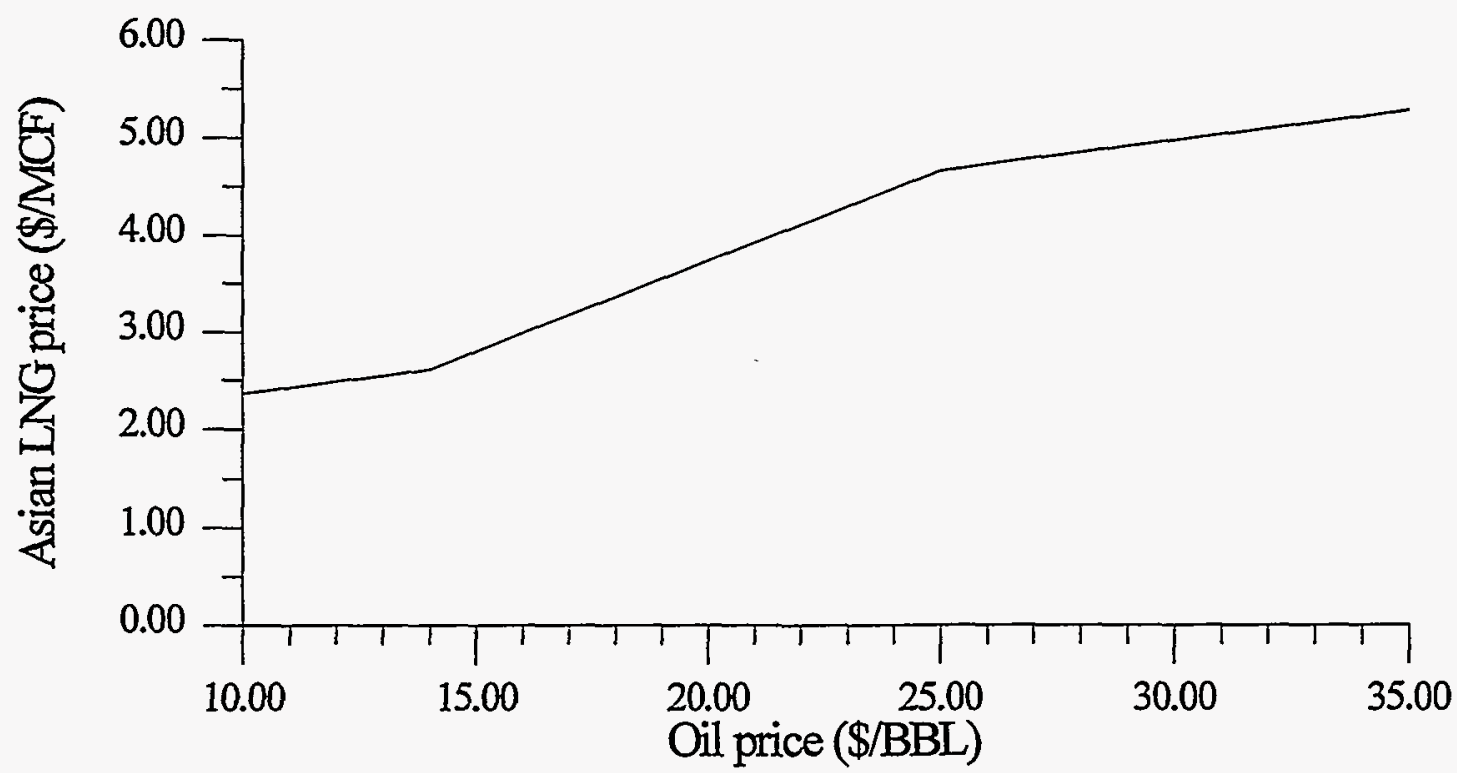

Figure B.7 LNG Prices showing high and low price restrictions (1/1/95\$).

To determine the price a North Slope producer would receive for gas sold, a producer's gas net-back fraction is applied to the Asian LNG price as determined above. Possible gas product net back fractions, as percentages, could vary depending on many factors. North Slope gas prices (1/1/95 \$/MCF) shown in Table B.5 are determined using the above calculation, oil prices in Table B.2, and net-back factors between 5 and $25 \%$ to illustrate the effects of varying gas product net back fractions.

Table B.5. North Slope gas sales prices for LNG project (\$/MCF, 1/1/95\$).

\begin{tabular}{|c|c|c|c|c|c|c|}
\hline \multirow{2}{*}{ Oil Price } & \multirow{2}{*}{$\begin{array}{c}2005 \text { Asian LNG } \\
\text { prices - \$/MCF }\end{array}$} & \multicolumn{5}{|c|}{2005 Gas prices at various net-back factors - \$/MCF } \\
\hline & & $5 \%$ & $10 \%$ & $15 \%$ & $20 \%$ & $25 \%$ \\
\hline 1995 Flat oil price & 3.86 & 0.19 & 0.39 & 0.58 & 0.77 & 0.97 \\
\hline AEO95 Low & 3.00 & 0.15 & 0.30 & 0.45 & 0.60 & 0.95 \\
\hline AE095 Reference & 4.76 & 0.24 & 0.48 & 0.71 & 0.95 & 1.19 \\
\hline AEO95 High & 5.44 & 0.27 & 0.54 & 0.82 & 1.09 & 1.36 \\
\hline
\end{tabular}

Gas prices, using 2005 oil prices, are shown as examples only in Table B.5. A producers net back gas price that gives the TAGS project owners a $10 \%$ return on investment is used in the base case. 
B.1.3.2 Gas Prices - GTL Scenario. The gas prices for a GTL scenario (the prices received by the unit owners and the gas cost to the plant owners) are estimated as follows:

North Slope gas price $=\frac{\text { world oil price }+ \text { liquids premium }}{B T U \text { conversion for GTL }} \times$ producer net back;

where: $B T U$ conversion for $G T L=\frac{5.75 \frac{M M B T U}{B B L}}{1.15 \frac{M M B T U}{M C F}}=5.00 \frac{M C F}{B B L}$.

The BTU conversion factor for the GTL scenario is less than for the LNG scenario because different liquids are being compared (ADNR, 1995c, p 60). For the LNG scenario, the BTU conversion is for crude oil imported into Japan, while in the GTL scenario the BTU conversion is for the distillate range GTL product. A gas product net back that gives the GTL plant owners a $10 \%$ return on their investment is used in the base case. Example gas prices are shown in Table B.6. These prices are slightly higher than those shown in Table B.5 because of the higher value assumed for the converted hydrocarbon liquids. Actual gas prices will be determined by economic conditions at the time of sale.

Table B.6. North Slope gas prices for GTL project (\$/MCF, 1/1/95\$).

\begin{tabular}{||l|c|c|c|c|c|c||}
\hline \multirow{2}{*}{\multicolumn{2}{c|}{ Oil Price in 2005 }} & \multicolumn{2}{|c|}{$\mathbf{2 0 0 5}$ Gas prices at various net-back factors (\$/MCF) } \\
\cline { 2 - 7 } & $\mathbf{5 \%}$ & $\mathbf{1 0 \%}$ & $\mathbf{1 5 \%}$ & $\mathbf{2 0 \%}$ & $\mathbf{2 5 \%}$ \\
\hline \hline 1995 Flat oil price & 18.00 & 0.20 & 0.40 & 0.60 & 0.80 & 1.00 \\
\hline AEO95 Low & 14.72 & 0.17 & 0.34 & 0.51 & 0.69 & 0.86 \\
\hline AE095 Reference & 22.21 & 0.24 & 0.47 & 0.71 & 0.95 & 1.18 \\
\hline AEO95 High & 25.36 & 0.26 & 0.53 & 0.79 & 1.06 & 1.32 \\
\hline
\end{tabular}

B.1.3.3 Wellhead Gas Price. The following definitions are used to calculate wellhead gas price.

- Wellhead Gas Price $=$ North Slope Gas Price less field pipeline tariffs. 


\section{B.1.4 Inflation Adjustment}

Historical information on the Gross Domestic Product Index was obtained from the U. S. Department of Commerce, Federal Reserve Bank of St. Louis' Federal Reserve Economic Database (FRED) (http://www.stls.org/fred/data/gdp, April 1996). A future inflation adjustment of $2.2 \%$ is used through the entire evaluation period. This is based on information in the Annual Energy Outlook 1995, with Projections to 2010, (EIA 1995). The historic and future inflation adjustment information is shown in Figure B.8.

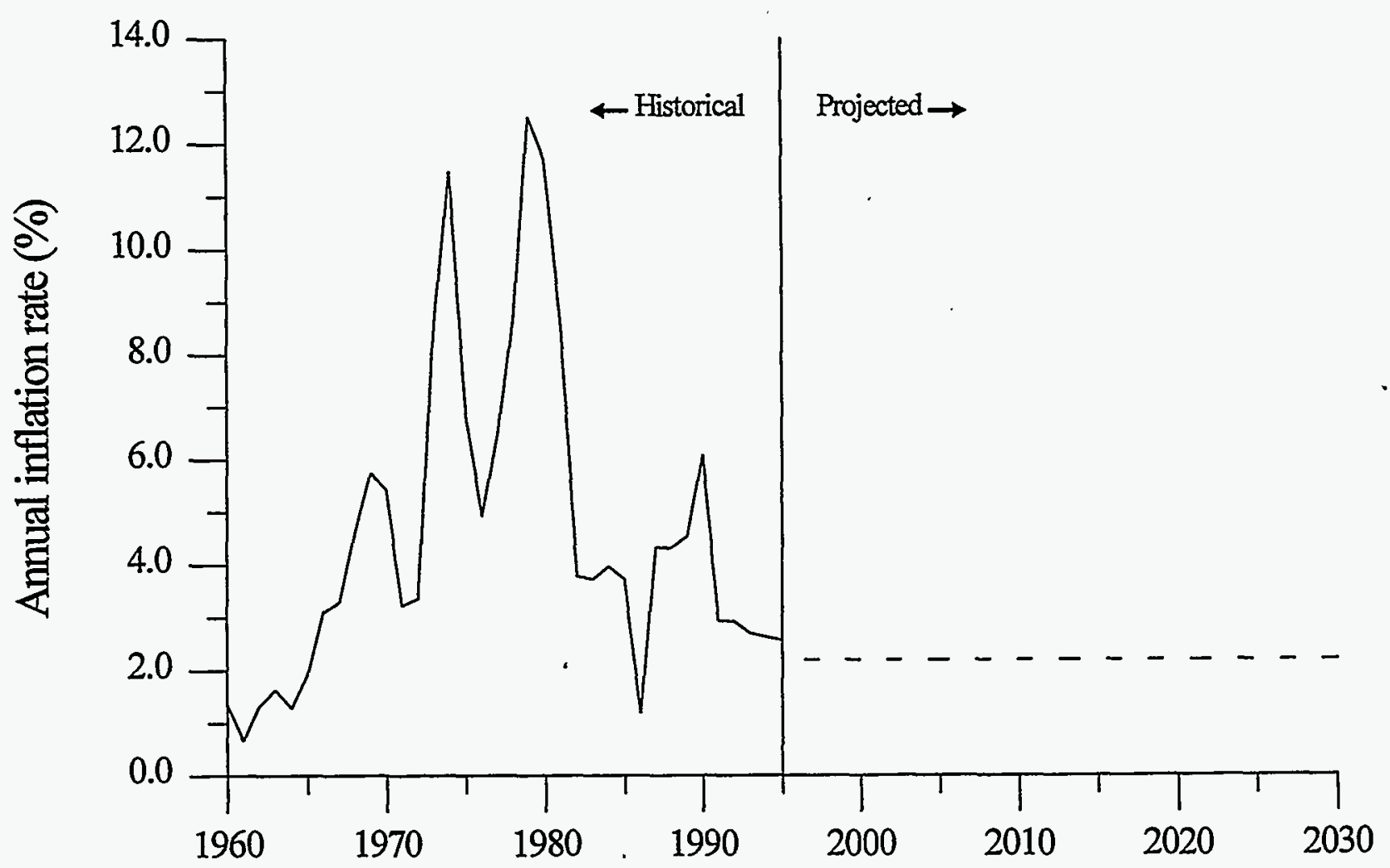

Figure B.8. Historical annual percent change in the Gross Domestic Product price deflator.

\section{B.1.5 Operating Costs}

Operating costs include, but are not limited to, the operating and maintenance costs of (a) facilities, (b) wells (including workovers), (c) roads, (d) pipelines, (f) solvent, (g) fuel, (h) overhead costs, (I) shared - facilities charges (infrastructure use, processed water, and compression costs), (j) estimated purchase cost of miscible injectant (MI). Operating costs also include the non-capital costs of environmental and regulatory compliance, (k) GTL plant gas feed stream purchase costs, (l) GTL operating and maintenance 
costs (O \& M), (m) LNG gas feed stream purchase costs, and (n) LNG project operating costs.

B.1.5.1 Oil Operating Costs. Operating costs are based on publicly available data, engineering judgment and experience for the existing oil operations. Generally, operating costs are determined by using cost per barrel of total fluid. Annual total fluid volumes are estimated using a water cut versus percent recovery data (Appendix B.1.5.1.1).

When a project is utilizing facilities of another project (shared facilities), that project's operating costs are reduced, and are replaced by the facility sharing fees paid to the processing facility. The operating cost for the processing facility is incrementally increased as a result of the increased volume of fluids processed.

B.1.5.1.1 Water-cut Data-Forecasts of operating costs are prepared, for some of the projects in this study, using a relationship between percent water cut and percent of ultimate recovery. The 1991 DOE publication (1991) developed this relationship for PBU and KRU using historical data with future data estimated on industry experience and from reservoir performance model results for the Milne Point Kuparuk and Endicott reservoirs. The Endicott model results are used directly in the Endicott evaluation. The MPU model water cut versus percent cumulative recovery relationship has been modified slightly for use in determining future total fluid production for the Milne Point Kuparuk, the Schrader Bluff, and the Northwest Milne Point area reservoirs. The KRU water-cut relationship was revised in the previous DOE Publication (1993). Review of recent KRU production data shows further revision of that relationship is not justified at this time. After review of the recent production data from PBU, that relationship is adopted without revision. These four current water-cut relationships are shown graphically in Figure A.2, Figure A.5, Figure A.8, and Figure A.10. The 1993 DOE publication (1993) developed a water-cut relationship for LPA, and is used in this evaluation without revision.

B.1.5.1.2 Facilities Sharing Fee-The determination of fees for the use of shared facilities is based on published information where available. For projects where no information is available on sharing fees, the determination of these fees is assumed to be similar to the method used to determine pipeline tariffs. Therefore, the tariff formula in Appendix B.1.1.1.4 is adapted for these calculations as follows:

Facilities sharing fee $=$

Facilities cost savings (1/1/95\$)

Estimated volume of total fluid processed for sharing project $x 3.35$ 
Facilities sharing fee $=\$ / \mathrm{BBL}(1 / 1 / 95 \$)$ of converted hydrocarbon liquids.

This formula is useful for projects where the basic infrastructure in already in place and may not provide good estimates for new developments in areas without existing facilities.

B.1.5.2 Gas Operating Costs. In PBU, operating costs are incurred in three phases of field operation. These are: (1) oil-only sales, (2) oil and gas sales, and (3) gas-only sales. Engineering judgment is used to determine the transition shares between oil and gas, of total operating costs and finally the level of gas only operating costs. This is discussed in detail in Appendix A.2.2.1.5.

There are no published estimates of operating costs for PTU. An empirical method is used to estimate total PTU operating costs (Appendix B.1.5.5).

B.1.5.3 GTL Plant Total Operating Cost. A Department of Energy study entitled "Economic Evaluation and Market Analyses for Natural Gas Utilization," (DOE 1995) included operating and maintenance (O\&M) cost estimates for various processes that can convert natural gas to several hydrocarbon materials. An O\&M cost of about $\$ 7.60$ (1/1/95\$) is shown for a plant design capacity of 58,000 barrels per day of converted liquids (gasoline/diesel range). This operating cost is used as a guide for these analyses. Because the ANS projects will require larger units to meet the forecasted rates, an $21 \%$ reduction in O\&M costs is assumed to be possible as a result of increased capacity, giving a GTL plant O\&M cost of \$6.00/BBL (1/1/95\$) of converted hydrocarbon liquids for use in the ANS evaluation.

The cost of plant feed is the price paid to the gas seller and is a part of the plant operating cost. Gas used for fuel and for heat or power generation is included in the overall conversion efficiency used in the economic evaluation. The total plant operating cost includes the cost of gas purchased from the producers in addition to the $\$ 6.00 / \mathrm{BBL}$.

B.1.5.4 TAGS Project Total Operating Costs. Direct operating costs are not available for the entire project nor for the separate segments of the TAGS project (i.e., plants, pipeline, and ships). As noted in Section 5, Tags economics are determined on a project total basis, therefore, operating are estimated using the empirical method discussed in Appendix B.1.5.5, using a 5\% factor.

LNG production, LNG tanker transportation, and pipeline transportation costs are available for 
comparison with the empirically derived operating costs (Hydrocarbon Processing, 1987). Those costs included taxes, debt retirement, interest, fuel and direct operating costs, however, they show the empirically derived costs to be reasonable on a project total basis.

B.1.5.5 Empirical Operating Cost Method. When there are no published estimates of operating costs available, an empirical method is used. For large projects, such as offshore U.S. and Europe, industry uses the cumulative inflated investment and a certain percentage factor to estimate annual operating costs. This factor varies, but most commonly is between $5 \%$ and $7 \%$. After all investments are completed, the operating cost for the final year of investment, is inflated annually thereafter. The operating cost may be lowered in later years to account for reduced operations.

\section{B.1.6 GTL Plant Efficiency.}

Of the total gas purchases by the plant, only a portion is converted to liquid hydrocarbon. The remainder is used for plant fuel and generation of electricity or is converted by the process to other byproducts. The liquids conversion process efficiency can range from about 80 to $88 \%$ and the overall product efficiency can range from about 62 to $69 \%$ (SNC, 1985), where total product efficiency is [(total feed) -(fuel usage) -(by-product volume) $] \div$ [(total feed) $]$. It is assumed that $25 \%$ of the plant feed will be used for fuel and that $80 \%$ of the remaining inlet stream will be converted to liquid hydrocarbons. The remaining $20 \%$ will be converted to by-products with any combustible materials supplementing the fuel stream. This results in an overall plant efficiency of $60 \%$ and is used in the GTL evaluations.

\section{B.1.7 Investments}

Future investments are based on available public information for each project. Other investment estimates are discussed in the following sections. These estimated investments are also included in each project description.

B.1.7.1 Field Development. Field development costs are separated between facilities investments and the cost to drill development wells.

B.1.7.1.1 Facilities Costs-There are 'other sources of data for estimating facility investments (NPC, 1984; MMS, 1985). However, in addition to some published data, a method was 
developed in the 1991 DOE publication (1991) that was based on data from developed North Slope projects. Data were tabulated on a project basis that included historical investment data and estimates of future investments. The future investments were based on public information. Investments for individual projects were related to the peak oil rate of the project and resulted in investment per barrel of peak production rate.

A facility cost factor was determined for PBU, Kuparuk River Unit (KRU), Milne Point Unit (MPU), Duck Island Unit (Endicott), and Lisburne Participating Area (LPA). The PBU facilities cost factor was excluded when the average factor was determined because PBU was responsible for setting up the core infrastructure and, in addition, the other four projects benefitted from technology improvements, joint use of facilities, reduced costs due to design modification, and use of in-place infrastructure. The average of the remaining facility cost factors is $\$ 16,210 / \mathrm{BBL}$ of peak rate $(1 / 1 / 95 \$)$. This factor may be increased by $10 \%$ to $20 \%$ for projects with development difficulties or projects located outside the PBU/KRU area.

B.1.7.1.2 Drilling Costs--Drilling costs are based on public information when available. Such drilling data are assumed to be applicable in different projects for similar development well schemes (i.e.,. extended reach wells, similar depths, same formation, etc.). When no public information is available, empirical methods can be used to estimate drilling costs (MMS, 1985; NPC, 1981).

B.1.7.2 GTL Plant. Estimated costs to construct a gas conversion facility on the North Slope are presented in a draft DOE report titled "Economic Evaluation and Market Analysis for Natural Gas Utilization (DOE, 1995). Two estimates are provided that include the placement of an operating infrastructure. PBU, which is assumed to be the site of a central ANS GTL plant, already has an in-place infrastructure. The installed investments were for a plant capacity of 14,500 barrels per day (BPD). A plant of that capacity is much smaller than required for this study. The study (DOE, 1995) also showed that quadrupling the plant size resulted in an estimated savings of about 33\%. To estimate the cost of a GTL plant to process ANS gas, it is assumed that: (1) no infrastructure investments are required at PBU, and (2) a savings is realized when the plant size is enlarged. It is assumed the larger plant size of $58,000 \mathrm{BPD}$ discussed in the report (DOE, 1995) can be modified to a size suitable for future plant feed volumes as they are developed. Depending on future technology this could be six units of about 50,000 BPD each for PBU and PTU or some larger version, such as 150,000 to 200,000 BPD per unit. The report shows an additional savings is possible of between 20 and $30 \%$ by building successive plants patterned on a first-of-kind process 
plant. For base case economics, it is assumed that for multiple plant constructions, a savings of $25 \%$ will be possible. Estimation of the investment required for a gas-to-liquid plant on the ANS varies between $\$ 27,700$ and $\$ 39,900(1 / 1 / 95 \$)$ per daily barrel of liquids (DBL) produced and is determined as illustrated in Table B.7.

Table B.7. Investment for a GTL plant on the Alaska North Slope.

\begin{tabular}{|c|c|c|c|}
\hline & Basic Unit & Enlarged Plant ${ }^{2}$ & Multiple Plant $t^{b}$ \\
\hline Plant w/infrastructure - BPD & 14,500 & 58,000 & \\
\hline Chem Systems (\$MM, 1995\$) & 1802.9 & & \\
\hline Less Infrastructure & -650.3 & & \\
\hline Net Plant Cost & 1152.6 & 3089.0 & 2316.8 \\
\hline Cost/DBL ${ }^{c}(\$ M, 1995 \$)$ & 79.5 & 53.3 & 39.9 \\
\hline Bechtel (\$MM, 1995\$) & 1250.6 & & \\
\hline Less infrastructure $^{d}$ & -450.2 & & \\
\hline Net Plant Cost & 800.0 & 2144.0 & 1608.0 \\
\hline Cost/DBL (\$M, 1995) & 55.2 & 37.0 & 27.7 \\
\hline \multicolumn{4}{|c|}{$\begin{array}{l}\text { a. Based on estimated savings of about } 33 \% \text {. } \\
\text { b. } 75 \% \text { of enlarged plant. } \\
\text { c. Daily barrel of plant output. } \\
\text { d. Reduction of about } 31 \% \text { based on Chem Systems estimate. }\end{array}$} \\
\hline
\end{tabular}

Discussion with industry representatives indicates that the difference in costs to fabricate, transport, and install identical processing facilities in West Texas and on the ANS can vary from 1.0 (under most ideal conditions) to 2, depending on the design configuration. The DOE report (1995) estimates for a plant on ANS resulted in costs about $50 \%$ higher (after deducting infrastructure estimates) than a plant constructed on the Gulf Coast. At the very best a gas conversion plant on the ANS would require the use of some existing equipment to result in a factor closer to 1 . However, as this is unlikely for a new plant installation investment, DOE's multiple plant investment range of between $\$ 27.7 \mathrm{M} / \mathrm{DBL}$ and $\$ 39.9 \mathrm{M} / \mathrm{DBL}$ is reasonable. The upper end of estimated ANS plant investment of about $\$ 40 \mathrm{M} / \mathrm{DBL}$ is used for base comparative economics. Lower and higher plant costs are used in sensitivity evaluations. 
GTL plant investments are based on total throughput volumes from PBU and PTU. The total investment of $\$ 11.8 \mathrm{~B}(1 / 1 / 95 \$)$ is scheduled over a 6-year period as required to process the forecasted annual gas production rates from PBU and PTU. The schedule developed is given in Table B.8.

Table B.8. GTL plant investment schedule (1995\$).

\begin{tabular}{|c|c|}
\hline Year & S, millions \\
\hline \hline $2003^{1}$ & 358 \\
\hline 2004 & 2,390 \\
\hline 2005 & 3,586 \\
\hline 2006 & 3,586 \\
\hline 2007 & 2,032 \\
\hline TOTAL & 11,952 \\
\hline 1. Includes two prior year expenditures for design permits and site acquisition. \\
\hline
\end{tabular}

B.1.7.3 LNG Project. The most recent estimate of the 14 MMPTA TAGS project total cost (including a gas conditioning plant, a gas pipeline, an LNG plant, storage, a marine terminal, and LNG tankers) is about $\$ 14$ billion (1995\$) (Alaska Conservation Foundation, 1994). Although discussions have indicated some reduction in investments may be possible, the $\$ 14$ billion per 14 MMPTA is used as a basis to scale up to the 17 MMPTA project evaluated in this work.

B.1.7.3.1 Conditioning Plant Cost. The cost of the North Slope conditioning plant is estimated to be $\$ 0.1$ billion per MMPTA (State of Alaska, 1996). For a 17 MMPTA project the conditioning plant total cost becomes $\$ 1.7$ billion.

B.1.7.3.2 Pipeline cost. The pipeline for the TAGS project can handle 14 MMPTA with three compressor stations, but can be increased to its design capacity of 25 MMPTA by the addition of 6 additional stations (Alaska Conservation Foundation, 1994). Pipeline cost (including 3 compressor stations) has been estimated to be $\$ 6.38$ billion (Alaska Conservation Foundation, 1994; FERC, 1995). Increasing the capacity from 14 MMPTA to 17 MMPTA requires the addition of 2 compressor stations to the pipeline. Each compressor stations costs about $\$ 0.100$ billion. ${ }^{a}$ Adding two stations to the pipeline increases the total

a. Yukon Pacific Corporation, personal communication, May 1996. 
cost for 17 MMPTA to $\$ 6.59$ billion.

B.1.7.3.3 LNG Plant Cost. Construction costs for a 14 MMTPA LNG plant are estimated to be $\$ 2.3$ billion in $1991 \$$ (FERC, 1995). Escalating that cost to $1995 \$$ and accounting for increasing the plant size to 17 MMPTA, the total cost for the LNG plant and facilities becomes $\$ 3.04$ billion

B.1.7.3.4 LNG Tanker Cost. To transport 14 MMTPA from Valdez to ports in the Far East, $15 \mathrm{LNG}$ tankers would be required at a cost of $\$ 3.35$ billion in $1991 \$$ (Alaska Conservation Foundation, 1994). Escalating that cost to $1995 \$$ and accounting for 4 more LNG tankers to transport the 17 MMPTA of LNG, the total cost for LNG tankers becomes $\$ 4.69$ billion in $1995 \$$.

B.1.7.3.5. Summary. The indicated breakdown between the different segments of the project is given in Table B.9.

Table B.9. LNG project investment breakdown.

\begin{tabular}{||c|c|}
\hline Segment & Cost $-1995 \$$, billions \\
\hline \hline Conditioning plant & 1.70 \\
\hline Pipeline & 6.59 \\
\hline LNG plant, storage, and dock & 3.04 \\
\hline LNG tankers (19) & 4.69 \\
\hline Total & 16.03 \\
\hline
\end{tabular}

Published information on the project timing (FERC, 1995) and the investment breakdown in Table B.9 are used to develop an estimated investment schedule. The assumed scheduling of the overall project with a start-up date of 2005 is given in Table B.10.

\section{B.1.8 Oil Production Forecasts.}

Annual production rates are determined for economic evaluation and can be used to determine ultimate project recovery estimates and future economically recoverable oil under the different price scenarios (Appendix B.1.1). 
Table B.10. LNG project investment schedule.

\begin{tabular}{|c|c|}
\hline Year & \% of Total Investments \\
\hline \hline 2000 & 3.8 \\
\hline 2001 & 6.6 \\
\hline 2002 & 15.2 \\
\hline 2003 & 20.3 \\
\hline 2004 & 22.9 \\
\hline 2005 & 11.4 \\
\hline 2006 & 11.4 \\
\hline 2007 & 5.9 \\
\hline 2008 & 2.5 \\
\hline
\end{tabular}

B.1.8.1 Historical Data. When sufficient interpretable historical production data is available (such as; ADOR, 1995; AOGCC, 1995), that data is used to predict future project producing rates. Those projections are modified as needed based on published project plans.

B.1.8.2 Oil Production Forecast Parameters. Before well test and/or production are available for use in estimating total project producing rates, empirical methods are used. Such methods are presented in a U.S. Department of the Interior publication by Young (1985) and NPC (1981). After the total recoverable reserve volume is determined, the annual peak production rate is set as a percentage of the ultimate recovery. The producing rates for the early years are increased until the peak rate is reached. The peak rate is held constant for a number of years, then the peak production rate is declined. The decline rate is usually between $12 \%$ and $15 \%$ per year. For smaller projects the life is about 15 years, but the life of larger projects may exceed 25 years. These factors are used as guidelines to prepare production forecasts. Modifications have been made using the engineering judgment and experience of the authors. These factors are listed in Table B.11.

\section{B.1.9 Gas and GTL Liquids Sales Forecasts}

The annual gas sales volumes from PBU and PTU are developed in Table A.5 and Table A.31. These gas sales volumes, or plant purchase volumes, are applicable to both LNG and GTL projects. 
Table B.11. Production forecast parameters.

\begin{tabular}{||l|c|c|c|c|c|c|c||}
\hline \hline Field Size - MMBO & $\begin{array}{c}\text { Peak \% of Ultimate Re- } \\
\text { covery }\end{array}$ & \multicolumn{2}{|c|}{$\begin{array}{c}\text { Yearly \% of Ultimate } \\
\text { Recovery (by year) }\end{array}$} & $\begin{array}{c}\text { Years at } \\
\text { Peak } \\
\text { Rate }\end{array}$ & $\begin{array}{c}\text { Decline } \\
\text { (\%) }\end{array}$ \\
\cline { 2 - 8 } & & 1 & 2 & 3 & 4 & & \\
\hline \hline $300^{a}$ & 7 & 3 & 5 & - & - & 4 & 15 \\
\hline 50 to 300 & 10 & 3 & 7 & - & - & 3 & 12 \\
\hline 300 to 725 & 10 & 3 & 7 & - & - & 4 & 15 \\
\hline 725 to 1350 & 10 & 3 & 5 & 7 & - & 4 & 15 \\
\hline 1350 to 3000 & 7 & 3 & 4 & 5 & - & 7 & 12 \\
\hline 3000 to 7250 & 6 & 1 & 3 & 4 & 5 & 8 & 12 \\
\hline a. Limestone reservoir like Lisburne & & & & & \\
\hline
\end{tabular}

Under the GTL sceanrio, these gas volumes are converted to hydrocarbon liquids by applying the overall plant efficiency of $60 \%$ (discussed in Section 5.1.6) to the BTU conversion factor of $5.00 \mathrm{MCF} / \mathrm{BBL}$ (discussed in Section 5.1.3.2). The converted liquid volumes are also shown in Table B.12.

\section{B.1.10 Royalty.}

Royalty is calculated by multiplying the royalty rate for a specific field by the gross wellhead revenue. The royalty rate ranges from $12.5 \%$ to about $20.0 \%$, depending on the field. The State royalty rate, if unknown, is assumed to be $12.5 \%$. In certain projects, royalty oil processing fees are paid by the State to the producers for treating the State's royalty oil to meet pipeline specifications.

B.1.10.1 Royalty Oil Processing Fee. Royalty oil processing fee is the price per barrel that the State is charged by the producer for processing the State's royalty oil. This charge was negotiated between the State and the producers and does not apply to all North Slope projects. The processing fee is deducted from the State's royalty. The established field oil processing fees are given in Table B.13.

Current information shows that certain of the oil pools in the evaluation are not allowed to deduct the royalty processing fee. These are: Milne Point Kuparuk, Milne Point Schrader Bluff, Northwest Milne Point, and Point Thomson. 
Table B.12. Annual gas sales and converted liquids volumes - GTL Project.

\begin{tabular}{|c|c|c|c|c|}
\hline \multirow{2}{*}{ Year } & \multicolumn{3}{|c|}{ Gas Sales (BCFD) } & \multirow{2}{*}{$\begin{array}{c}\text { Converted Liquid Sales } \\
\text { (MBD) }\end{array}$} \\
\hline & PBU & PTU & Total & \\
\hline 2005 & $\overline{0.41}$ & $\overline{0}$ & $\overline{0.41}$ & $\overline{49}$ \\
\hline 2006 & 0.82 & 0 & 0.82 & 98 \\
\hline 2007 & 1.23 & 0 & 1.23 & 148 \\
\hline 2008 & 1.64 & 0.44 & 2.08 & 250 \\
\hline 2009 & 2.05 & 0.44 & 2.49 & 299 \\
\hline 2010 & 2.05 & 0.44 & 2.49 & 299 \\
\hline 2011 & 2.05 & 0.44 & 2.49 & 299 \\
\hline 2012 & 2.05 & 0.44 & 2.49 & 299 \\
\hline 2013 & 2.05 & 0.44 & 2.49 & 299 \\
\hline 2014 & 2.05 & 0.44 & 2.49 & 299 \\
\hline 2015 & 2.05 & $\overline{0.44}$ & 2.49 & 299 \\
\hline 2016 & 2.05 & 0.44 & 2.49 & 299 \\
\hline 2017 & 2.05 & 0.44 & 2.49 & 299 \\
\hline 2018 & 2.05 & 0.44 & 2.49 & 299 \\
\hline 2019 & 2.05 & 0.44 & 2.49 & 299 \\
\hline 2020 & 2.05 & 0.44 & 2.49 & 299 \\
\hline 2021 & 2.05 & 0.44 & 2.49 & 299 \\
\hline 2022 & 2.05 & 0.44 & 2.49 & 299 \\
\hline 2023 & 2.05 & 0.44 & 2.49 & 299 \\
\hline 2024 & 2.05 & 0.44 & 2.49 & 299 \\
\hline 2025 & 2.05 & 0.44 & 2.49 & 299 \\
\hline 2026 & 2.05 & 0.44 & 2.49 & 299 \\
\hline 2027 & 2.05 & 0.35 & 2.40 & 288 \\
\hline 2028 & 2.05 & 0.00 & 2.05 & 246 \\
\hline 2029 & 2.05 & 0.00 & 2.05 & 246 \\
\hline 2030 & 2.05 & 0.00 & 2.05 & 246 \\
\hline 2031 & 2.05 & 0.00 & 2.05 & 246 \\
\hline 2032 & 2.05 & 0.00 & 2.05 & 246 \\
\hline 2033 & 2.05 & 0.00 & 2.05 & 246 \\
\hline 2034 & 2.05 & 0.00 & 2.05 & 246 \\
\hline 2035 & 2.05 & 0.00 & 2.05 & 246 \\
\hline 2036 & 0.28 & 0.00 & 0.28 & 34 \\
\hline Total & $21.8 \mathrm{TCF}$ & $3.18 \mathrm{TCF}$ & $24.98 \mathrm{TCF}$ & 3.0 Billion BBLS \\
\hline
\end{tabular}


Table B.13. Royalty oil processing fees.

\begin{tabular}{||l|c|}
\hline Field & \$/BBL (1/1/95\$) \\
\hline \hline Prudhoe Bay & 0.79 \\
\hline Kuparuk & 0.37 \\
\hline Endicott & 0.44 \\
\hline Lisburne & 0.79 \\
\hline Niakuk & 0.79 \\
\hline Point McIntyre & 0.79 \\
\hline \hline
\end{tabular}

\section{B.1.11 Discount Rate.}

The base year used for constant dollar analysis is $1 / 1 / 95$. The discount rates or hurdle rates used by individual companies are not known and will vary from company to company and over time based on their estimates of oil and gas prices, project risks, and competing investment options. The cumulative discounted total cash flow provides a reasonable measure for comparing future potential projects. For the purposes of this study, a nominal discount rate of $10 \%$ is used in all economic evaluations. However, in practice, operators may require a higher discount rate for projects with greater risk, such as Point Thomson Unit. 


\section{APPENDIX C}

\section{ECONOMIC MODEL}

\section{C.1 Model Description}

A commercially available financial software package ${ }^{a}$ is used to develop the Alaska economic model. This software allows the easy creation of a financial model, has extensive features for querying the model, construction of "what if" scenarios, and goal-seeking features. The economic model was previously described in Alaska Oil and Gas: Energy Wealth or Vanishing Opportunity? (DOE, 1991). The previous model is refined and modified for the current study.

\section{C.1.1 Model Parameters}

A discounted cash flow petroleum accounting model is used to evaluate the historical and projected economics of arctic Alaska oil resources. The model is constructed so the appropriate level of detail for the currently producing and known undeveloped fields can be used depending on the available information. Producing fields and known undeveloped fields are analyzed using historical and projected production and investment schedules reflecting the information known about these fields.

Geologic, geophysical, and lease acquisition costs are assumed to be sunk costs, and are excluded from economic calculations. All costs, oil prices, inflation, and discounting are calculated at the mid-year. Project capital is assumed to be $100 \%$ equity with no debt financing or leverage considered.

C.1.1.1 Resource Parameters. OOIP and ultimate hydrocarbon recovery factors are primary inputs. Historical and projected production schedules are directly entered into the model.

A percent water cut versus percent predicted ultimate recovery relationship is used to calculate water production. The water and oil production are summed to give total fluid production. This feature is used to calculate production operating costs on a per barrel of fluid lifted basis for some fields.

The number of development wells drilled is calculated using the development drilling investment

a. Interactive Financial Planning System, (IFPS). The use of a commercial product neither implies endorsement or recommendation. 
schedule and the cost per development well. Actual development well cost is used when available, otherwise the cost is estimated by average well-depth look-up table. Development wells are either producing wells or injection wells. The number of producing wells is determined as a percentage of total development wells. As a field nears depletion, the number of active producers is reduced as a specified function of ultimate recovery. This procedure simulates the late-life operations of a producing field, as individual uneconomic wells are shut-in. The average well production rate is calculated by dividing the total field production rate by the number of active producers. This allows calculation of production based severance tax, as discussed below. Field oil production terminates when the specified reserves are depleted.

C.1.1.2 Capital Investments. Project investments include exploration, delineation, and development well costs and production facilities. All investment costs are input as 1/1/95 dollars and inflated to mid-year then current dollars using the applicable inflation category:

- Historical and projected well costs, counts, and timing are directly entered for the producing and known undeveloped fields.

- Historical and projected facilities cost are directly entered.

- $\quad$ Offshore production platforms are directly entered for all cases.

C.1.1.2.1 Costs. Project costs are either tangible or intangible and treated differently for tax purposes. Tangible costs are assumed to be $100 \%$ of production facilities and $30 \%$ of development well costs. The balance is considered to be intangible.

C.1.1.2.2 Timing. The scheduling of the exploration, delineation, and development drilling programs is estimated and directly entered into the model. The actual project timing is determined by institutional, regulatory, economic, and environmental factors.

C.1.1.3 Operating Costs. Total field operating costs are calculated using a combination of cost components based on total fluid lifted, well workover cost, facilities cost-sharing fee, and MI. For each case studied, the actual cost components used varied. Table C.1 shows which cost components are used for each field.

A percent water cut versus percent of ultimate predicted recovery relationship is used to estimate water production. Historical reservoir water-cut performance is extrapolated for the projected cases using 
Table C.1. Cost components used for each field.

\begin{tabular}{||l|c|c|c|c|}
\hline \multicolumn{1}{|c|}{ Field } & $\begin{array}{c}\text { Total } \\
\text { Fluid Lifted }\end{array}$ & $\begin{array}{c}\text { Well } \\
\text { Workover }\end{array}$ & $\begin{array}{c}\text { Facilities Cost } \\
\text { Sharing }\end{array}$ & $\begin{array}{c}\text { Miscible } \\
\text { Injectant }\end{array}$ \\
\hline Prudhoe Bay & Yes & No & No & No \\
\hline Kuparuk River & Yes & No & No & No \\
\hline Lisburne & Yes & No & No & No \\
\hline Endicott & Yes & No & No & No \\
\hline Milne Point & Yes & No & No & No \\
\hline Point McIntyre & Yes & Yes & Yes & No \\
\hline Niakuk & Yes & No & Yes & No \\
\hline Schrader Bluff & Yes & Yes & Yes & No \\
\hline Northwest Milne Point & Yes & Yes & Yes & No \\
\hline \hline
\end{tabular}

the actual reported production history, while the known undeveloped cases use an analogous water-cut curve based on the estimated size of the resource and producing formation. Where pilot test or reservoir study data is available, this information is used. The oil production rate and recovery at any point in time is used to calculate the water production. The oil production rate and water production rate are summed for total fluid production rate. This approach incorporates historical and expected reservoir performance in the determination of operating cost based on total fluid production.

C.1.1.4 Inflation Adjustment. All costs are inflated to then current dollars from a 1/1/95 base using a mid-year inflation. Four types of inflation can be used:

- General inflation - assumed to be related to the Gross Domestic Product (GDP) implicit price deflator

- A transportation inflation factor

- A drilling inflation factor

- An oil inflation factor that consists of general inflation plus real oil price growth.

The historical annual percent change in the GDP price deflator is shown in Figure B.8.

C.1.1.5 Tax Calculations. The determination of the undepreciated state and federal balances and property tax base is required to estimate future income for the currently producing fields. Historical cases are run for Prudhoe Bay, Kuparuk River, Lisburne, Endicott, Milne Point, Point McIntyre, and Niakuk using 
the best available information for historical and announced oil prices, production rates, and investment

schedules and categories. The historical runs are made to year-end 1994 to provide an overlap for the forecast models. Year-end 1994 federal undepreciated balances, as calculated in the historical runs, are added to the depreciation for new investments starting in 1995. The year-end 1994 undepreciated balance depreciated for various time lengths to provide the best match of the 1994 to 1995 historical overlap time periods. While not exactly matching the historical depreciation schedule, the total values are in very good agreement. There is a minor affect for the first 3 to 4 years of the forecast economic runs. Unamortized IDC balances are treated in a similar fashion.

\section{C.1.1.5.1 Tax Calculation Definitions}

(1) Gross Revenue $=$ Field Production Volume of Oil and Gas $x$ Well Head Price.

(2) Royalty $=[$ Royalty Interest Rate $x$ Gross Revenue $]-[$ Oil Processing Fee $x$ Field Production Volume $x$ Royalty Interest Rate].

(3) Ad Valorem Property Tax Base $=$ [Previous Year Ad Valorem Property Tax Base - (Previous Year Ad Valorem Property Tax Base/Remaining Project Life)] x (Inflation Rate) + Previous Year Tangible Investment.

(4) Conservation Tax $=$ (Conservation Tax Rate + Conservation Surtax Rate $) \times$ Field Production Volume x (1 - Royalty Interest Rate).

(5) Income Before State and Federal Taxes = Gross Revenue - Operating Costs - Royalty - Severance Tax - Ad Valorem Tax - Conservation Tax.

(6) State Income Tax = (Income Before State and Federal Taxes - State Income Tax Depreciation) $\mathrm{x}$ State Income Tax Rate.

(7) State Income Tax Depreciation (Straight Line Basis) = Cumulative Total Capita1/Project Life.

(8) State Income Tax Depreciation (Units of Production Basis) = State Income Tax Depreciation Factor $x$ State Income Tax Depreciation Basis.

(9) State Income Tax Depreciation Factor $=$ Current Year Total Field Production/Current Year End Remaining Reserves.

(10) State Depreciation Basis = Previous Year State Depreciation Basis + Current Year Total Capital - Previous Year State Income Tax Depreciation.

(11) Federal Income Tax $=$ (Income Before State and Federal Taxes - Federal Income Tax Deduction - State Income Tax) x Federal Income Tax Rate. 
(12) Federal Income Tax Deduction = Federal Income Tax Depreciation + Amortized intangible drilling cost (IDC) + Expensed IDC.

(13) Federal Income Tax Depreciation (Oilfield Equipment) $=1.5 \times$ [(Current Year Tangible Capital + Previous Year Book Value) Depreciated on a 7-year 150\% continuous declining balance basis].

(14) Federal Income Tax Depreciation (Gas-To-Liquids Conversion Plants) $=1.5 \times$ [(Current Year Tangible Capital + Previous Year Book Value) Depreciated on a 10-year 150\% continuous declining balance basis].

(15) Federal Income Tax Depreciation (Gas Pipeline, LNG Plant, and LNG Tankers) $=1.5 \times$ [(Current Year Tangible Capital + Previous Year Book Value) Depreciated on a 15-year 150\% continuous declining balance bașis].

(16) Book Value $=$ Cumulative Tangible Investment - Cumulative Tax Depreciation.

(17) Tangible Capital $=$ Plant Capital $+0.30 \times$ Drilling Capital

(18) Intangible Capital $=0.70 \times$ Drilling Capital.

(19) Expensed $\mathbf{D C}=0.70 \times$ Intangible Drilling Capital.

(20) Amortized IDC = (Current Year Unexpensed Drilling Capital + Previous Year Unamortized IDC); amortized on a 5-year straight line basis.

(21) Total Capital $=$ Plant capital + Drilling Capital.

(22) Plant Capital $=100 \%$ Tangible.

(23) Drilling Capital $=30 \%$ Tangible $+70 \%$ Intangible.

(24) Operating Cash Flow = Income Before State and Federal Income Taxes - Federal Income Tax State Income Tax.

(25) Industry Cash Flow = Income Before State and Federal Income Tax - Federal Income Tax - State Income Tax - Total Capital.

(26) State Revenue $=$ Royalty + Severance Tax + Ad Valorem Tax + Conservation Tax + State Income Tax.

(27) Federal Revenue $=$ Federal Income Tax.

C.1.1.6 State of Alaska Taxes. A major improvement in this model relative to the previous study is the incorporation of Alaska tax law for the treatment of state depreciation, property tax, severance tax with an ELF for both oil and gas, conservation tax and surtax, royalty processing fees, and state income tax. State taxes are calculated before federal income tax and are a deduction in determining federal taxable income. One major change from the previous study was the incorporation of a state income tax loss carry-forward provision. No state income taxes are paid until all previous state income tax losses had been offset. This 
study focuses on project specific economics and does not attempt to take into account individual companies tax position. Two different approaches can be used, tax loss to offset other company income or to treat a tax loss as zero taxes with no offsetting effect. The tax loss carry-forward approach is essentially intermediate to the other two options.

C.1.1.6.1 Depreciation--The state of Alaska calculates depreciation on a units-ofproduction basis on the total investment (tangible and intangible) once the asset has been placed in service. A units-of-production depreciation factor is calculated using the yearly production divided by the year-end remaining reserves. The depreciable basis is the cumulative total investment less cumulative depreciation. The state depreciation is the product of the state depreciation factor and the depreciation basis. This amount is deducted as a non-cash expense.

C.1.1.6.2 Property Tax (Ad Valorem)--The state property tax base is calculated using the inflation adjusted cumulative tangible investment, less the previous year's property tax base divided by the remaining project life. This value is adjusted by the general inflation rate plus previous year tangible investment. The property tax (or ad valorem tax) is $2 \%$ of the current year property tax base.

C.1.1.6.3 Severance Tax--The state oil severance tax is calculated at $12.25 \%$ of the net wellhead value (i.e., less royalty oil) for the first 5 years of production and $15 \%$ thereafter, multiplied by the oil ELF with a minimum tax of $\$ 0.80$ (unescalated) per net barrel of production. Net production is defined as oil production less royalty. Similarly, the state gas severance tax is calculated at $10.0 \%$ of the net wellhead value, multiplied by the gas ELF, with a minimum tax of $\$ 0.064 / \mathrm{MCF}$.

C.1.1.6.3.1 Oil ELF. The oil ELF calculation used is the post-1989 formula, which is:

Oil ELF $=[1-300 / \text { Daily Average Well Rate (BOPD) }]^{\mathrm{x}}$ where:

$x=[150,000 / \text { Average Daily Field Rate (BOPD) }]^{1.5333}$.

C.1.1.6.3.2 Gas ELF. The gas ELF calculation is:

Gas ELF $=[1-3,000 /$ Daily Average Well Rate, $(\mathrm{MCF} /$ day $)]$ 
C.1.1.6.3.3 Future Producing Well Determination. The number of future active wells on an annual basis is required in severance tax calculations. The method developed in the $1991 \mathrm{DOE}$ publication (1991) to project the future active producers is adopted for use. Two sets of equations were developed to determine the future active producers in two different project sizes. The first set, for projects similar to PBU, is:

Set A - For the production period between $80 \%$ and $98 \%$ of ultimate recovery the current number of active producers is:

- Producers $=[\{181.1011-1.0112(\%$ of ultimate recovery $)\} \times$ maximum number of active producers $] \div 100$.

For the production period after $98 \%$ of ultimate recovery, the current number of active producers is:

- $\quad$ Producers $=[1845.3988-17.9939(\%$ of ultimate recovery $)] \times$ maximum active producers $] \div 100$.

The second set, for projects closer in size or smaller than the Kuparuk River Unit (KRU), is:

Set B - For the production period between $60 \%$ and $95 \%$ of ultimate recovery, the current number of active producers is:

- $\quad$ Producers $=[\{124.5528-0.4065$ (\% of ultimate recovery) $\} \times$ maximum active producers] $\div 100$.

For the production period after $95 \%$ of ultimate recovery, the current number of active producers is:

- $\quad$ Producers $=[\{458.3330-4.3330$ (\% of ultimate recovery) $\}$ x maximum active producers] $\div 100$.

Maximum active producers is assumed as the total cumulative producers drilled with no allowance for shutdown wells unless complete segments of the project are abandoned.

C-7 
C.1.1.6.4 Conservation Tax--The conservation tax rate is $\$ 0.004 / B B L$ of net production and the conservation surtax is $\$ 0.05 / \mathrm{BBL}$ of net production.

C.1.1.6.5 Income Tax Calculation--The state income tax rate is calculated as follows: State Income Tax Rate $=9.4 \% \times \frac{1}{3} \times\left(\frac{\text { Alaska Sales }}{\text { Worldwide Sales }}+\frac{\text { Alaska Production }}{\text { Worldwide Production }}+\frac{\text { Alaska Assets }}{\text { Worldwide Assets }}\right.$

Because it is difficult to independently determine any company's worldwide sales, production, and assets, a nominal effective state tax rate of $3 \%$ is used. This value compares favorably with the implicit effective rate from Deakin (1989). An effective rate of $1.5 \%$ to $3 \%$ is used by the ADR for revenue forecasting. ${ }^{\mathrm{a}}$

The state income tax is calculated as follows:

- $\quad$ Net Revenue $=$ Gross Revenue $-($ Royalty - Processing Fee $)$

- Net Before State Income Tax $=$ Net Revenue - Total Operating Cost - Severance Tax Conservation Tax - Conservation Surtax - State Property Tax - State Depreciation

- Net After State Income Tax $=$ Net Before State Income Tax - State Income Tax + State Depreciation.

The state depreciation is added back for the calculation of federal taxes.

C.1.1.7 Federal Taxes. Federal income taxes are calculated after the state of Alaska tax calculations, with state taxes treated as a deduction from federal income. The federal income calculations involve the treatment of IDCs, depreciation, and federal income tax. One major change from the previous study is the incorporation of a federal income tax loss carry-forward provision. No federal income taxes are paid until all previous federal income tax losses have been offset. This study focuses on project specific economics and does not take into individual companies tax position. Two different approaches could be used, tax loss to offset other company income or to treat a tax loss as zero taxes with no offsetting effect.

a. Alaska Department of Revenue, personal communication, May 1990. 
The tax loss carry-forward approach is essentially intermediate to the other two options.

C.1.1.7.1 Federal Amortization of IDCs--Federal tax law allows IDCs to be expensed and amortized and permits a more favorable treatment of depreciation. Current tax law permits $70 \%$ of the IDCs to be expensed in the year incurred and the balance amortized over 60 months. The model assumes that IDCs are $90 \%$ of exploration and delineation well costs and $70 \%$ of development well costs.

C.1.1.7.2 Federal Depreciation (producing facilities)--Federal depreciation is calculated using a 7 -year, $150 \%$ declining balance of the tangible investment with no switchover. This method is consistent with the approach used by the Alaska Department of Revenue. The tangible assets are assumed to have no salvage value at the end of the project. Federal law allows the choice of depreciation methods such as Accelerated Cost Recovery System (ACRS), straight line, declining balance, units of production, and sum-of-the-years digits with a switchover before the end of the depreciation life. No depletion allowance is used for the recovery of exploration and lease acquisition costs; these costs are assumed to be sunk costs.

C.1.1.7.3 Federal Depreciation (gas-to-liquids conversion plants)--The federal income tax depreciation is calculated by multiplying $1.5 \mathrm{X}$ [(current year tangible capital + previous year book value) depreciated on a 10-year, $150 \%$ continuous declining balance basis].

C.1.1.7.4 Federal Depreciation (gas pipeline, LNG plant, and LNG tankers) -- The federal income tax depreciation is calculated by multiplying $1.5 \mathrm{X}$ [(current year tangible capital + previous year book value) depreciated on a 15-year, $150 \%$ continuous declining balance]

C.1.1.7.5 Federal Income Tax Calculation--The federal income tax rate is $34 \%$ of the federal taxable income. Non-cash deductions are added back to net income for the determination of cash flow.

The federal income tax, net income, and operating and total cash flows are calculated as follows:

- Net Income Before Federal Income Tax $=$ Net After State Income Tax - Expensed IDC Amortized IDC - Federal Depreciation

- Net Income $=$ Net Income Before Federal Income Tax - Federal Income Tax 
- $\quad$ Operating Cash Flow $=$ Net Income + Federal Depreciation + Amortized IDC + Expensed Intangible Investment

- Total Cash Flow = Operating Cash Flow - Total Investment.

C.1.1.8 Economic Determination. The yearly total cash flow is discounted to determine the present worth of the future total cash flow. The base year for discussing constant dollars is as of January 1 , 1995. The economic limit is defined as the year operating cash flow is negative (after payout of the project). A nominal discount rate of $10 \%$ is used. The real discount rate is related to the nominal discount rate by the following equation from Stermole (1982).

$$
\left[1 /\left(1+i_{n}\right)\right]^{n}=[1 /(1+f)]^{n} \times\left[1 /\left(1+i_{r}\right)\right]^{n}
$$

where

$$
\begin{aligned}
& \mathrm{n}=\text { time periods } \\
& \mathrm{i}_{\mathrm{n}}=\text { nominal discount rate } \\
& \mathrm{f}=\text { inflation rate } \\
& \mathrm{i}_{\mathrm{r}}=\text { real discount rate. }
\end{aligned}
$$

With an inflation rate of $2.2 \%$ and a 32 year time period, the real discount rate for a nominal discount rate of $10 \%$ is $7.6 \%$.

The yearly present values are summed to determine the cumulative net present value of each case considered. The model does not directly calculate the internal rate of return (IRR), but the IRR can be determined by solving for the nominal discount rate that results in a cumulative net present value of zero at the end of the project.

\section{C.2 Model Validation}

The economic model was previously validated (DOE 1991) by comparison with the Young (1986) and the Deakin (1989) studies. For a discussion of the model validation see the above referenced study. 


\section{APPENDIX D \\ VALUES OF ECONOMIC ANALYSES}

Table D.1. Base values of input variables used in sensitivity analyses.

\begin{tabular}{|c|c|c|c|c|c|c|c|c|}
\hline \multirow{2}{*}{ Input variable } & & \multicolumn{3}{|c|}{ PBU } & \multicolumn{2}{|c|}{ PTU } & \multirow{2}{*}{$\begin{array}{l}\text { LNG } \\
\text { project }\end{array}$} & \multirow{2}{*}{$\begin{array}{l}\text { GTL } \\
\text { plant }\end{array}$} \\
\hline & & MGS & w/ LNG & w/ GTL & $\mathrm{w} / \mathrm{LNG}$ & w/GTL & & \\
\hline $\begin{array}{l}\text { prod net } \\
\text { back }\end{array}$ & $\%$ & - & 28.07 & 15.05 & 28.07 & 15.05 & 28.07 & 15.05 \\
\hline royalty rate & $\%$ & 12.5 & 12.5 & 12.5 & 14.25 & 14.25 & - & - \\
\hline \multirow{2}{*}{$\begin{array}{l}\text { state and fed } \\
\text { tax rate }\end{array}$} & fed & 0.34 & 0.34 & 0.34 & 0.34 & 0.34 & 0.34 & 0.34 \\
\hline & state & 0.03 & 0.03 & 0.03 & 0.03 & 0.03 & 0.03 & 0.03 \\
\hline $\begin{array}{l}\text { liquids } \\
\text { premium }\end{array}$ & \$/BBL & - & - & 5.00 & - & 5.00 & - & 5.00 \\
\hline \multirow{2}{*}{$\begin{array}{l}\text { field } \\
\text { pipeline } \\
\text { tariffs }\end{array}$} & gas - $\$ M C F$ & - & - & - & 0.16 & 0.16 & - & - \\
\hline & oil - \$/BBL & - & - & - & 2.64 & 2.35 & - & - \\
\hline $\begin{array}{l}\text { plant } \\
\text { efficiency }\end{array}$ & $\%$ & 一 & 一 & 一 & - & - & - & 60.0 \\
\hline investments & $\$$, millions & 1,786 & 1,786 & 1,786 & 911 & 911 & 16,026 & 11,952 \\
\hline \multirow{2}{*}{$\begin{array}{l}\text { op cost } \\
\text { factor }\end{array}$} & $\%$ inv & - & - & - & 一 & - & 5.0 & - \\
\hline & $\$ / B B L$ & - & - & - & - & - & - & 6.00 \\
\hline shrinkage & $\%$ & 一 & - & - & 一 & - & 8.78 & - \\
\hline $\begin{array}{l}\text { gas BTU } \\
\text { content }\end{array}$ & BTU/MCF & - & 1,150 & 1,150 & 1,150 & 1,150 & 1,150 & 1,150 \\
\hline LNG bonus & fraction & - & 1.1 & - & 1.1 & - & 1.1 & - \\
\hline
\end{tabular}


Table D.2. Variable sensitivity values for LNG scenario for AEO95 reference price.

\begin{tabular}{|c|c|c|c|c|}
\hline \multirow[b]{2}{*}{ Variable } & \multirow[b]{2}{*}{$\%$ change } & \multicolumn{3}{|c|}{ Net present value ( $10 \%$ discount rate) ( $\$$, millions) } \\
\hline & & PBU & PTU & Gas pipeline/LNG project \\
\hline Base (no change) & 0 & 11,051 & 354 & 0 \\
\hline \multirow[t]{2}{*}{ Producer net back } & -30 & 10,161 & 202 & 1,360 \\
\hline & +30 & 11,940 & 506 & $(1,378)^{a}$ \\
\hline \multirow[t]{2}{*}{ Royalty rate } & -30 & 11,799 & 393 & 一 \\
\hline & +30 & 10,302 & 315 & - \\
\hline \multirow{2}{*}{$\begin{array}{l}\text { State and Federal tax } \\
\text { rates }\end{array}$} & -30 & 14,153 & 471 & 849 \\
\hline & +30 & 8,422 & 249 & $(809)$ \\
\hline \multirow[t]{2}{*}{ Field pipeline tariffs } & -30 & - & 388 & - \\
\hline & +30 & - & 320 & - \\
\hline \multirow[t]{2}{*}{ Project investment } & -30 & 11,404 & 449 & 2,182 \\
\hline & +30 & 10,697 & 258 & $(2,214)$ \\
\hline \multirow[t]{2}{*}{ Operating cost factor } & -30 & 一 & - & 874 \\
\hline & +30 & - & - & $(886)$ \\
\hline \multirow[t]{2}{*}{ Shrinkage } & -30 & - & 一 & 339 \\
\hline & +30 & 一 & - & (184) \\
\hline \multirow[t]{2}{*}{ Gas BTU content } & -10 & 10,754 & 303 & $(1,031)$ \\
\hline & +10 & 11,347 & 405 & 1,020 \\
\hline \multirow[t]{2}{*}{ LNG bonus } & -20 & 10,458 & 253 & $(2,078)$ \\
\hline & +20 & 11,644 & 455 & 2,038 \\
\hline
\end{tabular}

a. Values in parentheses are negative. 
Table D.3. Variable sensitivity values for GTL scenario for AEO95 reference price.

\begin{tabular}{|c|c|c|c|c|}
\hline \multirow[b]{2}{*}{ Variable } & \multirow[b]{2}{*}{$\%$ change } & \multicolumn{3}{|c|}{ Net present value ( $10 \%$ discount rate) ( $\$$, millions) } \\
\hline & & PBU & PTU & GTL plant \\
\hline Base (no change) & 0 & 10,397 & 332 & 0 \\
\hline \multirow[t]{2}{*}{ Producer net back } & -30 & 9,816 & 234 & 931 \\
\hline & +30 & 10,977 & 429 & $(955)^{2}$ \\
\hline \multirow[t]{2}{*}{ Royalty rate } & -30 & 11,117 & 370 & 一 \\
\hline & +30 & 9,676 & 294 & 一 \\
\hline \multirow{2}{*}{$\begin{array}{l}\text { State and Federal } \\
\text { tax rates }\end{array}$} & -30 & 13,353 & 445 & 613 \\
\hline & +30 & 7,902 & 231 & (566) \\
\hline \multirow[t]{2}{*}{ Liquids premium } & -30 & 10,311 & 317 & $(422)$ \\
\hline & +30 & 10,482 & 347 & 417 \\
\hline \multirow{2}{*}{$\begin{array}{l}\text { Field pipeline } \\
\text { tariffs }\end{array}$} & -30 & - & 349 & - \\
\hline & +30 & - & 315 & - \\
\hline \multirow[t]{2}{*}{ Plant efficiency } & -30 & - & 一 & $(2,831)$ \\
\hline & +30 & - & - & 2,649 \\
\hline \multirow[t]{2}{*}{ Investments } & -30 & 10,750 & $427^{\circ}$ & 1,548 \\
\hline & +30 & 10,043 & 236 & $(1,618)$ \\
\hline \multirow{2}{*}{$\begin{array}{l}\text { Operating cost } \\
\text { factor }\end{array}$} & -30 & - & 一 & 666 \\
\hline & +30 & - & - & (677) \\
\hline \multirow[t]{2}{*}{ Gas BTU content } & -10 & 10,185 & 296 & (597) \\
\hline & +10 & 10,607 & 367 & 592 \\
\hline
\end{tabular}

a. Values in parentheses are negative. 



\section{APPENDIX E}

\section{BIBLIOGRAPHY}

Alaska Business Monthly (ABM), 1994, "Clock Running Out on TAGS," October 1994, p. 18.

Alaska Conservation Foundation (ACF), 1994, "North Slope Natural Gas Pipeline, Coming Soon to a Theater Near You?", August 1994.

Alaska Department of Natural Resources (ADNR), 1988, "Handouts at Point Thomson Unit WIO's Meeting with Division of Oil and Gas," July 5, 1988.

Alaska Department of Natural Resources, 1991, "Annual Progress Report, Plan of Development and Operation, Prudhoe Bay (Permo-Triassic) Reservoir," June 28, 1991.

Alaska Department of Natural Resources, 1991a, "Historical and Projected Oil and Gas Consumption," June 1991.

Alaska Department of Natural Resources, 1991b, "Second Plan of Development and Operations, Lisburne Participating Area," August 20, 1991.

Alaska Department of Natural Resources, 1991c, "Amended Tenth Plan of Development, Schrader Bluff Participating Area-Revised Development Scenario," September 20, 1991.

Alaska Department of Natural Resources, 1991d, "Eleventh Plan of Development and Operations-Milne Point Unit," September 23, 1991.

Alaska Department of Natural Resources, 1991e, "Point Thomson Unit Update of Eighth Plan of . Development and the Ninth Plan of Development", Exxon Company, USA, September 25, 1991.

Alaska Department of Natural Resources, 1991f, "Annual Progress Report, Plan of Development and Operations, Lisburne Participating Area," November 27, 1991.

Alaska Department of Natural Resources, 1991g, "Niakuk Heald Point Development; Project Description and Environmental Assessment," (At a 7/20/93 presentation to ADNR and AOGCC), December 1991.

Alaska Department of Natural Resources, 1992, "Ninth Plan of Development-Point Thomson Unit," January 3, 1992.

Alaska Department of Natural Resources, 1992a, "Endicott Reservoir Plan of Development and Operations-Duck Island Unit," February 17, 1992.

Alaska Department of Natural Resources, 1992b, "Sag Delta North Reservoir Plan of Development and Operations-Duck Island Unit," February 17, 1992.

Alaska Department of Natural Resources, 1992c, "Request for Deferral of Contraction of Prudhoe Bay Unit," February 28, 1992. 
Alaska Department of Natural Resources, 1992d, "Meeting Agenda-Update on Point Thomson Consensus Mapping," March 5, 1992.

Alaska Department of Natural Resources, 1992e, "Advance Plan of Exploration and Plan of Operations, Kuukpik Unit," March 5, 1992.

Alaska Department of Natural Resources, 1992f, "Annual Progress Report, Plan of Development and Operation, Prudhoe Bay (Permo-Triassic) Reservoir,", July 1, 1992.

Alaska Department of Natural Resources, 1992g, "Unit Plan of Development-Kuparuk River Unit," August 1, 1992 (submitted on June 30, 1992).

Alaska Department of Natural Resources, 1992h, "Unit Plan of Exploration and Unit Plan of Operations, Kuukpik Unit," August 7, 1992.

Alaska Department of Natural Resources, 1992i, "Filing of Prudhoe Bay Issues Resolution Agreement," August 21, 1992.

Alaska Department of Natural Resources, 1992j, "Tenth Plan of Further Development and OperationPoint Thomson Unit," September 29, 1992.

Alaska Department of Natural Resources, 1992k, "Twelfth Plan of Exploration, Development and Operations-Milne Point Unit," October 1, 1992.

Alaska Department of Natural Resources, 19921, "Third Expansion-Exploration Plan, Milne Point Unit," November 5, 1992.

Alaska Department of Natural Resources, 1992m, "Annual Progress Report, Plan of Development and Operations, Lisburne Participating Area," November 20, 1992.

Alaska Department of Natural Resources, 1992n, "Application to Expand the Prudhoe Bay Unit and Form the Pt. McIntyre Participating Area Within the Prudhoe Bay Unit," December 3, 1992.

Alaska Department of Natural Resources, 19920, "Notice of Intent to Expand the Prudhoe Bay Unit to Encompass the Pt. McIntyre Participating Area," December 8, 1992.

Alaska Department of Natural Resources, 1993, "Northstar Unit, Third Annual Progress Report, January 25, 1993.

Alaska Department of Natural Resources, 1993a, "Endicott Reservoir Plan of Development and Operations-Duck Island Unit," February 12, 1993.

Alaska Department of Natural Resources, 1993b, "Sag Delta North Reservoir Plan of Development and Operation-Duck Island Unit," February 12, 1993.

Alaska Department of Natural Resources, 1993c, "Application for Certification of North Prudhoe Bay State No. 3 (ADL-28297) as capable of producing in paying quantities; Request for Tract Operation of North Prudhoe Bay State No. 3; and Plan of Development and Operation for North Prudhoe Bay

Reservoir," May 17, 1993. 
Alaska Department of Natural Resources, 1993d, "Thetis Island Unit Outline," May 1993.

Alaska Department of Natural Resources, 1993e, "Third Expansion-Milne Point Unit," June 1, 1993.

Alaska Department of Natural Resources, 1993f, "Annual Progress Report, Plan of Development and Operation, Prudhoe Bay (Permo-Triassic) Reservoir," June 30, 1993.

Alaska Department of Natural Resources, 1993g, "Unit Plan of Development-Kuparuk River Unit," August 1, 1993 (submitted on June 30, 1993).

Alaska Department of Natural Resources, 1993h, "Eleventh Plan of Further Development and OperationPoint Thomson," September 27, 1993.

Alaska Department of Natural Resources, 1993i, "Thirteenth Plan of Exploration, Development, and Operations-Milne Point Unit," September 29, 1993.

Alaska Department of Natural Resources, 1993j, "Annual Progress Report, Plan of Development and Operations, Lisburne Participating Area," November 30, 1993.

Alaska Department of Natural Resources, 1993k, "Approval of Eleventh Plan of Development and served notice of State's intent to contract the Point Thomson Unit," December 17, 1993.

Alaska Department of Natural Resources, 19931, "Exxon Poised to Increase Domestic Petroleum Production (Exxon Perspectives)," December 1993.

Alaska Department of Natural Resources, 1994, "Endicott Reservoir Plan of Development and Operations-Duck Island Unit," February 14, 1994.

Alaska Department of Natural Resources, 1994a, "Sag Delta North Reservoir Plan of Development and Operations-Duck Island Unit," February 14, 1994.

Alaska Department of Natural Resources, 1994b, "Historical and Projected Oil and Gas Consumption," February 1994.

Alaska Department of Natural Resources, 1994c, "Kuparuk River Unit-Contraction Deferral Acreage," March 15, 1994.

Alaska Department of Natural Resources, 1994d, "Amendment to 13th Plan of Exploration, Development, and Operations-Milne Point Unit", April 7, 1994.

Alaska Department of Natural Resources, 1994e, "Prudhoe Bay Unit Expanded, Point McIntyre Participating Area Formed...," April 11, 1994.

Alaska Department of Natural Resources, 1994f, "Approval for lease operation of North Prudhoe Bay State No. 3, April 11, 1994.

Alaska Department of Natural Resources, 1994g, "Notice of Intent to Form the North Prudhoe Bay Participating Area," April 14, 1994. 
Alaska Department of Natural Resources, 1994h, "Prudhoe Bay Unit Expanded, Point McIntyre Participating Area Formed...," April 29, 1994.

Alaska Department of Natural Resources, 1994i, "Lease Committed to the West Beach Participating Area," April 29, 1994.

Alaska Department of Natural Resources, 1994j, "Annual Progress Report, Plan of Development and Operation, Prudhoe Bay (Permo-Triassic) Reservoir, June 30, 1994.

Alaska Department of Natural Resources, 1994k, "1994 Unit Plan of Development-ADNR letter requesting additional information," July 19, 1994

Alaska Department of Natural Resources, 1994l, "Second Amendment to 13th Plan of Exploration, Development, and Operations-Milne Point Unit," August 1, 1994.

Alaska Department of Natural Resources, 1994m, "Unit Plan of Development-Kuparuk River Unit," August 1, 1994 (submitted on June 30, 1994).

Alaska Department of Natural Resources, 1994n, "Annual Progress Report, Plan of Exploration, Kuukpik Unit," August 5, 1994.

Alaska Department of Natural Resources, 1994o, "Report to the AOGCC, PBU Pressure Management (in compliance with Conservation Order No. 290, Rule 5.)", August 17, 1994.

Alaska Department of Natural Resources, 1994p, "Application to Form the North Prudhoe Bay Participating Area within the Prudhoe Bay Unit, consisting of Alaska State Lease Numbers: ADL 28297 and ADL 34624," August 18, 1994.

Alaska Department of Natural Resources, 1994q, "1994 Kuparuk River Unit Plan of DevelopmentARCO letter furnishing additional information," August 24, 1994.

Alaska Department of Natural Resources, 1994r, "Third Plan of Development and Operations, Lisburne Participating Area," August 31, 1994.

Alaska Department of Natural Resources, 1994s, "Review of 13th and Proposed 14th Plan of Exploration, Development, and Operations-Milne Point Unit," September 21, 1994.

Alaska Department of Natural Resources, 1994t, "Twelfth Plan of Further Development and Operations (and Exxon's reply to State's intent to contract the Point Thomson Unit)," September 28, 1994.

Alaska Department of Natural Resources, 1994u, "Modification of the Application to Form the North Prudhoe Bay Participating Area within the Prudhoe Bay Unit, affecting Alaska State Lease Numbers: ADL 28297 and ADL 34624," October 14, 1994

Alaska Department of Natural Resources, 1994v, "Northstar Unit, Plan of Development," October 18, 1994.

Alaska Department of Natural Resources, 1994w, "Notice of Default, Northstar Unit", November 17, 1994. 
Alaska Department of Natural Resources, 1994x, "Annual Progress Report, Plan of Development and Operations, Lisburne Participating Area," December 1, 1994.

Alaska Department of Natural Resources, 1994y, "Amended Notice of Default, Northstar Unit," December 12, 1994.

Alaska Department of Natural Resources, 1994z, "Conservation Order No. 348 (Expand the affected area of Conservation Order No. 173)-Kuparuk River Oil Field," December 16, 1994.

Alaska Department of Natural Resources, 1994aa, "Approval of Eleventh Plan of Development for the Point Thomson Unit until April 30, 1995," December 22, 1994.

Alaska Department of Natural Resources, 1995, "Kavik Unit, Fifteenth Plan of Development and Operation," January 25, 1995.

Alaska Department of Natural Resources, 1995a, "Endicott Reservoir Plan of Development and Operations-Duck Island Unit," February 14, 1995.

Alaska Department of Natural Resources, 1995b, "Sag Delta North Reservoir Plan of Development and Operations-Duck Island Unit," February 14, 1995.

Alaska Department of Natural Resources, 1995c, "Historical and Projected Oil and Gas Consumption," March 1995.

Alaska Department of Revenue, 1991, "Revenue Sources Book," Fall 1991.

Alaska Department of Revenue, 1991a, "Estimated Prospective Tanker Rates for Alaska North Slope Crude Oil," Roger Marks, October 1991.

Alaska Department of Revenue, 1992, "Revenue Sources Book," Fall 1992.

Alaska Department of Revenue, 1993, "Revenue Sources Book," Fall 1993.

Alaska Department of Revenue, 1994, "Revenue Sources Book," Spring 1994.

Alaska Department of Revenue, 1994a, "Revenue Sources Book," Fall 1994.

Alaska Department of Revenue, 1995, "Revenue Sources Book," Spring 1995.

Alaska Journal of Commerce (AJC), 1993, "BP begins groundwork for Niakuk field on slope, "August 30, 1993, p. 1 .

Alaska Journal of Commerce, 1994, "New oil from Valdez vapors," January 3, 1994, p. 1.

Alaska Journal of Commerce, 1995, "BP looks for new ways to develop Badami oil field at Prudhoe Bay," February 27, 1995, p. 7.

Alaska Journal of Commerce, 1995a, "BP tunes production methods for pulling thick oil from sand," March 6, 1995, p. 17. 
Alaska Journal of Commerce, 1995b, "Money, ideas drive expansion of Milne Point," Márch 6, 1995, p. 18.

Alaska Journal of Commerce, 1995c, "BP's contract oil prices top $\$ 17$ per barrel," March 13, 1995, p. 1.

Alaska Journal of Commerce, 1995d, "Clinton backs lifting oil export ban but with several conditions,' March 13, 1995, p. 1.

Alaska Journal of Commerce, 1995e, "Knowles, ARCO agree upon $\$ 50$ million settlement over production royalty fees," March 13, 1995, p. 1.

Alaska Journal of Commerce, 1995f, "Street Talk - Oil and Gas," March 13, 1995, p. 5.

Alaska Natural Gas Transportation System (ANGTS), 1995, "A New Look," brochure circa January 1995.

Alaska Oil and Gas Conservation Commission, 1986, "Exhibit D to Duck Island Unit Agreement and Unit Operating Agreement," Revised May 1986.

Alaska Oil and Gas Conservation Commission (AOGCC), 1991, "Prudhoe Bay Unit Presentation to AOGCC in Support of Prudhoe Bay Miscible Gas Project Development and Amendment to Conservation Order No. 195, Rule 2," August 21, 1991.

Alaska Oil and Gas Conservation Commission, 1991a, "Exhibit D to Duck Island Unit Agreement," February 1991.

Alaska Oil and Gas Conservation Commission, 1992, "Conservation Order No. 290, Application for Expansion of the Miscible Gas Project (PBU), February 21, 1992.

Alaska Oil and Gas Conservation Commission, 1992a, "Monthly Bulletins, (Monthly Production Statistics)," January-December 1992.

Alaska Oil and Gas Conservation Commission, 1993, "West Beach Field Rules Hearing Testimony," January 13, 1993.

Alaska Oil and Gas Conservation Commission, 1993a, "Conservation Order No. 311, Prescribe pool rules for operation and development of the West Beach Pool," February 25, 1993.

Alaska Oil and Gas Conservation Commission, 1993b, "Point McIntyre Field Rules Testimony," March 24, 1993.

Alaska Oil and Gas Conservation Commission, 1993c, "Approval of the formation of the West Beach participating Area, Prudhoe Bay Unit," April 2, 1993.

Alaska Oil and Gas Conservation Commission, 1993d, "Area Injection Order No. 4A, Modify Area Injection Order 4 to include the Point McIntyre, Stump Island, and West Beach oil pools for the purpose of conducting enhanced recovery and disposal of Class II fluids," August 12, 1993, Revised

October 4, 1993. 
Alaska Oil and Gas Conservation Commission, 1993e, "Application for the Third Expansion of the Prudhoe Bay Unit Area and Formation of the Pt. McIntyre Participating Area", September 8, 1993.

Alaska Oil and Gas Conservation Commission, 1993f, "Point McIntyre Oil Field, Conservation Order No. 317, Classify New Oil Pools and Establish Pool Rules for Development and Operations in the Pt. McIntyre Oil Pool," July 2, 1993.

Alaska Oil and Gas Conservation Commission, 1993g, "Conservation Order No. 317, Classification of new oil pools and to prescribe rules for development of the Pt. McIntyre Oil Field," July 2, 1993, revised September 10, 1993.

Alaska Oil and Gas Conservation Commission, 1993h, "Niakuk Field Rules Hearing Testimony," October 28, 1993.

Alaska Oil and Gas Conservation Commission, 1993i, "ARCO Exhibits for Niakuk Field Rules Hearing," November 17, 1993.

Alaska Oil and Gas Conservation Commission, 1993j, "Monthly Bulletins, (Monthly Production Statistics)," January-December 1993.

Alaska Oil and Gas Conservation Commission, 1993k, "Application for the Third Expansion of the Unit Area and Formation of the Pt. McIntyre Participating Area (C. O. No. 317), August 18, 1993.

Alaska Oil and Gas Conservation Commission, 1994, "Conservation Order No. 329, (pool rules for Niakuk Pool)," January 11, 1994.

Alaska Oil and Gas Conservation Commission, 1994a, "Area Injection Order No. 10, Milne Point Unit," September 19, 1986, Amended May 3, 1994.

Alaska Oil and Gas Conservation Commission, 1994b, "North Star Unit Review," June 9, 1994.

Alaska Oil and Gas Conservation Commission, 1994c, "Monthly Bulletins, (Monthly Production Statistics)," January-December 1994.

Alaska Oil and Gas Conservation Commission, 1994d, "North Prudhoe Bay Oil Pool- Conservation Order No. 345," December 16, 1994.

Alaska Oil and Gas Conservation Commission, 1994e, "Kuparuk River Field, Conservation Order No. 349 (Northwest Milne Point), December 16, 1994.

Alaska Oil and Gas Conservation Commission, 1995, "Monthly Bulletin, (Monthly Production Statistics)," January 1995.

Alaska Oil and Gas Conservation Commission, 1995a, "Area Injection Order No. 14, Approval to inject fluids for enhanced recovery into the Niakuk Oil Pool," March 22, 1995.

Alaska Oil and Gas Conservation Commission, 1995b, "Conservation Order No. 198x, Kuparuk River Field, Kuparuk River Unit, Miscible Gas Enhanced Oil Recovery Project," September 8, 1995. 
Alaska Oil and Gas Reporter (AOGR), 1994, "The Platform: Guest Editorial: Bill McHugh, President and CEO of Yukon Pacific Corporation," November 28, 1994.

Alaska Oil and Gas Reporter, 1995, "The Platform", February 27, 1995, p. 2.

Alaska Oil and Gas Reporter, 1995a, "Sharpening Alaska's Competitive Edge," February 27, 1995, p. 3.

Alaska Oil and Gas Reporter, 1995b, "Alaska's oil companies ask for improved communication with state agencies," February 27, 1995, p. 4.

Alaska Oil and Gas Reporter, 1995c, "U.S. Sponsor Bails Out of ANGTS," February 27, 1995, p. 5.

Alaska Oil and Gas Reporter, 1995d, "Exxon May Lose Huge Slice of Point Thomson," February 27, 1995 , p. 6.

Alaska Oil and Gas Reporter, 1995e, "Alaska's Discovered, Undeveloped Fields," February 27, 1995, p. 7.

Alaska Oil and Gas Reporter, 1995f, "Amerada Hess Drops More Acreage," February 27, 1995, p. 8.

Alaska Oil and Gas Reporter, 1995g, "Texas Independent Takes Over Kuvlum," February 27, 1995, p. 9.

Alaska Oil and Gas Reporter, 1995h, "Alaska North Slope Production," February 27, 1995, p. 15.

Alaska Oil and Gas Reporter, 1995i, "Alaska Oil and Gas Taxes and Incentives," February 27, 1995, p. 18 ,

Alaska Oil and Gas Reporter, 1995j, "Political Winds Shift Nationally, ANWR Development Emerges A Winner," February 27, 1995, p. 21.

Alaska Oil and Gas Reporter, 1995k, "BP Exploration (Alaska) Inc. filed applications with state and federal (Cascade discovery)," February 27, 1995, p. 24.

Alaska Oil and Gas Reporter, 19951, "BP America's February term prices for Alaska North Slope crude...," February 27, 1995, p. 25.

Alaska Oil and Gas Reporter, 1995m, "BP Exploration said it wants to build a 28 mile underground pipeline (Badami), "February 27, 1995, p. 25.

Alaska Oil and Gas Reporter, 1995n, "Three North Slope exploratory wells were active at press time," February 27, 1995, p. 24.

Alyeska Pipeline Service Co., 1992, "Facing the Future, Committment, Challenge, Change," Remarks by James B. Hermiller, January 6, 1992.

Anchorage Daily News, 1995e, "Independent Buys Kuvlum", March 10, 1994, p. E-1.

Anchorage Daily News (ADN); 1990, "BP puts plans for Niakuk oil field on shelf," July 18, 1990, p. D-1. 
Anchorage Daily News, 1992, "ARCO Offers No Help, Exc: Gasoline Must Tap Buyers," February 8, 1992, p. B2.

Anchorage Daily News, 1993, "Long-delayed Niakuk going on-line," August 20, 1993, p. C-1.

Anchorage Daily News, 1994, "Point Mac shines in glum oil patch," April 2, 1994, p. A-9.

Anchorage Daily News, 1994a, "Oil starts to flow from Niakuk," April 14, 1994, p. D-6.

Anchorage Daily News, 1994b, "Profits at BP surge", November 2, 1994, p. D-4.

Anchorage Daily News, 1994c, "Gas line progress," December 27, 1994.

Anchorage Daily News, 1995, "BP picks contractors for tentative oil field,' January 11, 1995, p. D-2.

Anchorage Daily News, 1995a, "Oil field gets another look (West Sak)," January 22, 1995, p. A-1.

Anchorage Daily News, 1995b, "BP takes view to Juneau," January 31, 1995, p. D-1.

Anchorage Daily News, 1995c, "BP pumps harder at Milne Point field," February 23, 1995, p. 1.

Anchorage Daily News, 1995d, "Bill tries to uncap royalties," February 24, 1995, p. B-1.

Anchorage Daily News, 1995f, State considers oil-share sacrifice," March 11, 1995, p. A-1.

Anchorage Daily News, 1995g, "Dollars fall hits OPEC where it hurts," March 11, 1995, p. C-5.

Anchorage Daily News, 1995h, "Drivers nationwide protest use of reformulated gas," March 11, 1995, p. E-6.

Anchorage Times (AT), 1991, "Yukon Pacific Delays Startup of Natural Gas Pipeline Project," June 11, 1991.

Anchorage Times, 1991a, "Yukon Pacific Works on Timing of Slope Gas Tap," June 21, 1991.

Anchorage Times, 1991b, "Conoco Strikes Oil East of Prudhoe," July 27, 1992, p. A-1.

Anchorage Times, 1992, "Point McIntyre development plan set," May 12, 1992, p. D5.

Anchorage Times, 1994, "Debunking myths (TAGS)," January 31, 1994.

Anchorage Times, 1994a, "Harmony in '95," (reference date unknown).

ARCO Alaska, Inc. (ARCO), 1990, "DOE Alaska Energy Study draft (in-house memorandum), August 17, 1990.

ARCO Alaska, Inc., 1991, "Report on Security Analyst's Meeting" March 26, 1991. 
ARCO Alaska, Inc., 1992, "ARCO announces two discoveries west of the Kuparuk River Field," December 21, 1992.

ARCO Alaska, Inc., 1994, "Report on Securities Analyst Meeting," September 16, 1994.

ARCO Alaska, Inc. and BP Exploration, 1993, "Arctic Oil, Energy for Today and Tomorrow," Circa 1993.

Balachandran, U., J. T. Dusek, R. L. Mieville, P. S. Matya (Argonne National Laboratory), M. S. Kleefisch, S. Pei, T. P. Kobylinski, C. A. Udovich (Amoco Research Center), 1994, Proceedings of the Coal Liquefaction and Gas Conversion Contractor's Review Conference, U.S. Department of Energy, PETC, September 7-8, 1994, Pittsburgh, PA, pp. 677-686.

Bird, K. J., 1990, Regional Synthesis of Selected Provinces; North Slope, Alaska, "Economic Geology, Part III, Oil and Gas Section, DNAG," 1990, p. 34.

Brealy, R.A. and Meyers, S.C., 1988, "Principles of Corporate Finance, New York," McGraw-Hill Book Company Inc., 1988

British Petroleum, 1995, "BP Review of Natural Gas 1995.

Brown, Blaine, 1994, "Economic Analysis-Gasoline Manufactured by the Plasma Arc Process Compared to Petroleum Refining," EG\&G Inhouse Document, 1994.

Christian Science Monitor (CSM), 1995, "To Avoid Long Lines for Gas, Tap Alaska's Oil Reserves," May 18, 1995, p. 4.

Congressional Research Service (CRS), The Library of Congress, 1992, "Giant Oil Fields and Domestic Oil Production," March 9, 1992.

Cornot-Gandolphe, S. (CEDIGAZ), A. Rojey and C. Raimbault (Institut Francais du Petrole) (CED), 1995, "Development Prospects for International LNG Trade," Eleventh International Conference \& Exhitition on Liquefied Natural Gas, July 3-6, 1995.

Dautzenberg, F.M., R.L. Garten and G. Klingman, 1896, "Fuels from Remote Natural Gas, Defining the Reaearch and Development Challenge," June 1986.

Deakin, E.B., 1989, "Oil Industry Profitability-1969 through 1987," Alaska Department of Revenue, March 15, 1989.

Detering, B.A., 1995, "1995 Annual Report on Plasma Quench for Natural Gas Conversion Applications," DOE/INEL Internal Report, November, 1995.

Easley, G. W. and A. S. Lawal (Easley), 1993, "Optimization and Production Strategies for High GOR and Cycle Wells," Society of Petroleum Engineers, SPE 26091, May 1993.

Eilers, J., S.A. Posthuma, S.T. Sie, 1990, "The Shell Middle Distillate Synthesis Process (SMDS)," Catalysis Letters 7 (1990), pp. 253-270. 
Eisenberg, B., 1994, "Advanced Natural Gas Conversion Technology for Remote Natural Gas

Utilization," The Catalysis Society of Metropolitan New York Symposium, May 7-9, 1994.

Energy Daily, 1995, "Arco, BP: Market Will Demand Alaskan Gas After 2000," July 24, 1995.

Energy Information Administration, 1994a, "Annual Energy Review 1993," U.S. Department of Energy, July 1994.

Energy Information Administration, 1994b, "International Energy Outlook 1994," U.S. Department of Energy, July 1994.

Energy Information Administration, 1994c, "Natural Gas 1994, Issues and Trends," U.S. Department of Energy, July 1994.

Energy Information Administration, 1994d, "Crude Oil and Product Prices Expected to Rise in 1995 (EIA News Releases)," U.S. Department of Energy, November-December 1994.

Energy Information Administration, 1994e, "Costs and Indicies for Domestic Oil and Gas Field Equipment and Production Operations-1990 Through 1993," July 1994, DOE/EIA-TR-0568.

Energy Information Administration, 1995, "Annual Energy Outlook 1995," U.S. Department of Energy, January 1995.

Energy Information Administration, 1995a, "Supplement to the Annual Energy Outlook 1995," U.S. Department of Energy, February 1995.

Energy Information Administration, 1995b, "Petroleum Supply Annual 1994," Volume 2. June 1995, DOE/EIA-0340(94)2.

Energy Information Administration, 1995c, "Petroleum Marketing Annual 1994," August 1995, DOE/EIA-0478(94).

Energy Information Administration(EIA), 1994, "Annual Energy Outlook 1994, with Projections to 2010," U.S. Department of Energy, January 1994.

EPRI, 1982, "Plasma Processing for Materials Production," Research Project 1275-9, Palo Alto, California, December 1982.

Exhibition on Liquefied Natural Gas, July 3-6, 1995.

Federal Energy Regulatory Commission (FERC), 1985, "Settlement Agreement between the state and Alyeska owners with respect to Trans Alyska Pipeline System," June 28, 1985.

Federal Energy Regulatory Commission (FERC), 1995, "Final Environmental Impact Statement (Yukon Pacific LNG Project), March 1995.

Foothills Pipe Line LTD (FPLL), 1995, "Foot Hills Pipe Lines System-Brochure," 1995. 
Fox, J.M. III, Chen, T.P., and B.D. Degan, 1990, "An Evaluation of Direct Methane Conversion Processes," Chemical Engineering Progress, Vol. 86/No.4, April 1990, p. 42.

Fox, J.M., R.F. Geosits, A.H. Koenig and P.R. Danforth, 1988, "Remote Gas Processing and Marketing," Energy Progress, Vol. 8, No. 1, March 1988.

Gaffiney, Cline and Associates, 1994, "Perceptions of Alaska, Oil and Gas Market Research Project," August 1994.

Gas Research Institute (GRI), 1995, "1995 Policy Implications of the GRI Baseline Projection of U.S. Energy Supply and Demand to 1020," 1995.

Gladisch, H., 1962, "How Huels Makes Acetylene by DC ARC, " June 1962, Hydrocarbon Processing \& Petroleum Refiner, Vol. 41, p. 159.

Gold, D., Elektrotechn. und Maschinenbau 95, 3, 133-137, 1978.

Hawkshaw, H.J. and A. R. Flower, 1995, "Will New LNG Supplies Be Developed to Meet Asian LNG Demand to 2015?," Eleventh International Conference \& Exhibition on Liquefied Natural Gas, July 3-6, 1995.

Herold's Oil Headliner (HOH) 1995, Clinton Passes Alaska Export Bill, November 29, 1985.

Hydrocarbon Processing, 1987, “Costs to transport natural gas," April 1987, p. 47.

Improved Recovery Week (IRW), 1995, "Six-day Unitar Conference opens," February 13, 1995, Vol. 4, No. 6, p. $1 .$.

Improved Recovery Week, 1995a, "BPX, DOE to study Alaska heavy oil", February 13, $\quad 5$, Vol. 4, No. 6, p. 4.

Journal of Petroleum Technology (JPT), 1994, "The Lisburne Production Center," Society of Petroleum Engineers, January 1994.

Journal of Petroleum Technology, 1994a, "An Evaluation of Prudhoe Bay Horizontal and High Angle Wells After 5 Years of Production," February 1994, p. 150.

Journal of Petroleum Technology, 1995, "Natuna," Society of Petroleum Engineers, February 1995.

Maffia, G. J., 1993, "Natural Gas to Gasoline via Acetylene," September 1993.

Mahmood, S.M., D.K. Olsen and C.P. Thomas, 1995, "Heavy Oil Production from Alaska," In proceedings of the Sixth UNITAR International Conference on Heavy Crude and Tar Sands, February 12-17, 1995, Houston, Texas.

Mast, R.F., G.L. Dolton, R.A. Crovelli, R.H. Root, E.D. Attanasi, P.E. Martin, L.W. Cooke, G.B. Carpenter, W.C. Pecora, and M.B. Rose, 1989, "Estimates of Undiscovered Resources in the United States-A Part of the Nation's Energy Endowment, U.S. Department of Interior, U.S. Government Printing Office, 1989-242-338:80069, 1989. 
Mills, G. A., 1994, "Status and future opportunities for conversion of synthises gas to liquid fuels," Fuels 1994, Vol. 73, No. 8, pp. 1243-1279.

Minerals Management Service (MMS), 1985, Beaufort Sea Petroleum Technology Assessment, Technical Report No. 112, Han-Padron and Associates, March 1985.

National Petroleum Council (NPC), 1981, U.S. Arctic Oil and Gas, December 3, 1981.

Natural Gas Intelligence, 1995, "Sponsors Await Producers' Decision on Alaska LNG Project," January 30, 1995.

Offshore, 1994, "Extended reach drilling envelope expected to reach nine $\mathrm{km}$ by 2000 ," November 1994, p. 45.

Oil and Gas Journal (OGJ), 1995, "Plentiful natural gas headed for big growth in Mideast," January 23, 1995, pp. 51-56.

Oil and Gas Journal, 1995a, "Opening of ANWR still a hot issue in Congress," February 27, 1995, p. 64.

Oil and Gas Journal, 1995b, "Slope exploration slow, but hopes remain high," May 15, 1995, p. 55.

Oil and Gas Journal, 1995c, "North Slope operators pressing Marginal oil field development," May, 1, 1995.

Oil and Gas Journal, 1995d, "Slope exploration slow but hopes remain high," May 15, 1995, p. 55.

Oil and Gas Journal, 1995e, "Energy policy directions," January 23, 1995.

Oil and Gas Journal, 1995f, Crude prices, November 27, 1995, p. 86.

Oil and Gas Journal, 1995g, ANWR hypocrisies, November 6, 1995, p. 13.

Oil and Gas Journal, 1995h, Showdown near for ANWR leasing issue, November 6, 1995, p. 31.

Oil and Gas Journal, 1995i, Worldwide Look at Reserves \& Production, December 25, 1995, p. 44.

Oil Daily, 1994, "ARCO Alaska Pledges to Invest $\$ 800$ Million During Next 5 Years," September 12, 1994, p. 1.

Oil Daily, 1994a, "New Rules Require Single-Hull Oil Tankers to Have Escorts in Alaska, Northwest Waters," August 8, 1994.

Oil Daily, 1994b, "Government Policies Create 'Near Crisis' for Oil, Gas Industry, Alaska Report Says," September 15, 1994, p. 1 .

Oil Daily, 1994c, "Prudhoe's Reserves are 70\% Gone: State Study," September 19, 1994.

Oil Daily, 1995, "Firms Commit to Alaska Work as Reserves Fall," January 26, 1995, p. 1. 
Oil Daily, 1995a, "Asia Doesn't Need Alaska's Gas Until After 2005, Firms Say," July 24, 1995.

Pasha Publication, Inc., 1995, "Senate budget bill reopens Arctic refuge battle," May 11, 5.

Peebles, M.W.H., 1995, “Are the Boom Years of LNG Over?” Eleventh International Conference \&

Petroleum and Energy Intelligence Weekly (EIW), 1995, "Is Exxon Singing Same Old Natuna?", February 24, 1995, p. 1.

Petroleum Information Corporation (PIC), 1992, "Two Colville River Delta Area Discoveries Reported (Kuukpuk Unit), "Alaska Report, December 22, 1992, p. 5.

Petroleum Information Corporation, 1994, "Construction Essentially Finished at Prudhoe Bay," Alaska Report, May 13, 1994, p. 3.

Petroleum Information Corporation, 1994a, "Industry/Government Partnership Needed for Further Development of Alaska Oil Reserves," Alaska Report, November 22, 1994, p. 3.

Petroleum Information Corporation, 1994b, "North Slope Oil Prices End Year at $\$ 16.65-\$ 16.81 / \mathrm{Bbl}$ Level," Alaska Report, December 7, 1994, p. 1.

Petroleum Information Corporation, 1994c, "New Oil Production Tax, Gas Flaring Regulations Become Law," Alaska Report, December 7, 1994, p. 3.

Petroleum Intelligence Weekly (PIW), 1994, "Alaskan LNG Gets New Look from Producers, Users," October 17, 1994, p. 4.

Picknell, J. K. and W. H. Broman, 1993, "An Evaluation of Prudhoe Bay Horizontal and High-Angle Wells after 5 Years of Production," Society of Petroleum Engineers, SPE 26596, December 3, 1993.

Platt's Oilgram News, 1991(PLATTS), "Regulatory costs may hasten TAPS shutdown, Alyeska President Warns," January 15, 1992.

Platt's Oilgram News, 1993, "Prudhoe Reserves Get 1-Bil Boost," Vol. 71, No. 137, July 16, 1993, p. 2.

Platt's Oilgram News, 1994, "BP Warns of a 'Retreat' from Alaska," July 28, 1994.

Platt's Oilgram News, 1994a, "Alaska Methane Gas," July 28, 1994.

Platt's Oilgram News, 1994b, "Clock is Ticking on Alaska LNG Project," August 16, 1994, .

Platt's Oilgram News, 1994c, "Alaska Oil Industry is Said Near Crisis'," October 4, 1994, Vol. 72, No. 192, p. 2.

Platt's Oilgram News, 1994d, "New Attempts to Win Tax Break for Alaska's Marginal Oil Producers," October 4, 1994, Vol. 72, No. 192, p. 2.

Platt's Oilgram News, 1995, "Democrat Governor of Alaska Seeks New Era of Cooperation with Oil Cos.," January 10, 1995, p. 2. 
Platt's Oilgram News, 1995a, "ANS Output Slipped 2\% in 1994 to 1.583 - million b/d," January 10, 1995, p. 2.

Platt's Oilgram News, 1995b, "In Surprise, BP Raising E\&P Budget in Alaska," January 11, 1995, p. 5.

Platt's Oilgram News, 1995c, "Colville Gets a Number: 100-Mil Bbl in Reserves," May 8, 1995.

Platt's Oilgram News, 1995d, "Alaska Delays a Decision on North Star Proposal," May 8, 1995.

Platt's Oilgram News, 1995e, “ANS output is declining faster than anticipated," October 25, 1995.

Platt's Oilgram News, 1995f, “TAPS owners fighting over line space," October 25, 1995.

Robertson, D. B., J. S. Isby, S. A. Anderson, R. H. Mays, D. Hsu, and A. Hill, Undated print, "A MultiDisciplinary Approach to Horizontal Well Planning in the Prudhoe Bay Field, Alaska," Society of Petroleum Engineers, SPE 26055, Circa May 1993.

Rostrup-Nielsen, J. R. (Haldor-Topsoe A/S), 1994, "Catalysis and large scale conversion of natural gas," 4th European Workshop on Methane Activation, May 18, 1984.

Shields, G., J.M. Fox and S.V. Chaung, 1985, "Natural Gas Conversion to Liquids Fuels," 64th Annual GPA Convention, March 1985.

Singleton, A. H. And Regier, S., (1983), "Conversion of Remote Natural Gas to Hydrocarbon Liquids," GPA Convention, San Francisco, March 1983; and Hydrocarbon Processing, 62,71-74, May, 1983.

SNC Inc., 1985, "Conceptual Design and Techno-Economic Assessment of Three Electricity-Based Reactor Processes for Production of Liquid Fuels and/or Hydrocarbons from Natural Gas," prepared for CANMET, Energy Mines, and Resources, Canada, March 1985.

Standing, M.B., 1977, Volumetric and Phase Behavior of Field Hydrocarbon Systems, 1977 Society of Petroleum Engineers of AIME, Library of Congress, No. 52-11180.

State of Alaska, 1996, Memorandum prepared by the Alaska Department of Revenue, "Commercialization of North Slope Gas -- What Should the Stae B Doing?" January 22, 1996.

Stermole, F.J., 1982, "Economic Evaluation and Investment Decision Methods," Fourth edition, pp. $169-177,1982$.

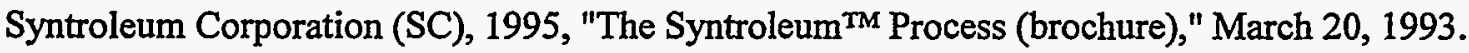

Szabo, D. J. and K. O. Meyers, 1993, "Prudhoe Bay: Development History and Future Potential," Society of Petroleum Engineers, SPE 26053, May 1993.

The Oil Daily, 1993, "ANS Flow Declines with Seasonal Drop, Work Disruptions," July 23, 1993, p. 2.

Tijm, P.J.A., H.M.H. van Wechem, and M.M.G. Senden, 1993, "The Shell Middle Distillate Synthesis Project-New Opportunities for Marketing Natural Gas," Alternate Energy '93 (Colorado Springs Symposium), April 27-30, 1993. 
U.S. Department of Commerce (DOC), 1994, Survey of Current Business, December 1994, Vol. 74, No. 12.

U.S. Department of Energy (DOE), 1991; Thomas, C.P., Doughty, T.C., 1Faulder, D.D., Harrison, W.E., Irving, J.R., Jamison, H.C., White, G.J.; "Alaska Oil and Gas - Energy Wealth or Vanishing Opportunity?" DOE/[D/01570-H1, January 1991.

U.S. Department of Energy, 1993, "Assessment of Costs and Benefits of Flexible and Alternative Fuel Use in the U.S. Transportation Sector," January 1993.

U.S. Department of Energy, 1993a; Thomas, C.P., Allaire, R.B., Doughty, T.C., Faulder, D.D., Irving, J.R., Jamison, H.C., White, G.J.; "Alaska North Slope National Energy Strategy Initiative." DOE/ID/01570-T164, May 1993.

U.S. Department of Energy, 1993b, “Assessment of Costs and Benefits of Flexible and Alternative Fuel Use in the U.S. Transportation Sector," December, 1993.

U.S. Department of Energy, 1994, "Exporting Alaskan North Slope Crude Oil, Benefits, and Costs," June 1994.

U.S. Department of Energy, 1995, "Economic Evaluation and Market Analyses for Natural Gas Utilization," Draft Report, April 15, 1995.

U.S. Department of the Interior (DOI), Bureau of Land Management (BLM), 1991, "Overview of the 1991 Arctic National Wildlife Refuge Recoverable Petroleum Resource Update," April 8, 1991.

U.S. Geological Survey (USGS), 1987, "Petroleum Geology of the Northern Part of the Arctic National Wildlife Refuge, Northeastern Alaska, Pt. Thomson Sand Data," Bulletin 1778, 1987.

U.S. Geological Survey, 1993, "The Future of Energy Gases," Circular 115, 1993.

U.S. Geological Survey, 1995, "1995 Assessment of United States Oil and Gas Resources," Circular 1118, 1995.

UIE Arc Plasma Review, 1988, “Arc Plasma Processes, A Maturing Technology in Industry, Chapter 7, Chemical Industries"

World Oil (WO), 1995, "Enhanced recovery engineering-thermal well design, completion and production practices," March 1995, p. 71.

World Oil, 1995a, "What's happening offshore, U. S. gas price dilemma solution," April 5, p. 33.

World Oil, 1995b, "Oil and gas in Washington, oil patch study again," April 1995, p. 37.

World Oil, 1995c, "Management issues, Competition for Capital heats up," April 1995, p. 39.

World Oil, 1995d, "What's happening in drilling, Innncentives, policies, and restricted areas," May, 1995, p. 25. 
World Oil, 1995e, "What's happening offshore, a few positive political signals," May 1995, p. 29.

World Oil, 1995f, "A world of oil, fire, and ice," May 1995, p. 31.

World Oil, 1995g, "Oil and gas in Washington, Positive progress possible," March, 1994.

Young, Y.S., W.S. Hauser, 1986, "Economics of OIl and Gas Production from ANWR for th Determination of Minimum Economic Field Size," Department of the Interior, Bureau of Land Management, 1986.

Yukon Pacific Corporation (YPC), 1995, "TAGS information package," Materials dates from 1992 to 1995. 